\title{
IUCN
}

\section{Ethics and Climate Change}

A Study of National Commitments

Donald A. Brown and Prue Taylor (Eds.)

\section{IUCN}





\section{Ethics and Climate Change}

A Study of National Commitments 



\section{Ethics and Climate Change}

A Study of National Commitments

Donald A. Brown and Prue Taylor (Eds.)

IUCN Environmental Policy and Law Paper No. 86 


\section{IUCN}

The designation of geographical entities in this book, and the presentation of the material, do not imply the expression of any opinion whatsoever on the part of IUCN concerning the legal status of any country, territory, or area, or of its authorities, or concerning the delimitation of its frontiers or boundaries.

The views expressed in this publication do not necessarily reflect those of IUCN.

Published by: $\quad$ IUCN, Gland, Switzerland in collaboration with the IUCN Environmental Law Centre, Bonn, Germany

Copyright: $\quad$ (C) 2015 International Union for Conservation of Nature and Natural Resources

Reproduction of this publication for educational or other non-commercial purposes is authorized without prior written permission from the copyright holder provided the source is fully acknowledged.

Reproduction of this publication for resale or other commercial purposes is prohibited without prior written permission of the copyright holder.

Citation: $\quad$ Donald A. Brown and Prue Taylor (Eds.) (2015).

Ethics and Climate Change. A Study of National Commitments IUCN, Gland, Switzerland. $x x x+170$ pp.

ISBN:

978-2-8317-1709-8

DOI: 10.2305/IUCN.CH.2015.EPLP.86.en

Cover design by:

IUCN Environmental Law Centre

Cover photo:

() shutterstock

Layout by:

layout \& more, Bonn

Available from:

IUCN Publications Services

Rue Mauverney 28

1196 Gland

Switzerland

Tel +41229990000

Fax +41229990010

books@iucn.org

www.iucn.org/publications 


\section{Contents}

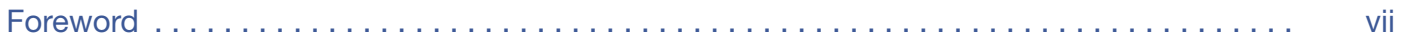

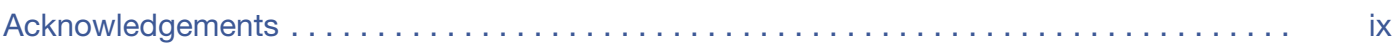

Editors $\ldots \ldots \ldots \ldots \ldots \ldots \ldots \ldots \ldots \ldots \ldots \ldots \ldots \ldots \ldots \ldots \ldots \ldots \ldots \ldots \ldots \ldots \ldots$

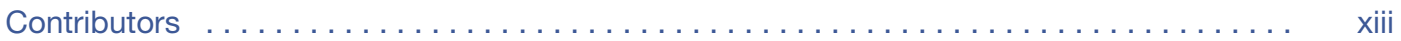

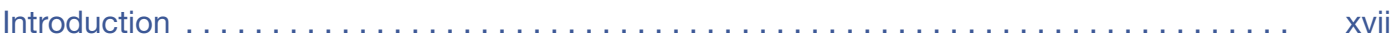

A Change in the Weather? Australia and Climate Change Politics 2007-2014

Peter D. Burdon

The Plurinational State of Bolivia's Consideration of Ethics and Justice Issues in Formulating Climate Change Policies

Beth Jean Evans

Canada's Consideration of Ethics and Justice Issues in Formulating Climate Change Policies Anne D. Fouillard

China's Consideration of Ethics and Justice Issues in Formulating Climate Change Policies

Sanna Kopra

Ethics and Justice in Climate Change Policies - Report on Italy

Alessandra Solazzo and Massimiliano Montini

Japan's Consideration of Ethics and Justice Issues in Formulating Climate Change Policies

Kathryn A. Gwiazdon

Kenya's Consideration of Ethics and Justice Issues in Formulating Climate Change Policies

Martin Oulu

New Zealand's Consideration of Ethics and Justice Issues in Formulating

Climate Change Policies

Chris Hadley

The Netherlands' Consideration of Ethics and Justice Issues in Formulating Climate Change Policies

Vivian Ike

Concerns of Ethics and Justice in Russian Climate Politics 
South Africa's Consideration of Ethics and Justice Issues in Formulating Climate Change Policies

Radhika Perrot

An Overview of South Korea's Consideration of Ethics and Justice in its Climate Policy Sun-Jin Yun and Rakhyun E. Kim

Thailand: Shirking Away from Ethical Responsibility to Respond to Climate Change Danny Marks

Uganda's Consideration of Ethics and Justice Issues in Formulating Climate Policies Akampurira Andrew

The United States of America's Consideration of Ethics and Justice Issues in Formulating Climate Change Policies

Donald A. Brown 


\section{Foreword}

Climate change is the most significant moral and environmental issue of our time. The collapse of the 2009 Copenhagen negotiations lead many to question whether the international community really had a moral compass to follow, beyond shallow declaratory statements and ambiguous phrases. The critical 2015 Paris negotiations will again put the actions and inactions of states squarely before the world's peoples. To use the jargon of the negotiations, what will it take to get states to lift the level of moral and legal ambition and deliver a result that meets the criteria required by the IPCC's $5^{\text {th }}$ Assessment Reports?

The IUCN's conservation mission and work programmes have included climate change for many years across a number of Commissions. The World Commission on Environmental Law ('WCEL'), for example, has a Specialist Working Group on Energy Law and Climate Change and the Environmental Law Programme works with a number of partner organisations on climate change issues. The IUCN and the WCEL have a strong commitment to global ethics as evident in the 1980 World Conservation Strategy and in the IUCN's endorsement of the Earth Charter in 2008. This publication continues the important task of specifically relating considerations of ethics and justice to climate change.

Donald Brown and Prue Taylor are world-renowned experts in the field of climate change ethics and leading members of the WCEL Ethics Specialist Group. They initiated this project and its publication. Their leadership attracted experts from fifteen nations who investigated moral and ethical considerations underpinning the climate commitments of their respective governments.

The fundamental question asked of all states is this: to what extent do their national climate change commitments take into account responsibility (for those most vulnerable) and fairness (a fair share of global greenhouse gas emissions)? It is well recognized that transparent answers to these fundamental questions will be central to the success of any future global climate change agreement. In the interests of creating necessary transparency and in bringing considerations of ethics and justice to the fore, this book contains fifteen highly informative country reports.

The reports concern China, the United States, Australia and Canada, together with three African states (South Africa, Kenya and Uganda), three European states (Italy, Netherlands and Russia), a selection from the Asia Pacific Region (Japan, South Korea, Thailand and New Zealand) and one South American state (Bolivia). The authors were asked to report against a standard set of questions to facilitate comparability between states. It is intended that this initial selection of reports will be added to (and in some instances updated) in the coming months via the project website: www.nationalclimatejustice.org. The objective is to create a repository of country reports that reveals the moral position of nations when determining their national commitments.

This book makes an important contribution to the task of relating ethics and justice to climate change in a manner that is timely and practical. Global cooperation can only be built on trust and this in turn requires the highest attention to the moral imperatives of climate change. This book tells us how 
committed states have really been. It also provides guidance for ongoing climate negotiations, for the further development of national policies and laws, for decision-makers in public and private sectors and indeed for everyone concerned with our common destiny.

Professor Klaus Bosselmann

Chair, Ethics Specialist Group

IUCN World Commission on Environmental Law 


\section{Acknowledgements}

This project owes its existence to a determination to make considerations of ethics and justice integral to climate change policy in a way that is practical, transparent and accessible. It is our objective to shine a light on the justifications that states currently use for developing mitigation and adaptation policy, and measure those justifications against some basic criteria agreed upon by most states.

The fifteen reports published in this book are the first in what we hope will become a comprehensive series covering as many nation states as possible. Our thanks go to all the authors with reports in this current collection. We have been energized by their interest and enthusiasm and we acknowledge their generosity in volunteering to research and write reports. Hopefully their efforts will inspire others to join us by contributing more national reports.

This project began with a workshop run at the IUCN Academy of Environmental Law Colloquium, Tarragona, in July 2014. It was through this vehicle that we were able to present our project to colleagues, solicit helpful suggestions on the research template, and gauge support. Our thanks go to all those who participated in this workshop.

Financial support was provided by our home Universities: Widener University School of Law (US) and the School of Architecture and Planning, University of Auckland (New Zealand). We are grateful for this assistance.

Finally, we would like to thank the wonderful team at the IUCN Environmental Law Centre in Bonn for working with us. The efforts of the director Alejandro Iza, together with Ann DeVoy and Anni Lukács, has enabled us to deliver this project as an e-book and in time for the UNFCCC, COP19 meeting in Lima, December 2014. To Mike Wagg, our tireless and very patient copy editor - your professional help was indispensable. To Nandita Rao and Anaya Mokashi, thank you for your proof-reading assistance. 



\section{Editors}

\section{Donald A. Brown, B.S., J.D, M.A. (Liberal Studies, Philosophy and Art)}

Professor Brown holds a BS in Commerce and Engineering Sciences from Drexel University, a JD from Seton Hall University School of Law, and MA in Liberal Studies majoring in philosophy and art from the New School University where he also was in the PhD program in philosophy. He is currently Scholar in Residence for Sustainability Ethics and Law and Professor, Widener University School of Law in Harrisburg. At Widener he teaches International Environmental Law, Human Rights Law, and Climate Change Law. He is also a part-time Professor, Nanjing University, Nanjing, China, where he lectures regularly on climate change ethics. $\mathrm{He}$ is also a contributing author to the Intergovernmental Panel on Climate Change (IPCC), 5th Assessment Report. Previously he was Associate Professor of Environmental Ethics, Science, and Law at the Pennsylvania State University where he taught interdisciplinary courses on climate change and sustainable development. Prior to that, he was an environmental lawyer for the states of Pennsylvania and New Jersey and Program Manager for United Nations Organizations at the United States Environmental Protection Agency's Office of International Environmental Policy. In this position he represented US EPA negotiating sustainability issues at the United Nations including climate change, international water issues, biodiversity, and Agenda 21. Mr Brown has written extensively on climate change and sustainability law and ethics and lectured widely around the world on these issues. His newest book is Navigating the Perfect Moral Storm: Climate Ethics (Routledge, Earthscan, 2012).

\section{Prue Taylor LLB, LLM (Hons), LLM (Envt'I \& Energy)}

Prue Taylor received her legal qualifications from Victoria University, New Zealand and Tulane University, USA. She currently teaches environmental and planning law at the School of Architecture and Planning, University of Auckland. She is the Deputy Director of the New Zealand Centre for Environmental Law and a member of the IUCN World Commission on Environmental Law and its Ethics Specialist Group. Prue's specialist interests are in the areas of climate change, human rights, biotechnology, environmental governance, ocean law and policy, property rights and environmental ethics. She has authored numerous books and articles in these areas. Her book An Ecological Approach to International Law: Responding to the Challenges of Climate Change (Routledge) won a NZ Legal Research Foundation Prize. In 2007 Prue received an outstanding achievement award from the IUCN in recognition of her contribution to law, ethics and climate change. Her most recent books are: Property Rights and Sustainability (Martinus Nijhoff, 2011), together with David Grinlinton; and Common Heritage of Mankind: A Bibliography of Legal Writing (Fondation de Malte, 2013), together with Lucy Stroud. 



\title{
Contributors
}

\author{
Akampurira Andrew, MA (Applied Ethics) \\ Country of affiliation: Uganda \\ $\mathrm{PhD}$ candidate, Applied Ethics \\ Department of Philosophy / Centre for Applied Ethics \\ Makerere University, Kampala, Uganda \\ andak288@yahoo.com
}

Donald A. Brown, BSJD, MA (Liberal Studies)

Country of affiliation: USA

Scholar in Residence and Professor, Sustainability Ethics and Law

Widener University School of Law, Harrisburg, Pennsylvania

dabrown57@gmail.com

Peter D. Burdon, GCertEd (Higher Education), BA, LLB, PhD

Country of affiliation: Australia

Senior Lecturer in Law

University of Adelaide

peter.d.burdon@adelaide.edu.au

Beth Jean Evans, MA (International Development Studies)

Country of affiliation: Canada

PhD candidate, Department of Political Science and School for the Environment

University of Toronto, Canada

bethjean.evans@utoronto.ca

Anne Fouillard, MES (Master of Environmental Studies)

Country of affiliation: Canada

President, Fouduck Group Limited

Self-employed

afouillard@eastlink.ca

Kathryn A. Gwiazdon, BA, JD, Esq.

Countries of affiliation: USA and Japan

Consultant, International Environmental Law and Ethics

kakintzele@gmail.com

Chris Hadley, PGDipES (Environmental Studies)

Country of affiliation: New Zealand

Academic researcher and $\mathrm{PhD}$ candidate

christopher hadley@hotmail.com 
Vivian Ike, BA (Hons) (International Relations and Peace Studies), MA (Political Science) Countries of affiliation: England and USA

Graduate student in Political Science

University of Southern Mississippi

rotanviva@yahoo.com

Rakhyun E. Kim, BSc, MSc, MEL, PhD

Countries of affiliation: South Korea, Australia, New Zealand

Research Fellow

ANU College of Law, The Australian National University

rakhyunkim@gmail.com

Sanna Kopra, MSocSci

Countries of affiliation: Finland and China

$\mathrm{PhD}$ candidate, International Relations

University of Tampere, Finland

Danny Marks, MA (International Affairs)

Country of affiliation: Thailand

$\mathrm{PhD}$ candidate, Human Geography

University of Sydney

danny.marks@sydney.edu.au

Massimiliano Montini, LLB, LLM

Country of affiliation: Italy

Professor of European Union Law; Director, Environmental Legal Team (ELT)

Department of Business and Law, University of Siena, Italy

massimiliano.montini@gmail.com

Martin Oulu, BSc, MSc

Countries of affiliation: Kenya, Sweden

Climate Change Consultant, Inscape Research \& Consulting, Nairobi, Kenya

PhD candidate, Human Ecology Division, Lund University, Sweden

ochiengmoulu@gmail.com

Radhika Perrot, PhD Fellow, UNU-MERIT, Maastricht University, Netherlands

Country of affiliation: South Africa

Senior Researcher

Mapungbwe Institute for Strategic Reflection (MISTRA), South Africa

radhikap@mistra.org.za 


\section{Alessandra Solazzo, LLB, LLM}

Country of affiliaton: Italy

Researcher, Environmental Legal Team (ELT)

Department of Business and Law, University of Siena, Italy

solazzoalessandra@gmail.com

Prue Taylor, LLB, LLM, LLM

Country of affiliation: New Zealand

Senior Lecturer

Deputy Director, NZ Centre for Environmental Law

University of Auckland, New Zealand

Prue.taylor@auckland.ac.nz

Katia Vladimirova, MSc (Economic History) (LSE), MA (Global Studies) (LSE \& Wroclaw) Countries of Affiliation: Italy, Belgium, USA

$\mathrm{PhD}$ candidate, Erasmus Mundus Joint Doctorate (Globalization, EU, Multilateralism) LUISS Guido Carli University, Rome

katya.vladimirova@gmail.com

Sun-Jin Yun, BA, MA, Phd

Country of affiliation: South Korea

Professor

Graduate School of Environmental Studies, Seoul National University

ecodemo@snu.ac.kr 



\title{
Introduction
}

\author{
Donald A. Brown and Prue Taylor
}

\section{Context - why issues of justice and ethics are so important and why they are being overlooked and buried}

Climate change is a problem with certain features that shout for attention for it to be seen as essentially an ethical and justice problem. These features include:

- First, it is a problem that is being caused by some people and nations in one part of the world who are putting other people and nations at great risk in another part of the world who have often done little to cause the problem. Both present and future generations are at great risk.

- Second, the harms to those at most risk are not mere inconveniences but potential catastrophic harms to life, health, and natural resources on which life depends.

- Third, climate change is a problem about which many of those people most at risk can do little to protect themselves by petitioning their governments. Therefore, the best hope of many of those most vulnerable to climate change is that high-emitting nations and people causing the problem will see that they have duties and obligations to the victims to avoid harming them.

- Fourth, because $\mathrm{CO}_{2}$ is well mixed in the atmosphere, all human activities are contributing to rising atmospheric concentrations, and a global solution to climate change requires all nations and peoples to limit their greenhouse gas (ghg) emissions to their fair share of safe global emissions. Therefore, those emitting high levels of ghgs must be willing to limit their ghg emissions to levels determined by principles of justice which determine their fair share of acceptable global ghg emissions.

For these reasons, climate change must be understood as fundamentally a problem of ethics and justice, an insight which has profound significance for policy formation because, among other things, high-emitting nations and entities may not as an ethical matter set climate change policy on economic self-interest alone. They must consider their ethical obligations to poor vulnerable people and nations that will be most harmed by human-induced warming. In fact, there are several policy issues that need to be faced in setting national climate policies that may not be thought of clearly or comprehensively until the nation faces the ethical issues that the policy question raises.

For instance, any national ghg emissions reduction commitment is implicitly a position on two important ethical issues. These are: (a) an atmospheric ghg concentration goal; and (b) the nation's fair share of safe global ghg emissions.

Because all ghg emissions will contribute to atmospheric ghg concentrations, any national target is implicitly a position on an acceptable concentration level of atmospheric ghgs. Yet the question of what is an acceptable atmospheric ghg concentration is an ethical question at its core because the atmospheric ghg level will determine the amount of harm that is experienced by vulnerable people and the ecological systems on which they depend.

Although nations have a clear ethical duty to limit their emissions to their fair share of safe global emissions, they also have a legal responsibility to prevent dangerous climate change. For instance, all nations have ethical duties not to harm others outside their jurisdiction under the 'no harm' principle 
expressly agreed to in the United Nations Framework Convention on Climate Change (UNFCCC, 1992: Preamble). Also, all nations have agreed to adopt policies and measures to prevent 'dangerous anthropocentric interference with the climate system' under the UNFCCC (UNFCCC, 1992: Art 2). Therefore, nations have a clear legal duty to prevent their ghg emissions from causing atmospheric concentrations to rise to levels that will create serious harms to others. And so, any proposed ghg emissions target must be understood to be implicitly a position on both its ethical and legal obligation to limit atmospheric ghg concentrations.

The international community has taken an initial position on what is an acceptable atmospheric ghg concentration in the 2009 Copenhagen climate negotiations when it was agreed to limit warming to $2{ }^{\circ} \mathrm{C}$ to prevent dangerous climate change. ${ }^{1}$ The international community also agreed to further assess whether the $2^{\circ} \mathrm{C}$ warming limit needs to be replaced by a more stringent $1.5^{\circ} \mathrm{C}$ warming limit to avoid dangerous climate change impacts.

Although the international community has identified and agreed to global warming limits, ethical issues remain about whether these warming limits are appropriate given that, even if warming is limited to $1.5^{\circ} \mathrm{C}$ or $2^{\circ} \mathrm{C}$, some vulnerable people are still likely to be severely harmed.

A $2^{\circ} \mathrm{C}$ warming limit was initially chosen because there is substantial scientific evidence that warming above $2^{\circ} \mathrm{C}$ could trigger rapid, non-linear climate change, threatening hundreds of millions of people around the world and the ecological systems on which life depends (Cointe et al, 2011). Even if very rapid climate change is not triggered by exceeding $2^{\circ} \mathrm{C}$ warming, vulnerable people (and ecological systems) will still be harshly harmed by this amount of warming (Cointe et al, 2011).

Stabilizing $\mathrm{CO}_{2}$ equivalent concentrations at 450 parts per million (ppm) would only result in a 50\% likelihood of limiting global warming to $2^{\circ} \mathrm{C}$ (Cointe et al, 2011). Yet atmospheric concentrations of $\mathrm{CO}_{2}$ have already reached $400 \mathrm{ppm}$ and are growing every year.

And so, the challenge facing the world to limit future warming to tolerable levels is extraordinarily daunting, and will likely require a level of global cooperation far beyond any other previous human problem.

Once an atmospheric stabilization goal is determined (that is, $450 \mathrm{ppm}$ ), it is possible to calculate a budget of total ghg emissions that the entire world must live within to achieve that atmospheric stabilization goal. In 2013 the Intergovernmental Panel on Climate Change (IPCC) identified the global carbon emissions budget needed to constrain global ghg emissions to limit warming to $2^{\circ} \mathrm{C}$ and thus give some hope of avoiding dangerous climate change (Freedman, 2013). This budget is of profound significance for national, state and regional ghg emissions reductions targets, yet it is infrequently an explicit element in national discussions about climate change policy. To give the world an approximately $66 \%$ chance of keeping warming below $2^{\circ} \mathrm{C}$, the entire global community must work together to keep global ghg emissions from exceeding approximately 270 metric gigatons of carbon dioxide equivalent emissions (a gigaton is one billion tons). The practical meaning of this budget is that when the 270 gigatons of carbon dioxide equivalent emissions have been emitted, the entire world's ghg emissions must fall to zero to give reasonable hope of limiting warming to the $2^{\circ} \mathrm{C}$. Since the world is now emitting carbon dioxide equivalent emissions at the approximate rate of 10 metric gigatons per year, the world will run out of emissions under the global budget in approximately 27 years. This is a daunting challenge for the world, particularly in light of the fact that global ghg emissions levels continue to increase. Given the very real restraints of a global carbon budget, any national ghg 
emissions target is implicitly a position on the carbon budget its national emissions reductions will achieve.

Any national ghg emissions target is also implicitly a position on that nation's 'fair share' of an acceptable global carbon budget. This issue of 'fairness' raises classic issues of distributive justice and therefore is an ethical issue at its core. And so, any nation's ghg emissions target is implicitly a position on what justice requires of the nation as a percentage of global emissions that will achieve a safe global carbon budget.

The 'fair' allocation question is often debated in international climate negotiations on the basis of what 'equity' requires and what 'common but differentiated responsibilities' require under the UNFCCC. This is so because nations agreed when they ratified the UNFCCC to adopt policies and measures to:

protect the climate system for the benefit of present and future generations of humankind, on the basis of equity and in accordance with their common but differentiated responsibilities and respective capabilities. (UNFCCC, 1992: Art 3)

While all ghg emissions targets are implicitly a position both on the global carbon budget issue and the equity and justice issue, our research has concluded that national policy-makers have very rarely discussed their implicit positions on these issues.

A strong case can be made that any government should be required to expressly identify its assumptions about what amount of the remaining global carbon budget their emissions target will achieve (in cooperation with others), as well as the equity and justice principles which were followed in determining the government's fair share of safe global emissions in setting the nation's emissions target. This is so because when these assumptions are made explicit, it becomes possible to evaluate any national target through an ethical lens.

For the reasons stated above, no nation may think concretely about what its ghg emissions target should be until it faces the two ethical issues that setting a national target raises - namely, the issues of an atmospheric ghg stabilization goal and the 'fair' allocation of a global carbon budget to achieve this goal. In the absence of this ethical reflection, it is all too easy for nations to determine their 'national contributions' according to purely self-interested criteria. Legal responsibility and ethical obligations are conveniently overlooked. National debate is directed towards what a nation can afford in terms of mitigation and adaptation.

Climate change policy-making must also face other important ethics and justice issues including who should be financially responsible for funding necessary adaptation measures in poor vulnerable countries which have done little to cause the problem, and what are the responsibilities of subnational governments, businesses, organizations, and individuals to reduce ghg emissions.

Every claim about what a nation should do in response to climate change has both a factual assumption (usually the domain of science) and normative claim (the domain of ethics and law). As a result, all claims about what a nation's climate policy should be have an implicit normative claim. For instance, a claim that a nation's climate policy must consider its economic interests is sometimes based upon the ethically dubious implicit claim that a nation's economic interests trump its ethical obligations to not cause great harm to others. If controversial normative assumptions of a nation's climate change policy are not made explicit, these controversial ethical positions on their climate change policies often remain obscured or hidden behind what appear to be, at first glance, 'value-neutral' scientific and economic claims. Because few citizens have been trained to spot ethical issues in technical 
arguments, it is all the more important that governments be required to expressly identify their ethical assumptions.

The most recent report of the Intergovernmental Panel on Climate Change, Working Group III, Chapter 3 summarizes the extant literature on ethical concepts that arise when determining adequate climate change policy (IPCC, 2014: Chap 3). Chapter 4 of this IPCC report summarizes the literature on the idea that nations should formulate their ghg emissions reduction targets on the basis of 'equity' (IPCC, 2014: Chap 4). The IPCC report, thus, summarizes a growing literature on ethical issues and concepts relevant to national responses and to the need of the international community to cooperate to achieve a global solution to climate change. It therefore provides some guidance on how nations should evaluate their ethical obligations for climate change. This is the first time an IPCC report has given such close and detailed attention to ethics and justice. It is reflective of a growing awareness that failure to address these issues will be a contributory factor to a failure to create global cooperation on limiting climate change.

Our research has concluded that most nations are either ignoring their ethical duties to the rest of the world in formulating national climate policies or basing their national climate policies on very controversial normative assumptions. In most nations, the normative assumptions behind climate change policy formulation have not been identified. For this reason, it is practically and, given the urgency of the need to reduce global ghg emissions, urgently important to find ways of subjecting national climate change policies to public scrutiny through an ethical lens. Currently, there is no international database on how nations have taken equity and justice into account in setting a national ghg reduction target or otherwise responded to the ethical dimensions of climate change. This project seeks to initiate such an information database by working with researchers around the world.

\section{Genesis of this project and intended contribution}

This study has been largely motivated by the widespread belief that unless nations lift their ghg emissions reductions to levels consistent with their equitable and ethical obligations, there is little hope that the international community will be able to prevent dangerous climate change and that as a result the hundreds of millions of the poorest people in the world and future generations will suffer the harshest consequences.

This project seeks to help deepen explicit ethical reflection around the world on national responses to climate change. The idea for the project was inspired in part by lessons learned from international human rights regimes which have been somewhat successful in advancing human rights by requiring nations to expressly explain how national policies protect and fulfil their human rights obligations.

A large and growing literature linking climate change with human rights has arisen in the last decade. ${ }^{2}$ In a recent open letter to States Parties to the UNFCCC, the Human Rights Council (17 October 2014) urged states to recognize the interdependence between climate change and the enjoyment of fundamental human rights by adopting urgent and ambitious mitigation and adaptation measures. Further, it called for the inclusion of language in a 2015 agreement requiring states to respect, protect, promote and fulfil human rights for all. The letter specifically notes that those least responsible (the poor in developing and developed nations) will suffer the gravest consequences.

One of the ways that human rights protections have been extended throughout the world is through provisions of human rights law that require nations to regularly report on their human rights compliance to committees and tribunals which have been formed at the international and regional level to monitor 
national human rights compliance (UN, 2014). When nations report to these bodies they must explain how they are complying with the human rights obligations that they have consented to when they ratified one of the human rights treaties.

This reporting process often begins with the nation submitting a report on its compliance with a specific human right which is followed by a review of the nation's compliance by the human rights committee established by the relevant treaty. Some human rights committees allow NGOs and other governments to submit reports on the nation's claims about its compliance with its human rights obligations. These comments on the nation's human rights performance usually trigger an obligation of the nation to submit a response to the comments.

This regular reporting on human rights compliance has led to improved human rights compliance by some nations through the creation of a clear public record on the nation's human rights compliance which allows governments and citizens around the world to pressure governments to live up to their human rights obligations.

This kind of public scrutiny on national compliance with human rights obligations needs to be replicated for ethical and justice obligations of nations for climate change given the importance of much greater national consideration of their ethical and justice-based obligations for climate change. Under the UNFCCC, nations currently have no duty to explain their assumptions on ethics, justice and equity implicitly entailed by their commitments on mitigation and adaptation.

This research project seeks to take the first steps in deepening public ethical scrutiny on national climate policy by developing a publicly available record on national compliance with ethical obligations for climate change similar to the reports that are now available on national compliance with human rights obligations. It is likely that human rights tribunals will also become more greatly engaged in creating public records on national compliance with human rights obligations to avoid climate change. However, public scrutiny is also necessary on ethical and justice issues not likely to be taken up by human rights tribunals, such as national compliance with distributive justice considerations in regard to ghg emissions targets and compensation for adaptation and losses and damages.

\section{Summary of some of the key themes arising in the reports}

This section summarizes some of the key themes evident in the reports contained in this study.

No nation expressly identified how their specific national climate policies and commitments have been formulated in direct response to their ethical obligations for achieving a safe global atmospheric concentration and to limit their emissions to their fair share of a carbon budget that will achieve the acceptable atmospheric concentration, or their ethical responsibility for funding for adaptation or losses in damages in vulnerable counties. Some nations acknowledge that their climate policies need to be guided by ethical principles - for instance, Bolivia, South Africa and Japan. Yet no nation expressly explains quantitatively how this was accomplished in setting their national policies, leaving the impression that economic self-interest influenced their actual commitments. Some nations, including the United States, acknowledge no need to consider ethical and justice considerations in formulating national climate policies.

Most reports revealed an absence of consideration of climate change policy within the broader context of sustainable development. Only a few mentioned the usefulness of the United Nations Millennium Development Goals as introducing broader ethical considerations that apply equally to 
climate change. It will be interesting to see if their replacement by the United Nations Sustainable Development Goals will encourage better integration. South Africa is credited with championing the responsibility of developed nations to address the equity aspects of climate change within the broader context of sustainable development. Perversely, the New Zealand government is making a deliberate retraction from the sustainable development concept.

In a number of countries (both developed and developing), climate change is not receiving significant public and political attention at the national level. In simple terms, climate change is not a priority. It is secondary to economic and financial issues (for example, Italy, Australia, New Zealand, the United States). As a related point, some nations primarily consider climate change as a means of achieving economic growth under the banners of 'green economy' or 'green growth'. The focus here is on using technological responses to climate change as a means of achieving economic advantage (Italy, the Netherlands, South Korea). This approach does not embrace the ethical and justice dimensions of climate change. In South Korea, for example, a green growth agenda was used as the platform for announcing voluntary emissions reduction targets. The nation's objectives were to become a leader in the global green market and to enhance its international status and reputation. In the Netherlands, most policy objectives are intended to provide affordable and clean energy supply, jobs, and market opportunities for clean technologies. In the case of South Africa, the potential of green jobs was linked to the broader objective of significant poverty eradication.

Governments in New Zealand and Australia were particularly explicit about economic prosperity as the primary justification for any climate change response. In Australia, the Gillard government emphasized economic prosperity over morality in these terms: 'History teaches us that the countries and economies that prosper are those that . . manage the change' (Morton, 2011, p1). In New Zealand there are frequent references to economic interests in policy advice to government and no reference to issues of ethics and justice. This is so despite that country's acknowledged responsibility towards small island developing states (SIDS). The New Zealand report reveals a particular kind of hypocrisy; while it refuses to be proactive of mitigation (for economic reasons), it might extend a helping hand with adaptation measures.

Few countries explain how their commitments on mitigation in regard to emissions reductions targets considered ethical and equity principles at all. Some countries such as South Africa acknowledged that national commitments must be based on equity and acceptable warming limits, but did not explain how the specific ghg emissions reductions commitments were derived or influenced by ethical principles, leaving the strong impression that actual numerical commitments were based upon national economic considerations that were not identified. No country explained quantitatively how their mitigation target commitments derived from specific equitable considerations such as historical or per capita emissions.

In contrast, Japan seems to be approaching climate change policy from a very different ethical perspective. The report uses the example of the Building a Low Carbon Society policy with its emphasis on low-consumption lifestyles and living in harmony with nature. Of all the nations reported on in this book, Bolivia is the exception. It draws strongly and explicitly upon ethical justifications for requiring deep cuts in national ghg emissions by other nations, together with financial contributions and holistic mitigation and adaptation measures, capable of both reducing poverty and vulnerability to climate change. While much of Bolivia's focus is on the performance of other nations, there is evidence that it is alert to its own actions. For example, the Bolivian Constitution enshrines the 
indigenous concept of 'buen vivir' (or 'living well'), which is seen as antithetical to consumer culture and unlimited economic growth.

A significant number of nations explicitly accept the 2 degrees warming limit (for example, Italy and the Netherlands), but the Australian government has neither confirmed nor denied its acceptance of this pivotal climate change factor. The United States has taken a slightly different approach, its failure to make any reference to either the 2 degrees warming limit (or global carbon budget) means that we can only speculate on the justification for its targets of $17 \%$ below 2005 levels by 2020 and $80 \%$ below 2005 by 2050 . Bolivia alone has denounced 2 degrees as unacceptable due to the high risk that this amount of warming poses to Mother Earth.

Despite the otherwise wide acceptance of the 2 degrees warming limit, the actual ghg emissions targets and timetables chosen do not meet the levels of reductions specified by the IPCC as necessary to keep atmospheric concentrations of ghg below 450ppm and the 2 degrees warming limit within range. This outcome is consistent with the work of the Climate Action Tracker. It highlights the significant gap between national commitments (individual and collective) and what is required to keep within 2 degrees. According to their work, the world is currently on target to hit warming of 3.7 degrees by 2100 (Climate Action Tracker, 2013).

A related theme is the use of conditional targets and timetables (for example, New Zealand, Australia, the European Union). The justification for this approach is not always clear, except in the case of New Zealand. The government has frequently referred to a determination to be a nation that neither 'leads nor lags' on climate change. The implication is that this nation fears economic disadvantage should it show any leadership (or ambition) on climate change policies.

While a number of nations are prepared to directly reference and support the 2 degrees warming limit, far fewer nations are prepared to link their emissions reduction targets to a global carbon budget and any determination of what their 'fair share' of that global budget might be. Interestingly, this is so even when a developed nation (such as the Netherlands) is pressing for a greater EU emissions reduction target for 2030. In other words, it is not using ethical arguments concerning fair share. The Australian report demonstrates that declaring moral leadership on climate change (for example, the Rudd government) will not alone be sufficient to negotiate political process and deliver robust ethically based climate change policies. Maintaining public commitment, generating and holding cross-party support, and managing vested interest in opposition will also be critical.

Virtually all of the reports reveal the need to look beyond the rhetoric of 'fair share', if and when it is used. We must question: what does this actually mean?; how is it calculated?; what levels of reduction will it actually deliver? In the case of New Zealand, for example, 'fair share' is not a reference to a share of the global carbon budget nor is it a reference to per capita emissions. It is a reference to that nation's contribution - as a percentage of global ghg emissions, which is very small. This definition of 'fair share' distracts attention from New Zealand's exceptionally high per capita emissions of 7.6 tonnes. The government's ethically corrupt definition of 'fair share' is used to convince the populace that the nation should not show any international leadership but do only its 'fair share'. As has been pointed out, this amounts to expecting the rest of the world to carry the burden of climate change, and not New Zealand.

In the case of Australia, politicians have been interpreted as using the language of ethics to protect purely national concerns. For example, the statement: 'Failure to do our fair share is not a clever position for Australia, which is the developed country most vulnerable to climate change. Especially 
when we are going through a once-in-history boom in incomes' (Department of Climate Change, 2011, p2) is seen to provide protection for Australian coal exports (which have grown to more than 300 million tonnes a year) and appeal to concern about climate change vulnerability. A similar approach is evident in the United States. Regulations to limit emissions from the electricity sector were justified as necessary to protect the health of Americans and not as being necessary to prevent harm to vulnerable people in other nations, or future generations.

South Africa provides an interesting contrast to New Zealand, Australia and the United States. As a Non-Annex I country it has apparently acknowledged its status as the highest ghg emitter on the African continent and announced a voluntary emissions reduction target, the objective of which is to make a 'fair contribution' to keep global concentrations within the range required to keep within the 2 degrees warming limit. South Africa openly acknowledges the need to voluntarily respond to climate change despite the deadlock in international negotiations. Yet the actual emissions reduction target identified by South Africa does not explain how it is quantitatively linked to an atmospheric warming limit or South Africa's fair share of safe global emissions. In fact, the South African target, because it is a commitment below business as usual, allows for large increases in South African ghg emissions by 2020 and 2025 without explaining how these increases are consistent with a specific understanding of what equity requires. Because all nations should understand they have an ethical duty to limit their ghg emissions without denying that many poor nations would be allowed to increase emissions in ways consistent with ethical principles, even developing nations should explain what specifically ethics and justice requires of them. One element in the South African approach is potentially worthy of emulation by other developing countries. It set a ghg emissions target, implicitly although not explicitly, at levels required of it by ethics and equity principles, but then asserted that the achievement of this target was contingent on getting financial support from developed countries. If developing nations did this they could make explicit what portion of an emissions reduction target was the responsibility of developed nations. However, if developing nations choose to follow this example, they will need to formulate an ethical and equity principle for where the line is drawn between who has financial responsibility.

In the case of EU Member States, the collective decision-making process of developed states (together the highest historic emitters) has not led to any greater ethical analysis, although there may be some opening with respect to gender issues (see Italian report). This is so despite the EU experience in using ethical principles to decide upon and allocate minimum contributions to each Member State (report on Netherlands).

Despite the lack of explicit reference to ethics and justice by most nations, two of the developing countries (South Korea excluded) are attempting to take positive mitigation action because they recognize the need and the responsibility toward their own nationals (South Africa and Uganda). Again, Bolivia is a special case. Its willingness to take mitigation measures, while linked to its own climate vulnerability, is conditional upon funding, technology, and developed countries meeting the full costs of developing countries' climate policy measures.

In stark contrast to the vague references to a 'fair share' of the global carbon budget by some nations, Bolivia is unequivocal. It has been emphatic that an 'equitable sharing of atmospheric space is an inalienable and fundamental right of all nations and people', and that developing countries whose contributions to global ghg levels have been very small should therefore be given 'atmospheric space' to pursue the priorities of economic and social development (Plurinational State of Bolivia, 2010). Thus, for Bolivia, the allocation of atmospheric space should be 'carried out according to the rights to development of Parties [to the UNFCCC] and to the rights of Mother Earth to adapt naturally to climate 
change' (Bolivia report). Bolivia is adamant that emissions reductions must take into account both historic emissions, continuing excessive per capita emissions, and absolute emissions.

Many of the reports provide a reminder that we must keep an eye both on what nations say and on what they actually do. As the China report points out, that nation's increasing emissions profile is partly attributable to the growth of 'offshore emissions' - that is, emissions from the manufacture of products demanded by and consumed in other countries. New Zealand is one of the few nations to withdraw from the second commitment period of the Kyoto Protocol.

Two national reports (New Zealand and Australia) revealed some reference to the concept of contraction and convergence, but no nation is implementing this approach.

Some reports, namely Australia and the United States, refer to the role of climate change denialists and opponents of climate change policy as contributing significantly to keeping ethics and justice off the agenda and economic interests at the forefront. In both these countries, the media and NGOs were identified as providing a weak counterbalance. The Russian report provides a unique perspective, with a significant number of government scientists being sceptical about climate change.

No national reports deny responsibility for contributions to adaptation and losses and damages, but no nations have made an express link between their ethical responsibility for supporting adaption and compensation for losses and damages in vulnerable countries and what they have committed to. Adaptation contributions seem to be left to the largess or interests of individual nations, leaving them free to withdraw (for example, Australia) or determine the scale and nature of contributions. Even when a nation is a major contributor to adaptation (for example, Japan), its activity is not explicitly linked to its own emissions targets. Related to this, there was a noticeable absence of explicit use of the concept of climate justice by developed nations. In contrast, Bolivia is using the concept of climate debt to mean liability for historic and continuing emissions and failure to take mitigation and adaptation actions. As the Bolivian report details, Bolivia is the champion on climate justice with a highly developed and multi-faceted concept that includes demands for a compensation mechanism beyond provision for adaptation of developing states. It apparently extends to addressing the root causes of climate change - namely, the exploitative economic systems and consumerist lifestyles. The United States, on the other hand, explicitly rejected the notion of climate debt and is hostile to compensation for losses and damages by high-emitting nations (that is, the Warsaw Mechanism).

Non-Annex I countries reported on have adopted a range of nationally appropriate mitigation actions (NAMAs). China's NAMA is described in these terms: 'China will endeavor to lower its carbon dioxide emissions per unit of GDB by $40-45 \%$ by 2020 compared to the 2005 level, increase the share of nonfossil fuels in primary energy consumption to around $15 \%$ by 2020 and increase forest coverage by 40 million hectares and forest stock volume by 1.3 billion cubic meters by 2020 from the 2005 levels' (Su, 2010). This approach is reported as enabling China to present itself as a responsible international citizen yet allowing it to preserve its position of resisting binding commitments for developing nations, arguing (in part) a lack of historic responsibility for climate change. Climate change policy has referenced both national interests (including a moral responsibility to pursue economic development to lift parts of its populace out of poverty) and human survival and development.

In the case of South Africa, NAMAs focus more on adaptation (due to the vulnerability of the nation) but have mitigation potential and are pivotal to overall climate change policy. In contrast, Uganda's NAMAs, while having mitigation potential, are not part of an overarching climate change policy. National mitigation efforts are considered to be highly dependent on technology transfer. Bolivia 
takes a very different approach to NAMAs. It rejects any national ghg emissions reduction targets on ethical grounds - assigning responsibility to developed nations. However, in adopting NAMAs it does so with the intent of demonstrating cooperation and in the expectation that developed nations will respond by meeting their own commitments, including funding of mitigation and adaptation. In fact, Bolivia's mitigation efforts are said to be conditional upon funding and technology transfer. Furthermore, Bolivia's position is that mitigation assistance should be viewed as payment of a climate debt (not a handout) - in rectification of historic injustices and continuing inequities. Many developing nations appear to believe that their status as a developing nation relieves them of all responsibility to limit their ghg emissions to their fair share of safe global emissions despite the fact that all nations have a responsibility to keep ghg emissions to levels consistent with equity and justice, even though some developing nations could argue that ethical principles justify significant expansion of their ghg emissions. South Africa is an interesting case in this regard. Although South Africa expressly acknowledged the need of all nations to limit their emissions to levels consistent with a warming limit and the nation's fair share of safe global emissions, it asserted it had a strong right to achieve economic growth to alleviate poverty and the socio-economic injustices created by apartheid without explaining how its target emissions reductions were consistent with any equity framework that could be applied universally.

Many nations have formal mechanisms ensuring public access to information and rights to participate in law-making. However, the prior act of policy development often resides in the exclusive domain of government (for example, the Netherlands), and as pointed out in the instance of Australia, governments usually define the issues for consultation, set the questions and manage the process. Limited opportunities to contest the ethical premises of policy would seem to be a critical omission given the finding that policy-makers themselves omit to explicitly engage in ethical reflection and the observation that 'the dominance of economic models has meant that the study of values and value change has been neglected' (Jamieson, 1992, p150).

An exception seems to be South Africa where a formal mechanism exists giving stakeholders input into the policy development process. The government's open processes on climate change and development have been attributed to an effort to provide redress for the previous closed governmental processes of the apartheid era. However, industry and mining interests have been most successful in directing national policy. South Africa's constitutional recognition of a right to the environment and to protection for the benefit of present and future generations also plays an important role in facilitating public involvement in policy-making. Both the Bolivian Constitution and the law recognizing the rights of Mother Nature have been highly instrumental in giving civil society (including indigenous peoples) a role in determining Bolivian climate change policy.

The reports reveal mixed involvement of subnational governments in climate change mitigation and adaptation and it is not clear that they are taking a more ethically robust approach. In the United States, for example, there is considerable activity by subnational governments but no express reference to ethics in determining reduction commitments.

As regards the role of NGOs, the media and others, some of the reports suggest that NGOs have become complicit in the failure of governments and civil society to subject climate change policy to ethical analysis. In Australia, for example, it is reported that many NGOs now frame their campaigns in purely instrumental or economic language and have become distant from their membership and grassroots issues, all in an effort to gain access to power and the attention of the media. In the United States, NGOs and the media have failed to subject arguments used to justify climate policy to ethical 
analysis. With very few exceptions, the press has utterly failed to cover climate change as an ethical and moral issue and instead has focused on the scientific and economic arguments against taking action - arguments that have been framed by opponents of climate change policies. The combined omission and focus on economic/scientific issues reinforces the view that cost is an acceptable (and value-free) justification for climate change policy. As a result, there is little opportunity to explore how ethical obligations can translate into practical advances for domestic climate change policy. In the case of the United States, the implications of this approach are enormous for vulnerable peoples, future generations and ecoystems, both domestically and globally.

Rather perversely, the Russian report suggests that the strategy of national and international NGOs to explicitly frame climate change in terms of Russian national interests and cost-benefit was essential to getting Russia to take any action on climate change, it having been determined that: 'Appeals to international obligations, to issues of international intra- and intergenerational justice, especially framed in monetary terms, have no success in triggering action or even response from the Russian government' (Russian report).

On the other hand, in the case of South Korea, NGOs are reported as being active in arguing climate justice and pushing the government to take a leadership role, commit to an ambitious target, and accept that differentiated responsibilities (based on historical emissions) are an obligation and not a choice. NGOs have been arguing for greater emissions reductions, but have been unsuccessful. The government is reported as giving far more attention to the voice of industry representatives.

Although this project has focused on the ethical issues that a nation must face because their climate policies must consider the ethical responsibilities of nations to prevent global warming and its likely very harsh consequences on people around the world, several reports also identified purely domestic ethical issues that nations need to consider in setting national climate policy. South Africa, for instance, identified their need to set national climate policies in response to the needs of poor and vulnerable people in South Africa. We agree that climate change policy-making raises ethical issues not only of international significance but of domestic importance. Given this, it is important for nations to expressly explain how ethical issues at the national level affected their response to their international ethical responsibilities. Failure to be clear about where lines have been drawn will encourage countries to allow domestic economic needs to eviscerate global responsibilities.

\section{Recommendations}

The reports in this study include recommendations for bringing issues of justice and ethics to the fore nationally. This section provides an overview of some of these recommendations and adds other recommendations that emerge from the findings of the reports.

\section{Raising public awareness of ethical and justice issues}

This could be achieved in a number of ways including by increasing public understanding of the work of the IPCC, in particular the concept of a global carbon budget which requires an allocation amongst all emitters and requires high emitters to reduce by greater amounts than others. Visual representations of equity issues may be helpful in this process, together with strong international voices in support of the IPCC's reports. The media, NGOs, education institutions, academia, businesses and other social actors must all become involved in lifting both public awareness and the ability of the public to engage in ethical critique and analysis. This must lead to greater prioritization of ethical and justice issues and 
to a demand that governments (operating at national and international levels) expressly justify climate change measures in ethical terms.

As subnational governments operate at the local level, they have a role and responsibility to help raise the awareness of local communities and to facilitate ethically responsible action. National governments have a role to play in supporting the coordinated actions of subnational governments.

\section{NGOs need to be held accountable and should be required to justify their poli- cies/actions in ethical terms}

NGOs need to be more radical and return to their grassroots memberships and issues. They could work together more proactively to amply their voices - for example, the 2009 Climate Change Ethics Forum under the auspices of UNESCO (see South Korea report).

\section{Exposure of vested interests}

Vested interests that operate in opposition to the development of ethical climate change policy need to be exposed by robust processes that prevent and expose unfair influence. The media should be encouraged to report on the background (affiliations and funding) of all stakeholders.

\section{More formal mechanisms for contesting national climate change policies need to be developed, as appropriate to individual countries}

Training for policy-makers and national politicians of the ethical issues inherent in climate change policy will also be required. National politicians should be encouraged to challenge the policies of incumbent governments by requiring justification for policies against criteria of ethics and justice. In practical terms, governments should be asked to explain how their emissions targets and timetables represent a fair share of the global carbon budget and meet the global objective of limiting warming to within 2 degrees.

\section{The need to maintain our commitment to these issues}

Given the propensity of nations to base domestic policy on national economic interest alone and in light of the vital importance of national responses based on ethical obligations, the kind of research undertaken in this book needs to be extended and continued to create a public record of national compliance with ethical obligations for climate change. The case studies in this book need to be periodically reviewed and extended as new issues arise and positions of governments change. This project has created a website, www.nationalclimatejustice.org, which will become the locus of this project's future work.

Our research leads us to conclude that not only does the international community need to find venues and mechanisms for holding nations accountable for their response to climate change on the basis of ethics and justice, but citizens concerned about climate change also need to demand that nationallevel debate about climate change expressly examines the potential ethical and justice failures of national policy. The widespread absence of consideration of the ethical and justice dimensions of national climate change policies that we have found in most nations leads to the inescapable conclusion that civil society needs to greatly increase general awareness of ethical failures of national climate policies. 
The conclusion that there is a great need for civil society to raise public awareness of the ethical issues entailed by climate change is also supported by the lack of coverage by the national media, in at least some nations, of the ethical dimensions of climate policies. In the United States, for instance, the media has consistently utterly failed to cover the ethical and justice issues which are at the heart of contention in international climate negotiations. The efforts of civil society alone are unlikely to be sufficient. There is little hope that nations will respond to their ethical obligations to reduce the threat of climate change if national-level NGOs also fail to make the ethical dimensions of national climate change policy visible in national climate change debates. If national-level NGOs raise the ethical problems with national responses to climate change it becomes more likely that the national media will cover these issues.

For these reasons, the goal of this project's research is to help deepen ethical reflection on the justifications for national climate change policies. It is also hoped that this ethical reflection will lead to public and political momentum towards far more ambitious and ethically responsible mitigation and adaptation responses. However, for this to occur, humanity must resolve to act in a more morally courageous and honest manner than we have thus far achieved.

\section{From Lima (COP 20) to Paris (COP 21).}

The results of our research were presented at a side-event to the Lima Conference of the Parties (COP) 20, in December 2014. As a result and in light of discussion at that event, a list of "Lessons Learned So Far" was created and is posted on the project website: www.nationalclimatejustice.org. We recommend that readers of this report consult that list, which will be added to (via the website) as this project progresses.

We would also like to draw the attention of readers to an interesting initiative that emerged at the Lima COP 20. Up until a few days before the end of the COP the text prepared by Ad Hoc Working Group on the Durban Platform for Enhanced Action, (ADP) included language that nations should submit, along with their national contributions, information that would allow nations and observers to understand:

$[\mathrm{H}]$ ow the commitment was fair and equitable and how it helped achieve the goal of holding the increase in global average temperature below $2^{\circ} \mathrm{C}$ or $1.5^{\circ} \mathrm{C}$ above pre-industrial levels and in order to enhance understanding among Parties of the intended nationally determined contributions, to provide opportunities for seeking and providing clarification to Parties and admitted observer organizations via electronic means,....and that nations are encouraged through the electronic means referred [to provide] written responses through the secretariat to questions for clarification within one month of the questions being made available. (UNFCCC, 2014a, ADP, 2-7_11 Dec 11)

In this way, the ADP text included a mechanism that would give governments and NGOs the ability to question governments on how their commitments helped achieve a safe global carbon budget and were fair and equitable. Many NGOs pushed for this text be strengthened to include a duty upon nations to respond to questions from other governments and NGOs. However, the draft text only provided that nations were "encouraged" to supply written responses. Ultimately, the final text adopted in Lima completely removed the requirements that nations "should" include information on fairness and environmental adequacy and replaced this with a discretionary "may" requirement. The final text also completely removed provisions that would have established the right of nations and NGOs to question governments about their commitments. The relevant final language is as follows: 
13. Reiterates its invitation to all Parties to communicate their intended nationally determined contributions well in advance of the twenty-first session of the Conference of the Parties (by the first quarter of 2015 by those Parties ready to do so) in a manner that facilitates the clarity, transparency and understanding of the intended nationally determined contributions;

14. Agrees that the information to be provided by Parties communicating their intended nationally determined contributions, in order to facilitate clarity, transparency and understanding, may include, as appropriate, inter alia, ... and how the Party considers that its intended nationally determined contribution is fair and ambitious, in light of its national circumstances, and how it contributes towards achieving the objective of the Convention as set out in its Article 2. (Decision-/ CP.20)

Ironically those most responsible for successfully stripping the text of language requiring mandatory reporting, has widely been reported to be a group known as the "Like Minded Developing Countries" or LMDCs (Third World Network, 2014). The LMDCs fought to have the mandatory provisions on reporting and the right to question nations removed from the final text because they believed it helped undermine the provisions in the UNFCCC which created a clear distinction between developed and developing countries under the concept of "common but differentiated responsibilities" (Third World Network, 2014). Despite the final outcome, this was a interesting initiative that illustrates a real effort to create a mechanism to hold nations to account. 


\section{Notes}

1 For a history of where the $2^{\circ} \mathrm{C}$ warming limit came from, see Cointe et al, 2011.

2 Some of the most comprehensive literature on the subject includes: Bodansky, 2010; Center for International Environmental Law, 2010; Humphries, 2010; Knox, 2009; OHCHR, 2009; World Bank, 2011.

\section{References}

Bodansky, D. (2010) 'Climate Change and Human Rights: Unpacking the Issues', Georgia Journal of International and Comparative Law, vol 38, no 3, pp511-524, http://papers.ssrn.com/sol3/papers.cfm?abstract id $=1581555$

Center for International Environmental Law (2010) Climate Change \& Human Rights: A Primer, http://www.ciel.org/ Publications/CC HRE 23May11.pdf

Climate Action Tracker (2013) 'In talks for a new climate treaty, a race to the bottom', 20 November, http:// climateactiontracker.org/news/151/In-talks-for-a-new-climate-treaty-a-race-to-the-bottom.html

Cointe, B., Ravon P.-A. and Guérin, E. (2011) $2^{\circ} \mathrm{C}$ : the history of a policy-science nexus, Working Papers no 19/11, Institute for Sustainable Development and International Relations, Paris, http://www. climateemergencyinstitute.com/uploads/2C_history.pdf

Department of Climate Change (2011) 'Final Report: Our Fair Share of Climate Action Much More Expensive without Carbon Pricing', Media release, 31 May, http://www.garnautreview.org.au/update-2011/media/110531final-report.pdf

Freedman, A. (2013) 'IPCC Report Contains "Grave” Carbon Budget Message', Climate Central, 4 October, http:// www.climatecentral.org/news/ipcc-climate-change-report-contains-grave-carbon-budget-message-16569

Human Rights Council, 'A New Climate Change Agreement Must Include Human Rights Protections for All', Open Letter dated 17 October 2014, http://newsroom.unfccc.int/media/127348/human-rights-open-letter.pdf

Humphreys, S. (ed.) (2010) Human Rights and Climate Change, Cambridge University Press, Cambridge, http:// www.cambridge.org/us/academic/subjects/law/human-rights/human-rights-and-climate-change

Jamieson, D. (1992) 'Ethics, Public Policy, and Global Warming', Science Technology \& Human Values, vol 17, no 2, pp139-153, http://philosophy.as.nyu.edu/docs/IO/1192/ethics_pub_policy.pdf

Intergovernmental Panel on Climate Change (IPCC) (2014) Working Group III, Climate Change 2014: Mitigation of Climate Change, http://www.ipcc.ch/report/ar5/wg3/http://www.ipcc.ch/report/ar5/wg3/

Knox, J. H. (2009) 'Climate Change and Human Rights Law', http://works.bepress.com/cgi/viewcontent. cgi?article $=1002 \&$ context=john_knox

Office of the High Commissioner on Human Rights (OHCHR) (2009) 'Report of the Office of the United Nations High Commissioner for Human Rights on the relationship between climate change and human rights', A/HRC/10/61, 15 January, http://www.ohchr.org/EN/Issues/HRAndClimateChange/Pages/Study.aspx

Morton, Adam (2011) 'Carbon tax countdown to July 2012 start date', The Age, 25 February, p1

Plurinational State of Bolivia (2010) 'Submission to the WG-LCA', http://pwccc.wordpress.com/2010/04/28/ submission-by-the-plurinational-state-of-bolivia/, accessed 10 August 2014

Su, W. (2010) Untitled letter from Su Wei, Director-General of Department of Climate Change, National Development and Reform Commission of China to Yvo de Boer, Executive Secretary of the UNFCCC Secretariat, 28 January, https://unfccc.int/files/meetings/cop_15/copenhagen_accord/application/pdf/chinacphaccord_ app2.pdf, accessed 11 August 2014

Third World Network (2014) Common but differentiated responsibilities' principle restored in COP 20 decision. Retrieved from http://twn.my/title2/climate/news/lima01/TWN update26.pdf

United Nations (2014), 'The United Nations and Human Rights', http://www.un.org/rights/dpi1774e.htm

United Nations Framework Convention on Climate Change (UNFCCC) (1992), 771 UNTS 107; S. Treaty Doc No. 102-38; U.N. Doc. A/AC.237/18 (Part II)/Add.1; 31 ILM 849 (1992) Preamble

World Bank, The (2011) Human Rights and Climate Change: A Review of the International Legal Dimensions, http:// siteresources.worldbank.org/INTLAWJUSTICE/Resources/HumanRightsAndClimateChange.pdf 



\title{
A Change in the Weather?
}

\section{Australia and Climate Change Politics 2007-2014}

\section{Peter D. Burdon}

This report responds to the research questions of the Project On Deepening National Responses to Climate Change On The Basis of Ethics and Justice, a joint project of the University of Auckland, School of Architecture and Planning and Widener University, School of Law, Environmental Law Center. The research questions and responses are as follows:

In April 2007 at the national conference of the Australian Labor Party, Kevin Rudd walked onto the stage. Rudd was just months away from toppling the then Prime Minister John Howard. ${ }^{2}$ The song 'A Change in the Weather' accompanied Rudd's approach to the platform. As several commentators have noted, this song was chosen to represent to voters that they could expect a significant shift in climate policy from a Labor government (Chubb, 2014, p3). The lyrics read:

\author{
No do you remember \\ I promised in winter \\ That our hearts would be lighter one day? \\ And sooner than later \\ the sky would be brighter \\ And everything would be ok?
}

For many, Australian's Rudd represented an energetic and moral leader. He was full of energy and the promise to flood Australia with new ideas and exciting projects. In his address to the national conference, Rudd promised to tackle climate change which he described as the 'great moral challenge of our generation'. His plan was 'to forge a national consensus' and examine how 'we best recognize as a nation to deal with this' (Kelly, 2007, p12). Upon becoming Prime Minister in December 2007 Rudd's first official act was to ratify the Kyoto Protocol at the 2008 UN Climate Change Conference in Bali. This act received a minute-long standing ovation and the Indonesian environment minister, Rachmat Witoelar commented: 'I think I speak for everyone here when I express a sigh of relief' (Fitzpatrick and Warren, 2007, p6).

The only discordant response came from environmental groups who sought to keep pressure on the government to fulfil the obligations of the Protocol and transition domestic energy consumption away from coal. ${ }^{3}$ Consciously following Rudd, a report prepared by the Institute for Sustainable Futures said that Australia now had a 'moral responsibility to adopt a steep target for emission cuts because of its higher per capita contribution to climate change' (Franklin and Ryan, 2007). As we will see, the government's confrontation with the coal industry would be a decisive factor in their own unravelling and paved the way for Australia's current regression on climate policy under the leadership of Tony Abbott and the Liberal National Party (LNP) government (Marr, 2010; Pearse, 2013; Chubb, 2014).

To answer the assigned questions for this study, I have consulted a range of primary and secondary sources, namely: policy-related government documents; media articles; public statements on climate change; and government statements to the UNFCCC. It must also be noted that during the period under investigation, Australia had four Prime Ministers and one election that shifted national politics from a centre-left to a centre-right government. ${ }^{4}$ As a result of these tumultuous events and the sheer complexity of pricing carbon in a country so dependent on coal, the Labor government abandoned 
moral or ethical justifications for climate action. Instead, the vast majority of public material reveals a deep focus on instrumental rationality (Weber, 1978, pp24-25), economic concerns, and for Australia to only do our 'proportionate share' of any global mitigation effort.

1. To what extent has the national debate about how the nation should respond to climate change by setting a ghg emissions reduction target expressly considered that the nation not only has economic interests in setting the target but also ethical obligations to those who are most vulnerable to climate change and that any national ghg emissions reduction target must represent the nation's fair share of safe global emissions? In answering this question, identify the national ghg emissions reduction target, if any, that the nation has made under the United Nations Framework Convention on Climate Change (UNFCCC).

Kevin Rudd's prime ministership was founded on his moral commitment to climate action. ${ }^{5}$ In February 2008, Prime Minister Rudd told Parliament that moving quickly on climate change was the only economically and morally defensible thing to do. Rudd argued: 'the costs of inaction on climate change are much greater than the cost of action' and that 'Australia must ... seize the opportunity now to become a leader globally' (Macintosh et al, 2010, p202). The cornerstone of Rudd's climate policy was the Carbon Pollution Reduction Scheme (CPRS). Penny Wong, the Minister for Climate Change, described the CPRS in the following terms: 'The successful introduction of this scheme will be the most significant economic and structural reform undertaken in Australia since the trade liberalisation of the 1980s' (Wong, 2008, p3).

In the course of the policy debate over the implementation of the CPRS it became gradually clear that ratifying the Kyoto Protocol was a largely symbolic act and that it would be the high point of Rudd's moral leadership on climate change. As Phillip Chubb suggested, Australia then entered 'the barren years, 2008-2010' (Chubb, 2014, pp14-15). A succession of reports, including the Green Paper on the Carbon Pollution Reduction Scheme (2008), The Wilkins Review of Australian Government Climate Change Programs (2008), The Garnaut Climate Change Reviews (2008 and 2011), and Treasury's Australia's Low Pollution Future (2008) all failed to reference Australia's moral responsibility to reduce emissions and our ethical obligations to vulnerable countries. Instead, government reporting focused on protecting Australia's 'international competitiveness', 'domestic economy' and limiting action to our 'appropriate' or 'full proportionate share' of any global mitigation effort.

In December 2008 the government released their White Paper detailing a greenhouse gas (ghg) emission reduction target of $5 \%$ below 2000 levels by 2020 . The target would only rise to $15 \%$ in the event of 'global agreement where all major economies commit to substantially restrain emissions and all developed countries take on comparable reductions to that of Australia' (Commonwealth of Australia, 2008). The target of 5\% was amended during the 2009-2010 budget and a new target was set at $25 \%$ by 2020 on 2000 levels but only if 'the world agrees to an ambitious global deal to stabilise levels of $\mathrm{CO}_{2}$ equivalent at 450 parts per million or lower by mid century' (Rudd, 2009). Legislation codifying this policy was defeated three times in Parliament. ${ }^{6}$

On 24 June 2010, Julia Gillard successfully challenged Rudd and became Prime Minister of Australia. As well as establishing a Climate Commission to provide expert advice and information on climate change, the government also commissioned an update to the Garnaut Review that was realized on 31 May 2011. Consistent with reports released under the Rudd government, the second Garnaut Review focused on economics and the importance of Australia 'contributing its proportionate part' 
to the global response to climate change. At the launch of the report, Ross Garnaut highlighted the importance of Australia transitioning to a low-carbon economy: 'Failure to do our fair share is not a clever position for Australia, which is the developed country most vulnerable to climate change. Especially when we are going through a once-in-history boom in incomes' (Department of Climate Change, 2011, p2).

On 27 September 2010 the Gillard government established an innovative policy-making body called the Multi-Party Climate Change Committee (MPCCC). ${ }^{7}$ On 24 February 2011 the MPCCC detailed the broad-brush strokes of a policy to pursue a fixed carbon price for three years as an interim measure, to evolve into an Emissions Trading Scheme (ETS) in 2015-17. The ETS would require major polluters to buy a permit for each tonne of carbon emitted from 1 July 2012. Following Garnaut, Gillard highlighted economic prosperity rather than morality to defend the policy: 'History teaches us that the countries and economies that prosper are those that get in and shape and manage the change' (Morton, 2011, p1). Further details of the policy emerged on 30 June 2011 when a ghg emissions reduction target was reset at $5 \%$ below 2000 levels by $2020 .{ }^{8}$ Moreover, the fixed carbon price was set at $A \$ 23$, with increases of $2.5 \%$ per annum in real terms. The government also made allocations for generous compensation and free permits for heavy-emitting power stations (Garnaut, 2008, pp13-46).

It took three months, from July to October 2011, for the Clean Energy Future Bill 2011 (Cth) to finally pass the House of Representatives by a 74 to 72 vote. Prime Minister Gillard stated: 'Today, the House of Representatives moved from words to deeds ... This Parliament today has grabbed the future with both hands ... we have got this done' (Kirk, 2011).

In the background to these developments, the then opposition leader Tony Abbott was successfully framing the debate and the popular public discourse on climate change. He immediately characterized the carbon price as a tax and argued that from 1 July 2012 the following disasters would occur: price rises will be unimaginable; power bills will jump by as much as $30 \%$; the coal, steel, cement, aluminium and motor industries will be destroyed; hundreds of thousands of jobs will be lost; and regional towns and cities will be wiped off the map. When judged against people's lived experience of the Clean Energy Future Bill 2011, each of these statements proved to be false (Chubb, 2014, pp240-249). Yet, Abbott was enormously successful in spreading his scare campaign. He described the government's policy as 'an utter betrayal of the Australian people' ${ }^{9}$ and even called for a 'people's revolt' which attracted overwhelming support from the coal industry and large sections of the media (Chubb, 2014, pp161-165).

Upon being elected Prime Minister in September 2013, Abbott immediately began to dismantle Australia's climate policy institutions. First, the government has put legislation in motion that would axe the Renewable Energy Target, the Clean Energy Finance Corporation, the Australian Renewable Energy Agency, the Climate Commission and the Climate Change Authority. Next, Abbott removed the Climate Change and Science portfolios from his Cabinet and dramatically cut staff in the Environment ministry and the Commonwealth Scientific and Industrial Research Organisation (CSIRO). Most importantly, on 17 June 2014 Abbott fulfilled his 2011 'blood pledge'10 and repealed the Clean Energy Future Bill 2011 (Cth), making Australia the first country in the world to abolish a price on carbon (Cox, 2014). ${ }^{11}$

Despite these moves, Abbott describes his government as 'conservationist' (Cox, 2014). His policy for reducing emissions is called 'direct action'. As early as 2010, Abbott claimed that he could match the Rudd government's target of a 5\% reduction over 2000 levels by 2020 by the planting of 20 million 
trees, creating a 'green army' of 15,000 people, offering homeowners rebates for solar cells, and helping industry and farmers store carbon in the soil. This policy has never once been justified in moral terms and instead is couched in an exclusively economic rationale. For example, upon releasing the policy he stated: 'The Coalition's direct action plan is careful, costed and capped' while the government's approach was a 'great big tax on everything' (Franklin, 2010, p10).

2. In making a national commitment to reduce ghg emissions under the UNFCCC, to what extent, if at all, has the nation explained how it took equity and justice into consideration in setting its ghg emissions reduction target?

Australian governments have frequently used the language of equity and justice when explaining national ghg targets. However, despite Rudd's vague description of climate change as a 'moral challenge' these arguments have always been directed at purely national concerns. This posture is most evident in the Abbott government's direct action plan which states: 'We will take direct action to reduce carbon emissions in a practical, affordable way inside Australia, not overseas' (LNP, 2014). Statements like this provide protection for Australian coal exports which have grown to more than 300 million tonnes a year (McKnight, 2013).

Perhaps the best example of how equity and justice questions have played out in domestic politics concerns commitments made by the Labor government to regional communities fearful of economic downturn and job losses as a result of the ETS. For example, on 16 July 2011 Gillard visited the Latrobe Valley, home of Hazelwood Power Station. ${ }^{12}$ She declared forthrightly to aggressive crowds that the government would 'stand alongside' them and not leave them 'in the lurch' (Chubb, 2014, pp226-227). Gillard backed up these commitments with strategic compensation funds (such as the Regional Structural Adjustment Fund of $A \$ 15$ million) and billions of dollars in compensation to industry (Hazelwood alone received $A \$ 265.9$ million). The disparity in compensation between communities and industry did not go unnoticed. ${ }^{13}$

3. Given that any national ghg emissions target is implicitly a position on achieving an atmospheric ghg concentration that will avoid dangerous climate change, to what extent has the nation identified the ghg atmospheric concentration stabilization level that the national emissions reduction target seeks to achieve in cooperation with other nations?

The Australian government and independent Australian scientists have a long history of participating in attempts to identify a ghg atmospheric concentration stabilization. For example, in March 1976 the Australian Academy of Science released a report that stated that human activities are likely to contribute to global warming. With respect to the period under examination, the government has relied principally on the Intergovernmental Panel on Climate Change 4th (2007) and 5th (2013) recommendation of $450 \mathrm{ppm}$ of $\mathrm{CO}_{2}$. This level was explicitly supported in the two Garnaut Reviews $(2008,2011)$ and all subsequent government reports. It is noteworthy that the current government has neither affirmed nor denied this figure. ${ }^{14}$

4. Given that any national ghg emissions target is implicitly a position on the nation's fair share of safe global emissions, to what extent has the nation identified the ethical and justice considerations that it took into account in allocating a percentage of global ghg emissions to the nation through the identification of a ghg emissions reduction commitment?

Both the original and updated Garnaut Reviews $(2008,2011)$ commissioned by the Labor government were critical of the Kyoto Protocol's position on 'common but differentiated responsibilities'. For 
example, the updated review (2011) argued that the principle 'fixed (and restrained) the ambition of individual countries and the global mitigation effort' and that the 'binary distinction between developed and developing countries no longer made sense'. However, alongside these arguments, the updated review argued that while all countries must enter commitments to constrain emissions, a distinction can be drawn on the way those constraints are set. The updated review notes: 'An international agreement can work with developed countries accepting targets for absolute reductions in emissions, and developing countries targets for reductions in emissions intensity' (Garnaut Review, 2011). ${ }^{15}$

To determine Australia's proportional share, the Garnaut Reviews $(2008,2011)$ advocated modified contraction and convergence (MCC) as the most suitable set of principles. This is itself an ethical position and works by first stabilising ghg emissions at an agreed safe level (contraction) and then distributing the permissible emissions under the contraction on an equal per capita basis globally for all countries (convergence). ${ }^{16}$ Thus, the Garnaut Reviews $(2008,2011)$ recommended an emissions reduction range from 27 tonnes per person in Australia to 2 tonnes per person in India. Both reviews also held that it was 'not practical' for developing countries to suddenly converge towards a low level of entitlements per person. Thus, the 'modification' part of MCC is to allow rapidly growing developing countries to operate within an emissions intensity target for the time being (Garnaut Review, 2008).

MCC was heavily criticized after the 2008 review. Commentators inside Australia argued that 'it was wasteful for Australia to do anything because Australia represented such a small proportion of global emissions' (Garnaut Review, 2011). By contrast, commentators from developing countries argued that it was unfair that current high-emitting countries should continue to occupy that position for a long time into the future. Further, some critics argued that account should be taken of the historical reality, that developed countries had been responsible for most of the accumulation of greenhouse gases that has brought the world to its current dangerous position.

The updated Garnaut Review (2011) does not engage with these criticisms in a thorough or sustained way. However, it does defend MCC on both ethical and practical grounds. The ethical justification notes that MCC 'does not place additional new hurdles in the way of raising living standards for millions of the world's poor at an early point in their countries' economic development'. Moreover, because MCC can hold costs to manageable levels, 'it is equitable that a higher proportion of those costs be borne by richer countries'. Alongside these arguments, the updated review also notes that MCC 'provides substantial headroom for developing-country growth and hence the ability for poorerincome countries to grow considerably before facing severe constraints on emissions' (Garnaut Review, 2011).

The current Abbott government has joined the United States, Japan and Russia in calling for developing countries to do more to cut carbon emissions and has stated that a future deal should treat all countries equally (Wynn, 2014). Moreover, the Abbott government sought to forge alliances with centre-right governments (such as Canada) to resist global moves towards carbon pricing, and in favour of more 'direct action' measures that promote domestic economic growth (Kenny, 2014).

\section{To what extent, if at all, has the nation acknowledged that nations emitting ghg above their fair share of safe global emissions have a responsibility to fund reasonable adaptation measures or unavoidable losses and damages in poor developing countries?}

Australia is the highest OECD carbon emitter in per capita terms and its affluence means it can afford to contribute significant funds for climate adaptation. Even so, there has been no acknowledgement (formal or otherwise) from either the Labor or the Liberal National government of climate debt. Under the 
Rudd/Gillard Labor government Australia provided A\$599 million over three years to assist developing countries that are particularly vulnerable to climate change. The Labor government was also an early contributor to the Green Climate Fund (GCF), providing $A \$ 500,000$ in 2012 to help get the new fund going, as well as almost $\mathrm{A} \$ 600 \mathrm{~m}$ on a precursor 'fast-start' fund (Lenore, 2013).

As stated above, the LNP direct action plan is explicitly focused on protecting ecosystems and reducing emissions 'inside Australia'. To support this objective, the government has provided $\mathrm{A} \$ 126$ million for national climate change adaptation programmes. Moreover, at the 2013 Commonwealth Heads of Government Meeting in Sri Lanka, Australia (and Canada) refused to pledge toward the GCF and labelled it the 'Green Capital Fund' (Su, 2013; Hannam, 2013). Following this declaration, the government cut funds to the Australian Agency for International Development (Koc, 2013) and has taken climate change off the agenda of the next G20 meeting to be held in Brisbane in November 2014 (Cox and Morton, 2014). The government has said that its commitment will not be modified until it sees the outcome of the 2015 Climate Summit in Paris (Miller, 2014).

\section{What formal mechanisms are available in the nation for citizens, NGOs and other interested organizations to question/contest the nation's ethical position on climate change?}

Australia has similar participatory mechanisms as other western democracies. The traditional Green and White Paper mechanisms, exposure drafts of legislation, focus groups and surveys are familiar ways of gathering citizens' views about particular initiatives. On legislative or policy matters affecting citizens at large, plebiscites may also be used. Sometimes, where policies have a particular impact on certain categories of citizens, governments go to considerable lengths to consult with the affected target groups and those who defend their interests. Nevertheless, it remains generally the case that governments define the issues for consultation, set the questions and manage the process.

\section{How is the concept of climate justice understood by the current government? Have they articulated any position on climate justice issues that arise in setting ghg emissions policy or in regard to the adaptation needs of vulnerable nations or people?}

The current LNP government in Australia has not articulated an official position on climate justice. On the international stage, Australia was ostracized at the 2013 UN Climate Change Conference in Warsaw, Poland. For the first time in 16 years, Australia did not send a ministerial-level representative to the talks (a dramatic shift from Rudd's direct advocacy during the 2008 Conference). Yvo de Boer, the former executive secretary of the UN Framework Convention on Climate Change, described this move as 'puzzling' and stated: 'I cannot remember a previous occasion when a major player in this process has not been represented at ministerial level at the high level segment of the talks' (UN Association of Australia, 2013). At the talks, Dr Justin Lee, the Australian Ambassador for Climate Change, delivered a short speech stating that while Australia did accept the scientific consensus on climate change, it would only take action that was 'fiscally and economically' responsible (UN Association of Australia, 2013).

In response, Chinese delegate Su Wei indirectly rebuked Australia. The South African Environment Minister, Edna Molewa, said that the way Australia scaled back its commitments sent a negative signal about its 'sincerity and commitment' to climate action (UN Association of Australia, 2013). Australia was also accused of climate change denial by the threatened Pacific Island country Tuvalu. During the talks, the International Climate Action Network awarded Australia 'Fossil of the Day' in response to its efforts to block progress at the negotiations (Climate Action Network, 2013). Coinciding with the 
conference, GermanWatch (2013) released its annual climate performance index, which positioned Australia alongside Canada as the worst-performing industrial country in the world.

\section{Are you aware of any regional, state, provincial, or local governments in your country that have acknowledged some ethical responsibility for climate change? If so, what have they said?}

A number of Australian cities have shown significant leadership on tackling climate change. For example, the Australian Capital Territory (ACT) government has a legislated target to reduce its emissions by $40 \%$ by 2020 and source $90 \%$ of its electricity from renewable sources by 2020 . The City of Sydney has achieved carbon neutrality in its operations and has a $100 \%$ by 2030 local electricity generation target (Rimmer and Wood, 2014). Other major cities, including Perth, Melbourne and Adelaide, all aim to achieve zero net emissions by 2020 .

This work has been championed by a number of city lord mayors who have advocated climate action. For example, Clover Moore, the Lord Mayor of Sydney, attended the Copenhagen Climate talks in 2009, supported the introduction of carbon pricing in Australia, and has championed the City of Sydney's plan to reduce greenhouse emissions, 'Sustainable Sydney 2030'. Commenting on the need for climate action, Moore writes: 'With a warming of two degrees - and projections show we are headed for a four to six degree change - we risk catastrophic climate change. ... While Sydney is moving towards a more sustainable future, climate change demands we do more' (Moore, 2013). Adelaide Lord Mayor Stephen Yarwood has discussed the role of cities in tackling climate change. Yarwood stated: 'Our 2013-2014 Business Plan \& Budget makes specific reference to crafting a city that uses fewer resources and supports local ecological systems . . . We believe in creating a well presented, clean and safe city that minimises its carbon footprint and offers residents all the amenities they require within the one space' (Climate Action Programme, 2014).

\section{Has your national government taken any position on or otherwise encouraged individuals, businesses, organizations, subnational governments, or other entities that they have some ethical duty to reduce greenhouse gas emissions?}

The Australian government has relied on individual actions and commitments to behaviour change at the personal and household level. In large part, this strategy has attempted to direct responsibility away from carbon-intensive industry and government and toward the individual or household. Perhaps the most obvious example of this was in 2007, when the Howard government entrained the individual responsibility model through its 2007 \$25 million Climate Clever campaign, titled 'Be Climate Clever: "I can do that"' (Pearse, 2007). The current liberal government articulates a strong rhetoric of initiative and personal responsibility. ${ }^{17}$ To date, however, this has not translated explicitly to the 'direct action' plan for climate change.

The rhetoric of individual responsibility was diluted under the Rudd Labor government which focused instead on market mechanisms to reduce emissions. However, complementing the government's ETS were a range of renewable energy and energy efficiency programmes. These included the Solar Homes and Communities Plan ${ }^{18}$ and the Green Loans Program which provided \$175 million over five years for home sustainability assessments and low-interest loans of up to $\$ 10,000$ to help homeowners to cover the costs of solar, water and energy efficiency products. ${ }^{19}$ Finally, while ultimately disastrous and politically damaging, ${ }^{20}$ the Home Insulation Program provided $\$ 2.7$ billion to cover the cost of installing free ceiling insulation (up to a prescribed limit) in 2.7 million homes. 


\section{What recommendations would you make to get the nation or civil society to take ethics and justice issues seriously in climate change policy formulation?}

One of the most disappointing developments in the ongoing struggle for climate action has been the professionalization of the NGO sector over the past two decades. To gain access to power and have their opinions communicated in the press, many NGOs now frame their campaigns in purely instrumental or economic language. At the same time, NGOs have become very sophisticated at employing the same techniques of lobbying and media management as industry. As a result, the staff of NGOs has shifted dramatically from the grassroots to people with lobbying and media skills (and the conservative political outlook that often goes with these professions). In response to this shift, Clive Hamilton (2011) notes that many NGOs have 'become insiders, remote from their members . . and whose attention is focused overwhelmingly on powerful political players and journalists. And as they become more distant from their members they pay more and more attention to their big donors, rarely known for their radicalism.'

In response, it is imperative that environmental organizations confront the full facts of climate science and develop a deep understanding of how power works in their country so that they can effectively highlight the essential ethical dimensions of climate change. This requires both a renewed environmental radicalism 'made up of those willing to put their bodies on the line' (Hamilton, 2011) and also a commitment to value rational action which is shaped by a constant commitment to ethical behaviour (Weber, 1977, p24). In this way, the environment movement can develop its message and frame the political debate (Lakoff, 2004). 


\section{Notes}

1 Thanks to Professor Matthew Rimmer from the Australian National University and Dr Rowena Maguire from Queensland University of Technology for their comments on an earlier version of this paper.

2 Julian Glover (2007) described the election as the first in the world to be determined by climate change policy.

3 In Australia, approximately $75 \%$ of our electricity is from coal-fired plants and Australian coal exports constitute one-third of the world's sea-borne coal trade (McKnight, 2013).

4 Kevin Rudd (Dec 2007-June 2010); Julia Gillard (June 2010-June 2013); Kevin Rudd (June 2013-September 2013); Tony Abbott (September 2013: Incumbent). For a detailed chronology of Australia's climate policy during this period see: http://www.aph.gov.au/About_Parliament/Parliamentary Departments/Parliamentary Library/ pubs/rp/rp1314/ClimateChangeTimeline.

5 Note that when Labor was in opposition they released a policy paper on Pacific island displacement called Our Drowning Neighbours (2006). The report enthusiastically called for a 'Pacific Climate Change Strategy' to provide assistance for mitigation, adaptation and emergency response efforts and intra-country evacuations, training, establishing an international coalition to accept climate change refugees, and assistance to preserve the cultural heritage of those evacuated and to establish a Pacific Climate Change Alliance.

6 The Carbon Pollution Reduction Scheme Bill (Cth) was introduced into the House of Representatives on 14 May 2009. The Senate rejected the bill on 13 August 2009. The bill was reintroduced on 22 October 2009 and was rejected again by the Senate on 2 December 2009. The bill was introduced for a third time on 2 February 2010. Deputy Prime Minister Julia Gillard became Prime Minister after an internal party challenge on 24 June 2010. As a result of this and the start of a new Parliament, the third CPRS legislation lapsed.

7 The MPCCC was resourced like a Cabinet committee but consisted of representatives from the Labor government, the Greens, independent Members of Parliament and four sitting experts. The government invited two members from the coalition but they did not accept.

8 Many stakeholders, including the Greens, signed on to the $5 \%$ target because they had faith that, after three years had passed, the world would be moving towards strong action on climate change. This, they hoped, would establish the conditions to secure a target bigger than $5 \%$.

9 Abbott characterized the policy as a 'betrayal' because Gillard stated on the day of her official campaign launch in 2010 that: 'There will be no carbon tax under the government that I lead.' Abbott exploited the general lack of understanding amongst the Australian public about the difference between carbon pricing and a tax.

10 Abbott stated that he would give the 'most definitive commitment any politician can give that this tax will go. This is a pledge in blood' (Franklin, 2011, p8).

11 A study from the Australian National University illustrated that a carbon price helped curb carbon emissions. The period under examination was between 1 July 2012 and 30 June 2014 (O'Gorman and Gotzo, 2014).

12 The WWF (2005) analysed 953 power stations in 30 countries. They found Hazelwood's greenhouse gas emissions were higher than any other large-scale coal-fired power plant.

13 For example, Loy Yang, chair of Regional Development Australia, gave voice to community outrage over the disparity between community and corporate assistance: '[we] have been put through the bloody grinder since 2008, thinking [our] future was pretty limited. And what have they seen from the Commonwealth? A complete lack of leadership' (Chubb, 2014, p238).

14 Tony Abbott has a long history of climate scepticism. For example, in September 2009 he described climate science as 'absolute crap' (Rintoul, 2009). More recently, in February 2014, Abbott appointed a senior business figure and climate change sceptic, Dick Warburton, to head a formal review of Australia's $20 \%$ renewable energy target (Arup, 2014).

15 This comment must also be read in light of the suggestion in the 2008 review that the transition from a developing to a developed country can take place when a developing country's emissions per person reach the (falling) average level of developed countries.

16 See further: http://www.gci.org.uk/. 
17 For example, the Liberal Party platform reads: 'Only in a society where opportunity, initiative and personal responsibility are fostered can prosperity be attained.' See further: http://share.liberal.org.au/info/docs/ federalplatform.pdf.

18 This programme was prematurely terminated in June 2009 after a massive cost overrun in the budget.

19 As announced in the 2008 budget, the GLP was supposed to consist of $\$ 300$ million over five years to provide 360,000 home sustainability assessments and up to 200,000 low-interest loans to improve household energy and water efficiency (DEWHA, 2008; Garrett, 2008).

20 Four insulation workers - all under the age of 25 - died installing insulation under the programme. In addition, between October 2009 and June 2010, 174 house fires were linked to HIP installations. 


\section{References}

ABC (2014) 'Pacific presidents speak out against Australia's stand on climate change', ABC News, 13 June, http:// www.abc.net.au/news/2014-06-13/pacific-presidents/5521478

Arup, Tom (2014) 'Climate sceptic Dick Warburton to head Tony Abbott review into renewable energy target', Sydney Morning Herald, 17 February, www.smh.com.au/federal-politics/political-news/climate-scepticdick-warburton-to-head-tony-abbott-review-into-renewable-energy-target-20140217-32vve.html

Australian Academy of Science (1976) 'Report of a Committee on Climatic Change, Report no. 1', Canberra, http:// dpl/Books/2013/AAS_ReportCommitteeClimaticChange.pdf

Australian Government (2008) Carbon Pollution Reduction Scheme, Green Paper, 1 July, http://pandora.nla.gov. au/pan/86984/20080718-1535/www.greenhouse.gov.au/greenpaper/report/pubs/greenpaper.pdf

Australian Government (2008) Australia's Low Pollution Future: The Economics of Climate Change Mitigation, 30 October, http://lowpollutionfuture.treasury.gov.au/lowpollutionfuture/default.asp

Chubb, Philip (2014) Power Failure: The Inside Story of Climate Politics under Rudd and Gillard, Black Inc. Agenda, Melbourne

Climate Action Network (2014) 'Australia awarded Fossil of the Day at UN Climate Talks for Trying to Reconvene Flat Earth Society', 10 June, http://www.climatenetwork.org/fossil-of-the-day

Climate Action Programme (2014) 'A Post-Carbon Economy', Climate Action News, 6 February, http://www. climateactionprogramme.org/climate-leader-interviews/a_post_carbon_economy

Commonwealth of Australia (2008) Australian Government Carbon Pollution Reduction Scheme: Australia's Low Pollution Future: White Paper, Commonwealth Government, Canberra

Commonwealth of Australia (2008) Carbon Pollution Reduction Scheme, Green Paper, July 2008

Cox, Lisa (2014) 'Carbon tax is gone: Repeal bills pass the Senate', The Sydney Morning Herald, 17 July, http:// www.smh.com.au/federal-politics/political-news/carbon-tax-is-gone-repeal-bills-pass-the-senate20140717-3c2he.html

Cox, Lisa and Morton, Adam (2014) 'Climate change "off G20 agenda"', The Sydney Morning Herald, 5 June, http://www.smh.com.au/federal-politics/political-news/climate-change-off-g20-agenda-20140604-39jdx. $\underline{\mathrm{html}}$

Department of Climate Change (2011) 'Final Report: Our Fair Share of Climate Action Much More Expensive without Carbon Pricing', Media release, 31 May, http://www.garnautreview.org.au/update-2011/media/110531final-report.pdf

Fitzpatrick, Stephen and Warren, Matthew (2007) 'Signature wins wild applause in Bali', The Australian, 4 December, http://www.news.com.au/technology/environment/signature-wins-wild-applause-in-bali/storye6frflp0-1111115024588

Franklin, Michael (2010) 'Tony Abbott's cut-through climate plan', The Australian, 3 February, http:// www.theaustralian.com.au/news/nation/tony-abbotts-cut-through-climate-plan/story-e6frg6nf1225826118352?nk=4a767fb189f5115681a421517e12cda4

Franklin, Michael (2011) ‘Tony Abbott slams “veiled socialism”', The Australian, 11 July, p8

Franklin, Michael and Ryan, Siobhain (2007) 'Rudd's Warm Kyoto Reception', The Australian, 4 December, http:// www.theaustralian.com.au/news/rudds-warm-kyoto-reception/story-e6frg6n6-11111115025783

Garnaut, Ross (2008) The Garnaut Climate Change Review, 30 September, http://www.garnautreview.org.au/ index.htm

Garnaut, Ross (2011) Garnaut Climate Change Review - Update 2011: Australia in the Global Response to Climate Change, 31 May, http://www.garnautreview.org.au/index.html

GermanWatch (2013) 'The Climate Change Performance Index 2013', https://germanwatch.org/en/5698

Glover, Julian (2007) ‘The lucky country?', The Guardian, 23 November, www.theguardian.com/environment/2007/ nov/23/climatechange.australia 
Hamilton, Clive (2011) 'A new brand of environmental radicalism', Crikey, 22 February, http://www.crikey.com. au/2011/02/22/hamilton-we-need-a-new-brand-of-environmental-radicalism/

Hannam, Peter (2013) 'Clouds over support for climate fund', The Sydney Morning Herald, 23 September, www. smh.com.au/federal-politics/political-news/clouds-over-support-for-climate-fund-20130922-2u81h.html

Kelly, Paul (2007) 'Green light on the hill is hard to miss', The Australian, 4 April, http://www.theaustralian.com.au/ opinion/columnists/green-light-on-the-hill-is-hard-to-miss/story-e6frg74x-11111113277884

Kenny, Mark (2014) 'Tony Abbott seeks alliance to thwart President Obama on climate change policy', The Sydney Morning Herald, 10 June, http://www.smh.com.au/federal-politics/political-news/tony-abbott-seeksalliance-to-thwart-president-obama-on-climate-change-policy-20140609-39t93.html

Kirk, Alexandra (2011) 'Gillard says House of Reps has moved from words to deeds on Carbon', ABC PM, 12 October, http://www.abc.net.au/pm/content/2011/s3338068.htm

Koc, Erdem (2013) 'End of the line for AusAID', SBS News, 1 November, http://www.sbs.com.au/news/ article/2013/11/01/end-line-ausaid

Lakoff, George (2004) Don't Think of an Elephant! Know Your Values and Frame the Debate: The Essential Guide for Progressives, Chelsea Green Publishing, Vermont

Labor Party (2006) Our Drowning Neighbours: Labor's Policy Discussion Paper on Climate Change in the Pacific

Liberal National Party (2014) 'We have a Plan for Real Action', https://www.liberal.org.au/our-plan/environment

Macintosh, A., Wilkinson, D. and Denniss, R. (2012) 'Climate Change', in C. Aulich and M. Evans (eds), The Rudd Government: Australian Commonwealth Administration 2007-2010, Australian National University ePress, Canberra

McKnight, David (2013) 'Might as well face it, we're addicted to coal', The Sydney Morning Herald, 8 August, http:// www.smh.com.au/comment/might-as-well-face-it-were-addicted-to-coal-20130808-2rkkk.html

Marr, David (2010) Power Trip: The Political Journey of Kevin Rudd, Quarterly Essay 38, Black Inc. Books, Melbourne

Miller, Daniel (2014) 'What is the Coalition's direct action climate change policy?', ABC News, 24 April, http://www. abc.net.au/news/2013-12-20/coalition-climate-change-direct-action-policy-explained/5067188

Moore, Clover (2013) 'Mayor Clover Moore: Why Sydney's sustainable future is bright', CNN, 6 September, http:// www.edition.cnn.com/2013/09/06/world/asia/mayor-clover-moore-sydney/

Morton, Adam (2011) 'Carbon tax countdown to July 2012 start date', The Age, 25 February, p1

O'Gorman, Marianna and Jotzo, Frank (2014) 'Impact of the Carbon Price on Australia's Electricity Demand, Supply and Emissions', http://econpapers.repec.org/paper/eenccepwp/1411.htm

Pearse, Guy (2007) 'Be Climate Clever but not Climate Conned: Seeing Through John Howard's Greenhouse Narcissism', Speech presented at Canberra Readers and Writers Festival, 23 September, http://www. highanddry.com.au/media/CWF_Speech.pdf

Pearse, Guy (2013) Big Coal: Australia's Dirtiest Habit, University of New South Wales Press, Sydney

Rimmer, Matthew and Wood, Charlotte (2014) 'Think global, act local: the role for councils in climate change', Crikey, 30 January, http://www.crikey.com.au/2014/01/30/think-global-act-local-the-role-for-councils-inclimate-change/

Rintoul, Stuart (2009) 'The town that turned up the temperature', The Weekend Australian, 12 December, p1

Rudd, Kevin (2009) 'A New Target for Reducing Australia's Carbon Pollution', media release, 4 May, http://parlinfo. aph.gov.au/parllnfo/download/media/pressrel/HFGT6/upload_binary/hfgt60.pdf

Su, Reissa (2013) 'Australia Viewed as "Anti-Climate", Tony Abbott Refuses to Join Green Climate Fund', International Business Times, 20 November, http://au.ibtimes.com/articles/523704/20131120/climatechange-australia-warsaw-united-nations-tony.htm\#.U9H_HICSw0-

Taylor, Lenore (2013) 'Cabinet rethinks Australia's backing of global Green Climate Fund', The Guardian, 8 November, www.theguardian.com/environment/2013/nov/08/australian-ministers-rethink-green-climatefund-commitment 
UN Association of Australia (2013) 'Australia ostracised for change in tact at Warsaw Climate Change Conference', 5 December, http://www.unaa.org.au/australia-ostracised-for-change-in-tact-at-warsaw-climate-changeconference.html

Weber, Max (1978) Economy and Society: An Outline of Interpretive Sociology, University of California Press, Berkeley

Wilkins, Roger (2008) Strategic Review of Australian Government Climate Change Programs, 31 July, http://www. finance.gov.au/sites/default/files/Climate-Report.pdf

Wong, Penny (2008) 'Climate Change Budget Overview 2008-09', http://www.climatechange.gov.au/sites/ climatechange/files/documents/03 2013/ccbo-200809.pdf

World Wildlife Fund for Nature (2005) 'Hazelwood tops international list of dirty power stations', 12 July, http:// www.wwf.org.au/news resources/?2320/Hazelwood-tops-international-list-of-dirty-power-stations

Wynn, Gerard (2014) 'Japan, Australia urge developing countries to do more on climate', Responding to Climate Change, 15 May, www.rtcc.org/2014/05/15/japan-australia-urge-developing-countries-to-do-more-onclimate/ 



\section{The Plurinational State of Bolivia's Consideration of Ethics and Justice Issues in Formulating Climate Change Policies}

\section{Beth Jean Evans}

This report responds to the research questions of the Project On Deepening National Responses to Climate Change On The Basis of Ethics and Justice, a joint project of the University of Auckland, School of Architecture and Planning and Widener University, School of Law, Environmental Law Center. The research questions and responses are as follows:

1. To what extent has the national debate about how the nation should respond to climate change by setting a ghg emissions reduction target expressly considered that the nation not only has economic interests in setting the target but also ethical obligations to those who are most vulnerable to climate change and that any national ghg emissions reduction target must represent the nation's fair share of safe global emissions? In answering this question, identify the national ghg emissions reduction target, if any, that the nation has made under the United Nations Framework Convention on Climate Change (UNFCCC).

Due to Bolivia's high level of vulnerability to the adverse impacts of climate change (see Wheeler, 2011) and continuing struggles with poverty, climate debate within Bolivia has overwhelmingly emphasized Bolivia's role as a victim, rather than a perpetrator, of the climate crisis. Because of its minute historical contribution to aggregate global ghg levels and low levels of current per capita ghg emissions, Bolivia argues that it should not be considered a pollutant country, much less a contributor to global warming (Republic of Bolivia, 2000). Responsibility to address and mitigate climate change therefore rests exclusively with developed countries whose historically disproportionate use of atmospheric space, high levels of per capita emissions and relative capabilities, and low levels of vulnerability to the adverse impacts of climate change make them ethically responsible. As Bolivia's representation to the United Nations states, 'We are not assigning guilt, just responsibility. As they say in the US, "If you break it, you buy it"' (Solon, 2009). Thus, although Bolivia signed and ratified the Kyoto Protocol and the United Nations Framework Convention on Climate Change (UNFCCC, or 'Convention') and as early as 1994 began to make changes to domestic political structures to facilitate participation in global climate efforts, it has not accepted a national ghg emissions reduction target (Republic of Bolivia, 2000).

Bolivia has, however, agreed to undertake certain domestic mitigation actions in the form of voluntary Nationally Appropriate Mitigation Actions (NAMAs) as outlined in Article 4.1 of the Convention, and in accordance with the ethical framework of 'common but differentiated responsibilities' for climate change. The potential cumulative impact of these NAMAs, according to a 2009 study, was estimated to be as high as 903 million tonnes of $\mathrm{CO}_{2}$ reduced between 2001 and 2012, with the majority of the reductions coming from changes made in the areas of land use, land use change, and forestry (Plurinational State of Bolivia, 2009).

Although Bolivia's decision not to set a national ghg emissions reduction target has drawn heavily on ethical justifications, its willingness to undertake NAMAs has been discussed largely in pragmatic 
terms. For example, Bolivia has explained its intent to undertake NAMAs as a means of demonstrating its cooperation with its mandate as a developing country under the UNFCCC, with the expectation that developed countries would 'acknowledge accordingly' by meeting their own commitments, including funding mitigation and adaptation activities in developing countries (Republic of Bolivia, 2000). Recognizing its particularly high level of vulnerability to climate change, Bolivia has also acknowledged that it is in its best interest to contribute to global mitigation efforts, namely through emissions reductions in land use, land use change, and forestry sectors (Republic of Bolivia, 2000, 2002). When discussing the conditions under which Bolivia will undertake such mitigation activities, however, ethical considerations once again come to the discursive forefront. Considerations of equity are of particular concern for Bolivia, which understands equity under the UNFCCC to mean that developing countries will continue to pursue their domestic development imperatives, only undertaking climate action to the extent that developed countries provide funding and technology, and agree to meet the full incremental costs of developing countries' climate policy measures (Plurinational State of Bolivia, 2012a).

Bolivia has also been quite emphatic that any mitigation assistance transferred from developed to developing countries should be seen as payment of a long-standing 'climate debt' owed by developed countries to developing countries for their unjust and inequitable accumulative use of atmospheric space (Plurinational State of Bolivia, 2010). This ethical framing of mitigation assistance as a repayment of debt rather than act of charity can be seen as an attempt by Bolivia to shift the climate debate away from its current focus on finding 'win-win' solutions that benefit developed and developing countries alike, towards one more closely focused on the rectification of historic injustices and continuing inequalities. One policy implication of this discursive shift could be an increase in opposition to the creation of global markets for carbon offsets, which are seen by many developing countries as inequitable and unreliable and therefore inappropriate means of debt repayment (Plurinational State of Bolivia, 2014, p4).

Finally, debates over Bolivian climate policy have tended to emphasize Bolivia's unique vulnerability to the impacts of climate change and continuing poverty, thus justifying a prioritization of Joint Mitigation and Adaptation (JMA) approaches over approaches aimed at mitigation alone (Plurinational State of Bolivia, 2009). For example, Bolivia has argued that developing countries' efforts to implement NAMAs and 'national adaptation programmes of action' (NAPAs) should be combined under a more holistic 'Climate Justice Mechanism', with any action taken by developing countries being first and foremost, 'contingent upon the evaluation of performance of developed countries in climate change' (Plurinational State of Bolivia, 2012a). Bolivia's opposition to the proposed market-based Reducing Emissions from Avoided Deforestation and Forest Degradation (REDD+) mechanism offers a concrete example of Bolivia's ethical principles at play. Bolivia has quite famously rejected the emergent REDD+ mechanism due in part to its prioritization of mitigation over adaptation and proposed links to carbon offset markets, submitting in its place a proposal for a non-market 'Joint Mitigation and Adaptation Mechanism for the Integral and Sustainable Management of Forests in Developing Countries' (Plurinational State of Bolivia, 2012b; see also Decision 2/CP.17, Paragraph 67 of the UNFCCC).

\section{In making a national commitment to reduce ghg emissions under the UNFCCC, to what extent, if at all, has the nation explained how it took equity and justice into consideration in setting its ghg emissions reduction target?}

In participating in national debates over climate change, the government of Bolivia has drawn heavily upon ethical justifications for a more equitable distribution of atmospheric space, demanding that developed countries not only undertake deep domestic emissions cuts to make room for the economic 
and social growth of developing countries, but also bear the financial burden of developing countries' mitigation efforts. Similarly, the government of Bolivia has justified its prioritization of holistic mitigation and adaptation measures capable of reducing domestic poverty and vulnerability to climate change over mitigation-only measures (particularly those that generate offsets for developed countries), as the latter are not seen as appropriate mechanisms for developed countries to repay the climate debt owed to developing countries.

3. Given that any national ghg emissions target is implicitly a position on achieving an atmospheric ghg concentration that will avoid dangerous climate change, to what extent has the nation identified the ghg atmospheric concentration stabilization level that the national emissions reduction target seeks to achieve in cooperation with other nations?

By the time of the Conference of the Parties to the UNFCCC in Copenhagen (2010), a consensus had emerged in support of the notion that reductions of 25 to $40 \%$ below 1990 levels by 2020 and 80 to $95 \%$ by 2050 would be needed in order to stabilize ghg concentrations at a level sufficient to limit global temperature increases to 2 degrees Celsius, the level above which catastrophic impacts were likely to occur (see IPCC, 2007). However, Bolivia has argued that a temperature increase of 2 degrees Celsius would lead to a $50 \%$ chance of irreversible damage to Mother Earth, an outcome which Bolivia found unacceptable ('People's Agreement'; Plurinational State of Bolivia, 2010). Thus, emphasizing its particular vulnerability to the adverse impacts of climate change, Bolivia denounced the Copenhagen outcome, and instead called for developed countries to honour an amendment to the Kyoto Protocol that calls for reductions of $50 \%$ below 1990 levels between 2013 and 2017 and reductions of 100\% below 1990 levels by 2040, thus limiting global warming to 1 degree Celsius ('People's Agreement'; Estado Plurinacional de Bolivia, 2010). Bolivia's own contribution to achieving this limit comes in the form of voluntary NAMAs, thus making Bolivia's decision not to set a national ghg emissions reduction target ethically consistent with its demands for deep emissions cuts by developed countries in order to limit global temperature rises to 1 degree Celsius.

4. Given that any national ghg emissions target is implicitly a position on the nation's fair share of safe global emissions, to what extent has the nation identified the ethical and justice considerations that it took into account in allocating a percentage of global ghg emissions to the nation through the identification of a ghg emissions reduction commitment?

Bolivia has been emphatic that an 'equitable sharing of atmospheric space is an inalienable and fundamental right of all nations and people' and that developing countries whose contributions to global atmospheric ghg levels have been minute should therefore be given 'atmospheric space' to pursue the overriding priorities of economic and social development (Plurinational State of Bolivia, 2010). As Bolivian ambassador to the UN, Pablo Solon, explains, 'It's not possible that only 20 percent of the world occupies 80 percent of the atmosphere with their emissions, because then what happens with the rest of the world is that we don't have any space for any kind of development, because you need to industrialize, and that's going to mean you are going to throw some greenhouse gas emissions into the atmosphere' (quoted in Aguirre and Cooper, 2010, p242). Thus, for Bolivia, the allocation of carbon space should be 'carried out according to the rights to development of Parties [to the UNFCCC] and to the rights of Mother Earth to adapt naturally to climate change' (Plurinational State of Bolivia, 2012a).

In calling for deep emissions cuts by developed countries, Bolivia argues that 'the scale and timing of emission reductions by Annex I countries must be sufficient to ensure that developed countries' 
historical debt for their excessive past consumption of environmental space, and their continuing excessive per-capita emissions, is fully repaid to developing countries' (Plurinational State of Bolivia, 2010). Contrary to developed countries' insistence that states cannot be held ethically responsible for the ghg emissions of generations prior to knowledge of the impacts of climate change (see Carey, 2005), Bolivia takes a long-term historical view, calling for the equitable (re)distribution of the global atmospheric space between developed countries and developing countries over the period 1750 to 2050 (Navarro, 2009).

For Bolivia, an equitable distribution of atmospheric space must address disparities both in terms of long-term absolute emissions levels, as well as per capita emissions levels, between developed and developing countries. Specifically, Bolivia argues that, 'Taking previous data into consideration ... Annex I countries should emit only 120 Gton of $\mathrm{CO}_{2}$ emissions considering that they encompasses [sic] only $16 \%$ of the world's population, and if taking into account their carbon debt of 568 Gtons, total emissions of developed countries should be negative of about -448 Gton', while developing countries, which represent $84 \%$ of the world's population, are entitled to a fair share of 630 Gton, which increases to 1198 Gton of $\mathrm{CO}_{2}$ emissions when the emissions debt owed to them by developed countries is taken into consideration (Plurinational State of Bolivia, 2012a, p3). Bolivia's decision not to set a national ghg emissions reduction target while at the same time calling for deep reductions amongst developed countries is therefore a reflection of a strong ethical position concerning the proper distribution of atmospheric space, based on long-term historical inequalities in both absolute and per capita emissions between developed and developing countries.

\section{To what extent, if at all, has the nation acknowledged that nations emitting ghg above their fair share of safe global emissions have a responsibility to fund reasonable adap- tation measures or unavoidable losses and damages in poor developing countries?}

Bolivia has taken a very firm stance on the ethical obligation of developed countries to not only fund mitigation activities within developing countries, but also to provide them with substantial adaptation assistance and additional compensation for losses and damages incurred due to the adverse impacts of climate change. Bolivia argues that it is the responsibility of those developed countries historically responsible for climate change to 'support and rehabilitate developing countries in addressing climate impacts', given that those who have contributed the least, and who have the least capacity, will be the most affected by climate change (Plurinational State of Bolivia, 2012a, p6). Bolivia thus considers both mitigation and adaptation funding to be part of the 'climate debt' which developed countries have an ethical obligation to repay:

[Developing] countries are not seeking economic handouts to solve a problem we did not cause. What we call for is full payment of the debt owed to us by Developed countries for threatening the integrity of the Earth's climate system, for over-consuming a shared resource that belongs fairly and equally to all people, and for maintaining lifestyles that continue to threaten the lives and livelihoods of the poor majority of the planet's population. ... Any solution that does not ensure an equitable distribution of the Earth's limited capacity to absorb greenhouse gases, as well as the costs of mitigating and adapting to climate change, is destined to fail. (Republic of Bolivia, 2009, cited in Bond, 2011)

Moreover, the ethical responsibility embodied under the notion of 'common but differentiated responsibilities' of the Convention for developed countries to provide developing countries with adaptation funding has been compounded in recent years by what Bolivia characterizes as an 'adaptation debt'. This concept refers to an additional ethical responsibility for adaptation funding resulting from developed countries' 'failure to honor payment of financing and compensation' in the 
past (Navarro, 2009). Thus, it is not simply developed countries' disproportionate contribution to atmospheric ghg emissions or higher capacity to pay for mitigation and adaptation that obligates them to fund adaptation in developing countries, but also their perceived lack of ambition in mitigating their own emissions combined with a failure to transfer sufficient amounts of financing to increase the adaptability and reduce the vulnerability of developing countries. In this context, Bolivia has called for developed countries to contribute $6 \%$ of their gross domestic product (GDP) to aid developing countries in their climate efforts, with $3 \%$ of this going towards adaptation (compared to the $0.5 \%$ of GDP provided for adaptation under the Copenhagen Accord), and 1\% each for technology transfer, capacity-building measures, and financing of mitigation actions in developing countries (Plurinational State of Bolivia, 2010; 'Comparison of the Cochabamba People's Agreement and the Cochabamba Accord', n.d.).

Bolivia has used similar ethical considerations in calling for the creation of a multilateral Loss and Damage Mechanism under the UNFCCC to further compensate developing countries for the present and future inevitable damages that are the 'unfortunate result of developed country Parties' insufficient ambition' in addressing their historical accumulation of greenhouse gases and achieving the objectives of the UNFCCC (Plurinational State of Bolivia et al, 2012, p1). For Bolivia, this mechanism needs to go 'beyond adaptation' to 'react to damage, rather than to simply raise adaptive capacity' by providing compensation and rehabilitation for the inevitable losses when adaptation is no longer possible (ibid, p3). Bolivia's mandate for this mechanism is broad, calling for compensation for sudden- and slowonset events, lost development opportunities, and both economic and non-economic losses as 'money cannot adequately compensate people for the loss of life or health, homes and assets, livelihoods, territory, culture, or ecosystems that will result from radical changes in climate' (ibid). In summation, Bolivia's ethical position is that countries who have long benefited from their disproportionate use of atmospheric space are now not only ethically obligated to repay the 'debt' this has created by funding mitigation and adaptation activities within developing countries, but also to compensate these countries for the inevitable losses and damages they will suffer due to developed countries' lacking ambition in the past in terms of both mitigation and adaptation.

\section{What formal mechanisms are available in the nation for citizens, NGOs and other inter- ested organizations to question/contest the nation's ethical position on climate change?}

Since Evo Morales became the first indigenous president of Bolivia in 2006, political inclusivity, at both the domestic and international level, has been a key tenet of Bolivia's conception of climate justice and ethics. At the domestic level, Morales' promise to 'govern by obeying the people' has given social movements and other civil society actors an increased voice in policy decisions, including those relating to the environment (Aguirre and Cooper, 2010; Kohl, 2010). For example, the new Bolivian Constitution approved in 2009 recognized 36 ethnic communities and granted them rights to be consulted by the state before the exploitation of non-renewable resources (Laing, 2012), if nothing else giving these actors a legal basis for questioning the nation's ethical position on climate change. Similarly, the 2010 Bolivian Ley de Derechos de la Madre Tierra (Law of the Rights of Mother Earth) was drafted in consultation with the five major grassroots movements in Bolivia and has since informed Bolivian climate change policy, highlighting another way in which civil society has played an important role in determining both the ethical basis and policy content of Bolivian climate policy.

Civil society actors have also participated in the formation of Bolivia's ethical position on climate change through their involvement in the People's Summit, held in Cochabamba, Bolivia in 2010. After openly denouncing the Copenhagen Conference for its failure to solidify an emissions reduction agreement, lack 
of ambition, and exclusionary participatory processes (Estado Plurinacional de Bolivia, 2010), Bolivian President Evo Morales proposed and hosted the Cochabamba Summit, stating that ' . . . if the leaders of the countries cannot arrive at an agreement, why don't the peoples then decide together?' (cited in Aguirre and Cooper, p239). Attended by more than 35,000 Bolivians, and with an agenda dominated by grassroots indigenous, community, social labour, and environmental movements, the resulting Cochabamba Agreement called for, amongst other things, a World Referendum on Climate Change as a means of directly involving the people in climate change policy decisions and explicit recognition of and full respect for the rights of indigenous peoples and Mother Earth ('Comparison of the Cochabamba People's Agreement and the Cochabamba Accord', n.d.). That the Bolivian government has drawn heavily upon the Cochabamba Agreement (which also inspired the Law of the Rights of Mother Earth) as the basis for its climate policy again points to the important role that civil society has played in the crystallization of the ethical principles of the Bolivian government as it relates to climate change.

Provisions for the inclusion of societal actors in the formation of Bolivian climate policy more specifically are referred to in both the Bolivian Climate Change Plan of 2002 (in the form of an Inter-institutional Climate Change Council) and the National Mitigation and Adaptation Plan of 2009 (Republic of Bolivia, 2002; Plurinational State of Bolivia, 2009), and in 2009 the Bolivian Platform for Climate Change was formed, which brought together representatives from large international NGOs and Bolivian rural social movements to debate and formulate Bolivian climate policy (Fabricant, 2013). Despite critiques of the inclusiveness of these various participatory processes (Aguirre and Cooper, 2010; Laing, 2012; Gustafson, 2013), the ethical position on climate change espoused by the Bolivian government seems tightly aligned with that of most major societal actors (see Wright, 2012), suggesting that the latter have played a significant role in determining climate ethics in Bolivia.

\section{How is the concept of climate justice understood by the current government? Have they articulated any position on climate justice issues that arise in setting ghg emissions policy or in regard to the adaptation needs of vulnerable nations or people?}

Bolivia's position on climate justice consists of five main principles. The first principle is that of distributive justice. This principle is evident through Bolivia's demands for deep emissions cuts by developed nations, without the use of offsets, in order to create 'atmospheric space' for the economic and social development of those countries who, due to their relative poverty, are most vulnerable to climate change. The second principle revolves around notions of procedural justice, and demands that developing countries, and marginalized groups within all countries, are given an increased role in determining climate policy. Bolivia's emphasis on participatory democracy in climate policy processes at both the domestic and international level is evidence of this priority. The third principle informing Bolivia's conception of climate justice is that of just compensation for current and historical injustices. This concept has been the motivation behind Bolivia's calls for significant funding flows from perpetrators of climate change (developed countries) to the victims (developing countries) to facilitate mitigation and adaptation and to compensate for losses and damages associated with climate change.

Bolivia also argues that achieving climate justice requires addressing the root problem of the climate crisis - the capitalist system and its culture of unbridled consumption. Bolivia has demonstrated this fourth tenet of climate justice through its opposition to the use of market-based mechanisms such as the proposed Reducing Emissions from Avoided Deforestation and Forest Degradation (REDD+) mechanism. Bolivia claims that such markets are not only unreliable, inconsistent, and inequitable (and therefore incongruent with the repayment of 'climate debt'), but also that they result in the 
'transfer of responsibilities for mitigation of climate change from developed to developing countries, fostering the latter to continue subsidizing the former' (Plurinational State of Bolivia, 2014, p4). This opposition to market-based mechanisms and capitalist culture are closely related to the fifth and final tenet of the Bolivian concept of climate justice - the need to recognize and respect diverse cultures and ways of knowing, in particular those of indigenous groups. In the case of REDD+, Bolivia has 'consistently questioned the linking of forests to global carbon markets for ethical reasons as this authorizes the effective conversion of Mother Earth, considered sacred by Bolivian society, into a commercial commodity' (ibid), and perpetuates a capitalist mentality of constant growth and consumption that it is antithetical to the indigenous concept of 'buen vivir' ('living well') enshrined in the Bolivian Constitution of 2009.

8. Are you aware of any regional, state, provincial, or local governments in your country that have acknowledged some ethical responsibility for climate change? If so, what have they said?

As mentioned above, there seems to be a general consensus, not only among Bolivian actors but developing countries more generally, that the ethical responsibility for mitigating climate change rests with developed countries. There is no evidence that any sub-state governments within Bolivia have taken a position contrary to this.

\section{Has your national government taken any position on or otherwise encouraged individ- uals, businesses, organizations, subnational governments, or other entities that they have some ethical duty to reduce greenhouse gas emissions?}

The ethical position of the Bolivian government concerning responsibility for climate change focuses on the obligations of developed countries towards those most vulnerable to the adverse impacts of climate change, rather than any ethical obligation on the behalf of actors within Bolivia to reduce their ghg emissions. However, Bolivia has recognized that the 'construction of a model of sustainable development in harmony and balance with Mother Earth' will require promoting climate and environmental responsibility in public and private actors, including those within Bolivia (Plurinational State of Bolivia, 2012a). As the head of the Bolivian climate negotiation delegation has noted, developing countries have little moral basis on which to critique developed countries if 'they themselves decide to copy the "American model"' (Orellana, 2012, author's translation). Therefore, in addition to calling for changes in the structural economic system and consumption patterns of developed countries (Republic of Bolivia, 2008), Bolivia has long recognized the need to replace the 'increasingly individualistic, consumerist, and utilitarian cultural values within Bolivian society' (Republic of Bolivia, 2002) with a more holistic respect for other people and the natural environment. The constitutionalization of the notion of 'buen vivir' and recognition of the rights of Mother Earth in the 2009 Bolivian Constitution might be considered a step in this direction, although the tensions that exist between the realization of these concepts and continuing economic reliance on extractive industries have been well-documented (Aguirre and Cooper, 2010; Bebbington and Bebbington, 2011, 2012).

\section{What recommendations would you make to get the nation or civil society to take ethics and justice issues seriously in climate change policy formulation?}

Issues of climate justice and ethics remain at the core of Bolivian climate policy formation, and will remain so as long as developed countries continue to shirk their ethical obligations as defined by the Bolivian state. The Bolivian state has been one of the key international proponents of climate 
justice, having spoken out in defence of its particular conception of climate justice in multiple forums. Although there have been accusations of inconsistency, and even hypocrisy, surrounding the Bolivian government's adherence to these ethical principles (for a discussion, see Aguirre and Cooper, 2010; Bond, 2012; Laing, 2012; Slunge and von Walter, 2013), the country is likely to remain the primary champion of global climate justice moving forward (Akin, 2012). 


\section{References}

Aguirre, J. C. and Cooper, E. S. (2010) 'Evo Morales, climate change, and the paradoxes of a social-movement presidency', Latin American Perspectives, issue 173, vol 37, no 4, pp238-244

Akin, J. (2012) 'Civil justice in the mountains: The Bolivian Andes as grounds for climate reform', Colorado Journal of International Environmental Law and Policy, vol 32, no 2, pp434-468

Bebbington, A. and Bebbington, D. H. (2011) 'An Andean Avatar: Post-neoliberal and neoliberal strategies for securing the unobtainable', New Political Economy, vol 15, no 4, pp131-145

Bebbington, D. H. and Bebbington, A. (2012) 'Post-what? Extractive industries, narratives of development and socio-environmental disputes across the (ostensibly changing) Andean region', in H. Haarstad (ed.) New Political Spaces in Latin American Natural Resource Governance, Palgrave Macmillan, Basingstoke, UK, pp17-38

Bond, P. (2012) Politics of Climate Justice: Paralysis Above, Movement Below, University of KwaZulu-Natal Press, Scottsville, South Africa

Caney, S. (2005) 'Cosmopolitan justice, responsibility and global climate change', Leiden Journal of International Law, no 18, pp747-775

'Comparison of the Cochabamba People's Agreement and the Cochabamba Accord' (n.d.), LINKS International Journal of Socialist Renewal, http://links.org.au/node/1752, accessed 4 September 2014

Estado Plurinacional de Bolivia (2010) 'Bolivia Decries Adoption of Copenhagen Accord II Without Consensus', http://pwccc.files.wordpress.com/2010/12/press-release-history-will-be-the-judge.pdf, accessed 20 August 2014

Gustafson, B. (2013) 'Close the NGOs: Asserting sovereignty or eroding democracy?', North American Congress on Latin America, https://nacla.org/blog/2013/12/31/close-ngos-asserting-sovereignty-or-eroding-democracy, accessed 20 August 2014

Intergovernmental Panel on Climate Change (IPCC) (2007) 'Climate Change 2007: Synthesis Report', IPCC Fourth Assessment Report (AR4), Geneva, Switzerland

Kohl, B. (2010) 'Bolivia under Morales: A work in progress', Latin American Perspectives, issue 172, vol 37, no 3, pp107-122

Laing, A. F. (2012) 'Beyond the zeitgeist of "post-neoliberal" theory in Latin America: The politics of anti-colonial struggles in Bolivia', Antipode, vol 44, no 4, pp1051-1054

Madrid, R. (2011) 'Bolivia: Origins and Policies of the Movimiento al Socialismo', in Steven Levitsky and Kenneth Roberts (eds) The Resurgence of the Latin American Left, John Hopkins University Press, Baltimore, MD, pp239-259

Navarro, A. (2009) 'Climate debt: The basis of a fair and effective solution to climate change', Presentation to Technical Briefing on Historical Responsibility (Plurinational State of Bolivia), http://unfccc.int/files/meetings/ ad_hoc_working_groups/lca/application/pdf/4_bolivia.pdf, 7 August 2014

Orellana Halkyer, R. (2013) 'Desarrollo con pobreza o la pobreza del desarrollo: Límites de la Madre Tierra, vulnerabilidad de las Metas del Milenio y del crecimiento', Universidad de la Cordillera/Fundación de la Cordillera, La Paz, Bolivia

'People's Agreement of Cochabamba', World People's Conference on Climate Change and the Rights of Mother Earth, 22 April 2010, Cochabamba, Bolivia, http://pwccc.wordpress.com/2010/04/24/peoples-agreement/, accessed 17 July 2014

Plurinational State of Bolivia (2009) 'Second national communication to the UNFCCC - executive summary' (BOL/ COM/7 E), http://unfccc.int/resource/docs/natc/bolnc2exsume.pdf, accessed 10 August 2014

Plurinational State of Bolivia (2010) 'Submission to the WG-LCA', http://pwccc.wordpress.com/2010/04/28/ submission-by-the-plurinational-state-of-bolivia/, accessed 10 August 2014

Plurinational State of Bolivia (2012a) 'The development of the Climate Justice Entity and its mechanisms' (FCCC/ AWGLCA/2012/MISC.4/Add.2), http://unfccc.int/resource/docs/2012/awglca15/eng/misc04a02.pdf, accessed 18 August 2014 
Plurinational State of Bolivia (2012b) 'Joint Mitigation and Adaptation Mechanism for the Comprehensive and Sustainable Management of Forest and the Mother Earth', La Paz, Bolivia, http://www.redd-monitor.org/wpcontent/uploads/2012/10/JOINT-MITIGATION-2.pdf, accessed 4 August 2014

Plurinational State of Bolivia (2014) 'Matters relating to methodological guidance for non-market based approaches, such as joint mitigation and adaptation approaches for the integral and sustainable management of forests as established in paragraph 50 of SBSTA 38', http://www4.unfccc.int/submissions/Lists/OSPSubmissionUp load/12_15_130452435512456801-Bolivia_NMBA.pdf, accessed 10 August 2014

Plurinational State of Bolivia et al (2012) 'The role of the Convention in enhancing the implementation of approaches to loss and damage associated with the adverse effects of climate change', Joint submission to the UNFCCC Subsidiary Body of Implementation, https://unfccc.int/files/adaptation/cancun adaptation framework/ loss and damage/application/pdf/submission bolivia for loss and damage cop 18.pdf, accessed 15 August 2014

Republic of Bolivia (2000) 'First national communication to the UNFCCC' (BOL/COM/1 B), http://unfccc.int/ resource/docs/natc/bolnc1e.pdf, accessed 15 August 2014

Republic of Bolivia (2002) 'National Climate Change Program: General bases for the application of the Bolivian national implementation strategy of the UNFCCC', La Paz, Bolivia, http://unfccc.int/resource/docs/natc/ boladd6, accessed 4 May 2014

Republic of Bolivia (2008) 'Contribution to the AWG-LCA and to the Chair's Note entitled "Ideas and proposals on paragraph 1 of the Bali Action Plan"', http://unfccc.int/files/kyoto protocol/application/pdf/ boliviabap08122008.pdf, accessed 15 August 2014

Slunge, D. and von Walter, S. (2013) 'Environment and climate change in Bolivia: Challenges and opportunities for development', SIDA's Helpdesk for Environment and Climate Change, University of Gothenburg and Swedish University for Agricultural Sciences, http://sidaenvironmenthelpdesk.se/wordpress3/wp-content/ uploads/2013/06/Bolivia-Environmental-Policy-Brief-Final-May-2013.pdf, accessed 29 July 2014

Solon, P. (2009) 'Plurinational Government of Bolivia press release: Bolivia responds to US on climate debt: "If you break it, you buy it"', Copenhagen, Denmark

Wheeler, D. (2011) 'Quantifying vulnerability to climate change: Implications for adaptation assistance', Working Paper 240, Centre for Global Development

Wright, K. (2012). 'Bolivian civil society COP18 statement - Doha', World Development Movement, http://wdm. org.uk/climate-change/bolivian-civil-society-cop18-statement-doha, accessed 2 August 2014 


\title{
Canada's Consideration of Ethics and Justice Issues in Formulating Climate Change Policies
}

\author{
Anne D. Fouillard
}

This report responds to the research questions of the Project On Deepening National Responses to Climate Change On The Basis of Ethics and Justice, a joint project of the University of Auckland, School of Architecture and Planning and Widener University, School of Law, Environmental Law Center. The research questions and responses are as follows:

1. To what extent has the national debate about how the nation should respond to climate change by setting a ghg emissions reduction target expressly considered that the nation not only has economic interests in setting the target but also ethical obligations to those who are most vulnerable to climate change and that any national ghg emissions reduction target must represent the nation's fair share of safe global emissions? In answering this question, identify the national ghg emissions reduction target, if any, that the nation has committed to under the United Nations Framework Convention on Climate Change (UNFCCC).

\section{Canada's response to climate change as a global ethical issue - the big picture}

The Canadian climate change context is complex. With a federation that includes a federal government, 10 provincial governments and three territorial governments, its climate action regime has been fraught with many issues: the Alberta oil sands, the lack of political will and commitment of the federal government to lead, the government's anti-science and climate change denying agenda, its geography, its climate and high per capita fossil fuel consumption, the downloading of federal climate policy leadership to the provinces, exponentially rising carbon emissions, and finally its withdrawals from both the Kyoto Accord (Suzuki, n.d.[a]) and the Desertification Treaty ${ }^{1}$ (Visser, 2013), Canada is at the back of the pack of all developed nations according to the Climate Action Network Europe, Germanwatch and the Washington-based Center for Global Development 'Commitment to Development Index' (CDI) (Barder and Krylová, 2013). This report claims that 'Canada still shows no intention of moving forward with climate policy and therefore remains the worst performer of 27 industrialized countries' (Canadian Press, 2013). Canada ranks at the bottom of developed nations in climate change policy for its highest ghg emissions per capita globally of large nations, its lack of development of renewable energy, and its lagging international climate policy (CBC, 2013; Canadian Press, 2013). Canada also distinguishes itself for rapid fossil fuel production and its being the first country to withdraw from Kyoto (Waldie, 2013). As well, a recent European report ranked Canada 55th of 58 countries in 2013 in terms of tackling ghg emissions, ahead of only Iran, Kazakhstan and Saudi Arabia (Canadian Press, 2013).

Canada, the sixth-largest oil producer and the third-largest natural gas producer, accounts for about $4.75 \%$ of the world's total production of oil, and a similar share of the world's total natural gas. By most estimates, Canada's share in the world's oil production is projected to increase to about $5.5 \%$ by 2040 . As the world's tenth-largest emitter of greenhouse gases (ghgs) in absolute terms, Canada's 
per capita emission levels are also consistently among the world's highest ${ }^{2}$ (IMF, 2014), according to the International Energy Agency (IEA), on energy-related $\mathrm{CO}_{2}$ emissions.

Canada ranks as the eighth-largest absolute emitter in the world. On a per capita basis (excluding countries with populations below 1 million), Canada is ranked the ninth-largest ghg polluter (Grant et al, 2013a). About $7 \%$ of Canada's total greenhouse gas emissions came from oil sands plants and upgrading in $2010 .{ }^{3}$ Oil sands plants and upgraders produced 48 million tonnes of greenhouse gases in 2010, an increase of 31 million tonnes over 2000 levels.

- Oilsands are the fastest-growing source of greenhouse gas emissions in Canada. Greenhouse gas emissions from oilsands have almost tripled (increased 2.9 times) in the past two decades. Planned growth under current provincial and federal policies indicates greenhouse gas emissions from oilsands will continue to rise, resulting in more than a doubling of emissions between 2010 and 2020, 48 million tonnes in 2010 to 104 million tonnes of greenhouse gases in 2020.

- Overall, Canada's annual GHG emissions are projected to increase by 20 Mt between 2005 and 2020, under currently announced federal and provincial policies. Emissions from the oilsands (including emissions from upgrading) are projected to grow by $73 \mathrm{Mt}$ over the same period. Because the ups and downs in emissions in other sectors largely cancel each other out, essentially the entire projected increase in Canada's emissions between 2005 and 2020 will come from the oilsands.

- If [the province of] Alberta were a country, its per capita greenhouse gas emissions would be higher than any other country in the world. (Pembina Institute website, 2014, footnotes omitted)

In 2009 the Intergovernmental Panel on Climate Change (IPCC) called for industrialized countries like Canada to adopt ghg reduction targets of $25 \%$ to $40 \%$ below 1990 levels by 2020 in order to prevent global average temperatures from rising more by than $2^{\circ} \mathrm{C}$ relative to the pre-industrial levels (Suzuki, n.d.[a]). In December 2009 Canada signed on to the Copenhagen Accord and committed to reduce ghg emissions to $17 \%$ below 2005 levels by 2020 - a much weaker position than its previous commitment to Kyoto (Gelfand, 2014; Suzuki, n.d.[a]). The government's position was that this represented a significant challenge in light of a strong projected economic growth being $31 \%$ larger (in real terms) in 2020 compared to 2005 levels (Environment Canada, 2013a). According to the Government of Canada (GOC), its approach was to 'encourage strong economic growth and job creation while achieving our environmental objectives' (Environment Canada, 2013a). As a result of collective action by governments, consumers and industry, Canada's 2020 emissions are projected to be 128 megatonnes (Mt) lower than they would have been under a no-action scenario.

The National Inventory Report (Environment Canada, 2014) compiled by the environmental agency of the GOC, stated that between 2005 and 2011 Canadian ghg emissions had decreased by $4.8 \%$, while the economy grew by $8.4 \%$ over the same period with an average annual decline in Canadian emissions intensity (emissions per unit of gross domestic product (GDP)) since 1990, a trend projected through 2020. By the end of 2013, Canada's Action on Climate Change (GOC website, 2014a) and Canada's Emissions Trends (Environment Canada, 2013a) both reported the same ghg emissions decrease but also confirmed that Canada was projected to achieve roughly half of its 2020 Copenhagen target reduction of 128Mt (Pullman, 2011). ${ }^{4}$ This was confirmed by Environment Canada's updated Emissions Trends (2013) which also reaffirmed further slippage from meeting its 2020 ghg emissions targets (GOC, 2014a). ${ }^{5}$ 
The GOC's strong support for a fossil fuel economy along with its formal withdrawal from the Kyoto Protocol means that Canada is on track to achieve less than half of its stated emissions reduction targets (Environmental Defence Fund, 2013, 2014a), which was also confirmed by the independent Commissioner of the Environment and Sustainable Development who warned that current and planned federal policies are too weak to reach these already weak targets (Gelfand, 2014).

The IPCC's call for industrialized countries is far more ambitious than Canadian policy. Groups like the Climate Change Action Network argued for new, more stringent Canadian emissions reduction targets. The Pembina Institute and the David Suzuki Foundation demonstrated that the 2020 target of 25\% reductions in Canada's emissions from 1990 levels were entirely feasible, and would not by any means damage the Canadian economy (Pembina Institute and Suzuki Foundation, 2009).

Bill C-311 in 2010, the Climate Change Accountability Act, was passed by the House of Commons by a strong majority in May 2010, only to be overturned by the unelected largely Conservative Senate later in November (350 or Bust, 2011; CBC, 2010). Bill C-311 required that the GOC set regulations to attain a medium-term target to bring ghg emissions $25 \%$ below 1990 levels by 2020, and a long-term target to bring emissions $80 \%$ below 1990 levels by 2050, establishing the same targets recommended by the Pembina Institute and Suzuki Foundation (2009). By setting this long-term target to bring emissions $80 \%$ below 1990 levels by 2050, a target more stringent than the Harper administration goal of a $17 \%$ cut in emissions from 2005 levels by 2020 , the Bill was pushing Canada to move forward on climate change. However, before the G20 meetings in June 2010, Canada's Prime Minister Harper made it clear that his focus was on the economy and everything else was 'just noise' (CBC, 2010), calling Bill C-311 a 'completely irresponsible' piece of legislation, without measures for achieving targets, other than by shutting down sections of the Canadian economy and throwing hundreds of thousands and possibly millions of people out of work (Galloway, 2010).

\section{Elements in Canada's climate strategy}

While Canada has articulated its climate policy intentions and commitments, these have been largely as official reaffirmations of existing programmes. Overall, Canada has failed to implement many of its commitments - often its approach has been to hinder progress internationally (G8 Research Group LSE/Oxford, 2008). Further, there has been shoddy reporting of its progress toward meeting its global responsibilities (Turner, 2014). The most recent GOC approach which represents various initiatives to reduce Canada's carbon footprint reduction is described below:

- From 2005 to 2012, Canadian ghg emissions decreased by $5.1 \%$ while the economy has grown by $10.6 \%$. The 2013 Canada's Emissions Trends report estimates that, as a result of the combined efforts of federal, provincial and territorial governments, consumers and businesses, ghg emissions in 2020 will be $734 \mathrm{Mt}$. This is $128 \mathrm{Mt}$ lower than where emissions would be in 2020 if no action were taken to reduce ghgs since 2005.

- Canada has worked collaboratively with the US towards common North American standards for ghg emissions from vehicles with Passenger Vehicles and Light Trucks projections where as a result of the regulations, average ghg emissions from 2025 vehicles are projected to be reduced by about $50 \%$ from those sold in 2008 . With respect to Heavy-duty Vehicles regulations, it is anticipated that the average ghg emissions from 2018 heavy-duty vehicles will be reduced by up to $23 \%$. 
- With regard to electricity, final regulations to reduce emissions from the coal-fired electricity sector were released, applying a stringent performance standard to new coal-fired electricity generation units and to coal-fired units (but this ignored antiquated coal-fired plants which continue to operate).

- In the case of renewable fuels, as of 15 December 2010, gasoline is required to contain an average $5 \%$ renewable content, with these regulations representing one pillar of the government's broader Renewable Fuels Strategy. Similarly, a 2\% renewable fuel requirement for diesel fuel has been implemented. Regulated ghg performance standards will be developed for the remaining major sources of emissions, with a focus on the oil and gas sector and other industrial emitters, but these regulations have yet to appear despite multiple promises from the GOC.

- Canada claims it is well placed to be a global leader in the development and deployment of carbon capture and storage (CCS) technologies because it has invested $\$ 3$ billion in funding in CCS demonstration projects although the feasibility of this technology has yet to be demonstrated.

- Canada as a member of the Global Research Alliance, announced an investment of \$27 million towards its Agricultural Greenhouse Gases Program (AGGP) where Canadian farmers will become more competitive and profitable through improved access to, and adoption of, beneficial management practices that mitigate ghgs. An initial \$19.6 million was approved for 18 projects to bring farmers, the agricultural community and academia together to work on advancing research, technology transfer and adoption of beneficial management practices to mitigate agricultural ghg. (GOC website, 2014b).

Because Canada has not finalized the regulations necessary to achieve the Canadian Copenhagen target, there is little hope that Canada will achieve its target.

\section{The tar sands/oil sands' role in Canadian ghg emissions}

The main problem with the Canadian climate policy as set out so far is that it does not adequately take into consideration the oil sands industry which as the fastest-growing source of ghg pollution has plans to triple production exceeding all other subsectors in ghg emissions by a large margin. The International Monetary Fund (IMF) reported that while the share of the energy sector in Canada's GDP (by industry) has remained around 10\% over the last decade (a figure which varies depending on the source), unconventional oil and gas output (tar sands) recorded the highest growth among all the industries in Canada (60\% cumulative between 2007 and 2013), offsetting the decline in conventional energy output. Unconventional energy had until recently attracted an increasing share of Canada's overall investment, while energy products became the largest item in Canada's total goods exports (IMF, 2014, pp4-5). See Figure 1.1. 
Figure 1.1 Projected change in absolute ghg emissions

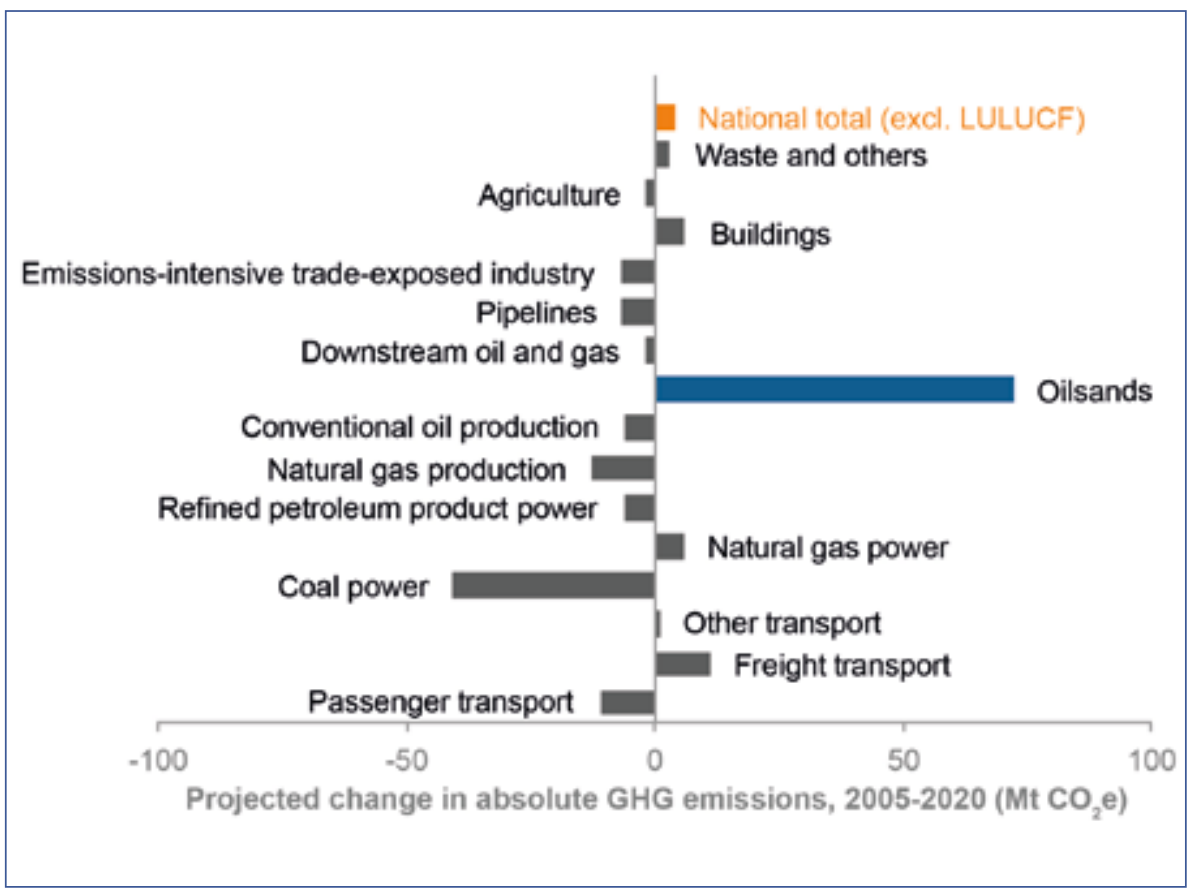

Source: Partington and Demerse, 2013, p4.

Although ghg emissions from the production and upgrading of the oil sands (where upgrader plants in oil sands production process bitumen through fractional distillation and/or chemical treatment so it can be more easily handled by oil refineries and pumped through pipelines) look relatively small relative to the global total, these oil sands emissions alone are actually larger than the emissions from many countries as a whole. If Canada's oil sands emissions are compared against other countries' emissions, Canada ranked as the 56th-largest emitter out of a total of 142 countries, similar to Portugal (Grant et al, 2013a, pp12-13). According to the Pembina Institute, even though emissions per barrel did improve in the oil sands for a period of time, absolute emissions (total emissions per year) across the industry have been steadily increasing with emissions from oil sands upgrading (Grant et al, 2013a, p7) and processing nearly tripling between 1990 and 2010. GOC projections showing emissions are likely to double again between 2010 and 2019 (Grant et al, 2013a, p10) leads to the conclusion that growth in ghg emissions from increasing oil sands production is a key reason why Canada is not on track to meet its 2020 climate goal.

While other sectors across Canada are making progress on reducing ghg emissions, the rapid growth in emissions from the oil sands is set to undo the progress made in other sectors. Closing the gap between current emissions and Canada's 2020 target will require slowing the planned growth of oil sands emissions substantially with significant increases in effort from industry, as well as at all levels of government policy (Grant et al, 2013a, p11), and that is not set to happen especially given the projected growth in approved oil sands projects. See Figure 1.2 Oil sands expansion reflecting regulators' approval of more than 5 million barrels of bitumen production per day. 
Figure 1.2 Oil sands expansion

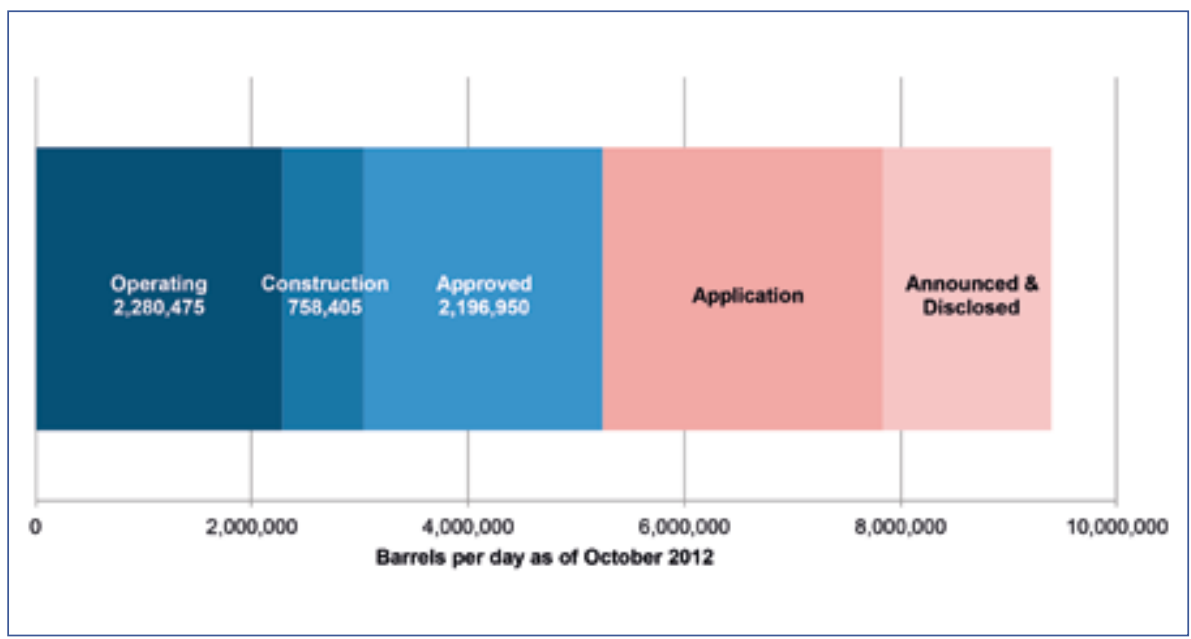

Source: Oilsands Review, October 2012, from Grant et al, 2013a, p2, 2013b, p2.

Figure 1.3 highlights oil sands ghg emissions should the GOC continue with current policies.

Figure 1.3 Oil sands ghg emissions (past and forecast) under existing policies

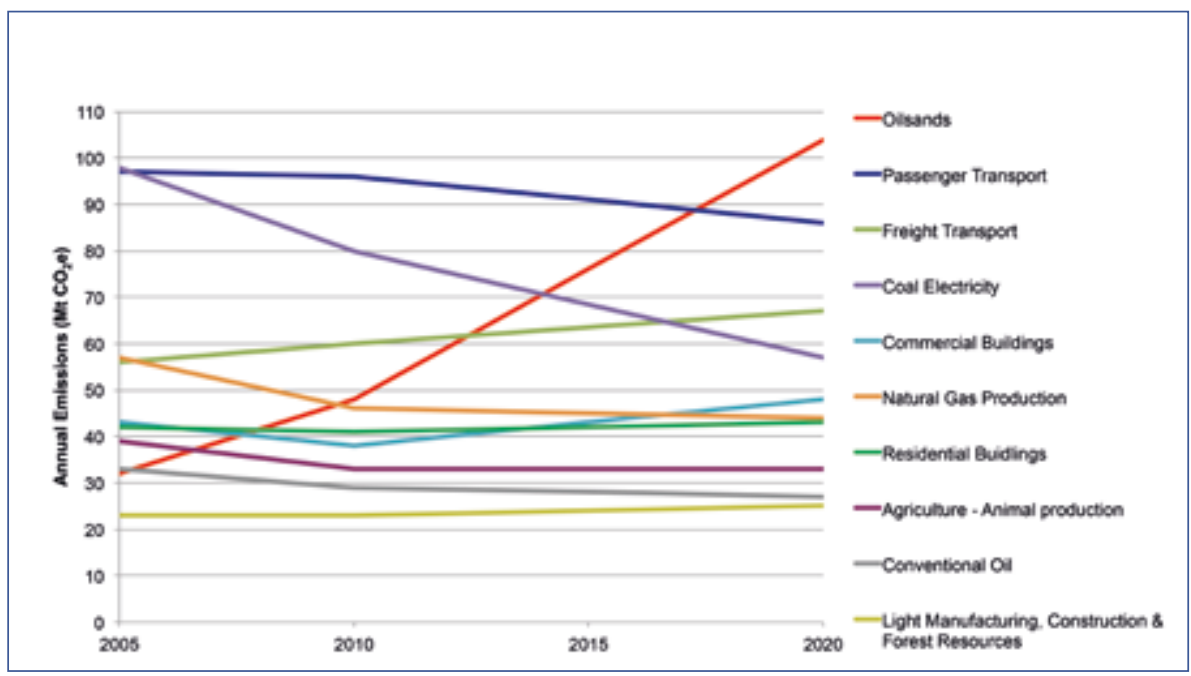

Source: Grant et al, 2013a, p11, from Canada's Emissions Trends (2012).

By the end of this decade, oil sands emissions are projected to exceed those of other major categories, and if Canada is to meet its 2020 climate change targets it will have to address oil sands emissions or rely on other sectors to make even steeper reductions in their emissions (Grant et al, 2013a, p11) (to date, the only two sectors that have been partially regulated with regard to ghg are coal and the automotive sector). ${ }^{6}$ 


\section{Canadian obstructionist role in international climate negotiations}

Since 2006, Canada has also been accused of working to undermine the UNFCCC negotiations. In fact, Canada has been the winner of the Fossil of the Year award. ${ }^{7}$ The Fossil of the Day and Fossil of the Year awards are given by environmental organizations daily and at the end of international climate conferences to countries that are the most obstructionist in international climate negotiations. In 2007 and in 2009, as well as a special Lifetime Unachievement Fossil Award awarded to it in 2013 (climatenetwork.org, 2013), Canada has consistently won this award, sometimes multiple times during the same year at the same conference. Winners are awarded the Fossil Award 'for bringing a totally unacceptable position into Copenhagen and refusing to strengthen it one bit. Canada's 2020 target is among the worst in the industrialized world, and leaked cabinet documents revealed that the government is contemplating a cap-and-trade plan so weak that it would put even that target out of reach' (Mang, 2009).

Although Canada withdrew from the Kyoto Protocol, it still remains a party to the United Nations Framework Convention on Climate Change. GOC documents say that the federal government has continued to engage at the international level through the UNFCCC negotiations. Work also started in developing a post-2020 ghg target for the country to be brought forward by Canada prior to the first quarter of 2015. However, Canadian climate policy trends in 2014 indicated the opposite; generally the perception was a loss in federal political will, stalled equivalency, and an abundance of provincial policy labs (Sawyer et al, 2014). What is being observed are many provinces addressing ghg reductions, each in their own laboratory fashion, and in the absence of federal government leadership (Gelfand, 2014).

At COP19 in Warsaw (2013), Canada asked for a Fair, Comprehensive, Global Climate Change Agreement supporting the Durban Platform for Enhanced Action, committed to a negotiations progress toward a single, new international climate change agreement that included: meaningful and transparent commitments from all major emitters (difficult for Canada given the measurement system); supported constructive and ambitious global action (with little collaboration from Canada over time); balanced environmental protection and economic prosperity (GOC evidence points to the contrary especially with oil sands/tar sands ghg emissions); and a long-term focus (GOC website, 2013). Canada's actions to date do not lend credibility to this position.

\section{Canada's justice/equity commitment}

Principles to determine any nation's fair share of safe global emissions have been debated in international climate negotiations under the topic of 'equity'. Under the Greenhouse Development Rights (GDR) framework, one of five or six equity frameworks to have received international support and respect (for example, the most recent IPCC report, Working Group III, Chapter 4 identifies several efforts and examples of burden sharing proposals), a country like Canada has three related obligations:

(1) to rapidly reduce its own domestic emissions;

(2) to provide its share of the financial and technology support necessary to enable developing countries to make their own rapid low-carbon transitions; and

(3) to support the vulnerable people and communities who will be most impacted by climate change as they try to adapt to a new, less hospitable world.

More specifically, Canada's fair share obligations within the GDR framework is $2.7 \%$ of the global mitigation requirement, or about $470 \mathrm{MtCO}_{2} \mathrm{e}$, by 2020 or $2.7 \%$ of the global adaptation burden 
(Athanasiou et al, 2009). The GOC obligations to mitigate are illustrated in Figure 1.4. Note that the mitigation obligations are reflected in the amber area as calculated by the GDR framework under a $2^{\circ} \mathrm{C}$ emergency stabilization pathway. Note that Canada's emissions allocation falls all the way to zero by about 2025, and then continues to drop. For comparison, of two targets that are shown as prominent in the Canadian climate policy debate, the first (dashed) is the governmental target that would bring 2020 emissions to $3 \%$ below 1990 levels; the second (dotted) would bring Canadian emissions to a level $25 \%$ below 1990 levels in 2020 .

Figure 1.4 Canada's mitigation obligations

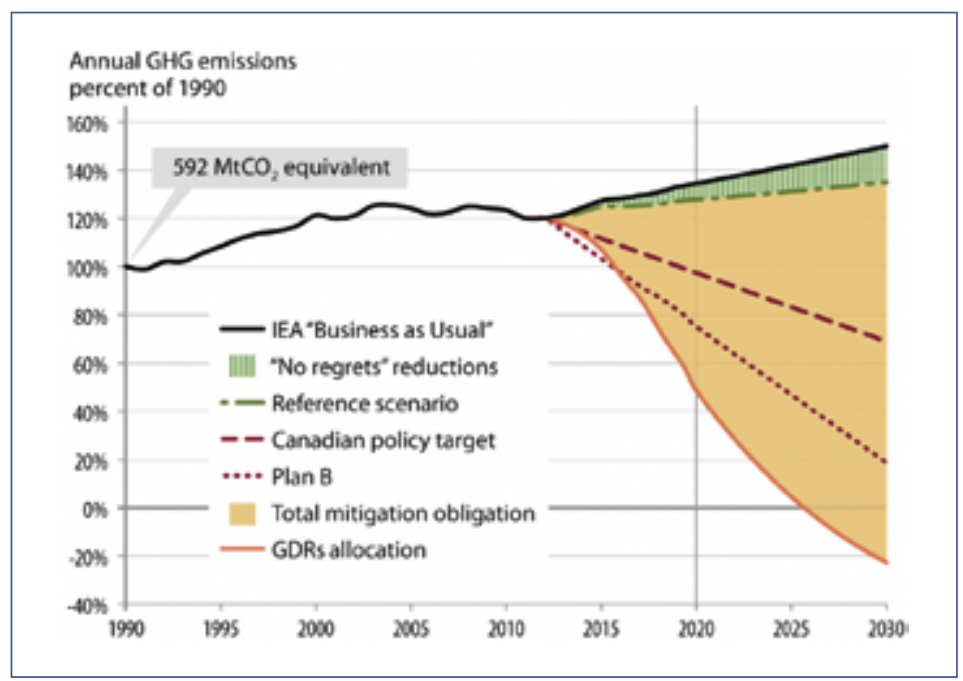

Source: Athanasiou et al, 2009, p4.

Historically, Canada has fallen short of its obligations. In 2000, Canada ranked ninth out of 186 countries in terms of per capita ghg emissions without taking into account land use changes. In 2005 it ranked eighth. In 2009, Canada was ranked seventh in total ghg emissions behind Germany and Japan (The Guardian, 2011).

Although ethics and justice may have been implicit in Canada committing to a climate policy prior to then, since 2006, the government has been explicit in its negation of responsibilities to the UNFCCC. The previous Liberal government of Canada had developed a plan to meet our Kyoto targets, including mandatory emissions cuts for large factories and power plants; a voluntary agreement with automakers to improve fuel efficiency in Canadian vehicles; a climate fund to purchase emissions reduction credits from Canada and abroad; and a partnership fund to assist provinces and municipalities in making infrastructure investment projects to decrease ghg emissions largely based on incentives and voluntary initiatives. The Liberal government never implemented the plan as it lost the election in January 2006 setting in motion a move backwards on climate policy. Harper as the newly elected Conservative Prime Minister announced that Canada would not meet these commitments under his government, despite several opposition-sponsored bills calling for government plans of emissions reduction measures. This position taken by the Conservative government was widely criticized globally by APEC, at Commonwealth Summits and in numerous UNFCCC conferences (G8 Research Group LSE/Oxford, 2008). Since that time, Canada's position has been degraded. Although Canada was a signatory to the Kyoto Protocol and active in the negotiations that led to the Kyoto Protocol 
in 1997, the Liberal government at the time signed the accord in 1997 and ratified it in Parliament in 2002 (G8 Research Group LSE/Oxford, 2008). Despite both signing on and ratifying it, little action was ever taken to meet Canada's ghg emissions reduction targets by $6 \%$ below 1990 levels. By late 2011, Canada instead invoked its legal right to formally withdraw from the Kyoto Protocol (The Star, 2011; United Nations, 2011), becoming the first country ever to do so, provoking very strong criticism from other ratifying countries.

Canada is now left with the worst climate change policy of all wealthy nations ranking it the fourthworst among all nations, says a survey from environmental umbrella group Climate Action Network. Canada 'still shows no intentions to move forward on climate policy and thereby leave its place as the worst performer of all western countries' reads the preamble to the Climate Change Performance Index 2013 (Germanwatch, 2013). It ranked 58th out of 61 countries surveyed in the latest issue of the index, ahead of only Kazakhstan, Iran and Saudi Arabia. The index measures current emissions levels, emissions trends, energy efficiency, efforts at renewable energy, and government climate policy. Canada received a ranking of 'poor' on energy efficiency, and a ranking of 'good' on emissions trends. But it received the worst grade - 'very poor' - on current emissions, renewable energy and climate policy (Tencer, 2012).

The government's approach to alternatives has been to discount the low-carbon proposals from environmentalists as coming from eco-terrorists and radicals (McCarthy, 2014; Tello, 2014). An editorial in the Hill Times in April 2014 by Diane Beckett challenged this assumption, saying that the likes of the IMF, the World Bank and the UN hardly qualified as the 'tree huggers' that they were caricatured by the Conservative government. She went on to report that the International Energy Agency stated that two thirds of proven reserves of oil, gas and coal will have to stay in the ground to hold global warming to 2 degrees Celsius, a conclusion also reached by Kairos (Dillon, 2014a), the internationally recognized limit of manageable climate change. Yet the Canadian government is moving toward increasing ghg emissions, announcing that it is delaying for up to two years the release of long-promised regulations to reduce emissions in the oil sands - all this with the US plan of 2013 announcing that it will meet its commitments. Canada has stood against the position of Plan B (Eco-Business, 2013), the UN Global Compact, the World Business Council for Sustainable Development and the World Economic Forum which all call for action on climate change (Beckett, 2014).

Little evidence can be seen of the federal government's commitment to address the issues within a climate justice framework. There is no mention of either 'ethics' or 'social justice' in two recent GOC publications: Canada's Sixth National Report on Climate Change - 2014, a 288-page document, nor the most recent document from Natural Resources Canada (NRCAN) entitled Canada in a Changing Climate: Sector Perspectives on Impacts and Adaptation (2014) (292 pages). The latter represented a straightforward, data-driven, thoughtful analysis of the status of the planet's climate and the likely impact of a changing climate on Canada's environment, economy and society. Rather, it acknowledged more work is needed by governments to help Canadians cope with health, economic and environmental threats posed by global warming. It stated that Canada had failed to live up to this country's capacity to adapt to change and the ever-growing knowledge base on the effects of ghg emissions, referring to barriers to adjustment to climate change that include lack of scientific knowledge, 'limited motivation' and 'issues related to governance'. This heralded the first official acknowledgement of Canada's climate policy failures from a GOC document since 2006.

Increasingly the pressure is on - Canada's lack of a comprehensive plan for ghg reductions has compelled such institutions as the International Energy Agency, the International Monetary Fund and 
the World Bank to state that Canada must put a price on carbon, an action yet to be taken by the Canadian federal government (Tremonti, 2014). From the Canadian perspective, public opinion is also moving forward. Earlier this year, Canada 2020, a progressive think tank, released an opinion survey that convincingly highlighted the wide gap between public expectations and the Conservative government's abysmal failure to articulate a credible policy to mitigate the carbon output from oil sands reducing Canada's overreliance on fossil fuels. Fully $77 \%$ of Canadians are concerned about climate change, the poll found. Even more, $84 \%$ want Ottawa to show international leadership. And $47 \%$ would support a carbon tax to deter fossil fuel use - even if it hit them hard in the pocket by pushing up energy costs by $10 \%$ (The Star, 2014a). Evidently, a disconnect exists between the position of the GOC which clearly does not reflect the desires and aspirations of the majority of Canadians.

Since the Conservative government came to power, Canada's ethical failures on climate change have been recognized by various coalitions and groups where positions against the federal government's pro-industry adversarial machinations in the national and global environment have been made clear. With its energy scenario dominated by the Alberta tar sands and a Conservative government promoting, advocating, legislating and subsidizing an extractive-sector economy of oil and gas as well as mining, committed scientists and activists, coalitions of non-governmental organizations (NGOs), academic institutes, labour and independent research institutions have been largely responsible for continued efforts in pursuing solutions to the ghg dilemma.

According to the United Church of Canada (UCC), climate justice is one of the key ethical and moral challenges of our time (UCC, n.d.). As human-induced climate change is a result of industrialized countries releasing a disproportionate amount of ghg into the atmosphere we all share, a quick technological fix to climate change cannot be applied. ${ }^{8}$ We are creating an ecological debt to lessdeveloped countries, the most vulnerable, all other forms of life on the planet, and to the future. The countries with the largest 'footprint' (negative impact) among the nations must now take on this responsibility and pay their climate debt (Athanasiou et al, 2009; Dillon, 2014c; Kairos, 2010, 2014; Green Economy Net, 2011).

\section{Ethical issues at the domestic level}

Thus far, this report has considered Canada's response to ethical issues that arise when formulating Canadian policies because of the global scale of the climate change problem. However, climate change policy formation in Canada has also raised ethical issues about how climate change policy-making is affecting Canadian citizens' rights. When Canada formulates climate change policies, there are additional ethical and justice issues that arise under Canadian law, namely the Charter of Rights and Freedoms (GOC, 2014e) and human rights that Canadians have under international human rights law. ${ }^{9}$

\section{Human rights}

Climate change violates many human rights, including three of the most fundamental and least controversial rights: namely, the right to life, the right to health, and the right to subsistence (Caney, 2010). Climate change violates the right to life because climate change will and is killing people through more intense storms, floods, droughts and killer heat waves. Climate change violates the right to health by increasing the number of people suffering from disease (Whittington, 2014; Suzuki Foundation, n.d.; Suzuki, n.d.[b]), death and injury from heat waves, floods, storms and droughts, increases in the range of malaria and the burden of diarrhoeal diseases, cardio-respiratory morbidity 
associated with ground-level ozone, and the number of people at risk from dengue fever. Climate change violates the right to subsistence by increasing: droughts, which will undermine food security; water shortages and sea-level rise, which will put some agricultural areas under water; and flooding, which will lead to crop failure.

Caney explains that other human rights are affected by climate change but an understanding that climate change violates these three rights puts the claim that climate change violates human rights on the most uncontroversial grounds (Caney, 2010).

\section{Canada's lack of environmental rights, and the GOC failure to protect its citizens}

Canada, unlike many other nations, has no express right to a healthy environment in domestic law (Suzuki Foundation, 2014b), but Canadian citizens have human rights under international human rights law including the right to life, health, and security rights that will be violated by likely climate change impacts to Canada. The failure of Canada to establish ghg emissions targets that represent Canada's fair share of safe global emissions leads to the conclusion that the Canadian government's inadequate climate change policies are violating Canadian human rights because climate change in Canada will likely lead to storms that kill people, undermine food security in parts of Canada, destroy water supplies in some parts of Canada, and have other adverse impacts on life, health, and ecological systems on which life depends.

Canadian citizens' rights to life, health and security will be violated unless the Canadian government demonstrates leadership and develops a science-based climate change strategy that reduces Canadian ghg emissions to the Canadian fair share of safe global emissions (Suzuki Foundation, 2014b; Findlay and Dufour, 2014). This will require more scientific resources to invest in climate change-related research, a credible scientific basis for understanding how all sectors of the Canadian economy are contributing to Canadian ghg emissions, and a transparency in developing climate change policies that will allow Canadians and scientific institutions to evaluate Canadian climate change policies.

\section{Violation of indigenous rights under the Canadian Charter of Rights and Freedoms ${ }^{10}$}

Canada has had a blatant disregard for aboriginal land, treaty and inherent rights and has failed to recognize the Canadian Charter of Rights and Freedoms and the United Nations Declaration on Indigenous Rights (AFCN website, 2014; Alberta Oil, 2014; CBC, 2014). NGOs and native peoples have made repeated calls for the protection of fresh-water resources, the boreal forest, human health, and the protection of traditional rights of aboriginal communities. The federal government's failure to respect aboriginal rights with regard to pipelines and their construction on native lands are evidence of the GOC incapacity to address and regulate social licence ${ }^{11}$ and proper review processes including consultation with First Nations. Government and industry's failure to recognize these fundamental aboriginal rights has resulted in numerous court challenges where the judiciary is ruling on issues relating to the Charter of Rights and Freedoms (Uechi, 2014). ${ }^{12}$

In a lawsuit aiming in part to protect indigenous rights, one of the largest unions filed a suit against the Northern Gateway pipeline to stop transportation of oil sands material from Fort McMurray, Alberta to Kitimat, British Columbia, some of which would pass through indigenous traditional lands. The union 
alleged that the Stephen Harper government was attempting to ride roughshod over Canadian jobs, First Nations' rights, and environmental concerns (Nuttall, 2014).

Part of the aboriginal arguments focus on their traditional land rights and responsible sustainable development, asking for a respect for not only their indigenous rights but what they perceive as their environmental rights to clean water, species protection including flora and fauna, and cultural integrity. For example, in the Athabasca Chipewyan First Nation, early in 2014, Chief Adam, a witness at the Standing Committee on Natural Resources on The Cross-Canada Benefits of the Oil and Gas Industry, stressed that the Athabasca Chipewyan First Nation people do not want to stop development but would like the governments of Alberta and Canada to impose regulations that guide industry for sustainable and responsible development in this region (Uechi, 2014). In April 2014 Chief Adam added:

\begin{abstract}
'Environmental justice is simple. Unlike the people in the cities who have been removed from the lands for decades - in some cases, for centuries - our people are directly connected to the lands, waterways and to the very species that call these areas home. When the land, water and species experience injustice from contamination, de-watering, clear-cutting or even complete destruction, it's not just the environment that suffers - it's our people, our culture and our rights, too. The environment is not something separate from our people; it is a part of us. We need to stop accepting that the environment is a status quo casualty of development and that economic assimilation is the way of the future for our First Nation. So we see environmental justice and social justice as the same thing.' (Alberta Oil, 2014)
\end{abstract}

Later in July 2014, the Athabasca Chipewyan First Nation (ACFN) announced they would no longer participate in the TransCanada Grand Rapids Pipeline, referring to it as the 'Mother of All Pipelines' feeding projects like the Energy East Pipeline (Delaney, 2014; Environmental Defence, 2014b, 2014c). ${ }^{13}$

With regard to the controversial Keystone XL pipeline projects, Chief Adam claimed that Alberta Energy Regulator (AER) had put the First Nations in an impossible position to effectively participate in the public process designed to consider the pipeline by failing to do adequate studies or environmental assessments on the impacts of the pipeline on aboriginal and treaty rights as well as impacts to hunting, fishing and trapping and the incomplete Caribou Protection Plan. Yet TransCanada Corp was granted a fast-tracked hearing by the AER despite serious questions about the review process.

The Union of British Columbia Indian Chiefs, Grand Chief Stewart Philip, announced at least nine legal challenges based on the historic Supreme Court decision (CBC, 2014) which ruled unanimously in favour of the aboriginal land rights of the Tsilhqot'in First Nation. ${ }^{14}$ Considered a ground-breaking, game-changing and precedent-setting decision, it recognized the land claim of a British Columbia First Nation. It ruled that logging, fossil fuel extraction and mining operations on or near aboriginal lands must have the consent from affected aboriginal groups. Proponents of these challenges believe the case will have a direct bearing not only on projects like the Northern Gateway pipeline, which crosses four territories with aboriginal claims and which extends across the country to Quebec and the East Coast in areas where there are no land treaties, but on other pipelines.

This Supreme Court decision requires that government consult and accommodate First Nations concerns in a pipeline review even as the land claim is under way. If the First Nations group does not consent to the pipeline on its lands, the government can only go against the First Nations' wishes once it has proven its justification with a lawsuit against the First Nations group. This can occur only through the filing of a complicated Constitutional challenge to the Charter of Rights and Freedoms which would ultimately result in a very long, time-consuming litigious process (Matthews, 2014). 
2. In making a national commitment to reduce ghg emissions under the UNFCCC, to what extent, if at all, has the nation explained how it took equity and justice into consideration in setting its ghg emissions reduction target?

The Canadian government renews its claims frequently that it is the economy, above all else, that drives, especially when it comes to ghg reductions. Ostensibly, this approach is there to protect jobs, which are a right, but the overall objective appears to be the protection and facilitation of the petroleum's industry's interests rather than those of the public. Canada's commitment to reduce ghg emissions is framed in an economic context - the message being that, as a country, we will not reduce ghg emissions at the expense of jobs. A reprofiling of ghg information to suit the government's political purposes has occurred: 'Under the UNFCCC, the Government's approach is to encourage strong economic growth and job creation while achieving its environmental objectives' (GOC, 2014a). Hence, it would be fair to say that Canada has not explained explicitly whether it takes equity and justice into account when it negotiates with the UNFCCC.

3. Given that any national ghg emissions target is implicitly a position on achieving an atmospheric ghg concentration that will avoid dangerous climate change, to what extent has the nation identified the ghg atmospheric concentration stabilization level that the national emissions reduction target seeks to achieve in cooperation with other nations?

Canada has failed as evidenced by its own Environment Canada to comply with its ghg reduction targets, a position also confirmed by its independent government-appointed Commissioner of the Environment and Sustainable Development in her last report tabled in October 2014 (Gelfand, 2014).

4. Given that any national ghg emissions target is implicitly a position on the nation's fair share of safe global emissions, to what extent has the nation identified the ethical and justice considerations that it took into account in allocating a percentage of global ghg emissions to the nation through the identification of a ghg emissions reduction commitment?

Again, there has been no strong commitment to allocate a percentage of global ghg emissions by identifying our national fair share of ghg emissions in a reductions target and complying with this commitment. There is no evidence that the GOC has considered any justice issues in decision-making on national ghg emissions.

5. To what extent, if at all, has the nation acknowledged that nations emitting ghg above their fair share of safe global emissions have a responsibility to fund reasonable adaptation measures or unavoidable losses and damages in poor developing countries?

Prior to Copenhagen, the defunct Canadian International Development Agency (CIDA), which was recently merged into the Department of Foreign Affairs, Trade and Development (DFATD) in 2013, is now a branch within the foreign aid ministry of the Canadian government; in its previous incarnation, CIDA was stopped from funding any climate change-related efforts in developing countries (personal communication, retired CIDA employee, August 2014). In 2009 Canada contributed to Climate Change Financing (GOC, 2014a) or fast-start financing (FSF), the Copenhagen fast-start commitment where industrial countries 'provided new and additional resources . . a approaching USD $\$ 30$ billion for the period of 2010-2012 with a balanced allocation between adaptation and mitigation' (CCIC blog, 2013). Canada claimed this contribution as the country's largest ever investment in international climate change-related support contributing to ghg emissions reduction and increased adaptation. Funding 
was provided for a 2011 to 2013 window on climate change mitigation and adaptation projects in developing countries in over 60 countries; their special focus was on adaptation, clean energy technology and transfer, and sustainable forests and agriculture (GOC, 2014a). The Canadian Climate Change website reports a 'commitment to provide its fair share of fast-start financing. Over the faststart period, $\$ 1.2$ billion in new and additional climate change financing was issued, at approximately $\$ 400$ million in each of the three years. . . . [Funds were] committed at the project level . . . [with] support . . . delivered primarily through multilateral channels, but also directly to Canada's bilateral partners and in partnership with civil society and the private sector' (Environment Canada, 2013b, 2014).

An independent assessment of FSF commissioned by the Canadian Coalition for Climate Change and Development (C4D) examined whether new and additional money had been allocated, and challenged whether Canada had met its fair share - that is, did it provide a balance between loans and grants and mitigation and adaption? The results demonstrated that the 'new and additional money' may have come at the expense of other aid. Canada did give its fair share, about $4 \%$ for a total of $\$ 1.2$ billion (Government of Canada, 2013a; Pembina Institute and C4D, 2013). Findings were mixed, however, between the loans and grants and adaptation and mitigation - it appears that more than $\$ 615$ million will be returned to Canada over the life of the loan programmes, thereby reducing the value of Canada's total fast-start finance by more than $50 \%$. From the perspective of financing for adaptation, only $18 \%$ of FSF Canadian funding went towards it - a far stretch from the balanced allocation between adaptation and mitigation called for by the Copenhagen Accord, and interpreted by many to be a $50 / 50$ split. What followed did not portray Canada as a long-term committed supporter of adaptation and mitigation. A new set of pledges for 2013-2015 for $\$ 400$ million to be designated for the FSF programme were also not forthcoming (CCIC blog, 2013).

\section{What formal mechanisms are available in the nation for citizens, NGOs and other interested organizations to question/contest the nation's ethical position on climate change?}

Historically, a very integrated collaboration between government, industry, scientists and academics as well as civil society and NGOs guided climate change policy from 1998 onward to help Canada meet its Kyoto target. The National Climate Change Process (NCCP) initiative established 16 separate multi-stakeholder processes, known as Issue Tables. Although this multi-stakeholder process represented the work of some 450 'experts' from government, industry and environmental groups who evaluated Canada's ghg emissions and ways to reduce these, offering a balanced and credible source of information on ghg management, its website (www.nccp.ca) was closed, at least since $2007 . .^{15}$ Closure of the website meant that the historical information and institutional memory collected and developed is no longer available to the public and researchers (Pendergast, 2007) although it retained important contextual and climate science information. This signalled the beginning of suppression of credible scientific information by the government and the lack of open and transparent governance.

The Standing Committee on Natural Resources (NRCAN, 2014) on The Cross-Canada Benefits of the Oil and Gas Industry would have been one way of remediating the perception that Canadian citizens, NGOs and other interested organizations could have been included in a transparent and consultative debate on issues of ghg. The original motion of this committee called for a study of the benefits experienced from developing the energy industry, with a focus on oil and gas. Although the study should also have included the benefits of hydro, wind, tidal, nuclear, biomass and other renewable 
and clean energy resources, the Conservative majority on the committee opted to only examine the benefits of oil and gas.

In conclusion, there has not been a concerted stakeholder process led by the federal government. Rather, a piecemeal approach to consultation on a project-by-project basis is the order of the day. Consultations/public hearings as required by law with aboriginal peoples and First Nations have fallen short according to the Commissioner of the Environment and Sustainable Development, especially with regard to aboriginal lands where First Nations actually lay claim to much of the land where the bitumen is being mined and through which it is transported (Gelfand, 2014).

\section{How is the concept of climate justice understood by the current government? Have they articulated any position on climate justice issues that arise in setting ghg emissions policy or in regard to the adaptation needs of vulnerable nations or people?}

This was discussed at length under ethical issues in questions 1, 3, 4, 5 and 6.

\section{Are you aware of any regional, state, provincial, or local governments in your country that have acknowledged some ethical responsibility for climate change? If so, what have they said?}

Although the Canadian federation now has failed to develop adequate climate change policies, some of the provinces have filled the policy gap. In 2013, advances by Ontario on coal-fired electricity, the launch of Quebec's cap-and-trade system with a permit linking to California, and British Columbia's commitment and extensive carbon review were notable. The Western Climate Initiative (WCI), a provincial and territorial dialogue on common carbon policy issues, also emerged (Sawyer et al, 2014). In addition to carbon pricing schemes in some provinces, municipal governments are leading regional efforts to combat climate change in the country. Hundreds of communities across our country are increasingly opposing Harper on his pro-industry position in the tar sands (Delaney, 2014; Matthews, 2014).

The provinces have been able to find some common ground, establishing an ongoing carbon policy dialogue, with the help of the International Emission Trading Association (IETA) consolidating them into a more coherent group on the foundational elements of carbon policy in Canada (Sawyer et al, 2014). The IETA facilitated the piecing together of a compartmentalized federal sector-by-sector process. In the absence of federal government leadership, the dialogue provided an important forum for the provinces to move closer together on carbon policy.

It would seem that Canada is now stuck with a fragmented carbon policy map where opportunities need to be sought for subnational alignment at the provincial level - that is, the provinces need to continue the dialogue and examine ways to align foundation elements of their policies for an eventually more cohesive federal policy. The idea is to look for opportunities to 'link by degrees' as the path forward to set up systems now that can minimize misaligned ghg provincial policy, offsetting protocols and building subnational carbon bridges toward a more standardized subnational policy. What seems to be the most promising are provincial policy labs, innovation by individual provinces, a common carbon design, and a forum where provinces can learn from each other (Sawyer et al, 2014) for eventual federal alignment when appropriate leadership arises. For more information on current ghg policy timelines, see Appendix 1.

The Arctic as a region is another important aspect of climate change policies in Canada. At COP19, Canada's Minister of Environment and Chair of the Arctic Council stated that the 'Arctic Council States 
remain firmly committed to work alongside other countries under the UNFCCC to reach - as a matter of urgency - an ambitious, inclusive, durable and flexible protocol . . a applicable to all Parties by 2015 which will meet the long term goal aimed at reducing greenhouse gas emissions so as to hold the increase in global average temperature below $2^{\circ} \mathrm{C}$ above pre-industrial levels' (Arctic Council, 2013).

\section{Has your national government taken any position on or otherwise encouraged individuals, businesses, organizations, subnational governments, or other entities that they have some ethical duty to reduce ghg emissions?}

To date, Canada has seen relatively few examples of implementation of specific changes to reduce vulnerability to future climate change, or take advantage of potential opportunities. Most of these examples of actions preparing for climate change impact can be found at the municipal level in Canada where small innovations are dependent on the public and political will of its citizens (De Souza, 2013). In conclusion, the GOC has not integrated ethics into its approach to climate change domestically.

\section{What recommendations would you make to get the nation or civil society to take ethics and justice issues seriously in climate change policy formulation?}

Until there is a change in government, there will not likely be substantive changes in Canada's climate policy. Given the obstacles that confronted forces that favoured a reduction of ghg emissions, climate analysis in Canada has moved forward and various coalitions and groups have cobbled together a relatively solid consensus. Ranging from expert witnesses, scientists, media, First Nations, labour unions and broad coalitions, recommendations underpinned by an ethical and social justice approach to climate change policy were made. Justice and ethics may sometimes be implicit in the recommended approaches, but in all cases there is recognition that Canada, as a country, must meet its global responsibilities in climate policy.

Hannah McKinnon speaks to the need to refocus on developing an advanced energy mix that will protect our climate, our communities and help us move towards a robust 21 st-century economy 'if Canada were to make meaningful investments in the exploding clean energy economy: the market share that Canadians could have in this multi-trillion dollar economy could leap from $\$ 9$ billion to $\$ 60$ billion by 2020 with the right support. And it could position Canada to play meaningfully in this century's smarter, advanced energy economy. . . . If Canada can make the right choice . . . we would have a safer environment, and be able to seize the incredible opportunities to invest in the sophisticated clean technology that is going to power this century' (McKinnon, 2014a, 2014b).

Dr Mousseau of the University of Montreal says there should be no conflict between developing both clean energy/renewable energy and developing fossil resources. Canada has a huge variety of natural resources and needs a comprehensive sustainable energy strategy based on both renewable and fossil resources, a strategy developed by the federal government in consultation and cooperation with the provinces, territories, First Nations, industry and the public (NRCAN, 2014) with the incorporation of sustainable development and its basic principles: economic, social and environmental security - a long-term view on how to develop our natural resources while preserving the integrity of our environment for future generations. He also noted that Canada's renewable and non-renewable energy resources vary greatly from region to region. Canada can't simply focus on fossil fuels, which aren't renewable. It also has to support renewable energy resources (NRCAN, 2014).

In a call for more balance, Chief Aaron L. Sam of Lower Nicola Indian Band in British Columbia calls for the development of a National Energy Strategy to move forward in a way that benefits everyone (not just a few). He suggests that the GOC spearhead a collaborative initiative where First Nations 
communities affected by energy development, those concerned about the environment, academics, energy industry, business leaders, and representatives from the three levels of government engage in the process of developing this strategy. A National Energy Strategy will help find creative and effective ways to have a more sustainable and diverse economy; it will be socially relevant for all Canadians today and in the future; and it will be mindful of the impact that the production, transportation and consumption of energy (especially from fossil fuel sources) have on the environment (Uechi, 2014).

Robert Lefort of UNIFOR, Canada's largest private-sector union, with more than 305,000 members working in every major sector of the Canadian economy, states Canadian global responsibilities more explicitly: developing the National Energy Strategy recognizes Canada has some responsibilities in the world where growth is not at the expense of sustainability and the full life-cycle analysis includes not only the extraction of the resource, but also its refining, marketing, and ghg emissions measurement with an achievable target.

Additionally, responsible development of oil and gas resources also requires obtaining legitimate social licence from First Nations communities where Chief Allan Adam (Chipewyan First Nation) pleaded for 'a strategy whereby First Nations people are heavily engaged in the process of developing a regulatory process for protecting the ecosystem while continuing to build an economic platform' (NRCAN, 2014, p64).

According to an Environmental Defence report in 2013, there are steps to be taken by industry and the Alberta and the Canadian governments to begin to build credibility when it comes to environmental protection and a commitment to do Canada's fair share when it comes to action on climate change. These would include slowing the exponential expansion of the tar sands as Canada cannot meet any meaningful climate targets with this growth. Making polluters pay would be the first step toward the long-promised oil and gas regulations, with assurance from credible experts that a meaningful hard cap on tar sands emissions could be achieved and easily integrated into a future carbon pricing mechanism.

Canada's failure to acknowledge the need to move as a nation toward a low-carbon economy has disadvantaged it competitively from an economic perspective as well as globally with regard to renewable energies. Canada has also disgraced itself on the international diplomatic stage as a country that once led on difficult issues. Several contributions to the Standing Committee on The CrossCanada Benefits of the Oil and Gas Industry (NRCAN, 2014) indicated the need to acknowledge the lower oil demand and lower oil prices in policy choices and economic planning. These also highlighted how the marriage between the Conservative government and industry have resulted in a concerted effort to do away with all of the environmental checks and balances to facilitate further growth of the government's extractive-sector strategy (Max Paris, 2013). Other contributors to the Standing Committee, such as Dobson of Pembina Institute (NRCAN, 2014, p60), and other researchers and coalitions (Trottier and Suzuki Foundations, 2013; Blue Green Canada, 2012; Green Economy Net, 2011), have recommended a shift toward investing in sectors such as clean energy for a more lowcarbon economy. But the focus of the committee did not include revenue-sharing, benefit-sharing, resource access or legacy measures according to the New Democratic Party (NDP) Dissenting Opinion (NRCAN, 2014); rather, it focused on a narrow review of the economic benefits of the oil and gas sector without ensuring a balanced view on associated risks and challenges (NRCAN, 2014).

Blue Green Canada, an alliance of Canadian labour unions, environmental and civil society organizations advocating for working people and the environment, maintains that Canada's growing economic 
reliance on oil, driven by higher oil prices and increased oil production has exposed the country to great volatility related to swings in global oil prices as evidenced in mid-October 2014 . The oil sands now supply over half of Canadian oil production and the rise of oil has led to job losses in other sectors as our Canadian currency becomes a petrodollar which has caused the country to fall short of our commitments to reduce emissions and prompted the removal of long-standing environmental protection measures - our national environmental legal and regulatory framework (CBC, 2013; Dupuis, 2013; Scoffield, 2012). Blue Green Canada believes that Canada stands to lose opportunities in the transition toward renewable energy which despite global economic collapse has experienced solid growth. Developing a credible plan for a clean energy transition and the restoration of meaningful federal support for clean energy and efficiency programmes is another imperative.

Technologically speaking, the transition to clean energy that would result in reducing ghg is possible. 'The analysis shows that the most important technological approaches for achieving major reductions in Canada's GHG emissions are: capture and storage of carbon dioxide from the oil and gas industry and power plants; reduction of "fugitive" emissions from the oil and gas industry and from landfills; increased energy efficiency throughout the economy (e.g., in vehicles and buildings); increased production of renewable energy (e.g., wind power accounts for 18 per cent of electricity generated in 2020 when meeting the $2^{\circ} \mathrm{C}$ target); [and] replacement of fossil fuels by cleaner electricity (e.g., for heating buildings)' (Pembina Institute and Suzuki Foundation, 2009). These conclusions were confirmed by a recent study, An Inventory of Low-Carbon Energy for Canada (Suzuki Foundation, Canadian Academy of Engineering, and Trottier Family Foundation, 2013), whose objective was 'to chart a course for an 80 per cent reduction in Canada's energy-related GHG emissions by 2050, using 1990 levels of 500 megatonnes (Mt) as a baseline', concluded that the 'prospects for a transition to a low-carbon future depend not so much on the availability of the necessary physical resources, or on the cost and performance of any particular technology, as on the integrative strategies that combine the individual elements in systems that can deliver affordable, reliable, sustainable energy services' (Trottier and Suzuki, 2013; Suzuki, 2013).

All of the elements for a low-carbon economy are there - what is needed is the political will to advance that many have for years advocated (Athanasiou et al, 2009). Canada should adopt a realistic, sciencebased approach to the current climate negotiations and reject partial solutions that will fail to deliver a rapid and sustained decline in domestic and global ghg emissions.

The plight of developing countries should be recognized while acknowledging that prosperity and development are inevitably accompanied by ghg emissions. Countries such as Canada must lead by example. Transparent metrics of capacity and responsibility as the best foundations for a new climate agreement are needed not only in Canada but also to help bridge the international divide. Canada should become a genuine partner with the Global South recognizing the need for an inclusive green economy based on accelerated decarbonization and social justice. The GOC should work to ensure that the next global climate regime protects and promotes true sustainable development and should offer to pay its 'fair share' of the global climate change burden, by reducing its own domestic ghg emissions and supporting international mitigation and adaption efforts. And Canada should also adopt ambitious mitigation targets as indicated by the GDR analysis or similar respected frameworks to help establish the international financial and technology-transfer frameworks needed to realistically achieve these targets.

Finally, through combining justice and ethical recommendations together, the Green Economy Network is in a position to call for concrete proposals on a green economy vision that provides good green 
jobs; clean renewable energy use facilitated by a transition from a fossil fuels economy to a clean and low-carbon renewable energy economy; promotion of energy conservation and efficiency through an implemented national action plan for retrofitting buildings and green designs for new buildings. In this transition process to an inclusive green economy, workers should be transferred and trained in industries undergoing adaptation to new or green industries. Finally, this process would result in setting and meeting medium- and long-term ghg emissions reduction targets, reinstating Canada as a country that meets its global responsibilities.

\section{Appendix 12013 Canadian ghg policy timeline}

\begin{tabular}{|c|c|}
\hline Policy & Timeline \\
\hline $\begin{array}{l}\text { Ontario phases out coal-fired electricity in } 2013 \\
\text { Ontario Ending Coal for Cleaner Air Act } 2013\end{array}$ & $\begin{array}{l}\text { Announced: } 9 \text { January } 2013 \\
\text { Confirmed: } 25 \text { November } 2013\end{array}$ \\
\hline $\begin{array}{l}\text { Ontario discussion paper on cap-and-trade for } \\
\text { industrial emitters }\end{array}$ & January 2013 \\
\hline $\begin{array}{l}\text { GOC releases final regulations to reduce ghg } \\
\text { emissions from Heavy Duty Vehicles }\end{array}$ & February 2013 \\
\hline $\begin{array}{l}\text { National Inventory Submissions } 2013 \text { report } \\
\text { to UNFCCC }\end{array}$ & 15 April 2013 \\
\hline $\begin{array}{l}\text { Alberta and Swan Hills Synfuels end carbon capture and } \\
\text { storage agreement }\end{array}$ & 25 February 2013 \\
\hline $\begin{array}{l}\text { Manitoba Greening of Government Vehicles } \\
\text { Regulation }\end{array}$ & 25 March 2013 \\
\hline Manitoba Green Building Regulation & 25 March 2013 \\
\hline BC Auditor General report on Pacific Carbon Trust & March 2013 \\
\hline $\begin{array}{l}\text { Nova Scotia Amendments to Ghg \& Air Quality } \\
\text { Regulations }\end{array}$ & $\begin{array}{l}\text { June } 2013 \text { Consultation Paper } \\
\text { September } 2013 \text { Royal Gazette II }\end{array}$ \\
\hline $\begin{array}{l}\text { Manitoba launches process to develop new } \\
\text { climate/green plan }\end{array}$ & 30 July 2013 \\
\hline $\begin{array}{l}\text { New England Governors' and Eastern Canadian } \\
\text { Premiers' } 2012 \text { Climate Change Action Plan renewed }\end{array}$ & September 2013 \\
\hline Canada's Emissions Trends, 2013 & 24 October 2013 \\
\hline Ontario Greener Diesel Notice & 1 November 2013 \\
\hline $\begin{array}{l}\text { Quebec regulations linking cap-and-trade with } \\
\text { California }\end{array}$ & 13 November 2013 \\
\hline Quebec auction of ghg permits & 3 December 2013 \\
\hline $\begin{array}{l}\text { GOC, } 2014 \text { Canada's Sixth National Report on } \\
\text { Climate Change - } 2014\end{array}$ & Released in December 2013 \\
\hline $\begin{array}{l}\text { GOC/NRCAN, } 2014 \text { Canada in a Changing Climate: Sector } \\
\text { Perspectives on Impacts and Adaptation }\end{array}$ & 30 July 2014 \\
\hline
\end{tabular}

Source: IISD, February 2014; updated by author August 2014. 


\section{Notes}

1 In itself a climate driven convention. The interrelationship among drought, land degradation and desertification (DLDD) and climate change is reflected in the objectives of both Conventions, and provides the basis for mutual integration. Article 4, paragraph 2(a) of the UNCCD and Article 4, paragraph 1(c) of the UNFCCC explicitly support common actions in dryland ecosystems. The aim of UNCCD to address DLDD in the climate change negotiation and implementation processes is based on Article 8, paragraph 1 of its Convention and on the 10year strategic plan and framework to enhance the implementation of the Convention (2008-2018), specifically operational objective 1, outcome 1.1 and operational objective 2, outcome 2.5. The rationale for this support is also contained in several decisions on synergies, including Decision 8/COP.9 and the current work programme of the secretariat (UNCCD, n.d.).

2 In 2011 Canada's industrial sector accounted for the largest portion of national emissions at 38\%, followed by transportation at $24 \%$. Electricity generation accounts for a relatively smaller portion of national emissions (13\%) since only a fifth of Canada's total power generation is from combustion sources. Source: IMF (February 2014) Canada: Selected Issues, IMF Country Report No. 14/28.

3 Upgrading is the process that converts bitumen into a product with a density and viscosity similar to conventional light crude oil. This is accomplished by using heat to 'crack' the big molecules into smaller fragments. Adding high-pressure hydrogen and/or removing carbon can also create smaller hydrocarbon molecules. Most of the energy for upgrading is obtained from by-products of the process (Centre for Energy, 2011).

4 In the past, the GOC has deliberately excluded data documenting a $20 \%$ increase in annual pollution from the Alberta tar sands (Pullman, 2011).

5 The report concludes Canada is not on track to meet its ghg emissions targets, has delayed monitoring of oil sands pollutants and lacks plans to monitor the oil sands beyond next year, and has no clear guidelines regarding what projects require environmental assessments (Suzuki, 2014; Gelfand, 2014).

6 GOC has implemented regulations setting progressively more stringent standards for passenger automobiles and light-duty trucks and has introduced proposed regulations to further improve fuel efficiency and reduce ghg emissions from vehicle models beyond 2017. In March 2013 the GOC released final regulations that establish progressively more stringent emissions standards for heavy-duty vehicles such as full-size pick-ups, semi-trucks, garbage trucks and buses. GOC has also issued regulations to ban the construction of traditional coal-fired electricity generation units (GOC, 2014a).

7 The Fossil of the Day or of the Year is presented at UNFCCC climate negotiations and awarded to the countries which have done the most to block progress at the talks. The Fossils, represented by lumps of coal, are presented in an elaborate awards ceremony daily and the winners are chosen by a vote of the Climate Action Network (fossiloftheday.tumblr.com/). At consecutive climate change conferences, international environmental organizations name Canada 'Fossil of the Day', designating 'countries that do the most to disrupt or undermine UN climate talks'.

8 From the IPCC Working Group Report Summary for policy-makers: 'Human influence has been detected in warming of the atmosphere and the ocean, in changes in the global water cycle, in reductions in snow and ice, in global mean sea level rise, and in changes in some climate extremes (see Figure SPM.6 and Table SPM.1). This evidence for human influence has grown since AR4. It is extremeny likely that human influence has been the dominant cause of the observed warming since the mid-20th century' (IPCC, 2013).

9 The Canadian Charter of Rights and Freedoms legislated in 1982 speaks of different rights pertaining to this ethical analysis of Canadian ghg emissions. It outlines several fundamental rights and freedoms that come into play. These are: (a) the freedom of conscience and religion (that is the right to choose); (b) the freedom of thought, belief, opinion and expression, (including freedom of the press and other media of communication); (c) the freedom of peaceful assembly; and (d) the freedom of association. Among other rights is the ability to apply to a court of competent jurisdiction to obtain such remedy as the court considers appropriate and just in the circumstances. Very germane to this analysis and entrenched in law and the Constitution are 'Aboriginal rights and freedoms not affected by Charter which guarantee certain rights and freedoms that flow from aboriginal, treaty or other rights or freedoms that pertain to the aboriginal peoples . . including the Indian, Inuit and Métis peoples'. (These rights ascertain the recognition of existing aboriginal and treaty rights specifying rights that now exist by way of land claims agreements, or that may be acquired.) Over and above these rights are equalization and regional disparities' rights that guarantee equal opportunities for the wellbeing of (all) Canadians (between provinces); furthering economic development to reduce disparity in opportunities; and 
providing essential public services of reasonable quality to all Canadians - these are interpreted as equal rights for all Canadians no matter the province (and territory) one inhabits (GOC, 2012) (GOC, 2014e).

10 When the Constitution was patriated in 1982, the Canadian Charter of Rights and Freedoms became a fundamental part of it. The Charter takes precedence over other legislation because it is 'entrenched' in the Constitution, the supreme law of Canada (GOC, 2012).

11 "Social licence" is not a concept found in Canadian law. It is a concept generated not by legislatures or the courts but by businessmen and elaborated by their supporting experts in the law as well as the social and natural sciences. It is based on observation of consensus in the world community that developer/neighbour relations cannot go on as they were and the pragmatic observation that world-wide interactions between industry and its neighbours have entered into an obviously new era. Quite suddenly it became much less easy for industry to exercise its duly granted legal licence to develop without fear of effective local and increasing world-wide opposition to development. Social Licence has become the normal means of dealing with Social Risk' (Knox, 2010).

12 As indicated in letter to the Prime Minister by the Chief of the Tsilhqot' Nation: 'As you have seen in the Supreme Court of Canada Tsilhqot'in decision, it is vital that First Nations are sitting at the table when there is any dialogue about natural resource development in this country. As you know, a genuine process of consultation and accommodation must take place before First Nations can consent to natural resource development projects', and further confirmed in an article by Uechi (2014).

13 With respect to pipelines, the Energy East pipeline by TransCanada Corp, a Harper 'nation building' project and a priority of the Conservative government, is proposed to create a network of old and new pipelines stretching over $4400 \mathrm{~km}$ from southern Alberta to St John, New Brunswick, making it one of the longest pipelines in North America. Built through six provinces, hundreds of towns and cities, thousands of waterways and 180 First Nations communities, producing 32Mt of ghg emissions, it is expected to transport daily shipments of 1.1 million barrels of tar sands oil, conceivably putting hundreds of communities at risk. The construction of this pipeline would effectively solve one of the tar sands industry's transportation to market problems as it would be facilitating export to markets in Europe, China, India and the US (Delaney, 2014).

14 The Supreme Court of Canada has granted declaration of aboriginal title to more than 1700 square kilometres of land in British Columbia to the Tsilhqot'in First Nation, the first time the Court has made such a ruling regarding aboriginal land (CBC, 2014).

15 It was difficult to find any information on the NCPC process, its tenure as well as its closure. 


\section{References}

350 or Bust (n.d.) 'What the Heck IS Canada's Climate Policy?', 350orbust.com/what-the-heck-is-canadas-policyon-climate-change/?blogsub=confirmed\#blog subscription-3

350 or Bust (2010) 'Harper's Stacked Senate Aborts Climate Bill and Admits No Shame', 350orbust.com/2010/11/18/ harpers-stacked-senate-aborts-climate-bill-and-admits-no-shame/

AFCN website (2014) 'Athabasca Chipewyan First Nation pulls out of Grand Rapids Hearings: Citing Prejudiced Process that favors Industry', 15 July, http://acfnchallenge.wordpress.com/2014/07/15/athabascachipewyan-first-nation-pulls-out-of-grand-rapids-hearings-citing-prejudiced-process-that-favorsindustry/, accessed August 2014

Alberta Oil (2014) 'Athabasca Chipewyan First Nations Chief draws a line in the sands - Chief Allan Adam talks oil sands development and treaty rights', 8 April, www.albertaoilmagazine.com/2014/04/allan-adam-neilyoung-fort-mcmurray/

Arctic Council (2013) 'Arctic States Release Statement to UNFCCC COP XIX', 20 November, www.arctic-council. org/index.php/en/resources/news-and-press/news-archive/818-statement-to-the-unfccc-cop-xix

Athanasiou, Tom (2014) 'As Dire as It Sounds, IPCC is an Understatement', Earth Island Journal, 3 April, www.earthisland.org/journal/index.php/elist/eListRead/as_dire_as it_sounds_ipcc_report_is_an understatement/

Athanasiou, Tom, Kartha, Sivan, Baer, Paul and Kemp-Benedict, Eric (2009) Canada's Fair Share in a Climate Constrained World - An analysis of Canada's climate obligations under the Greenhouse Development Rights Framework, climateactionnetwork.ca/archive/e/issues/climate-justice/gdr-canada-fair-share-es.pdf

Bagley, Katherine (2012) 'Scientists Decry Canadian Undermining of Climate Science', 28 November, www. bloomberg.com/news/2012-11-27/scientists-decry-canadian-undermining-of-climate-science.html

Barder, Owen and Krylová, Petra (2013) 'Commitment to Development Index 2013', www.cgdev.org/sites/default/ files/CDI2013/cdi-brief-2013.html

Beckett, Diane (2014) 'No one will be untouched by climate change - Scientists, world leaders, business people speak with one voice', The Hill Times, 7 April, http://www.hilltimes.com/opinion-piece/politics/2014/04/07/ no-one-will-be-untouched-by-climate-change/38060

Bianchi, Ed (2014) ‘Coming Back to the Treaty Relationship', 1 June, www.kairoscanada.org/sustainability/the-tarsands/coming-back-to-the-treaty-relationship/

Blue Green Canada (2012) More Bang for Our Buck - How Canada Can Create More Energy Jobs and Less Pollution, http://bluegreencanada.ca/sites/default/files/resources/More\%20Bang\%20for\%20Buck\%20 Nov\%202012\%20FINAL\%20WEB.pdf

Canadian Press (2013) 'Canada ranks worst on climate policy among industrialized countries: report', 18 November, www.macleans.ca/general/canada-ranks-worst-in-developed-world-on-climate-policy-european-report/

Caney, Simon (2010) 'Climate change and the duties of the advantaged', Critical Review of International Social and Political Philosophy, vol 13, no 1, pp203-228

CBC (2010) 'Killed climate change bill flawed: Harper - Defeating legislation passed by House unprecedented, opposition parties say', 17 November, www.cbc.ca/news/politics/killed-climate-change-bill-flawed-harper1.882364 ?ref $=$ rss

CBC (2013) 'Canada quietly pulls out of UN anti-droughts convention', posted by Canadian Press, 27 March, www.cbc.ca/news/canada/canada-quietly-pulls-out-of-un-anti-droughts-convention-1.1388320

CBC (2014) 'Tsilhqot'in First Nation granted B.C. title claim in Supreme Court ruling', 26 June, www.cbc.ca/news/ politics/tsilhqot-in-first-nation-granted-b-c-title-claim-in-supreme-court-ruling-1.2688332

CCIC blog (2013) 'Fast start, slow finish on Canadian climate finance', posted by Fraser Reilly-King, 5 November, www.ccic.ca/blog/fast-start-slow-finish-on-canadian-climate-finance/

Centre for Energy (2011) Canada's Oil Sands, November, 3rd edn, http://www.centreforenergy.com/shopping/ uploads/12.pdf?28102014234231 
Climate Action Network Canada (n.d.) Dirty Oil Diplomacy - The Canadian Government's Global Push to Sell the Tar Sands, climateactionnetwork.ca/wp-content/uploads/2012/03/CAN_Dirty_Oil_Diplomacy.pdf

Climate Action Network Canada (2010) The Tar Sands' Long Shadow: Canada's Campaign to Kill Climate Policies Outside our Borders, climateactionnetwork.ca/archive/e/publications/can-tar-sands-long-shadow.pdf

Climate Action Network website, climatenetwork.org/fossil-of-the-day, accessed October 2014

Climate Citizen, takvera.blogspot.ca/2014/09/un-climate-summit-advances-pledges.html, accessed 14 October 2014

Delaney, Gordon (2014) 'Protesters target Trudeau - Anti-pipeline group wants Liberal leader to fight TransCanada plan', 24 August, thechronicleherald.ca/novascotia/1231690-protesters-target-justin-trudeau-in-chester

De Souza, Mike (2013) 'Stephen Harper's government edited message about taking climate change seriously', 30 December, o.canada.com/technology/environment/stephen-harpers-government-edited-message-abouttaking-climate-change-seriously

Dillon, John (2014a) Movement for Divesting from Fossil Fuels Gaining Strength, www.kairoscanada.org/wpcontent/uploads/2014/05/BP38-FossilFuelDivestment.pdf

Dillon, John (2014b) 'Northern Gateway decision a turning point in indigenous relations', article originally posted in The Hill Times, 7 July 2014, www.kairoscanada.org/sustainability/northern-gateway-decision-a-turningpoint-in-indigenous-relations/

Dillon, John (2014c) 'Tar Sands', www.kairoscanada.org/sustainability/tar-sands/

Dupuis, John (2013) 'The Canadian War on Science: A long, unexaggerated, devastating chronological indictment', 20 May, scienceblogs.com/confessions/2013/05/20/the-canadian-war-on-science-a-long-unexaggerateddevastating-chronological-indictment/\#comments

Eco-Business (2013) 'Branson and Zeitz launch "Plan B for Business"', 19 June, www.eco-business.com/news/ branson-and-zeitz-launch-plan-b-business/

Environment Canada (2013a) Canada's Emissions Trends, October, www.ec.gc.ca/ges-ghg/985F05FB-47444269-8C1A-D443F8A86814/1001-Canada's\%20Emissions\%20Trends\%202013 e.pdf

Environment Canada/Government of Canada (2013b) Canada's Fast-Start Financing - Delivering on Our Copenhagen Commitment, May, ec.gc.ca/Publications/default.asp?lang=En\&xml=5FA4A8BB-78C0-472490CF-AA6133D3333E and unfccc.int/files/cooperation_support/financial_mechanism/fast_start_finance/ application/pdf/1190 canada fast-start financing e.pdf

Environment Canada (2014) National Inventory Report 1990-2012: Greenhouse Gas Sources and Sinks in Canada - Executive Summary, http://www.ec.gc.ca/Publications/default.asp?lang=En\&xml=A91164E0-7CEB4D61-841C-BEA8BAA223F9

Environmental Defence Fund (2013) Canada's Climate Credibility Gap, http://environmentaldefence.ca/reports/ canada\%E2\%80\%99s-climate-credibility-gap, accessed August 2014

Environmental Defence Fund (2014a) 'Canadians dramatically overestimate the contribution of tar sands to Canadian economy', environmentaldefence.ca/reports/canadians-dramatically-overestimate-contributiontar-sands-canadian-economy, accessed August 2014

Environmental Defence Fund (2014b) 'Energy East - Our Risk - Their Reward’, environmentaldefence.ca/issues/ tar-sands/energy-east, accessed August 2014

Environmental Defence Fund (2014c) 'Energy East: Pipeline Details - Tar Sands', environmentaldefence.ca/issues/ tar-sands/energy-east-pipeline-details, accessed August 2014

Findlay, Scott and Dufour, Paul (2014) 'Calling for a 21st Century STI Strategy', Research Money, 13 March, evidencefordemocracy.ca/blog/calling-21st-century-sti-strategy

Fossil of the Day or of the Year, fossiloftheday.tumblr.com/, accessed September 2014

G8 Research Group LSE/Oxford (2008) The G8 and Climate Change since Heiligendamm - Final Compliance Report for the G8 and Outreach Five Countries, www.g8.utoronto.ca/oxford/g8rg-lseox-final-2007.pdf 
Galloway, Gloria (2010; updated 2012) 'Tory Senate overturns opposition bill for first time on climate change', www.theglobeandmail.com/news/politics/tory-senate-overturns-opposition-bill-for-first-time-on-climatechange/article1803609/

Gelfand, Julie (2014) 2014 Fall Report of the Commissioner of the Environment and Sustainable Development, www.oag-bvg.gc.ca/internet/English/parl_cesd_201410_e_39845.html

Germanwatch (2013) Climate Change Performance Index 2013, germanwatch.org/en/download/7158.pdf

GDR (2013/2014) 'Three salient global mitigation pathways, assessed in light of the IPCC carbon budgets', gdrights.org/gdrs-scorecard-calculator-information/mitig-path-overview/

Government of Canada (1982) Constitution Act, 1982 - Canadian Charter of Rights and Freedoms, laws-lois. justice.gc.ca/eng/const/page-15.html

Government of Canada (2006) 2006 - Canada's Fourth National Report on Climate Change - Actions to Meet Commitments Under the United Nations Framework Convention on Climate Change, unfccc.int/resource/ docs/natc/cannc4.pdf

Government of Canada (2013a) Canada's Fast-Start Financing - Delivery on Our Copenhagen Commitment, ec.gc.ca/Publications/default.asp?lang=En\&xml=5FA4A8BB-78C0-4724-90CF-AA6133D3333E

Government of Canada (2014a) Canada's Sixth National Report on Climate Change - 2014, http://ec.gc.ca/ Publications/default.asp?lang=En\&xml=6FF30D6E-B8E3-4102-86E7-652D156E020A

Government of Canada/NRCAN (2014b) Canada in a Changing Climate: Sector Perspectives on Impacts and Adaptation, full report of 298 pages, www.nrcan.gc.ca/sites/www.nrcan.gc.ca/files/earthsciences/pdf/ assess/2014/pdf/Full-Report_Eng.pdf, and synthesis of 18 pages, www.nrcan.gc.ca/sites/www.nrcan. gc.ca/files/earthsciences/pdf/assess/2014/pdf/Synthesis_Eng.pdf

Government of Canada (2013b) 'Canada's Priorities at COP 19 - A Fair, Comprehensive, Global Climate Change Agreement', www.climatechange.gc.ca/Content/F/A/C/FAC4B67D-ED85-4CB1-93D0D589677966E9/1613 COP19 Priorities factsheet E 01 web.pdf

Government of Canada (2014c) Highlights of Canada's Sixth National Communication and First Biennial Report on Climate Change, ec.gc.ca/cc/16153A64-BDA4-4DBB-A514-B159C5149B55/6458_EC_ID1180-MainBook high_min\%20FINAL-s.pdf

Government of Canada (2014d) 'Timeline: Action on Climate Change', www.climatechange.gc.ca/default. asp?lang=En\&n=1CD1DFC3-1

Government of Canada (2014e) 'Rights and Freedoms in Canada', www.justice.gc.ca/eng/csj-sjc/just/06.html, accessed August 2014

Government of Canada website (2014a) 'Canada's Action on Climate Change - Reducing Greenhouse Gases', climatechange.gc.ca/default.asp?lang $=E n \& n=4 F E 85 A 4 C-1$

Government of Canada website (2014b) 'Facts on Canada's Climate Change', www.climatechange.gc.ca/default. asp?lang=En\&n=72F16A84-1

Government of Canada website (n.d.) 'Canada's Priorities at COP 19', http://www.climatechange.gc.ca/default. asp?lang=En\&n=FAC4B67D-1, accessed August 2014

Grant, Jennifer, Huot, Marc, Lemphers, Nathan, Dyer, Simon and Dow, Matt (2013a) Beneath the Surface - A review of key facts in the oil sands debate, Pembina Institute, www.pembina.org/reports/beneath-the-surface-oil sands-facts-201301.pdf

Grant, Jennifer, Angen, Eli and Dyer, Simon (2013b) Forecasting the impacts of oilsands expansion, www.pembina. org/reports/oilsands-metrics.pdf

Green Economy Net (2011) Making the Shift to a Green Economy - A Common Platform of the Green Economy Network, http://www.greeneconomynet.ca/section/8

IMF (2014) Canada: Selected Issues, IMF Country Report No. 14/28, www.imf.org/external/pubs/ft/scr/2014/ cr1428.pdf

IPCC (2013) 'Summary for Policymakers', in Climate Change 2013: The Physical Science Basis - Contribution of Working Group I to the Fifth Assessment Report of the Intergovernmental Panel on Climate Change, 
Cambridge University Press, Cambridge, www.climatechange2013.org/images/report/WG1AR5_SPM FINAL.pdf

Kairos (2010) 'Drawing a Line in the Sand: Why Canada needs to limit tar sands expansion and invest in a green economy', www.kairoscanada.org/wp-content/uploads/2010/12/Sust-Tar-DrawingLine.pdf

Knox, Tony (2010) 'Social Licence and Canadian Aboriginal Law', paper delivered at the Insight 6th Annual Western Canada Aboriginal Law Forum, 11 and 12 May, www.knoxlex.com/knox_insight-conf_soc-lic.pdf

Mang, Eric (2009) 'Stephen Harper and the Conservatives: A year in review', rabble.ca/blogs/bloggers/ ericmang/2009/12/stephen-harper-and-conservatives-year-review

Matthews, Richard (2014) 'Historic Canadian Supreme Court Ruling Dis-Empowers Fossil Fuel Industry', 1 July, http://www.thegreenmarketoracle.com/2014/07/historic-canadian-supreme-court-ruling.html

Max Paris Environment Unit (2013) 'Energy industry letter suggested environmental law changes - Greenpeace says oil and gas companies got what they wanted from Ottawa', www.cbc.ca/news/politics/energy-industryletter-suggested-environmental-law-changes-1.1346258

McCarthy, Shawn (2014) 'Environmental extremism a rising threat to energy sector, RCMP warns', 14 September, www.theglobeandmail.com/report-on-business/industry-news/energy-and-resources/environmentalextremism-a-rising-threat-rcmp-warns/article20594114/

McKinnon, Hannah (2014a) 'Canada's Tar Sands Don't Affect Our Economy As Much As You Think', 8 April, www. huffingtonpost.ca/hannah-mckinnon/canadas-tar-sands-a-bad-r_b_5111807.html

McKinnon, Hannah (2014b) 'No future for tar sands', published in The Monitor and on CCPA, 1 July, https://www. policyalternatives.ca/publications/monitor/no-future-tar-sands

NRCAN (2014) The Cross-Canada Benefits of the Oil and Gas Industry - Report of the Standing Committee on Natural Resources, presented to the 41st Parliament, Second Session, June, www.parl.gc.ca/ HousePublications/Publication. aspx?Docld=6644319\&Language=E\&Mode=1\&Parl=41\&Ses=2

Nuttall, Jeremy (2014) 'Union files Enbridge pipeline suit’, 15 July, vancouver.24hrs.ca/2014/07/15/union-filesenbridge-pipeline-suit

Partington, P. J. and Demerse, Claire (2013) Context for climate action in Canada, Pembina Institute, www. pembina.org/reports/climate-context-20131009.pdf

Pembina Institute and Suzuki Foundation (2009) Climate Leadership and Economic Prosperity, www.pembina.org/ reports/climate-leadership-report-en.pdf

Pembina Institute and C4D (2013) Protecting our Common Future: An Assessment of Canada's Fast-Start Climate Financing, www.pembina.org/reports/c4d-protecting-our-common-future.pdf

Pembina Institute website (2014) 'Climate Impacts', www.pembina.org/oil-sands/os101/climate

Pendergast, Duane (2007) 'Letter to Environment Minister John Baird', www.computare.org/Support\%20 documents/Letters/Letters\%202007/Baird\%2007_11.htm

Pullman, Emma (2011) 'Canada Hides 20 Percent Tar Sands Annual Pollution Increase from UN', www.desmog.cal canada-hides-20-percent-tar-sands-annual-pollution-increase-un

Sawyer, David and Gass, Philip (2014) Regulating Carbon Emissions in Canada - Climate Policy Year in Review, Policy Brief from IISD, February, www.iisd.org/sites/default/files/publications/canadian_carbon_policy_ review_2013.pdf

Saxifrage, Barry (2013) 'Climate Snapshot - Tar Secret \#2: What percentage of Canada's GDP comes from the tar sands?', published in the Vancouver Observer blog on Climate Change, www.vancouverobserver.com/ blogs/climatesnapshot/tar-secret-2-what-percentage-canadas-gdp-comes-tar-sands

Scoffield, Heather (2012) 'Omnibus bill only the latest move in profound changes for environment, natives', www. macleans.ca/general/omnibus-bill-only-the-latest-move-in-profound-changes-for-environment-natives/

Suzuki, David (n.d.[a]) 'Canada and the Kyoto Protocol', www.davidsuzuki.org/issues/climate-change/science/ canada-climate-change/canada-and-kyoto/ 
Suzuki, David (n.d.[b]) 'The Air we Breathe', www.davidsuzuki.org/issues/health/science/air-quality/the-air-webreathe/

Suzuki, David (2013) 'Canada is ready for a transformative energy experience', www.davidsuzuki.org/blogs/ science-matters/2013/05/canada-is-ready-for-a-transformative-energy-experience/

Suzuki Foundation (n.d.) 'Broken Ground - On the frontlines of a fractured landscape', brokenground.ca/

Suzuki Foundation (2014a) 'Commissioner's report shows Canada must do more for environment', 16 October, http://www.davidsuzuki.org/blogs/science-matters/2014/10/commissioners-report-shows-canada-mustdo-more-for-environment/

Suzuki Foundation (2014b) 'What human right is recognized by 110 nations but not Canada', https://www. facebook.com/DavidSuzuki/.../a.../10152646515803874/ and email alert

Tencer, Daniel (2012) 'Canada Climate Change Policy Ranks Worst In Wealthy World: Climate Action Network', The Huffington Post, 5December, www.huffingtonpost.ca/2012/12/05/canada-worst-climate-policy_n_2246238. $\underline{\mathrm{html}}$

Tello, Carlo (2014) 'Canada more at risk from environmentalists than religiously inspired terrorists', 16 September, www.vancouverobserver.com/news/canada-more-risk-environmentalists-religiously-inspired-terroristsrcmp

The Guardian (2011) 'World carbon dioxide emissions data by country: China speeds ahead of the rest', www. theguardian.com/news/datablog/2011/jan/31/world-carbon-dioxide-emissions-country-data-co2

The Star (2011) 'Canada first nation to withdraw from Kyoto Protocol', www.thestar.com/news/canada/2011/12/12/ canada first nation to withdraw from kyoto protocol.html

The Star (2012) 'Conservative Bill C-30 will let police spy on Canadians online', www.thestar.com/opinion/ editorialopinion/2012/02/14/conservative_bill_c30_will_let_police_spy_on_canadians_online.html

The Star (2013) 'Why is Canada the only country to quit UN anti-drought convention?: Editorial', www.thestar. com/opinion/editorials/2013/03/30/why is canada the only_country to quit un antidrought convention editorial.html

The Star (2014) 'Barack Obama's push for new greenhouse gas cuts challenges Ottawa: Editorial', http:// www.thestar.com/opinion/editorials/2014/08/29/barack_obamas_push_for_new_greenhouse_gas_cuts_ challenges_ottawa_editorial.html

Tremonti, Anna Maria (2014) 'IPCC Climate Change Report: Official prophecy of doom?', 31 March, www.cbc.ca/ thecurrent/episode/2014/03/31/ipcc-climate-change-report-official-prophecy-of-doom/

Trottier Family Foundation and Suzuki Foundation (2013) The Trottier Energy Futures Project - An Inventory of LowCarbon Energy for Canada, March, www.davidsuzuki.org/publications/downloads/An\%20Inventory\%20 of\%20Low-Carbon\%20Energy\%20for\%20Canada.pdf

Turner, Chris (2014) 'How Shoddy Reporting is Stunting Canada's Climate Change Conversation', desmog. ca/2014/06/25/how-shoddy-reporting-stunting-canada-s-climate-change-conversation

Uechi, Jenny (2014) 'Chief blasts Harper for pushing oil pipeline, blatantly ignoring climate change', 31 July, www. vancouverobserver.com/news/lower-nicola-indian-band-chief-blasts-harper-government-letter-aboutkinder-morgan-pipeline

United Church of Canada (UCC) website (n.d.) 'Ethical Challenge of Climate Change', www.united-church.ca/ ecology/climate/ethical, accessed August 2014

United Nations (2011) Canada: Withdrawal from the Treaty of the Kyoto Protocol, unfccc.int/files/kyoto_protocol/ background/application/pdf/canada.pdf.pdf, accessed August 2014

United Nations Convention to Combat Desertification (UNCCD) website (n.d.) 'Why does Climate Change relate to desertification?', www.unccd.int/en/programmes/Thematic-Priorities/CC/Pages/default.aspx, accessed October 2014

Varcoe, Chris (2014) 'Alberta revising climate change plan, no changes in works on emissions', www.calgaryherald. com/business/Alberta+revising+climate+change+plan+changes+works+emissions/9934252/story.html/ 
Visser, Joseph (2013) 'Harper accused of turning Canada into "North Korea of environmental law" after UN drought treaty withdrawal', 28 March, news.nationalpost.com/2013/03/28/harper-accused-of-turning-canada-intonorth-korea-of-environmental-law-after-un-drought-treaty-withdrawal/

Waldie, Paul (2013) 'Canada dead last in ranking for environmental protection', 18 November, www.theglobeandmail. com/news/world/canada-dead-last-in-oecd-ranking-for-environmental-protection/article15484134/

Western Climate Initiative (WCl) website (n.d.), 'History', www.westernclimateinitiative.org/history, accessed 1 September 2014

Whittington, Les (2014) 'Federal climate change report warns of economic, health impacts - Governments not doing enough to help Canadians adapt to damages of global warming', published in the Toronto Star, 5 November, $\quad$ www.thestar.com/news/canada/2014/06/24/federal_climate_change_report_warns_of economic health impacts.html 



\section{China's Consideration of Ethics and Justice Issues in Formulating Climate Change Policies}

\section{Sanna Kopra}

This report responds to the research questions of the Project On Deepening National Responses to Climate Change On The Basis of Ethics and Justice, a joint project of the University of Auckland, School of Architecture and Planning and Widener University, School of Law, Environmental Law Center. The research questions and responses are as follows:

1. To what extent has the national debate about how the nation should respond to climate change by setting a ghg emissions reduction target expressly considered that the nation not only has economic interests in setting the target but also ethical obligations to those who are most vulnerable to climate change and that any national ghg emissions reduction target must represent the nation's fair share of safe global emissions? In answering this question, identify the national ghg emissions reduction target, if any, that the nation has committed to under the United Nations Framework Convention on Climate Change (UNFCCC).

Since 2006, China has been the largest $\mathrm{CO}_{2}$ emitter in the world and in 2012 it accounted for 29\% of the world's total CO2 emissions (PBL Netherlands Environmental Assessment Agency, 2012, p8). Although China's economic wealth - and greenhouse gas (ghg) emissions - has increased significantly since the establishment of the United Nations Framework Convention on Climate Change (UNFCCC), China continues to belong to the Non-Annex I countries. Hence, it has no national ghg emissions reduction target under the UNFCCC, but it has made a nationally appropriate mitigation action (NAMA) commitment as follows:

China will endeavor to lower its carbon dioxide emissions per unit of GDB by $40-45 \%$ by 2020 compared to the 2005 level, increase the share of non-fossil fuels in primary energy consumption to around $15 \%$ by 2020 and increase forest coverage by 40 million hectares and forest stock volume by 1.3 billion cubic meters by 2020 from the 2005 levels. (Su, 2010)

In international negotiations on climate change, the Chinese government insists that it is a 'responsible developing country' that takes climate change very seriously, yet that it has neither a historical responsibility nor the financial resources to mitigate climate change, and that it is in need of financial and technological support. As the Chinese government wants to avoid any binding requirements in international climate politics, it aligns its interests in conjunction with other developing countries. It underlines the UNFCCC principle of 'common but differentiated responsibilities' and opposes binding emissions reductions for developing countries. For years, China refused to commit to any kind of emission reductions and demanded that developed countries shoulder all responsibility for climate change mitigation for historical reasons. China compromised its position in the 2007 UN Bali Conference, where it and other developing countries committed themselves to implement nationally appropriate mitigation actions in the context of sustainable development that are supported and enabled by measurable, reportable, and verifiable technology, as well as financing and capacitybuilding. Since adaptation is 'an essential component in the framework of sustainable development to address climate change', China demands developed countries provide developing countries with 
technological and financial support to develop their adaptation capacity (National Development and Reform Commission, 2008).

Since the late 2000s, the Chinese government has taken important steps towards moderating the future growth of the country's greenhouse gas emissions. In June 2007 the government published its first comprehensive climate policy document entitled the National Climate Change Programme. In August 2009 the National People's Congress of China Standing Committee passed a resolution actively responding to climate change; the first climate change resolution adopted by China's top legislative body. The resolution declared:

To respond to climate change is an important opportunity and challenge for China's economic and social development. To actively respond to climate change is of great importance to China's overall economic and social development and people's vital interests, and significant to human survival and the development of all countries. (Standing Committee of the National People's Congress, 2009, author's translation)

The resolution underlined the principle of scientific development and vowed to strengthen China's legal framework addressing climate change. In November 2009 China announced a 'voluntary' but 'nationally binding' target to reduce carbon emission intensity per unit of GDP in 2020 by $40-45 \%$ from that in 2005. It was estimated that there would not be a reduction in China's overall emissions as China's GDP (and emissions as well) was expected to double by 2020 , but the target would prevent ghg emissions to double by that time (Xinhua, 2009). In March 2011 the target was incorporated into the 12th Five-Year Plan (2011-2015), which decided to cut energy consumption per unit of GDP by $16 \%$ by 2015 , and CO2 emissions by $17 \%$, respectively. In addition, the non-fossil fuels proportion of overall primary energy consumption was raised to $11.4 \%$ (compared to $8.3 \%$ in 2010). In 2013 China announced it would introduce a climate change law within the following two years (Globe International, 2013). In addition, a carbon tax is also planned to be introduced (Xinhua, 2013b).

China is the world's largest consumer of coal, which is the main source of carbon dioxide from fossil fuels. As coal is also one of the most important sources of China's heavy air pollution, there are strong domestic incentives to decrease the use of coal - or as discussed in Beijing, even to ban the use of it (Xinhua, 2014). There have been signs that China will set a national cap on coal starting in 2016 (Buckley, 2014). Furthermore, Chinese Premier Li Keqiang 'declared war' on pollution in 2014. The government is focused on reducing the levels of particles PM2.5 and PM10 by improving energy efficiency, raising the proportion of electricity generated by renewables and nuclear power, developing low-carbon technology, reducing vehicle exhaust emissions, and shutting down outdated industrial plants and energy producers, for instance (Li, 2014). All of these efforts will no doubt have positive effects on climate change mitigation as well.

Because of these efforts, 'China is likely to see emissions peak at a time when the country's per capita GDP is half that of developed countries when they saw emissions peak', estimated China's chief negotiator to the UN climate change talks in 2012 (Xinhua, 2012). However, the Chinese government has not announced in which year it expects China's emissions to peak, although China's energy demand is forecasted to peak between 2030 and 2035 (Xinhua, 2013). China's science and technology minister has unofficially predicted that the emissions peak 'would definitely come between 2030 and 2040' (Watts, 2009). 
2. In making a national commitment to reduce ghg emissions under the UNFCCC, to what extent, if at all, has the nation explained how it took equity and justice into consideration in setting its ghg emissions reduction target?

The Chinese government strictly denies being responsible for causing climate change and demands that developed countries shoulder their historic responsibility. As Xie Zhenhua, China's chief negotiator at the UN climate change talks, puts it, it would be, 'unfair and unreasonable to hold China to absolute cuts in emissions at the present stage, when its per capita GDP stands at just 5,000 U.S. dollars' (Xinhua, 2012). Because 128 million Chinese people continue to live below the state's official poverty line of 2300 yuan a year (US\$362) (Xinhua, 2011), the Chinese government emphasizes that China has a moral responsibility to maximize economic growth. Therefore, China refuses to commit to any binding emission reduction targets.

China also reminds the world that per capita emissions are much lower in China than in developed countries. For instance, China emitted 7.1 tonnes of $\mathrm{CO}_{2}$ per capita in 2012, while the US emitted 16.4 tonnes per capita (PBL Netherlands Environmental Assessment Agency, 2013, p4). What China does not mention is that per capita emissions of the richest $10 \%$ of Chinese are well above those of the poorest $10 \%$ of Americans (Harris, 2011, p231). The number of affluent Chinese is growing rapidly: in 2013 China became the world's third-richest country in terms of household wealth, and there were 1.123 million reported millionaires and more people with wealth above US\$50 million than any other country outside the USA (Credit Suisse Research Institute, 2013, p48). The number of Chinese millionaires is estimated to almost double by 2018 , rising to 2.1 million (Credit Suisse Research Institute, 2013, p43).

3. Given that any national ghg emissions target is implicitly a position on achieving an atmospheric ghg concentration that will avoid dangerous climate change, to what extent has the nation identified the ghg atmospheric concentration stabilization level that the national emissions reduction target seeks to achieve in cooperation with other nations?

As China has not committed to absolute emissions cuts, it has not identified the ghg atmospheric concentration stabilization level that its policies would seek to achieve. Instead, China has announced only relative emissions reductions and demands that developed countries cut their emissions for historical reasons.

4. Given that any national ghg emissions target is implicitly a position on the nation's fair share of safe global emissions, to what extent has the nation identified the ethical and justice considerations that it took into account in allocating a percentage of global ghg emissions to the nation through the identification of a ghg emissions reduction commitment?

China stresses that, as a developing country, it has no responsibility to cut $\mathrm{CO}_{2}$ emissions. China admits that its ghg emissions are going to continue to grow due its growing energy consumption. However, China assures the world that its emissions growth is justified because it is caused by poverty alleviation and is necessary to raise the living standard of the Chinese poor. The government has not indicated what kind of development level it should achieve before making an emissions reduction commitment nor when it is expecting to meet that level. 


\section{To what extent, if at all, has the nation acknowledged that nations emitting ghg above their fair share of safe global emissions have a responsibility to fund reasonable adaptation measures or unavoidable losses and damages in poor developing countries?}

For years, China has criticized international climate negotiations for focusing too much on climate change mitigation and paying too little attention to adaptation, thus failing to 'meet the actual needs of developing countries, in particular least developed countries and small island countries' (National Development and Reform Commission, 2008). China demands that developed countries provide developing countries with effective and concrete support to develop adaptation strategies and improve their adaptation capacity. In 2008 China proposed the establishment of both an 'International Institution for Climate Change Adaptation' and an 'Adaptation Fund' under the UNFCCC (National Development and Reform Commission, 2008). China demands that climate change mitigation and adaptation should pay attention to poverty eradication, and that all climate actions should support the achievement of the United Nations' Millennium Development Goals.

Despite its rapidly increasing economic wealth, China continues to represent itself as the leader of developing countries in international climate negotiations. China aligns its climate politics with all the other developing countries' (the G77) interests and uses rhetoric intended to entwine their interests with its own. It accepts no sub-categories between developed and developing countries because the government does not want to have binding emissions reductions nor abdicate its financial and technological benefits. The Chinese government stresses its friendship with developing countries and argues that 'China has never separated itself from other developing countries and will never do so' (Wang, 2013). However, China is no longer a 'very poor' country and its enormous ghg emissions inevitably cause unavoidable losses and damages in poor developing countries. It is only a matter of time until developing countries, especially the least developed countries and small island states, also start to ask China to reduce its emissions. Naturally, the Chinese government wants to ensure that it will not become isolated in international negotiations and therefore it has begun to advocate cooperation amongst the so-called BASIC (Brazil, South Africa, India and China) countries as well. Despite the group's huge internal differences, such as the level of $\mathrm{CO}_{2}$ emissions per capita, the BASIC group forms a quite united, but informal, alliance, highlighting the historical climate responsibility of developed countries and resisting legally binding emissions reductions for developing countries.

\section{What formal mechanisms are available in the nation for citizens, NGOs and other interested organizations to question/contest the nation's ethical position on climate change?}

Although environmental NGOs are nowadays quite well tolerated in China, participation of citizens, NGOs, and other interested organizations in (foreign) policy decision-making continues to be limited. There are no formal mechanisms available for public participation in questioning China's ethical position on climate change.

There were no environmental NGOs in China before the Friends of the Earth was founded in 1994. Today, there are more than 3500 environmental NGOs (Liu, 2012), with China Civil Climate Action Network (CCAN) being the umbrella organization of NGOs active in climate change groups. Environmental NGOs play an important role in raising public awareness on climate change and environmental problems within China.

Previously, only government think-tanks and research institutions were invited to participate in (environmental) policy-making processes but it seems the government is opening up some of the 
processes to NGOs as well. For example, CCAN took an active part in the formulation of China's National Climate Law by organizing workshops, meeting with government officials, and submitting a recommendation paper for the National Development and Reform Commission that is in charge of preparing climate change law (CCAN, 2011).

\section{How is the concept of climate justice understood by the current government? Have they articulated any position on climate justice issues that arise in setting ghg emissions policy or in regard to the adaptation needs of vulnerable nations or people?}

As explained in answers to previous questions, the Chinese government understands the concept of climate justice in terms of historical responsibility. According to China's 'development first' principle, developing countries do not have an obligation to control emissions before they achieve a certain level of development. The claim is naturally justified from the least developed countries' point of view, but one can wonder if China truly is a typical representative of developing countries.

From China's point of view, there is a big difference between the nature of emissions in developed and developing countries. It distinguishes two categories of emissions: first, developed countries' excessive and unjustified 'luxury emissions'; and second, developing countries' 'subsistence emissions'. In the words of China's former President Hu Jintao, 'a significant share of China's total emissions fall under the category of subsistence emissions necessary to meet people's basic needs' (Hu, 2008). By highlighting the value of development, the Chinese government establishes disincentives to set binding emissions requirements for it. In addition, the Chinese government has increasingly started to refer to 'transferred emissions' or 'offshore emissions' which are produced in China but only due to the consumption needs of developed countries. In President Hu Jintao's words, 'as a result of changes in the international division of labor and manufacturing relocation, China faces mounting pressure on international transferred emissions' (Hu, 2008).

Many studies have indeed shown that due to China's export-driven development strategy, a lion's share of its emissions are 'offshore emissions'. For instance, Wang and Watson calculate that 23\% of China's $\mathrm{CO}_{2}$ emissions are caused by manufacturing goods exported to Western consumers (Wang and Watson, 2007). In addition, Guan et al point out that half of China's emissions increase is caused by export production such as electronics, metals, chemicals and textile production (Guan et al, 2009). At the same time, some developed countries seem to have achieved slowdowns or even cutbacks of their ghg emissions - but apparently only because they have outsourced their factories and emissions to 'pollution havens', in, say, China. For example, when taking into account imported consumptionbased emissions, the total emissions of the United Kingdom have increased by approximately $10 \%$ since 1993, although territorial emissions have decreased during the last couple of decades. Around $30 \%$ of the UK's imported emissions are caused by imports from Asian developing economies, and half of this, from China (Committee on Climate Change, 2013, p9). This makes the UK one of the largest net importers of emissions, while China is the largest net exporter.

\section{Are you aware of any regional, state, provincial, or local governments in your country that have acknowledged some ethical responsibility for climate change? If so, what have they said?}

The Chinese government recognizes that it cannot follow the industrialization path of developed countries. It announces that it will 'never repeat it' but 'will adopt comprehensive policies to slow down the speed of emission growth and to try to reach emission peak as early as possible' (Xie, 2010). This is a difficult task, as China's former Premier Wen Jiabao notes: 
If we look at the world history of development, we will see that developed countries encountered their resource and environmental challenges in phases in the course of 200 years of industrialization. But we are confronted with the challenges all at the same time. In addition, we have to address in a much shorter timeframe the issue of energy conservation and pollution control which has taken developed countries decades to tackle after their economies became highly developed. The difficulties we face are therefore unprecedented. (Jiabao, 2008)

From China's perspective, it is not fair to criticize their total ghg emissions because a significant proportion of them are 'offshore emissions' caused by exports. As China's Foreign Ministry spokesman, Qin Gang, said in 2007:

The developed countries move a lot of manufacturing industry into China. A lot of the things you wear, you use, you eat are produced in China. On the one hand, you shall increase the production in China, on the other hand you criticize China on the emission reduction issue. (The New York Times, 2007)

\section{Has your national government taken any position on or otherwise encouraged individuals, businesses, organizations, subnational governments, or other entities that they have some ethical duty to reduce greenhouse gas emissions?}

The Chinese government has encouraged central and local governments, businesses and individuals to practise 'low-carbon lifestyle' living by issuing a wide variety of policies and action plans. These policies do not include any encouragement to consider ethical issues but China argues that international expectations of its global responsibility should be closely linked to its development stage.

More than thirty Chinese provinces and cities have started low-carbon pilot programmes to initiate energy- and resource-efficient development models for society and industry. In 2012 China issued preliminary carbon emissions trading system (ETS) regulations and launched pilot programmes for carbon emissions trading in five major cities (Beijing, Tianjin, Shanghai, Chongqing and Shenzhen) and two provinces (Guangdong and Hubei). The government plans to expand the carbon emissions trading system nationwide in 2016 when the 13th Five-Year Plan comes into effect (Xinhua, 2012b).

Public education campaigns have been initiated all over China in order to increase public awareness of environmental problems, climate change, energy conservation and low-carbon ways of living. Media coverage on climate change has increased significantly, and many public-interest advertisements, articles and documentaries on climate change have been broadcast on TV and radio, and published in newspapers, for instance. Since 2013, National Low-Carbon Day has also been celebrated. In 2013 a thousand young environment ambassadors were chosen to improve young people's environmental awareness (National Development and Reform Commission, 2013).

To encourage businesses to improve energy efficiency and promote green growth, the Chinese government has issued various strategies and action plans such as the Action Plan for Addressing Climate Change in Industry (2012-2020) (National Development and Reform Commission, 2013).

\section{What recommendations would you make to get the nation or civil society to take ethics and justice issues seriously in climate change policy formulation?}

When criticizing China's total ghg emissions, two important aspects should be remembered. First, it should be noted that per capita emissions are much lower in China than in developed countries. Second, the lion's share of China's increasing ghg emissions are caused by Western consumer demand. However, current international climate politics tends to focus on total emissions and to penalize countries that produce goods rather than the countries that consume them. If these 'offshore emissions' were officially acknowledged, it would make international negotiations fairer, generate 
trust, and may increase China's willingness to take a more active role in global efforts to mitigate climate change. That is why I suggest that the post-Kyoto negotiations should pay more attention to consumption of states and individuals rather than states' territorial emissions caused by production.

Again, it should also be noted that the ghg emissions of millions of affluent Chinese individuals do not differ from those of stereotypical Western consumers. From a cosmopolitan perspective, all affluent people, including affluent Chinese, have the capability and responsibility to reduce ghg emissions (see, for example, Harris, 2010). As Harris suggests, the UNFCCC principle of 'common but differentiated responsibilities' among people (instead of among countries) would better capture the global role of affluent (Chinese) individuals and therefore pay more attention to ethics and justice issues globally (Harris, 2011).

Without developed countries', especially the US's, serious commitments and ambitious climate mitigation strategies, China will continue to focus on a developing country status and remain unlikely to bear more international responsibility. Developed countries should also advance their genuine understanding of the Chinese way of thinking and acting; they should not continually focus on blaming China for its irresponsibility, but should respect the efforts of the Chinese government, as apportioning blame does not usually consolidate the mutual trust needed in international cooperation. It seems that the Chinese are very frustrated because developed countries do not recognize the hard work and progress they have made in the area of climate change mitigation. By 'giving face' to the Chinese and by recognizing China's progress in several policy areas including environmental issues, and by allowing China to play a more important role in international politics, developed countries could encourage the Chinese government to shoulder more responsibility on contemporary global issues.

Finally, China's permanent seat on the UN Security Council brings special responsibilities for the Chinese government. From this vantage point, it can be argued that China has a moral duty to shoulder more responsibility than minor states and it cannot escape its obligation to adopt serious climate change mitigation policies. In the end, in addition to the US, China is the only country whose national policy can make a global difference.

\section{Acknowledgements}

The author would like to thank the Joel Toivola Foundation for financial support for the research on which this national report is based. 


\section{References}

Buckley, Chris (2014) 'China's Plan to Limit Coal Use Could Spur Consumption for Years', The New York Times, 24 July, http://www.nytimes.com/2014/07/25/world/asia/chinese-plan-to-reduce-coal-use-could-allowincreases-for-years.html, accessed 17 August 2014

CCAN (2011) ‘CCAN NGOs Provide Recommendations for China's New Climate Change Legislation', 13 October, http://www.c-can.cn/en/node/679, accessed 13 August 2014

Committee on Climate Change (2013) 'Reducing the UK's carbon footprint', http://www.theccc.org.uk/wpcontent/uploads/2013/04/Reducing-carbon-footprint-report.pdf, accessed 2 August 2014

Credit Suisse Research Institute (2013) Global Wealth Report 2013, https://publications.credit-suisse.com/tasks/ render/file/?fileID=BCDB1364-A105-0560-1332EC9100FF5C83, accessed 23 August 2014

Globe International (2013) 'Minister Xie Zhenhua announces Chinese Climate Law within 1 to 2 years at GLOBE Event in Beijing', http://www.globeinternational.info/news/item/xie-zhenhua-launches-legislation-study-inbeijing, accessed 2 August 2014

Guan, Dabo, Peters, Glen P., Weber, Christopher L. and Klaus Hubacek (2009) 'Journey to world top emitter - an analysis of the driving forces of China's recent $\mathrm{CO} 2$ emissions surge', Geophysical Research Letters, vol 36, no 4, L04709

Harris, Paul G. (2010) World Ethics and Climate Change: From International to Global Justice, Edinburgh University Press, Edinburgh

Harris, Paul G. (2011) 'Chinese responsibility for climate change', in Paul G. Harris (ed.) China's Responsibility for Climate Change: Ethics, fairness and environmental policy, Policy Press, Bristol

Hu, Jintao (2008) ‘Remarks at the Major Economies Meeting On Energy Security and Climate Change', http://www. fmprc.gov.cn/mfa eng/wjdt_665385/zyjh_665391/t473739.shtml, accessed 5 November 2014

$\mathrm{Li}$, Keqiang (2014) 'Report on the Work of the Government', Delivered at the Second Session of the Twelfth National People's Congress on March 5, 2014, http://news.xinhuanet.com/english/special/2014-03/14/c_133187027. htm, accessed 2 August 2014

Liu, Sha (2012) 'Environmental NGOs grow across China but still struggle for support', Global Times, 12 June, http://www.globaltimes.cn/content/714330.shtml, accessed 13 August 2014

National Development and Reform Commission (2007) China's National Climate Change Programme, en.ndrc.gov. cn/newsrelease/200706/P020070604561191006823.pdf, accessed 2 August 2014

National Development and Reform Commission (2008) 'Mr. Xie Zhenhua unveiled "Initiative By China on Enhancement of Developing Countries' Adaptation Capacity"', http://en.ccchina.gov.cn/Detail. aspx? newsld=38737\&Tld=107, accessed 2 August 2014

National Development and Reform Commission (2013) 'China's Policies and Actions for Addressing Climate Change', en.ndrc.gov.cn/newsrelease/201311/P020131108611533042884.pdf, accessed 2 August 2014

PBL Netherlands Environmental Assessment Agency (2013) 'Trends in Global $\mathrm{CO}_{2}$ Emissions: 2013 Report', October, http://www.pbl.nl/sites/default/files/cms/publicaties/pbl-2013-trends-in-global-co2-emissions2013-report-1148.pdf, accessed 14 August 2014

Standing Committee of the National People's Congress (2009) [Resolution of the Standing Committee of the National People's Congress on Making Active Responses to Climate Change]', http://www.npc.gov.cn/npc/ xinwen/rdyw/wj/2009-08/27/content 1516165.htm, accessed 2 August 2014

Su, Wei (2010) Untitled letter from Su Wei, Director-General of Department of Climate Change, National Development and Reform Commission of China to Yvo de Boer, Executive Secretary of the UNFCCC Secretariat, 28 January, https://unfccc.int/files/meetings/cop_15/copenhagen_accord/application/pdf/chinacphaccord app2.pdf, accessed 11 August 2014

The New York Times (2007), 'China rejects criticism of its carbon emissions', 21 June, http://www.nytimes. com/2007/06/21/business/worldbusiness/21iht-emit.4.6262722.html, accessed 5 November 2014

Wang, Tao and Watson, Jim (2007) 'Who Owns China's Carbon Emissions?', Tyndall Briefing Note No. 23, http:// www.tyndall.ac.uk/publications/briefing_notes/bn23.pdf 
Wang, Yi (2013) 'Exploring the Path of Major-Country Diplomacy With Chinese Characteristics', http://www.fmprc. gov.cn/eng/zxxx/t1053908.shtml, accessed 2 August 2014

Watts, Jonathan (2009) 'China's carbon emissions will peak between 2030 and 2040, says minister', The Guardian, 6 December, http://www.theguardian.com/environment/2009/dec/06/china-carbon-emissionscopenhagen-climate, accessed 2 August 2014

Wen, Jiabao (2008) 'Strengthen International Technology Cooperation and Address Climate Change Actively. Speech at the Beijing High-level Conference on Climate Change: Technology Development and Technology Transfer', 7 November, http://jm.chineseembassy.org/eng/xw/P020081113418748745558.pdf, accessed 2 August 2014

Xie, Zhenhua (2010) 'Speech at the High Level Segment of COP16\&CMP6', 8 December, http://unfccc.int/files/ meetings/cop_16/statements/application/pdf/101208_cop16_hls_china.pdf, accessed 2 August 2014

Xinhua (2009) 'China announces targets on carbon emission cuts', 26 November, http://news.xinhuanet.com/ english/2009-11/26/content_12544181.htm, accessed 2 August 2014

Xinhua (2012a) 'China vows emissions cutting efforts ahead of Doha conference', 22 November, http://news. xinhuanet.com/english/china/2012-11/22/c_123983609.htm, accessed 2 August 2014

Xinhua (2012b) 'China eyes nationwide emission trading programs in 2016-2020: official', 6 December, http:// news.xinhuanet.com/english/china/2012-12/06/c_132024197.htm, accessed 11 August 2014

Xinhua (2013a) 'China's energy demand to peak in 20 years: expert', 25 May, http://news.xinhuanet.com/english/ china/2013-05/25/c_132408324.htm, accessed 2 August 2014

Xinhua (2013b) 'China to introduce carbon tax: official', 9 February, http://news.xinhuanet.com/english/china/201302/19/c 132178898.htm, accessed 11 August 2014

Xinhua (2014) 'Smoggy Beijing to ban coal use', 4 August, http://news.xinhuanet.com/english/china/201408/04/C_133531366.htm, accessed 17 August 2014 



\section{Ethics and Justice in Climate Change Policies - Report on Italy}

\section{Alessandra Solazzo and Massimiliano Montini}

This report responds to the research questions of the Project On Deepening National Responses to Climate Change On The Basis of Ethics and Justice, a joint project of the University of Auckland, School of Architecture and Planning and Widener University, School of Law, Environmental Law Center. The research questions and responses are as follows:

1. To what extent has the national debate about how the nation should respond to climate change by setting a ghg emissions reduction target expressly considered that the nation not only has economic interests in setting the target but also ethical obligations to those who are most vulnerable to climate change and that any national ghg emissions reduction target must represent the nation's fair share of safe global emissions? In answering this question, identify the national ghg emissions reduction target, if any, that the nation has made under the United Nations Framework Convention on Climate Change (UNFCCC).

The Italian debate about the ethical and justice implications of climate change is still at a starting point. A study of the University of Sassari, Italy (Various authors, 2008), shows that the private sector is slowly becoming aware of the issue, but that government and public institutions lack interest, and that the general problem of climate change has not been receiving a primary role in this period of economic and financial crisis. National ghg emissions targets are mostly accepted only as a way to fulfil obligations that have been established at international or European level; or thought of as tools for achieving national economic growth, from a 'green growth' or 'green economy' perspective, with no reference to any ethical dimension.

The United Nations Framework Convention on Climate Change (UNFCCC), establishing that the overall global annual mean surface temperature increase should not exceed 2 degrees Celsius above pre-industrial levels, was approved on behalf of the European Union by Council Decision 94/69/EC. Regarding the emissions reduction target, the Kyoto Protocol objective for the EU is to attain an $8 \%$ emissions reduction by 2012 with respect to 1990. Within this $8 \%$ framework, each Member State, according to its size, population and industrial activity, has a specific national target, which for Italy is $6.5 \%$, corresponding to an average reduction of $485.7 \mathrm{MtCO}_{2} /$ year. ${ }^{1}$ This target has been set by the Inter-Ministerial Committee for Economic Planning (CIPE), chaired by the Ministry of Economy and Finance, which is in charge of the programme for ghg emissions reductions at a national level, and it is now contained in Law n. 120/2002. ${ }^{2}$

Meanwhile, in 2009, the EU adopted the '2020 climate and energy package', ${ }^{3}$ the primary aim of which is to increase the EU's energy security and strengthen its competitiveness, with ethical and justice implications of climate change not specifically taken into account. The integrated approach of the 2009 package, in particular, is based on three key objectives, known as '20-20-2020 targets':

- a $20 \%$ reduction in EU greenhouse gas emissions from 1990 levels (binding);

- raising the share of EU energy consumption produced from renewable resources to $20 \%$ (binding);

- a $20 \%$ improvement in the EU's energy efficiency (indicative). 
In application of the emissions reduction objective, Decision 406/2009/EC of the European Parliament and of the Council of 23 April $2009^{4}$ lays down the minimum contribution of each Member State. Italy has a reduction target of $-13 \%$ by 2020 with respect to 2005 emissions. This target has been implemented at the national level by Law n. 96/2010. ${ }^{5}$

With regard to mitigation, Italy, as part of the European Union, does not set its own mitigation target, which is determined within the EU context, and does not have an independent ghg mitigation strategy. Unlike mitigation, adaptation to climate change is more related to the country's specific features. In such a context, firstly, assessment of local and regional vulnerabilities is needed; secondly, on that basis, it is possible to take appropriate action to prevent or minimize the damages of climate change. Consequently, with respect to adaptation, the EU Member States have more flexibility to determine and implement their own national adaptation strategies.

With regard to Italy at present, the priority of the Italian Ministry for the Environment, Land and Sea (IMELS) towards climate change regards the adoption of a National Adaptation Strategy (NAS) and/ or a National Adaptation Plan (NAP), as required by the White Paper of the European Commission, $\operatorname{COM}(2009) 147,{ }^{6}$ and which is mandated by the 2009 European 'climate and energy package'. The preparatory documents drafted by experts for the Italian National Adaptation Strategy, ${ }^{7}$ which contain scientific or economic studies on the negative impacts of climate change on some vulnerable regions of the country, do not contain any reference to climate justice and ethics issues. Also, the draft National Adaptation Strategy does not contain a study on specific social and ethical implications, or on how climate can impact on vulnerable sectors of society. Nonetheless, even though a specific debate has not yet emerged, the draft is inspired by the principle of sustainability. Such a principle, including also social aspects, can be considered an instrument by which to drag ethics and justice issues into the debate about climate change. For instance, taking into account the vast Italian cultural heritage, and considering that the impoverishment of such a valuable resource would represent a significant loss for future generations, a study on climate change impact on cultural heritage has been considered together with the other working preparation papers (Bonazza, 2012). This effort to consider Italian cultural heritage has been transposed to a specific paragraph of the draft of the National Adaptation Strategy (see p51). At the corporate level, a study on corporate social responsibility (CSR) released by a research centre of Bocconi University, Milan, shows that climate change is not accorded very high consideration by those involved in the Italian small and medium-sized enterprises' (SMEs) ${ }^{8}$ supply chain, but that it is at least taken into account, together with traditional corporate issues, as the following table demonstrates (Perrini, Vurro, 2011): 
Figure 1.1 Average Likert-scale ratings (1-5) of the employees of 760 Italian SMEs (2011)

\begin{tabular}{|c|c|c|c|c|c|c|}
\hline & $\begin{array}{l}\text { Agricultural and } \\
\text { food industry }\end{array}$ & $\begin{array}{l}\text { Construction } \\
\text { sector }\end{array}$ & $\begin{array}{l}\text { Information and } \\
\text { Communication } \\
\text { Technology } \\
\text { (ICT) }\end{array}$ & $\begin{array}{l}\text { Manufactoring } \\
\text { sector }\end{array}$ & $\begin{array}{l}\text { 'Business to } \\
\text { business' } \\
\text { activities }\end{array}$ & Other \\
\hline $\begin{array}{l}\text { Protection of } \\
\text { business } \\
\text { reputation }\end{array}$ & 4.32 & 4.50 & 4.20 & 3.90 & 3.64 & 4.34 \\
\hline Transparency & 3.58 & 4.50 & 3.65 & 3.83 & 3.96 & 4.31 \\
\hline $\begin{array}{l}\text { Human } \\
\text { resources } \\
\text { enhancement }\end{array}$ & 3.58 & 4.13 & 4.38 & 4.08 & 3.96 & 4.28 \\
\hline $\begin{array}{l}\text { Human rights } \\
\text { protection }\end{array}$ & 3.42 & 3.88 & 3.55 & 3.65 & 3.88 & 3.88 \\
\hline $\begin{array}{l}\text { Climate } \\
\text { change }\end{array}$ & 3.26 & 3.88 & 2.65 & 3.13 & 3.25 & 3.28 \\
\hline $\begin{array}{l}\text { Collaboration } \\
\text { in the supply } \\
\text { chain }\end{array}$ & 3.79 & 4.50 & 3.90 & 3.67 & 3.72 & 3.94 \\
\hline $\begin{array}{l}\text { Security and } \\
\text { traceability }\end{array}$ & 4.26 & 4.38 & 3.33 & 4.02 & 3.32 & 4.19 \\
\hline $\begin{array}{l}\text { Design and } \\
\text { launch of } \\
\text { ethical and } \\
\text { environmen- } \\
\text { tally friendly } \\
\text { products }\end{array}$ & 3.53 & 3.75 & 3.2 & 3.29 & 2.88 & 3.81 \\
\hline $\begin{array}{l}\text { Knowledge and } \\
\text { competence } \\
\text { transfer }\end{array}$ & 3.32 & 3.88 & 3.71 & 3.27 & 4 & 4.19 \\
\hline $\begin{array}{l}\text { Relationship } \\
\text { stability and } \\
\text { trust }\end{array}$ & 4.21 & 4.63 & 4.33 & 3.79 & 4.36 & 4.47 \\
\hline $\begin{array}{l}\text { Link with local } \\
\text { areas and local } \\
\text { communities }\end{array}$ & 3.58 & 4.13 & 3.33 & 2.85 & 3.16 & 3.72 \\
\hline
\end{tabular}

Translated to English by the author (p37 of the report).

Even though the debate on climate justice and ethics at the institutional and business level is not yet very developed, citizens and organizations are starting to play their part in linking climate change and ethical issues, as the following examples demonstrate.

The Italian Climate Network (ICN), together with many environmental associations, such as WWF and university research teams like LUISS Sostenibile, established a think-tank on intergenerational equity, with the aim of presenting ideas and concrete proposals (developed by a working group of very young Italian citizens, called YOUNGO) to the next 2014 Lima COP 20 and 2015 Paris COP $21 .{ }^{9}$ The advocacy pressure on policy-makers of the young Italian citizens' delegation will also show the commitment of Italy to tackling climate and responsibility issues, and will have particular importance because initiatives will be presented for the first time during the Italian presidency semester of the EU Council from July 2014 to December 2015. 
A very active network of associations, committees and labour unions, named Rete Italiana per la Giustizia Ambientale e Sociale (RIGAS), specifically refers to climate and environment justice and social equity. Through its initiatives it gives a concrete meaning to the UN Millennium Developed Goals in Italy, organizing citizens' mobilizations, and improving institutions' awareness of climate and justice. For instance, during the 2009 'Stand Up Against Poverty and Climate Change' campaign, RIGAS invited many local governments all around Italy (e.g. the municipalities of Rome and Florence) to tie ribbons into symbolic knots to remind world leaders of the promises made at the Millennium Summit in 2000.

At the academic level, there are several research centres which are studying climate ethics: from an international policy point of view, such as Centro euro-Mediterraneo sui cambiamenti climatic (CMCC); ${ }^{10}$ or, from a philosophical and social point of view, Fondazione Lanza. ${ }^{11}$

2. In making a national commitment to reduce ghg emissions under the UNFCCC, to what extent, if at all, has the nation explained how it took equity and justice into consideration in setting its ghg emissions reduction target?

The ratification of the Kyoto Protocol by Law n. 120/2002 does not contain any reference to these themes. Moreover, it is important to bear in mind that the Italian emissions reduction target $(6.5 \%$ below 1990 levels by 2012) has been decided within the European framework of $8 \%$. Accordingly, as shown by the University of Sassari study, Italy's and the European Union's institutions are almost at the same level of awareness in taking equity and justice into consideration in setting their ghg emissions reduction targets, meaning that European awareness is not very high either.

Nonetheless, a Resolution on women and climate change was adopted in 2012 by the European Parliament (2011/2197(INI)). ${ }^{12}$ It contains a very detailed and accurate analysis of this specific issue, meaning that steps are also being taken to give climate ethics a more relevant role in the European (and, consequently, national) context. For instance, observing that climate change is not genderneutral, the Parliament welcomes the growing awareness of the gender aspect of climate change in the high-level climate talks, and calls for the other European institutions and Member States to consider introducing $40 \%+$ female quotas in their delegations. Moreover, Members call on the Commission to "develop a principle of "climate justice" given that the greatest injustice of our failure to tackle climate change effectively would be the detrimental effects on poor countries and populations, and on women in particular'. Such a statement could be considered as a way to potentially open the door to a broader understanding of climate justice and ethics.

3. Given that any national ghg emissions target is implicitly a position on achieving an atmospheric ghg concentration that will avoid dangerous climate change, to what extent has the nation identified the ghg atmospheric concentration stabilization level that the national emissions reduction target seeks to achieve in cooperation with other nations?

Decision 406/2009/EC of the European Parliament and of the Council, referred to above, regarding the efforts of Member States to reduce their greenhouse gas emissions to meet Europe's ghg emissions reduction commitments up to 2020 , explicitly states that:

The ultimate objective of the United Nations Framework Convention on Climate Change (UNFCCC), which was approved on behalf of the European Community [today European Union] by Council Decision 94/69/ EC [OJ L 33, 7.2.1994, p. 11], is to stabilise greenhouse gas concentrations in the atmosphere at a level that would prevent dangerous anthropogenic interference with the climate system. ${ }^{13}$ 
Moreover, it also states that:

[T]he overall global annual mean surface temperature increase should not exceed $2 \mathrm{C}$ above pre-industrial levels, which implies that global greenhouse gas emissions should be reduced to at least $50 \%$ below 1990 levels by 2050. The [European Union]'s greenhouse gas emissions covered by this Decision should continue to decrease beyond 2020 as part of the [EU]'s efforts to contribute to this global emissions reduction goal. Developed countries, including the EU Member States, should continue to take the lead by committing to collectively reducing their emissions of greenhouse gases in the order of $30 \%$ by 2020 compared to $1990 . .^{14}$

The Decision also leaves Member States free to impose higher targets than those imposed at the European level:

This Decision should be without prejudice to more stringent national objectives. Where Member States limit the greenhouse gas emissions covered by this Decision beyond their obligations under this Decision in order to meet a more stringent objective, the limitation imposed by this Decision on the use of greenhouse gas emission reduction credits should not apply to the additional emission reductions to attain the national objective. ${ }^{15}$

As far as Italy is concerned, being part of the European Union, it also refers to the IPCC's 2 degrees limit, through the internal adoption of the EU's Decisions and Directives. Moreover, being also part of the UNFCCC, Italy has to periodically provide a National Communication containing information and evaluations regarding both the evolution of $\mathrm{CO}_{2}$ and other ghg emissions and the reduction strategies. In the last Communication, released in December $2013,{ }^{16}$ it is interesting to read that:

Whereas Italy will continue its efforts to reduce greenhouse gas emissions at national level, Italy believes that enhancing international cooperation with a view to reduce global emissions so as to hold the increase in global temperature below 2 degrees Celsius, will continue to be a major global challenge. . . I Italy welcomes the result of the latest United Nations climate conference ... held in Warsaw and is ready to do its part to prepare the ground for the adoption by 2015 of a new legally-binding global agreement containing emission commitments by all countries and enhancing the institutional framework to promote sustainable development both in developing and developed countries.

4. Given that any national ghg emissions target is implicitly a position on the nation's fair share of safe global emissions, to what extent has the nation identified the ethical and justice considerations that it took into account in allocating a percentage of global ghg emissions to the nation through the identification of a ghg emissions reduction commitment?

There is no record of the ethical and justice considerations that were taken into account in allocating a percentage of global ghg emissions to the nation through the identification of a ghg emissions reduction commitment in the Italian national debate. However, the mitigation targets are not set by Italy on its own, but are rather established within the European Union context.

5. To what extent, if at all, has the nation acknowledged that nations emitting ghg above their fair share of safe global emissions have a responsibility to fund reasonable adaptation measures or unavoidable losses and damages in poor developing countries?

In accordance with the requirement of Article 2, paragraph 3 of the Kyoto Protocol on the minimization of adverse effects, climate policies in Italy are formulated and implemented in a way that minimizes the potential adverse impacts on other Parties to the Convention, including adverse effects regarding social, environmental and economic impacts in developing countries. 
Moreover, the commitment of the Italian Ministry for the Environment, Land and Sea to tackle climate change and encourage technology transfer in less developed countries is strongly expressed in the Decree (DLGS 13/03/2013) which implements EU Directive 2003/87/EC. In fact, this will define the criteria for the allocation of revenues from auctioning of $\mathrm{CO}_{2}$ rights. In particular, it is established that $50 \%$ of those revenues will be dedicated to projects addressed at reducing emissions from deforestation and forest degradation, to improve technology transfer, as well as to promote adaptation measures to climate change in the least developed countries. This Decree accomplishes several objectives. For instance, it contributes to the Global Fund on Climate Change created in Poznan (COP 14/MOP 4) and meets the commitment undertaken in the Durban Conference (COP 17/MOP 7), in favour of less developed countries.

In 2013 the Italian Development Cooperation, a Department of the Ministry of Foreign Affairs, in charge of cooperation with foreign countries, confirmed its support of the Millennium Development Goals (MDG) integration process and it developed and adopted innovative methods of systemic integration of decision support. These methods promote a systematic approach to development, aimed at reducing the risks of conflict between conservation objectives and those aimed at fighting poverty on a political level, as well as in carrying out projects. This has been reflected in the formal adoption of environmental guidelines that have to be followed by Italian cooperation projects where both human rights and climate change or environmental issues are involved. ${ }^{17}$

Italian cooperation is mostly focused on the Mediterranean area, which is very vulnerable to climate change and, mostly, on the less developed countries in that area, such as Egypt, Morocco, Tunisia, Lebanon and Yemen. In doing so, Italy, in fact, uses a specific fund for MENA countries made available by the World Bank in the specific field of adaptation to climate change. ${ }^{18}$

Moreover, since 2010 , Italy has contributed to approximately US $\$ 13.270$ million in official development assistance (ODA), according to OECD Development Assistance Committee (DAC) estimates (p167 of the IMELS's National Communication under the UNFCCC, referred to in answer to the third question). The Italian Ministry of Foreign Affairs has disbursed around 32 million EUR for bilateral cooperation with developing countries for climate change-related activities. As far as Italian NGOs' cooperation with developing countries is concerned, it can be noted that quite a few of the NGOs that make their contribution to the debate about climate ethics have a Catholic background. ${ }^{19}$

\section{What formal mechanisms are available in the nation for citizens, NGOs and other interested organizations to question/contest the nation's ethical position on climate change?}

A recent participatory mechanism has been made available for citizens and organizations to question/ contest the nation's ethical position on the climate change adaptation strategy. A draft of the National Climate Change Adaptation Strategy, containing the analysis of the proposed policies on such an issue, has been released by the Ministry for the Environment and made available to the public for feedback.

Many NGOs, other interested organizations and individual citizens have submitted their opinions about the draft and their comments are now being analysed by the Ministry. For instance, the organization Legambiente has underlined the importance of the application of social equity criteria for water supply cost. The aim is to discourage the waste of water and promote an efficient use of this precious resource through the application of eco-compatible practice, as the introduction of a tariff divided in two rates: one part of it to be the same for everybody and one part to be lower for poorer people. They 
have called it 'social sustainability'. Such a procedure of public consultation has followed a period of meetings and consultations, where members of public institutions have met organizations and other stakeholder representatives to hear their points of view on the policies that have been proposed, in order to unite all the elements gathered and use them to write the draft which is now under the assessment of the Ministry.

\section{How is the concept of climate justice understood by the current government? Have they articulated any position on climate justice issues that arise in setting ghg emissions policy or in regard to the adaptation needs of vulnerable nations or people?}

In his statement to the United Nations General Assembly the Prime Minister of Italy, Mario Monti, in 2012 stated that the:

area of climate change, sound and balanced management of land and marine resources, involving strengthened trans-boundary cooperation, deserves closer political attention and common application. Some challenges are particularly pressing. Tackling climate change through coordinated emissionreduction policies is a prerequisite to substantially reducing - and possibly stopping - the serious degradation of planet Earth's fragile ecosystems, on which our lives depend. In line with our joint strategic objectives to overcome the financial crisis, we attach great importance to innovative sources of financing for development. ${ }^{20}$

Recently, talking about the Italian presidency of the Council of the European Union, commenced in July 2014, the Italian Prime Minister Matteo Renzi stated:

Regarding climate change policy and the effort towards a different quality of the environment, we are going to participate in the UN Summit both as Italy, and as part of the European Union. As also the UN meeting of Paris, planned for next year, is getting closer, Europe wants to demonstrate its strong commitment to green economy policies, but it is of the utmost importance that this commitment will not simply be an empty slogan, but it must be the right occasion for a changing of the paradigm of economic development. $^{21}$

Some of the other crucial points of the official programme of the Italian presidency of the Council regarding the environment include: real economy, 'industrial renaissance', with a particular focus on SMEs as well as energy and climate policies for 2030 that will be at the heart of growth initiatives. The Italian presidency will also work to reduce the serious social 'spread' in European societies, to finance growth and support investment in sectors that are key for the future of children, such as environmental protection. ${ }^{22}$ It will also focus on sustainable development issues through the creation of positive synergies with Expo Milano 2015, whose central topic is 'Feeding the planet. Energy for life'. ${ }^{23}$

Even though at some points the programme seems very close to establishing a link between ethics and climate change the issue is never directly faced.

\section{Are you aware of any regional, state, provincial, or local governments in your country that have acknowledged some ethical responsibility for climate change? If so, what have they said?}

The European Commission, in accordance with the 2009 White Paper referred to above, recognizes that some individuals or businesses may be able to respond to market signals or environmental changes brought about by climate change: 'autonomous adaptation'. However, this autonomous adaptation is unlikely to be optimal because of uncertainty, imperfect information, or financial constraints. This is why the EU invites Member States to take action, not to leave adaptation efforts to individuals or businesses (White Paper, p6). 
The Covenant of Mayors is an initiative launched by the European Commission to endorse and support the voluntary efforts deployed by local authorities in tackling climate change and implement sustainable energy policies, with the aim of fulfilment of the EU's climate and energy targets for 2020 (Rangone et al, 2013). At present the Covenant involves more than four thousand European cities, half of which are Italian. Considering the voluntary commitment of participants in the Covenant, they have the responsibility to create a network of good practices all around Europe, so as to bring about a real change of private and public behaviours and stimulate a similar approach to climate change in other actors. The Covenant also plays an important role in creating awareness on climate change and ghg reduction among citizens. Being developed at the local level, it is easier for citizens to be involved in the Covenant initiatives, and to understand and take measures for reducing their impact on climate change.

Also at the local level, an interesting initiative is the Siena Carbon Free project, which aims to create a province which is able to balance the emissions released in the atmosphere by different local activities, through strategies of calculation and the adoption of actions for the absorption and offsetting of ghg emissions, by 2015.

The ghg inventories of the Province of Siena were developed according to the 2006 IPCC National Greenhouse Gas Inventories and the principles of the ISO14064-1 standard of certification, which postulate a voluntary participation of the involved organization. Such an inventory, which is the first case study in Europe in which the joint application of these methodologies is applied to a large government system $\left(3821 \mathrm{~km}^{2}\right)$, could also be repeated in similar contexts and this characteristic makes Siena Carbon Free a very innovative initiative (Bastianoni et al, 2014). ${ }^{24}$

Siena Province stated that it 'believes that $\mathrm{CO}_{2}$ emissions are one of the big environmental problems in the world and that it is an absolute priority to lower the level of $\mathrm{CO}_{2}$ emissions by the help and the involvement of the whole community because every community should feel responsible for emissions'. The reasons behind the decision to undertake the Siena Carbon Free 2015 project are as follows:

- ethical: answering the emergency to do something now to reduce emissions;

- political: involving diverse components of society;

- environmental: having positive effects on different environmental components;

- technical: the project is measurable and presupposes the development of technologies and solutions.

Regarding the aim of taking concrete actions to encourage the involvement of citizens, Siena Province has also stated that:

In 2012, Siena Province elaborated a strong Communication Plan that is very incisive: 200.000 euro are the committed resources to distribute information to the families, stakeholders and administrators, to the whole community about $\mathrm{CO}_{2}$ reduction. Through a radio-television campaign, brochures and meetings, Siena Province would like to get in touch with citizens, stakeholders and administrators to demonstrate the best practices to reduce $\mathrm{CO}_{2}$ in order to involve the whole community in the achievement of the carbon free goal. ${ }^{25}$

The Siena Carbon Free 2015 programme has been very successful and the goal of the project to absorb and offset ghg emissions that are produced in the whole province has been already reached (2013 on 2011 data), giving the Tuscan initiative the chance to become a reference model for other public authorities worldwide. 


\section{Has your national government taken any position on or otherwise encouraged individuals, businesses, organizations, subnational governments, or other entities that they have some ethical duty to reduce greenhouse gas emissions?}

The Italian Ministry for the Environment, Land and Sea has led an intensive programme on the environmental footprint of goods/services (carbon footprint and water footprint) to experiment on a large scale and optimize different evaluation systems of environmental performance, taking into account the differences of each economic sector, in order to harmonize and make them repeatable. ${ }^{26}$ Moreover, the initiative aims to identify companies' procedures of carbon management and to support the use of low-carbon content technologies and good practices in the manufacturing process. These activities represent:

- an environmental driver but also a competitive tool for the whole system of Italian companies, that takes into account the importance of the 'eco-friendly' requisites of products on the market;

- an important means for economic development towards a more sustainable economy;

- an opportunity to create a new awareness for users, to encourage increasingly responsible choices and good practices.

This effort to spread a more responsible use of products can be seen as a way to start to think about how important each citizen's choice is, and to increase solidarity behaviours. For instance, launched in July 2011, VIVA Sustainable Wine ${ }^{27}$ is a project conceived by the IMELS for 'made in Italy' sustainable wine to measure and improve the environmental quality of the production chain and to encourage eco-sustainability in the Italian wine industry. The wine industry represents a crucial sector in the national economy. Moreover, wine production plays a core role for Italian culture and for environmental protection, in close connection with the safety of products and the health of consumers, but it is also a sector which is very vulnerable to climate change.

Even though these initiatives have not been explicitly framed by ethical considerations, it is very interesting to note how both of them recognize some of the value of climate ethics - for instance, the need of transparency and of solidarity and, in the case of VIVA, also the importance of sustainable preservation of an industry, which has repercussions in the landscape, in the social arena, and in the cultural traditions of many Italian regions.

10. What recommendations would you make to get the nation or civil society to take ethics and justice issues seriously in climate change policy formulation?

Considering that we are talking about climate change 'ethics', I think it is crucial that we also should be aware of the moral responsibility that derives from our studies. It is very important not to talk about climate change ethics and justice only within research teams, in an academic context, or during experts' conferences. It is surely important to continue to study such an issue and strengthen our knowledge about it, but, at the same time, being aware of this knowledge, which is also starting to grow in the Italian academic scenario, we should share it with institutions and civil society. We cannot simply talk about ethics without also practising ethical behaviours.

Remaining in our offices, writing reports about the risks caused by climate change to social equity, gender issues, and intergenerational responsibility, will not be of any help in changing the situation. After having registered the minimal awareness of institutions about the topic, we have to assume responsibility ourselves and act accordingly. The Millennium Development Goals have already placed a focus on the interconnection between many issues within the climate change debate, and I believe 
this could be a good starting point for a wider debate about climate ethics. Acknowledging their 'moral duty' should commit researchers to educating students, first of all, but also communities, in general, to be aware of the important role that ethics and justice in climate change policies would have in leading to a better quality of life for present and future generations.

Firstly, researchers should start promoting and talking about such an issue within their network of personal and professional contacts. In this phase it is also important to create networks and partnerships not only between different departments of a university, but also between different universities and research centres, because knowledge cannot be fragmented and bureaucratic obstacles should be removed (Mercalli, 2013).

Secondly, even though it takes time and energy, it is important that researchers should commit their efforts to involving public institutions in the development of concrete projects. For instance, they could propose even a small initiative that, at the local level, would make some difference in terms of public awareness of climate ethics and justice. Improving citizens' awareness would lead to an easier involvement of public opinion in the decision-making process and this will lead also to better and shared policies.

Of course, as noted earlier, there are already some mechanisms for the involvement of civil society in the public decision-making process, but sometimes these mechanisms are only formalities, which do not have a big impact on final decisions. This has to be stopped and I believe that the stronger the interest of private citizens is within such a context, the stronger also will be the attention that institutions would give to citizens' comments or requests. 


\section{Notes}

1 A complete description of the Italian National System can be found in the document 'National Greenhouse Gas Inventory System in Italy. Year 2013', http://www.isprambiente.gov.it/en/publications/reports?set language=en, accessed 8 September 2014.

2 Legge 120/2002, Ratifica ed esecuzione del Protocollo di Kyoto alla Convenzione quadro delle Nazioni Unite sui cambiamenti climatici, fatto a Kyoto l'11 dicembre 1997 (GU n.142 del 19-6-2002 - Suppl. Ordinario n. 129), http://www.normattiva.it/uri-res/N2Ls?urn:nir:stato:legge:2002;120, accessed 15 September 2014.

3 European Commission, Climate Action, 'The 2020 climate and energy package', http://ec.europa.eu/clima/ policies/package/index en.htm, accessed 11 August 2014.

4 Decision No 406/2009/EC of the European Parliament and of the Council of 23 April 2009 on the effort of Member States to reduce their greenhouse gas emissions to meet the Community's greenhouse gas emission reduction commitments up to 2020, http://eur-lex.europa.eu/LexUriServ/LexUriServ. do?uri=OJ:L:2009:140:0136:0148:EN:PDF, accessed 8 September 2014.

5 Legge 4 giugno 2010, n. 96, Disposizioni per l'adempimento di obblighi derivanti dall'appartenenza dell'Italia alle Comunità europee - Legge comunitaria 2009. (10G0119) (GU n.146 del 25-6-2010 - Suppl. Ordinario n. 138), http://www.normattiva.it/uri-res/N2Ls?urn:nir:stato:legge:2010;96, accessed 11 August 2014.

6 White Paper of the Commission of the European Union, COM(2009) 147, 'Adapting to climate change: Towards a European framework for action', http://eur-lex.europa.eu/LexUriServ/LexUriServ.do?uri=COM:2009:0147:FI N:EN:PDF, accessed 16 September 2014.

7 Italian Ministry for the Environment, Land and Sea (IMELS), Elementi per una Strategia Nazionale di Adattamento ai Cambiamenti Climatici, Documento per la consultazione pubblica, 12 September 2013, http:// www.minambiente.it/sites/default/files/archivio/comunicati/Conferenza_29_10_2013/Elementi\%20per\%20 una\%20Strategia\%20Nazionale\%20di\%20Adattamento\%20ai\%20Cambiamenti\%20Climatici.pdf, accessed 11 August 2014.

8 For a definition of SME in the European context, see http://ec.europa.eu/enterprise/policies/sme/facts-figuresanalysis/sme-definition/index en.htm, accessed 8 September 2014.

9 Italian Climate Network Onlus, http://www.italiaclima.org/attivita/equita-intergenerazionale-il-think-tank/, accessed 31 July 2014.

10 Centro Euro-Mediterraneo sui Cambiamenti Climatici (CMCC), http://www.cmcc.it/it/, accessed 8 September 2014.

11 Fondazione Lanza, Studi e ricerche in Etica Applicata, http://www.fondazionelanza.it/it/, accessed 11 August 2014.

12 European Parliament Resolution of 20 April 2012 on women and climate change (2011/2197(INI)), http://www. europarl.europa.eu/sides/getDoc.do?pubRef=-//EP//TEXT+TA+P7-TA-2012-0145+0+DOC+XML+V0//EN, accessed 11 August 2014. In the same year, another Resolution (2012/2035(INI) of 11 September 2012) was adopted by the European Parliament, on 'Women and Green Economy', http://www.europarl.europa.eu/sides/ getDoc. do?type=REPORT\&reference=A7-2012-0235\&language=EN, accessed 11 August 2014.

13 Introduction of the Decision 406/2009/EC of the European Parliament and of the Council of 23 April 2009 (point 1). See above, note 4.

14 Point 2. See above, note 4.

15 Point 17. See above, note 4.

16 Ministry for the Environment, Land and Sea Sixth National Communication under the UN Framework Convention on Climate Change, Italy, December 2013, https://unfccc.int/files/national_reports/annex_i natcom/submitted_natcom/application/pdf/ita_nc6_resubmission.pdf, accessed 31 July 2014 .

17 Ministero degli Affari Esteri, Direzione Generale per la Cooperazione allo Sviluppo, 'LINEE GUIDA AMBIENTE', Settembre 2011, http://www.cooperazioneallosviluppo.esteri.it/pdgcs/Documentazione/Normativaltaliana/ Linee\%20Guida\%20Ambiente\%20CORRETTO.pdf, and Ministero degli Affari Esteri, Direzione Generale per la Cooperazione allo Sviluppo, The Italian Cooperation for Environment, 'The global context', http://www. cooperazioneallosviluppo.esteri.it/pdgcs/italiano/speciali/Speciale\%20Ambiente/Intro.Eng.htm, accessed 16 September 2014. 
18 The World Bank, Middle East and North Africa, 'Adaptation to Climate Change in the Middle East and North Africa Region', http://web.worldbank.org/WBSITE/EXTERNAL/COUNTRIES/ENAEXT/0,, contentMDK\%3A21596766 pagePK\%3A146736 piPK\%3A146830 theSitePK\%3A256299,00.html, accessed 31 July 2014; Cooperazione Italiana allo Sviluppo, http://www.cooperazioneallosviluppo.esteri. it/pdgcs/italiano/speciali/Clima/ltalia.htm, accessed 31 July 2014. There are different forms of funding and financial collaboration: 1) Since the Italian Ministry of Foreign Affairs has very close connections with MENA countries, and since the World Bank has a diverse loan portfolio and a range of projects across the MENA region, a dedicated office of the World Bank opened in Rome in 2001, so as to strengthen their common commitment in such an area. Moreover, a Technical Assistance Program was launched on May 2009: the World Bank, the government of Italy and the European Commission cooperate to address climate change in the region. The regional cooperation framework aims to assist countries in the Middle East and North Africa (MENA) region in making their development more resilient to climate change and less carbon intensive by focusing on adaptation, carbon emission reduction and knowledge sharing; 2) As a member of the UNFCCC, Italy also contributes to a World Bank fund that was developed during the Bali Conference and is specifically dedicated to adaptation to climate change; 3 ) Moreover, there is a general fund called Middle East and North Africa (MENA) Multi-Donor Trust Fund (MDTF): Italy is not one of the countries that participated at its establishment, but every country can collaborate and give its contribution to the fund.

19 Crea un clima di giustizia, Appello, http://www.cooperazioneallosviluppo.esteri.it/pdgcs/documentazione/ Report/2009-01-01_AppelloCreaClimaGiustizia.pdf. See also Fondazione Lanza, above, note 11, accessed 31 July 2014.

20 Italian Government, Presidenza del Consiglio dei Ministri, Statement by the Prime Minister of Italy, Mario Monti, to the United Nations General Assembly, http://www.governo.it/Presidente/Interventi/dettaglio. asp? $d=69280 \& p g=1 \% 2 C 2062 \% 2 C 4711 \% 2 C 7001 \% 2 C 9353 \% 2 C 11790 \% 2 C 13814 \% 2 C 13857 \& p g \_c=5$, accessed 16 September 2014.

21 Translation by the author of Matteo Renzi's statement addressed to the Italian Parliament (25 June 2014): 'Andremo, come Italia, al vertice delle Nazioni Unite, ma anche con una politica europea rispetto ai temi del climate change, dell'investimento su un ambiente diverso. L'Europa vuole avere la bandiera, anche in vista, poi, dell'appuntamento di Parigi del prossimo anno, di un investimento sulla green economy che non sia semplicemente uno spot a parole, ma sia la possibilità di un cambio di paradigma dello sviluppo economico.' Camera dei Deputati, http://www.camera.it/leg17/410?idSeduta=0251\&tipo=stenografico, accessed 31 July 2014.

22 Programme of the Italian Presidency of the Council of the European Union, http://italia2014.eu/media/1349/ programma en1_def.pdf, accessed 11 August 2014.

23 The non-commercial universal exposition that will take place in Milan, Italy, from 1 May to 31 October 2015, http://www.expo2015.org/en/index.html, accessed 16 September 2014.

24 Province of Siena, Siena Carbon Free, http://www.provincia.siena.it/Aree-tematiche/Energia/Siena-CarbonFree, accessed 11 August 2014. Siena Carbon Free is part of a wider project of the University of Siena (Ecodynamics Group) called REGES: Control and certification of the decrease of greenhouse gas emissions in the area of the Province of Siena, http://www.ecodynamics.unisi.it/?p=213\&lang=en, accessed 16 September 2014.

25 Province of Siena, Siena Carbon Free, 'Goal Reached’, http://www.provincia.siena.it/var/prov/storage/original/ application/395f72cc44c6d83188ca1d561cf453be.pdf, accessed 16 September 2014.

26 Ministry for the Environment, Land and Sea, The Italian Environmental Footprint Program, http://www. minambiente.it/pagina/italian-environmental-footprint-program, accessed 31 July 2014.

27 Valutazione dell'Impatto della Vitivinicoltura sull'Ambiente (VIVA) means 'assessment of the vineyard and wine production impact on the environment', http://www.viticolturasostenibile.org/Home.aspx, accessed 11 August 2014. 


\section{References}

Bastianoni, S., Pulselli, F. M., Marchi, M. et al (2014) 'The connection between 2006 IPCC GHG inventory methodology and ISO 14064-1 certification standard - A reference point for the environmental policies at sub-national scale', Environmental Science \& Policy, vol 44, pp97-107, http://www.sciencedirect.com/ science/article/pii/S1462901114001385, accessed 16September 2014

Bonazza, A. (2012) 'Impatto dei cambiamenti climatici sul patrimonio culturale', Istituto di Scienze dell'Atmosfera e del Clima, ISA - CNR - Bologna, Italy, http://www.minambiente.it/sites/default/files/archivio/allegati/vari/ incontro_27_02_2012_dgsec_bonazza.pdf, accessed 8 September 2014

Mercalli, L. (2013) 'The courage to jump into the fray', Ecoscienza, vol 5, http://www.arpa.emr.it/ecoscienza/rivista. asp?id=37, accessed 8 September 2014

Perrini, F. and Vurro, C. (2011) 'L'implementazione della CSR nei rapporti di filiera delle piccole e medie imprese. Un'analisi quantitativa del contesto italiano', Punto di Contatto Nazionale, DGPIC, Centro CReSV, Università Commerciale Luigi Bocconi, http://pcnitalia.sviluppoeconomico.gov.it/download/ricerca-bocconi-su-csrpmi-e-filiere.pdf, accessed 8 September 2014

Rangone, N., Ziller, J. et al (2013) Policies and Regulations for Local Sustainable development. The Covenant of Mayors, Editoriale Scientifica, Napoli 



\section{Japan's Consideration of Ethics and Justice Issues in Formulating Climate Change Policies}

Kathryn A. Gwiazdon

This report responds to the research questions of the Project On Deepening National Responses to Climate Change On The Basis of Ethics and Justice, a joint project of the University of Auckland, School of Architecture and Planning and Widener University, School of Law, Environmental Law Center. The research questions and responses are as follows:

1. To what extent has the national debate about how the nation should respond to climate change by setting a ghg emissions reduction target expressly considered that the nation not only has economic interests in setting the target but also ethical obligations to those who are most vulnerable to climate change and that any national ghg emissions reduction target must represent the nation's fair share of safe global emissions? In answering this question, identify the national ghg emissions reduction target, if any, that the nation has committed to under the United Nations Framework Convention on Climate Change (UNFCCC).

Japan has been a world leader in responding to climate change since hosting the Kyoto Protocol in 1997. Its adaptation and mitigation strategies largely focus on three main areas:

(1) reducing ghg emissions publicly, privately, nationally and internationally, in harmony with nature, and while realizing a sustained economic growth;

(2) actively promoting international cooperation in order to share knowledge, technology and experience; and

(3) leading the field in the technological innovation that responds to climate change. (Ministry of the Environment, Government of Japan, 2013, 2014)

Domestically, Japan has a strong legal foundation to address climate change, including numerous state and local programmes and policies. Internationally, the state remains an active party in international negotiations and treaties relating to climate change, as well as providing immense financial and technological assistance to developing nations. Much of Japan's success in the climate change debate seems to be due to the integration of the private and public sectors in addressing climate change and the numerous public awareness campaigns that are linked to Japanese culture and a respect for nature.

Japan's climate change policies show an explicit understanding of the ethical considerations in the climate change debate, including but not limited to protecting cultural heritage and recognizing the rights of future generations. In 1998 Japan passed the Law Concerning the Promotion of Measures to Cope with Global Warming. The purpose of the law is to acknowledge the responsibilities of government, businesses and individuals in responding to climate change on a global and local level in order to ensure the health and culture of present and future generations. The law states that it is the responsibility of businesses to highlight and enhance 'sinks', or ghg emissions reduction programmes, and it is the responsibility of individuals to limit ghg emissions in their daily lives. In 2009, when announcing the Hatoyama Initiative, a programme to give financial assistance to developing nations 
that are vulnerable to climate change, Japanese Prime Minister Yukio Hatoyama stated: 'Political leaders have a responsibility to future generations to create a sustainable society by transforming the social structure that we have known since the industrial revolution' (Ministry of Foreign Affairs, 2009, and Japan International Cooperation Agency, 2009).

The Foreword of the Fourth Basic Environment Plan, first drafted in 1993, states:

There is a growing need to reconsider our values placing too much emphasis on the pursuit of material wealth, and the prevailing socioeconomic activities and lifestyles marked by mass-production, massconsumption, and mass-disposal. It is the present generation's obligation to pass on to the future generations a well conserved and healthy environment, both globally and domestically. This obligation applies to all humankind. (Ministry of the Environment, 1993)

The main body of Japanese environmental law, with the foundation being the Basic Environment Law, also highlights Japan's view that environmental conservation is a global responsibility and that individuals, as well as businesses and nations, have a fair share of the burdens. The Fourth Basic Environment Plan emphasises fair and equitable cost-bearing between generations, regions and entities, as well as the importance of strengthening the community through intergenerational interaction. Other ethical underpinnings include the recognition that society is deeply interconnected and interdependent, and that technological development and scientific knowledge is key to achieving success in environmental conservation. This newest version of the Basic Environment Plan also adds important post-Fukushima policy measures.

Japan was well on its way to achieving its Kyoto Protocol targets prior to the Tōhoku earthquake and tsunami, or the Great East Japan Earthquake of 2011, and the corresponding Fukushima nuclear disaster. In fact, Japan achieved an $8.2 \%$ reduction target of 1990 levels for the first commitment period under the Kyoto Protocol (which set reduction targets at 6\% for 2008-2012). The earthquake, however, damaged several nuclear reactors, leading to a decrease in nuclear energy and an increase in coal energy. Coal energy increases ghg emissions, while at the same time raising energy costs. Due to these major shifts in energy policy, in November 2013 at the COP19 in Warsaw, Japan announced its abandonment of the Kyoto Protocol targets (25\% of the 1990 level by 2020) and instead set a more realistic target of 3.8\% reduction of the 2005 level by 2020 (The Star Online, 2013). Even this figure is not firm, however, as the emissions reduction effect of nuclear energy continues to be analysed (Ministry of the Environment, 2013, 2014). To date, Japan has not accepted the Doha Amendment to the Kyoto Protocol, which formalizes the second commitment period of the Kyoto Protocol, 20132020. However, Tokyo was selected as the host of the 2020 Olympic Games, and hopes to show the world that it is possible to be a low-carbon, yet economically strong, society that lives in harmony with nature (Ishihara, 2013). In addition, Japan will continue to pursue the goal of $80 \%$ reduction in ghg emissions by 2050 , as stated by its Fourth Basic Environment Plan, and as required of industrialized nations under the UNFCCC; and remains committed to the $50 \%$ global reduction target by 2050 .

In order to halve global emissions by 2050 , Japan is implementing the Building a Low Carbon Society towards 2050 Project, which states that all countries, organizations and entities have to take action based on the following philosophies:

(1) carbon minimization in all sectors;

(2) a revolution toward a simpler way of life that realizes a richer quality of life, away from mass-consumption, and building a new society in which value is placed on family and community ties, 
health, interactions with mother nature, and in the 'Mottainai' spirit (meaning it is a shame to let something go to waste without realizing its full potential); and

(3) co-existence with nature, where local communities place importance on harmony with nature and promote nature-friendly technologies. (Ministry of the Environment, 2007)

The UN Development Program (UNDP) notes that developing countries, and the poorest people who live in them, are the most vulnerable to climate change. Since 2008, Japan has hosted and funded the Cool Earth Partnership, a UNFCCC programme that gives loans and technical assistance to Small Island Developing States and Least Developed Countries. More recently, Prime Minister's Shinzo Abe's diplomatic strategy 'Actions for a Cool Earth' highlights technological potential, leadership and partnership across the globe (Ministry of the Environment, 2013, 2014). Japan's responses to climate change expressly consider obligations to vulnerable nations, but it is difficult to find express consideration of vulnerable individuals or communities within Japan. The state does account for climate change's effect on the fishing industry, rice yields, imported food and food costs, changing cherry blossom seasons (affecting culture), as well as the increase in floods and typhoons (for example, Hiroshima mudslides in 2014), guerrilla storms over Tokyo's 'heat island', increased heat waves and overall temperatures (for example, the increase in mosquitos and dengue fever in Tokyo in 2014), and so forth. It seems to be silent, however, on the socio-economic issues inherent in the climate change debate. (See, generally, Ministry of Education, Culture, Sports, Science and Technology, Japan Meteorological Agency, Ministry of the Environment, 2012.)

It is important to note that this silence does not seem to be particular to the climate change debate, and so may be more indicative of the culture choosing not to highlight socio-economic problems, as opposed to the culture not considering vulnerable people. Indeed, it is very clear throughout the environmental policy that all people are considered. The Japanese are a very proud and honourable people, and historically do not tend to bring attention to what may be seen as a weakness to those outside of Japan (for example, identifying a vulnerable sector within Japan that needs particular attention). Panhandling, for instance, is considered shameful and is therefore rarely seen. The poor are simply not as visible as in other nations, but that does not mean that they do not exist. Even with something as potentially disastrous as Fukushima, Japan has appeared hesitant to highlight failure in order to seek assistance.

Although Japan has not made an explicit connection between its climate change policies and protecting vulnerable people (it has acknowledged vulnerable habitats and industries) within Japan, the laws, culture and actions of the Japanese people show a very real concern for the protection of all life, regardless of station (for instance, vulnerable) and regardless of reason (for instance, climate change). Of course, it would be helpful for the national and international debate if Japan were to make such an explicit connection, as the culture and livelihoods of the islands and communities of Okinawa Prefecture, the poorest prefecture in Japan, and the thousands of islands and communities within the Ryukyu (or Nansei) Islands, are all particularly, and perhaps disproportionately, threatened by climate change. However, as long as Japan continues to promote a responsibility of all, to all, perhaps actions are better than words.

In March 2014 Japan launched a new climate change campaign called 'Fun to Share' (Ministry of the Environment, 2014). Although it acknowledges that, unfortunately, much of the international climate change debate calls for grave restraint and predicts a future full of struggle, the Fun to Share programme wants to show that, through the sharing of knowledge and technology (or 'lifestyle innovations'), people can still enjoy their daily lives while supporting a low-carbon society. The following excerpt from 
the campaign launch anticipates a nation actively embracing climate change action, for the enjoyment and benefit of all:

Please imagine the future, a couple of decades from now. Imagine the town you currently live [in] is overflowing with green. The children are even more energetic than they are now, running around actively. You feel at peace under the greenery with your loved ones. Also imagine the future in which the northeast coast of Japan is again surrounded by rich nature and filled with people's laughter. Let's share our wishes and make the earth's future a wonderful one that we create together. We hope you also start your own 'Fun to Share' everyday life to realize a low-carbon society! (Ministry of the Environment, 2014)

\section{In making a national commitment to reduce ghg emissions under the UNFCCC, to what extent, if at all, has the nation explained how it took equity and justice into consideration in setting its ghg emissions reduction target?}

Unfortunately, the terms 'justice' and 'equity' are largely absent from official government documents concerning climate change, unless it is in relation to fairness in the application of any international framework to all participating major economies. For example, in the submission of its Sectoral Approach to the Bali Action Plan, Japan states: 'In order to make such national actions globally ambitious and sustainable, it is indispensable to ensure equity based on the principle of common but differentiated responsibilities [CBD] and respective capabilities' (Government of Japan, 2008). However, as with many other developed nations, reference to the CBD principle seems to be more for purposes of accounting for historical and present emissions, as well as the capabilities of vulnerable nations, as opposed to any promotion of climate justice.

One growing concern for Japan where issues of equity are starting to become more prevalent is the impact of climate change on its food systems. This may be an area of opportunity for the climate justice debate. Weather changes are already affecting the quality of rice yields and the quantity and quality of marine life. Japan currently imports more than $60 \%$ of its food, and imported food means increased costs, so raising the question of not only who can afford food, but who can afford diversity in food choices? At the same time as the costs of imported food is rising, local and organic foods are becoming trendy and popular among younger, wealthier generations (younger and wealthier because they are living with their parents longer), thereby raising the costs of local foods. This is unfortunately opening the door to Western-style, inexpensive and largely unhealthy food options for the average citizen. The result is that life expectancies are gradually lowering, such as in Okinawa. The Okinawan community and diet was once hailed as the healthiest on the planet. However, in 2013, its women lost their number one spot for the first time since 1975, and the life expectancy of its men has been plummeting for several years (as of 2013, they are now 30th in the nation) (Japan Update, 2013). Okinawa is not only the poorest prefecture, but also has a large number of Americans due to the military bases, and therefore a large number of Western fast-food restaurants. So, if one response to climate change is for a government to promote local foods (to avoid large field acquisitions, the mass spraying of pesticides, a low-carbon footprint regarding travel, and so on), what if the locals cannot afford the local foods?

It is important to look at these topics as potential opportunities to expand the climate justice debate, as Japan has achieved great success in its public campaigns to inform and engage individuals (for example, Team Minus $6 \%$ or Fun to Share). Around $98 \%$ of respondents in a 2007 survey agreed that climate change was either a 'very serious problem' or a 'somewhat serious problem' (British Embassy, Tokyo, 2014). With such a strong base of civil society aware of the seriousness of climate change, there is great potential to further inform them about issues concerning climate justice. 
3. Given that any national ghg emissions target is implicitly a position on achieving an atmospheric ghg concentration that will avoid dangerous climate change, to what extent has the nation identified the ghg atmospheric concentration stabilization level that the national emissions reduction target seeks to achieve in cooperation with other nations?

Japan acknowledges its global responsibility for reducing ghg emissions, its role in current levels, and its role in historical emissions. When speaking on global responsibility, Japan also tends to highlight the main emitters, particularly its neighbour China as well as the United States, the two nations that are responsible for $40 \%$ of the world's $\mathrm{CO}_{2}$ emissions and more than one third of global ghg emissions. 'Japan's Climate Change Policies' (2014) states that Japan is responsible for $3.8 \%$ of the world's $\mathrm{CO}_{2}$ emissions and $2.7 \%$ of global ghg emissions, ranking it 5th and 7th, respectively (Ministry of the Environment, 2013, 2014).

Japan did a thorough assessment of its global, local and corporate targets in 2007 and concluded that 'we have the result of Japan's required share of GHG emissions reduction in 2050, which is between $40 \%(37 \%)$ and $90 \%(93 \%)$. It is inevitable for an issue with scientific uncertainty to have a range' (Criteria (Target-Setting) Team, 2007).

Japan is currently creating frameworks beyond the 2-degrees mark in its National Adaption Plan to be launched in the summer of 2015. This plan encompasses risk management and collaboration with local governments (looking at climate, geography, culture) (Nomoto, 2014).

4. Given that any national ghg emissions target is implicitly a position on the nation's fair share of safe global emissions, to what extent has the nation identified the ethical and justice considerations that it took into account in allocating a percentage of global ghg emissions to the nation through the identification of a ghg emissions reduction commitment?

To date, it appears that Japan has not explained the ethical and justice considerations it took into account in developing its $3.8 \%$ reduction target of 2005 levels. However, the 2007 report by the TargetSetting Team does advance a 'multilateral target-setting scenario', which considers equity, equality and justice as important values. The document takes into account not only the emissions and targets of other nations, but several political scenarios, and concludes that global safe targets can be met, 'when an equity or justice idea prevails throughout the world' (Criteria (Target-Setting) Team, 2007).

5. To what extent, if at all, has the nation acknowledged that nations emitting ghg above their fair share of safe global emissions have a responsibility to fund reasonable adaptation measures or unavoidable losses and damages in poor developing countries?

'Developing countries will have to bear the brunt of the further impacts of climate change, although they have historically contributed the least to the greenhouse gases in the atmosphere today,' said Yuri Onodera of Friends of the Earth Japan (Friends of the Earth International, 2014).

As noted above, international cooperation is one of the three main tiers of climate change policy in Japan. It includes loans to developing nations, as well as sharing information and technology. This immense financial and technical support shows Japan's commitment to lowering total global ghg emissions, but it is unclear if the support is to directly compensate for its own high levels. Japan currently ranks 5 th in the world for its $\mathrm{CO}_{2}$ emissions and 7th for its global ghg emissions. 
Since 2009, Japan has funded the Cool Earth Partnership, a UNFCCC programme that gives loans and technical assistance to Small Island Developing States and Least Developed Countries. International assistance seems to be the one area in Japan's climate change policy framework that expressly highlights socio-economic issues. It pays particular attention to disaster prevention, water and food security (UNFCCC, 2014 and Ministry of Foreign Affairs, 2014).

Much of its philosophy is based upon the concept that low-carbon lifestyle models (whether in an individual's daily life or a company's technological development) already exist in Japan, and it is the responsibility of the Japanese to be a leader, highlight these models and share them across the world. This desire to lead may also provide a great opportunity for the climate justice debate, as if Japan is more explicitly aware of the ethical considerations of climate change, it will want to share them with the world.

Japan is also promoting the establishment and implementation of the 'Joint Crediting Mechanism (JCM)' in which it facilitates the diffusion of advanced low-carbon technologies, products, systems, services and infrastructure as well as implementation of mitigation actions, and contributes to sustainable development of developing countries. Japan has held consultations for the JCM with developing countries since 2011 and signed the bilateral document for the JCM with Mongolia, Bangladesh, Ethiopia, Kenya, Maldives, Vietnam, Lao PDR, Indonesia, Costa Rica and Palau (Ministry of the Environment, 2013, 2014).

Japan also continues to provide substantial funds for climate change research, as well as develop laws and incentives for its major industries to advance low-carbon technology.

6. What formal mechanisms are available in the nation for citizens, NGOs and other interested organizations to question/contest the nation's ethical position on climate change?

There are innumerable active national and local climate change campaigns, across all sectors. Due to the already high public awareness of the seriousness of climate change, finding a formal medium to voice concern over the nation's policy is not difficult. After all, some of the most important aspects of Japanese culture, life and wellbeing are also being visibly affected by climate change: for example, the cherry blossom tree, marine life and rice quality. At the highest levels, the Ministry of the Environment and the Ministry of Foreign Affairs each handle climate change policy and are responsive to citizen inquiry. News sources often cover climate change, and are not hesitant to link extreme weather patterns, heat and health problems, severe typhoons, dengue fever outbreaks, and so forth, to climate change. Environmental and climate change NGOs are prevalent, and each of them has particular avenues for public and private campaigns. Japan is truly leading the world in climate change awareness, which is the first step to climate change action.

7. How is the concept of climate justice understood by the current government? Have they articulated any position on climate justice issues that arise in setting ghg emissions policy or in regard to the adaptation needs of vulnerable nations or people?

No formal government documents (in English) could be found which specifically discuss climate justice. Implicit and explicit considerations are discussed above.

8. Are you aware of any regional, state, provincial, or local governments in your country that have acknowledged some ethical responsibility for climate change? If so, what have they said? 
No formal local government documents (in English) could be found which specifically discuss ethical responsibility for climate change. Implicit and explicit considerations are discussed above.

9. Has your national government taken any position on or otherwise encouraged individuals, businesses, organizations, subnational governments, or other entities that they have some ethical duty to reduce greenhouse gas emissions?

Implicit and explicit considerations are discussed above.

10. What recommendations would you make to get the nation or civil society to take ethics and justice issues seriously in climate change policy formulation?

As such a large proportion of Japanese society is already aware of the seriousness of climate change, the next step would be to follow up the success of several of the public campaigns and connect climate justice (information and action steps) to the daily life of the average citizen. This initiative would also require strong political leadership to begin the process. NGOs and local government action would naturally follow, as was the process with climate change policy development.

The most important aspect would be to accentuate the ethical issues in the existing climate change debate. For example, to highlight:

(1) the food crisis in relation to the quality and quantity of marine life and rice yields, as well as the increased costs of exports and the increased costs of local, organic foods;

(2) the food crisis in relation to life expectancy, in which Japan is currently a world leader and should fight to remain so;

(3) how climate change is affecting the cultural identity and spirituality of the Japanese, including the changing cherry blossom trees and closeness, respect for and harmony with nature (humans are harming such a powerful symbol of Japanese culture); and

(4) the role of nuclear energy and viable sustainable alternatives post-Fukushima.

The Great East Japan Earthquake of 2011 triggered huge changes in Japan's energy policy, yet it also raised awareness about energy and global warming. The opportunity should not be lost to also raise important climate justice considerations. In raising these issues, it is also important to highlight what makes Japan proud, and an important tier in its climate change policy: technological innovation. For example, in late 2013, Japanese company Kyocera finished construction on the Kagoshima Nanatsujima Mega Solar power plant, the world's first floating solar power plant; and in late 2014, two more development projects were announced. This type of innovation could be announced hand in hand with the implications it has for climate justice, as a viable alternative to nuclear power. 


\section{References}

British Embassy, Tokyo (2014) 'Climate Change: Impacts on Japan', www.natureasia.com/ja-jp/advertising/ sponsors/climate-change/policy

Criteria (Target-Setting) Team (2007) Interim Report of Criteria (Target-Setting) Team: Japan's GHG Emissions Reduction to be required in 2050, Japan Low Carbon Society towards 2050 Project, http://2050.nies.go.jp/ report/midterm/file/S-3-2_MidtermReport_e.pdf

Friends of the Earth International (2014) 'Scientists expected to warn of more extreme weather due to climate change', 26 March, http://www.foei.org/news/scientists-expected-to-warn-of-more-extreme-weather-dueto-climate-change/

Government of Japan (2008) 'Submission on Sectoral Approach [to the Bali Plan]', http://unfccc.int/files/kyoto_ protocol/application/pdf/japan_sectoralapproach_rev.pdf

Government of Japan (2013) Japan's First Biennial Report under the United Nations Framework Convention on Climate Change, https://www.env.go.jp/en/focus/docs/files/20140319-82.pdf

Ishihara, Nobuteru (2013) 'Statement by Nobuteru Ishihara, Japanese Minister of the Environment, at COP19/ CMP9', www.env.go.jp/en/earth/cc/statement131120.pdf

Japan International Cooperation Agency (2009) 'JICA and Climate Change: From the Latest Satellite Technology to Wind Farms in Africa', www.jica.go.jp/english/news/focus_on/climate/climate_1.html

Japan Update (2013) 'Okinawa women lose No. 1 spot in life expectancy', March 7, http://www.japanupdate. com/2013/03/okinawa-women-lose-no-1-spot-in-life-expectancy/

Major, Jon (2014) 'Japan: "solar islands” replace nuclear power', The Ecologist, 13 September, http://www. theecologist.org/News/news_round_up/2550618/japan_solar_islands_replace_nuclear_power.html

Ministry of Education, Culture, Sports, Science and Technology, Japan Meteorological Agency, Ministry of the Environment (2009) Synthesis Report on Observations, Projections, and Impact Assessments of Climate Change: Climate Change and Its Impacts in Japan, http://www.env.go.jp/en/earth/cc/report_impacts.pdf

Ministry of Education, Culture, Sports, Science and Technology, Japan Meteorological Agency, Ministry of the Environment (2012) Consolidated Report on Observations, Projections and Impact Assessments of Climate Change: Climate Change and Its Impacts on Japan FY2012, http://www.env.go.jp/en/earth/cc/impacts FY2012.pdf

Ministry of the Environment, Government of Japan (1993) Law No. 91: Basic Environment Law, http://www.env. go.jp/en/laws/policy/basic/index.html

Ministry of the Environment, Government of Japan (1998) Law No. 117: Law for Promotion of Countermeasures to Global Warming, www.env.go.jp/en/laws/global/warming

Ministry of the Environment, Government of Japan (1993) 'The Basic Environment Plan: Foreword', http://www. env.go.jp/en/policy/plan/basic/foreword.html

Ministry of the Environment, Government of Japan (2007) 'Building a Low Carbon Society: First Draft', https:// www.env.go.jp/earth/info/pc071211/en.pdf

Ministry of the Environment, Government of Japan (2009) 'Third Basic Environment Plan', http://www.env.go.jp/ en/policy/plan/3rd_basic/outline.pdf

Ministry of the Environment, Government of Japan (2010) Japan's Fifth National Communication under the United Nations Framework Convention on Climate Change, http://www.env.go.jp/en/earth/cc/framework.html

Ministry of the Environment, Government of Japan (2012) ‘Fourth Basic Environment Plan', http://www.env.go.jp/ en/focus/docs/files/20120427-01_01.pdf

Ministry of the Environment, Government of Japan (2013), 'Warsaw Climate Change Conference', http://www.env. go.jp/en/earth/cc/cop19_summary.html

Ministry of the Environment, Government of Japan (2013, 2014) 'Japan's Climate Change Policies', http:// www.env.go.jp/en/focus/docs/files/20130412-68.pdf (2013) and http://www.env.go.jp/en/focus/docs/ files/20140318-83.pdf (2014) 
Ministry of the Environment, Government of Japan (2014) 'Launch of a New Climate Change Campaign, "Fun to Share"', http://www.env.go.jp/en/focus/140521.html and http://funtoshare.env.go.jp/

Ministry of Foreign Affairs, Government of Japan (2009) 'Japan's Official Development Assistance White Paper 2009, Part I, Chapter 3, Section 1', www.mofa.go.jp/policy/oda/white/2009/html/honbun/b1/s3_1

Ministry of Foreign Affairs, Government of Japan (2014) 'Financial Mechanism for “Cool Earth Partnership”', http:// www.mofa.go.jp/policy/economy/wef/2008/mechanism.html

Ministry of Foreign Affairs, Government of Japan (2014) 'Statement by Prime Minister Shinzo Abe at the Plenary Session of the UN Climate Summit 2014', http://www.mofa.go.jp/ic/ch/page3e_000235.html

Nomoto, Takuya (2014) 'IPCC Fifth Assessment Report (Impacts, Adaptation and Vulnerability)', Japan Environment Quarterly, vol 6, June, www.env.go.jp/en/focus/jeq/issue/vol06/topics.html\#c1

The Star Online (2013) 'Japan drastically scales back greenhouse gas emissions target', 15 November, www. thestar.com.my/News/Regional/2013/11/15/Japan-drastically-scales-back-greenhouse-gas-emissionstarget/

UNFCCC (2014) 'Funding Options for Adaptation: Cool Earth Partnership', http://unfccc.int/adaptation/ workstreams/implementing_adaptation/items/4884.php 



\section{Kenya's Consideration of Ethics and Justice Issues in Formulating Climate Change Policies}

\section{Martin Oulu}

This report responds to the research questions of the Project On Deepening National Responses to Climate Change On The Basis of Ethics and Justice, a joint project of the University of Auckland, School of Architecture and Planning and Widener University, School of Law, Environmental Law Center. The research questions and responses are as follows:

1. To what extent has the national debate about how the nation should respond to climate change by setting a ghg emissions reduction target expressly considered that the nation not only has economic interests in setting the target but also ethical obligations to those who are most vulnerable to climate change and that any national ghg emissions reduction target must represent the nation's fair share of safe global emissions? In answering this question, identify the national ghg emissions reduction target, if any, that the nation has made under the United Nations Framework Convention on Climate Change (UNFCCC).

In response to the threat posed by climate change, Kenya developed a National Climate Change Response Strategy (NCCRS) in 2010. This was followed in 2013 by the National Climate Change Action Plan (NCCAP), a five-year plan to operationalize the NCCRS. A draft Climate Change Bill (2012) driven primarily by Civil Society Organizations (CSOs) under the auspices of the Kenya Climate Change Working Group (KCCWG) has also been presented and discussed in Parliament, but is yet to be passed into law. The country ratified the UNFCCC on 30 August 1994, and acceded to the Kyoto Protocol on 25 February 2005. Being a developing country and, therefore, part of Non-Annex I countries, Kenya has no legally binding greenhouse gas (ghg) emissions reduction targets under the UNFCCC. However, under the Copenhagen Accord, developing countries are to identify and report on Nationally Appropriate Mitigation Actions (NAMAs) in the context of sustainable development. NAMAs refer to any action that reduces emissions in developing countries and is prepared under the umbrella of a national governmental initiative (UNFCCC, 2014a). They can be policies directed at transformational change within an economic sector, or actions across sectors for a broader national focus. NAMAs are supported and enabled by technology, financing and capacity-building, and are aimed at achieving a reduction in emissions relative to 'business as usual' emissions in 2020 .

Kenya is seeking support for the implementation of a NAMA for accelerated geothermal electricity development (Falzon et al, [2014]; UNFCCC, 2014b). This is the first and only fully developed NAMA proposal by the country, and is based on scenarios developed in the 2013 Action Plan. This particular NAMA is expected to contribute to directly abating approximately $3.77 \mathrm{MtCO}_{2}$ e per year in 2020 , and require an estimated US $\$ 4.25$ billion to fully implement. Its implementation is, however, aspirational as it is conditional on financing, technology transfer and capacity-building support from the private sector and international community. In general, the NCCAP identifies six mitigation sectors, namely: energy, transport, industry, agriculture, forestry, and waste management, each with several low-carbon development options and abatement potential. The government of Kenya hopes to develop these into implementable NAMAs in the near future (GoK, 2013). 
Although not obligated to set any binding ghg reduction targets, being a Party to the UNFCCC, Kenya is still bound by the relevant principles and provisions of the Convention. This includes Article 3(1) which states that 'The Parties should protect the climate system for the benefit of present and future generations of humankind, on the basis of equity and in accordance with their common but differentiated responsibilities and respective capabilities' (emphasis added). Kenya's National Climate Change Response Strategy is critical of the Copenhagen Accord as having omitted the clause relating to 'historical responsibility', terming this 'a great violation of one of the key principles of the UNFCCC' (GoK, 2010a, p26). Nevertheless, it argues that 'it is perhaps a good move forward in trying to find a solution to the climate crisis. This is because current climate science tells us that much more (in terms of mitigation) still needs to be done if we are to escape the worst effects of climate change; hence the compelling need to involve both developed and developing countries in mitigation' (GoK, 2010a, p26). This demonstrates the country's selfless and strong view of its own ethical obligations to play its part in safeguarding the climate system, no matter the historical responsibility of the developed countries. It also underscores the country's view that reducing global ghg emissions requires a global partnership between both developed and developing countries, whether these are binding or voluntary. Indeed, several studies have indicated that the developing country mitigation pledges could amount to more mitigation than developed country pledges (for example, Kartha and Erickson, 2011; Oulu, 2014).

A case can be made that because of its negligible historical contribution to global ghg emissions, low current per capita emissions, serious vulnerability to climate change, high poverty levels and low adaptive capacity, any ghg reduction measure undertaken by Kenya can be considered as representing its fair share of safe global emissions. This stems from the arguments and rationale advanced by the drafters and Parties to the UNFCCC which classified Kenya and other developing countries as NonAnnex I countries with no legally binding ghg emissions reduction targets. Therefore by taking ghg emissions reduction actions even though they do not have to under the UNFCCC, the country is, by implication, considering its ethical obligations to those who are most vulnerable to climate change, some of whom happen to be its own citizens, but also includes those in other developing countries. Indeed, Kenya's express consideration of its ethical obligations beyond its own citizens can be seen from its justification for undertaking mitigation action. The Action Plan states that 'transitioning to a low-carbon development pathway would ensure that the country's contribution to global emissions remains low and, importantly, ... . demonstrates Kenya's leadership in the global fight against climate change' (GoK, 2013, p63). It is important to keep in mind that for quite some time, and even to date, mitigation is rarely a priority area of focus for many developing countries, at least as compared to adaptation.

In summary, Kenya's voluntary ghg emissions reduction target in its proposed NAMA and identified mitigation measures outlined in its National Climate Change Action Plan, although not expressly so stated, can be seen as considering its ethical obligations in the following ways:

(1) The mitigation actions it seeks to undertake are aimed at contributing to the sustainable development of its citizens, a majority of whom are poor and very vulnerable to climate change.

(2) By undertaking emissions reduction actions even though they do not have to under the UNFCCC in order to 'demonstrate global leadership in the fight against climate change', the country is demonstrating its ethical and moral responsibility to reduce ghg emissions no matter its historical or current contribution, and awareness that the eventual beneficiaries are those most vulnerable to climate change wherever they may be, and future generations. 
(3) By claiming financial, technological, and capacity assistance from the developed world which bears significant historical responsibility, Kenya is, by implication, ensuring that the Annex I countries acknowledge and honour their ethical obligations to those most vulnerable to climate change.

2. In making a national commitment to reduce ghg emissions under the UNFCCC, to what extent, if at all, has the nation explained how it took equity and justice into consideration in setting its ghg emissions reduction target?

There is no direct explanation of how equity and justice has been considered in setting the ghg emissions reduction target in Kenya's single NAMA, or proposed mitigation strategies. However, linking the country's proposed NAMA back to its National Climate Change Action Plan accentuates certain statements which can be construed as explanatory of how equity and justice considerations have been taken into account. The NCCAP states that building climate resilience in as low-carbon a way as possible will help Kenya achieve sustainable development and meet its long-term development goals since action on climate change and development are interlinked. It underscores the point that a low-carbon climate resilient development pathway should be tailored to the country's unique circumstances, while noting that Kenya has little historical or current responsibility for global climate change. In particular, the Action Plan declares that the country's mitigation (and adaptation) actions are aimed at '[i]mproving lives of the poor and vulnerable' since '[t]he human impacts of climate change are often experienced most acutely by the poor, who are often women and children' (GoK, 2013, p27). Apart from reducing ghg emissions, increasing the share of geothermal power can provide lowcost base load generation while facilitating economic activity and development, such as increased access to energy (Falzon et al, [2014]). Moreover, the NAMA and ghg emissions reduction efforts will contribute to the implementation of the Constitution of Kenya which guarantees every Kenyan the right to a clean and healthy environment.

Although the mitigation actions are primarily geared towards benefiting Kenyan citizens, there is direct reference to the poor and most vulnerable in terms of their special status and how the mitigation actions stand to benefit them. Moreover, it should be appreciated that the benefits of the actions in terms of reduced global ghg emissions are not confined to Kenya's territorial borders, but extend to other poor and vulnerable developing countries, a perspective which is reinforced by the country's commitment to demonstrate global leadership through its climate change actions. The mitigation actions also have an intergenerational equity perspective as future generations also stand to benefit.

3. Given that any national ghg emissions target is implicitly a position on achieving an atmospheric ghg concentration that will avoid dangerous climate change, to what extent has the nation identified the ghg atmospheric concentration stabilization level that the national emissions reduction target seeks to achieve in cooperation with other nations?

Kenya largely ascribes to the ghg atmospheric concentration stabilization levels endorsed by the Intergovernmental Panel on Climate Change (IPCC), the scientific advisory arm of the UNFCCC. The NCCRS makes reference to Article 2 of the UNFCCC as calling on world governments 'to take action aimed at reducing and stabilizing concentrations of GHGs "in the atmosphere at a level that would avoid dangerous anthropogenic interference with the climate system"' (GoK, 2010a, p23). The NCCRS further makes reference to and acknowledges the Copenhagen Accord as having adopted 'the widely accepted scientific view that global temperature increase by 2100 should not exceed $2^{\circ} \mathrm{C}$, which is 
considered the safe upper limit' (Gok, 2010a, p26). Nevertheless, the NCCRS stresses that many are of the opinion that the reduction targets under the Copenhagen Accord are still likely to overshoot the global average temperature increase beyond the desired $2^{\circ} \mathrm{C}$, and is cognizant of the fact that some climate models show that the current emissions pathway leads us to a much warmer world of $3^{\circ} \mathrm{C}$ and upward. This means that while Kenya's efforts, both domestically and globally in cooperation with other nations, are geared towards attaining the 'widely accepted' desired global atmospheric stabilization level of not more than $2^{\circ} \mathrm{C}$ rise in temperatures, it is aware that this might not be adequate, and opines that much more, beyond the Copenhagen Accord reduction targets and pledges, should be done.

4. Given that any national ghg emissions target is implicitly a position on the nation's fair share of safe global emissions, to what extent has the nation identified the ethical and justice considerations that it took into account in allocating a percentage of global ghg emissions to the nation through the identification of a ghg emissions reduction commitment?

Refer to the answer to the first question.

5. To what extent, if at all, has the nation acknowledged that nations emitting ghg above their fair share of safe global emissions have a responsibility to fund reasonable adaptation measures or unavoidable losses and damages in poor developing countries?

As already mentioned, Kenya generally ascribes to the principles, policies and strategies proposed or endorsed by the IPCC and UNFCCC. The NCCRS states that adaptation 'is both a matter of need and equity' (GoK, 2010a, p25). It explains the need aspect on the basis of the fact that the negative impacts of climate change fall disproportionately on those least able to bear them. The Strategy also notes that '[t]he debate around adaptation covers what should be done, how much it will cost, who should pay for it, and how much such payments should be distributed, managed and accounted for' (emphasis added) (GoK, 2010a, p24). The country's answer to 'who should pay for it' is implied from its note of the existence of and intention to benefit from the two funds under the UNFCCC, Least Developed Countries Fund (LDCF) and the Special Climate Change Fund (SCCF), as well as the Adaptation Fund (AF) established under the Kyoto Protocol (GoK, 2010a). These funds, as the Strategy itself acknowledges, mainly constitute pledges by industrialized donor countries and agencies.

The NCCRS sees the carbon market, specifically the Clean Development Mechanism (CDM) and Voluntary Carbon Markets (VCM), as 'an opportunity for developing countries to raise additional revenues for GHG emission reducing projects that also contribute to sustainable development' (GoK, 2010a, p5). Moreover, it seeks to enhance 'technology transfer from the industrialised countries to Kenya' (GoK, 2010a, p9). This position is similar to that taken by the Kenyan government in the Action Plan which notes that, internationally, there is a call for enhanced action on technology development, transfer, and diffusion of environmentally sound technologies and corresponding know-how to developing countries (GoK, 2013).

The adaption funds, carbon markets (especially CDM) and technology transfer under the UNFCCC are express or implicit acknowledgements that nations emitting ghg above their fair share of safe global emissions have a responsibility to fund reasonable adaptation measures or unavoidable losses and damages in poor developing countries.

6. What formal mechanisms are available in the nation for citizens, NGOs and other interested organizations to question/contest the nation's ethical position on climate change? 
The strongest and most commonly used formal mechanisms through which Kenyan citizens, NGOs and other interested organizations can get involved in and question the country's ethical, or indeed any other, position on climate change is the 2010 Constitution. Public participation is one of the national values and principles of governance enshrined in Article 10 of the Kenyan Constitution. It binds all state organs, public officers and all persons to observe this principle whenever they enact, apply or interpret any law, or make or implement public policy decisions (GoK, 2010b). The Kenyan courts have, in several instances, declared null and void public policy decisions made without respecting this public participation principle (see, for example, Kenya Law, 2014).

Operationalization of this constitutional public participation provision often takes different forms depending on the particular policy, ministry, or institution in charge of the process. For example, in the formulation of the National Climate Change Response Strategy, stakeholder consultations and workshops organized by the Ministry of Environment and Mineral Resources were held throughout the country whereby individuals, CSOs and other interested parties gave their input. The Action Plan was guided by the technical input of a cross-sectoral Climate Change Taskforce which was comprised of representatives from relevant government agencies, CSOs, academia and the private sector, while many individuals participated in a large number of consultations held throughout the country. A similar process was followed in preparation of the draft Climate Change Authority Bill 2012.

\section{How is the concept of climate justice understood by the current government? Have they articulated any position on climate justice issues that arise in setting ghg emissions policy or in regard to the adaptation needs of vulnerable nations or people?}

Although the Kenyan government has not clearly explained its understanding of climate justice, several policy statements and positions on various climate justice issues, as illustrated in the response to some of the earlier questions, do suggest an outline of its understanding of climate justice. This can be summarized thus: the unequal historical and current responsibility for ghg emissions impacts on people unequally, and those most responsible and who have the capacity are morally obliged to do more to reduce ghg emissions and assist the less responsible and most vulnerable to adapt.

Interestingly, the KCCWG which developed the draft Climate Change Authority Bill 2012 is more explicit in its working with climate justice, stating on its website that it is 'a forum that brings together Civil Society Organizations in Kenya and donor partners, government departments and agencies working on climate change and for climate justice; for the purpose of creating synergies, harmonizing and strengthening of efforts in the design and implementation of activities that address climate change and lobbying and advocating for favorable national policies in the promotion of climate justice for all, especially the most vulnerable' (emphasis added) (KCCWG, 2014). How this has influenced or will influence the government's understanding and position on climate justice is not yet clear.

\section{Are you aware of any regional, state, provincial, or local governments in your country that have acknowledged some ethical responsibility for climate change? If so, what have they said?}

The 2010 Kenyan Constitution introduced a devolved system of government whereby there are two separate and distinct levels of government: national and county. The County Governments Act 2012 requires county governments to make their development plans in a manner that aligns national and county government policies. Environment and climate change is a function of both the national and county governments and requires concurrent jurisdiction across both levels. According to the National Climate Change Action Plan, counties are to develop their own climate change policies, legislation 
and action plans in line with the national policies and legislation. Because the counties only became operational after the general election in 2013, many counties are yet to or are in the process of developing their climate change policies and laws. However, when they finally do so, it is highly likely that they will follow the ethical responsibility or position taken by the national government as already outlined in the earlier questions of this report.

\section{Has your national government taken any position on or otherwise encouraged individuals, businesses, organizations, subnational governments, or other entities that they have some ethical duty to reduce greenhouse gas emissions?}

The Kenyan government subscribes to the notion that all nations, no matter their historical or current responsibility for ghg emissions, have an ethical and moral duty to safeguard the climate system for the benefit of current and future generations, based on their capacity, as encapsulated in Article $3(1)$ of the UNFCCC. Moreover, mitigation interventions are viewed as beneficial to the sustainable development of the country (for example, promotion of energy efficiency and renewable energy technologies, tree planting, and so on). To operationalize this principle, the Kenyan government in its National Climate Change Response Strategy (NCCRS) and National Climate Change Action Plan (NCCAP) identifies several actions which stakeholders in various sectors should undertake to reduce ghg emissions. Their implementation includes proposals, suggestions, directions and encouragement to various stakeholders to act to reduce their ghg emissions.

\section{What recommendations would you make to get the nation or civil society to take ethics and justice issues seriously in climate change policy formulation?}

Kenya as a country and many CSOs working on climate change issues have noticeably taken ethics and justice issues into consideration while advocating for or formulating climate change policies. Nevertheless, the situation can be improved through the following:

- There is need to actively think through and expressly state or explain their understanding of and position on why and how to integrate ethics and justice into the formulation of climate change policies. This will make it easier to better evaluate the policies in terms of their achievement of ethics and justice objectives.

- In line with the preceding point, concerted and targeted capacity-building and awarenesscreation efforts on climate justice and ethics should be initiated, especially for decision-makers at both national and county levels. The civil society which is more erudite in this area can play a significant role in raising the profile of ethics and justice issues and advocating their mainstreaming into government policies.

- More focus should be put on the lateral (horizontal) dimension of ethics and justice without, of course, neglecting the vertical dimension. So far, and understandably so, more emphasis seems to have been put on the vertical dimension (a North-South/developed-developing countries perspective). There is need to ensure that climate change policies target and actually benefit the majority poor and vulnerable in Kenyan society rather than the few rich, elite, and/or gatekeepers. The trickle-down effect of international funds to the very poor and vulnerable is still wanting. Corruption but also genuine capacity challenges remain key bottlenecks. Developing countries should foster South-South partnerships, especially in the areas of knowledge sharing, as well as technology transfer. Concepts such as Ubuntu (humanity to others) should find more expression and utilization in climate change management. 
- More research ought to be carried out, especially on different global cultural/anthropological understandings and operationalization of the concepts of ethics and justice, and their application to climate change negotiations and management. 


\section{References}

Falzon, J., Veum, K., van Tilburg, X., Halstead, M., Bristow, S., Owino, T., Murphy, D., Stiebert, S. and Olum, P. (n.d. [2014]) NAMA for accelerated geothermal electricity development in Kenya, http://www. mitigationmomentum. org/downloads/NAMA proposal_Kenya.pdf, accessed 21 August 2014

Government of Kenya [GoK] (2010a) National Climate Change Response Strategy, http://cdkn.org/wp-content/ uploads/2012/04/National-Climate-Change-Response-Strategy April-2010.pdf, accessed 19 August 2014

Government of Kenya [GoK] (2010b) Constitution of Kenya, http://www.kenyalaw.org:8181/exist/kenyalex/ actview.xql?actid=Const2010, accessed 20 August 2014

Government of Kenya [GoK] (2012) County Governments Act 2012, http://www.parliament.go.ke/plone/statutorydocuments/county-governments-act-no-17-of-2012, accessed 23 August 2014

Government of Kenya [GoK] (2013) National Climate Change Action Plan 2013-2017, http://www.kccap.info/, accessed 19 August 2014

Kartha, S. and Erickson, P. (2011) Comparison of Annex 1 and non-Annex 1 pledges under the Cancun Agreements, Stockholm Environment Institute, Stockholm

Kenya Climate Change Working Group [KCCWG] (2014), http://www.kccwg.org/about-us/about-the-kenyaclimate-change-working-group-kccwg, accessed 23 August 2014

Kenya Law (2014) Petition No. 532 of 2013 Consolidated with Petition Nos 12, 35, 36, 42 \& 72 of 2014 and Judicial Review Miscellaneous Application No. 61 of 2014, http://kenyalaw.org/caselaw/cases/view/97000/, accessed 26 August 2014

Oulu, M. (2014) 'Climate Change Governance: Emerging Legal and Institutional Frameworks for Developing Countries', in W. Leal (ed.) Handbook of Climate Change Adaptation, Springer-Verlag, Hamburg

UNFCCC (2014a) 'Mitigation - NAMAs, Nationally Appropriate Mitigation Actions', http://unfccc.int/focus/ mitigation/items/7172.php, accessed 19 August 2014

UNFCCC (2014b) 'Public NAMA, Kenya', http://www4.unfccc.int/sites/nama/SitePages/Country. aspx? Countryld=90, accessed 22 August 2014 


\section{New Zealand's Consideration of Ethics and Justice Issues in Formulating Climate Change Policies}

\section{Chris Hadley}

This report responds to the research questions of the Project On Deepening National Responses to Climate Change On The Basis of Ethics and Justice, a joint project of the University of Auckland, School of Architecture and Planning and Widener University, School of Law, Environmental Law Center. The research questions and responses are as follows:

1. To what extent has the national debate about how the nation should respond to climate change by setting a ghg emissions reduction target expressly considered that the nation not only has economic interests in setting the target but also ethical obligations to those who are most vulnerable to climate change and that any national ghg emissions reduction target must represent the nation's fair share of safe global emissions? In answering this question, identify the national ghg emissions reduction target, if any, that the nation has made under the United Nations Framework Convention on Climate Change (UNFCCC).

New Zealand (NZ) ratified the UNFCCC as an Annex I developed country party in 1993. The UNFCCC states that its ultimate objective is 'stabilization of greenhouse gas concentrations in the atmosphere at a level that would prevent dangerous anthropogenic interference with the climate system' (United Nations, 1992, Art 2).

NZ Ministry for the Environment (MfE) analysis shows that NZ's gross greenhouse gas (ghg) emissions have increased from 60.6 million tonnes of carbon dioxide equivalent $\left(\mathrm{MtCO}_{2} \mathrm{e}\right)$ in 1990 to $76 \mathrm{MtCO}_{2} \mathrm{e}$ in 2012, a 25\% increase from 1990 levels (MfE, 2014). Methane from dairy cattle and carbon dioxide $\left(\mathrm{CO}_{2}\right)$ from road transport are the major contributors to this increase (MfE, 2013b). NZ's gross ghg emissions continue and are projected to keep increasing from 1990 levels (MfE, 2013b). Under a NZ government policies and measures scenario, NZ's gross ghg emissions are projected to rise to $77,218.3$ gigagrams $(\mathrm{Gg}) \mathrm{CO}_{2}$ e by 2020 - a $29 \%$ increase from 1990 levels - and $82,244.2 \mathrm{GgCO}_{2}$ e by 2030 - a 38\% increase from 1990 levels (MfE, 2013b).

NZ's first commitment period (CP1) responsibility target under the Kyoto Protocol to the UNFCCC of $0 \%$ on 1990 levels is forecasted to be met and has been able to be done so through the use of forest sinks (MfE, 2013b; MfE, 2014). ${ }^{1}$ However, a 2011 NZ government-appointed review panel's report on NZ's primary emissions mitigation policy, the NZ Emissions Trading Scheme (NZ ETS), explains that forestry sinks cannot be relied upon to meet future post-2020 and beyond targets (Emissions Trading Scheme Review Panel (ETS Review Panel), 2011, p22). Furthermore, MfE analysis also shows that forestry sinks cannot be relied upon to meet 2020 targets, with NZ's forestry sector projected to become a net source of $\mathrm{CO}_{2}$ from around 2017 to 2023 (MfE, 2013b). The 2011 NZ ETS Review Panel report also highlights in relation to the ongoing need to reduce emissions, the importance of NZ's high per capita emissions rate, as well as that NZ's particular emissions profile has already been factored into NZ's CP1 target (ETS Review Panel, 2011). 
In 2012 the NZ government decided not to sign up to a legally binding Kyoto Protocol second commitment period (CP2) but to instead make a voluntary pledge. Following the decision not to sign up to the CP2 the NZ government announced in 2013 its UNFCCC 2020 ghg emissions reduction target. NZ currently has a non-binding unconditional responsibility target of $5 \%$ below 1990 levels by 2020 . This $-5 \%$ by 2020 target is well below the authoritative Intergovernmental Panel on Climate Change's (IPCC) recommendation for developed nations of reducing ghg emissions by $25 \%$ to $40 \%$ below 1990 levels by 2020 for the world to have any reasonable chance of limiting warming to the UNFCCC agreed target of less than 2 degrees Celsius. The incumbent NZ government is also maintaining a conditional 2020 reduction target range of $10 \%$ to $20 \%$ below 1990 emissions (see answer to question 2 below for the list of conditions relating to this target and to the adoption of a 2050 target).

To answer some of this project's questions, a focus has been placed on publicly available NZ Cabinet papers (see, for example, www.mfe.govt.nz/issues/climate/emissions-target-2020/).

The NZ government has not expressly considered that the nation not only has economic interests in setting a ghg emissions reduction target but also ethical obligations to those who are most vulnerable to climate change. ${ }^{2}$ This observation is supported by the author's recent study of numerous, publicly available, NZ government policy-related documents on climate change from 1990 to 2012 (Hadley, 2014). In the author's study, only one document had treated ethics expressly and only one other document had referred to ethics (Hadley, 2014). The author's aforementioned findings come despite the incumbent NZ Prime Minister, John Key, stating in a 2009 interview with the Sydney Morning Herald that 'the world has a "moral obligation" to deal with climate change' (Fray, 2009). This statement appears to indicate that he sees the relevance/fundamental importance of ethics to the climate change debate, but this understanding is not reflected in NZ's policy-related debate and policy outcomes (Hadley, 2014).

However, there has been what could be deemed as very limited implied consideration that the nation not only has economic interests in setting a ghg emissions reduction target (and emission reductions in general) but also ethical obligations to those who are most vulnerable to climate change. For example, the author is aware of a couple of NZ government climate change policy-related documents in the last five years that refer very briefly to NZ's 'obligation' under the UNFCCC (ETS Review Panel, 2011; MfE, 2011c), and in a 2009 Cabinet paper by the incumbent government seeking a Cabinet decision on NZ's 2020 ghg emissions reduction target, it states that: '[one of NZ's primary climate change objectives is] to secure an effective long term global agreement to meet the objective of the United Nations Framework Convention on Climate Change (UNFCCC) to stabilise greenhouse gas concentrations in the atmosphere at a level that prevents dangerous human induced climate change' (MfE, 2009b, p1). Entitled 'Climate Change: New Zealand's 2020 Emissions Reduction Target', this paper explains that as input to the negotiations on commitments for post-2012, all other UNFCCC developed countries have announced their ghg reduction targets for 2020, which frame expectations for a binding second commitment period or equivalent future international agreement (MfE, 2009b).

It is also worth noting in relation to the implied consideration of ethical obligations, that the author's study also found three important cases of advocacy where prior NZ governments were seen to urge the objective of the UNFCCC to the international community and an instance where a prior government was deemed to have urged national citizens to support the UNFCCC's objective (Hadley, 2014).

In terms of to what extent the NZ government has expressly considered that any national ghg emission reduction target must represent the nation's fair share of safe global emissions, again there has 
been no express consideration but rather what could be deemed as at least one instance of implied consideration - namely, the 2009 Cabinet paper which states that 'New Zealand's primary climate change objectives . . . [include] that New Zealand does its fair share as part of a global effort' (MfE, 2009b, p1).

With the support of various databases, ${ }^{3}$ the author is not aware of any instances in the NZ mainstream media where climate change has been covered as an ethical and moral issue. This observation is supported by the finding that there is very little coverage of the ethical dimensions of climate change in the media or in public debates in general (Brown, 2013).

There are a few mainstream news articles that criticize the current NZ government on not doing enough on the issue of climate change, but these do not explore the fundamental ethical and justice dimensions of the government's particularly narrow self-interested approach to climate change policy (Hadley, 2014) (see Coates, 2012; Waikato Times, 2013; Nelson Mail, 2014). Therefore, the public debate has failed to recognize the enormous practical significance for NZ climate change (and associated sustainability policies) of understanding climate change as an ethical problem (Brown, 2011; Brown, 2013; Hadley, 2014).

One 2012 news article covering NZ's 2020 reduction target quotes the Green Party's opposition MP Dr Kennedy Graham as saying in regards to NZ doing its fair share to combat climate change: 'We are expecting the rest of the world to carry the burden. This is breathtakingly impudent' (Day, 2012). The article states that the ongoing weakening of the NZ ETS raises further questions over the government's commitment to its climate change obligations, and that globally NZ has the 11th highest level of emissions per capita (Day, 2012). It also quotes the executive director of the Sustainability Council of New Zealand Simon Terry as saying that 'Climate change is everyone's responsibility ... New Zealand is one of the highest emitters in the world, per person, so we actually have a special responsibility' (Day, 2012). An explicit and very brief mention of ethics is included in the text suggesting its relevance to the debate, but not in a capacity that shows its practical significance for NZ climate change and associated sustainability policies.

\section{In making a national commitment to reduce ghg emissions under the UNFCCC, to what extent, if at all, has the nation explained how it took equity and justice into consideration in setting its ghg emissions reduction target?}

The author is not aware of any instance where the incumbent NZ government has expressly stated how it has taken justice into account when setting its ghg emissions reduction target. However, the 2009 Cabinet paper on 'New Zealand's 2020 Emissions Reduction Target' outlines four indicators that can be used to help determine a fair target for New Zealand:

- equal cost approach

- GDP per capita

- emissions per capita

- past emissions approach

Although the paper does not specify which indicators it has used in determining its stated 2020 target range, an associated MfE briefing note explains that the equal cost approach is an important starting point (MfE, 2009d). The briefing note explains that the equal cost approach involves taking into account circumstances such as population growth, mitigation potential and relative wealth, but warns against using this approach alone and so highlights the concept of 'contraction and convergence' 
which it explains looks at long-term equal per capita emissions as a complementary indicator to moderate the equal cost estimates (MfE, 2009d). Contraction and convergence is considered by many to be an approach that attempts to take equity and responsibility issues into account (Ad hoc Working Group on Long-term Cooperative Action (AWG-LCA), 2012).

In recommending that NZ announce a conditional emissions target range, the 2009 Cabinet paper states:

We propose a target range of between $12 \%$ and $20 \%$ below 1990 levels by 2020 subject to a global agreement that sets the world on a pathway to limit global average temperature rise of not more than 2 degrees Celsius, comparable efforts by developed countries, actions by advanced and major emitting developing countries fully commensurate with their respective capabilities, effective rules for land use, land use change and forestry (LULUCF), and full access to a broad and efficient international carbon market. If these conditions are not fully met, New Zealand would reserve the right to reconsider the stringency of its target. Where New Zealand would set its final target within the range if our minimum conditions are met, would depend on the overall quality and ambition of the final agreement. (MfE, 2009b, pp1-2)

The paper further states: 'This conditionality enables New Zealand to adapt its target as the negotiations evolve to ensure an appropriate balance between the ambition of the target and its impact on New Zealand's international competitiveness and domestic economy compared to those of other countries' (MfE, 2009b, p1). In 2009 the NZ Cabinet agreed to a target range of between 10\% and $20 \%$ below 1990 levels by 2020 subject to the minimum aforementioned conditions from the 2009 Cabinet paper being met (NZ Cabinet, 2009b). In formally announcing this agreed 2020 target range to the international community, NZ's Ambassador for Climate Change Dr Adrian Macey states that 'New Zealand's target reflects its fair share of ambitious global mitigation efforts' (MfE, 2009e).

In NZ's 2009 Fifth National Communication under the UNFCCC the former Minister for Climate Change Issues Nick Smith states: 'The New Zealand Government is committed to doing its fair share in combating climate change' and 'In setting our 2020 target [to cut NZ's emissions by 10\% to $20 \%$ below 1990 levels] the Government has balanced New Zealand's economic opportunities with its environmental responsibilities and made a commitment to securing a global agreement to limit temperature increases to two degrees' (MfE, 2009c, pv). The Fifth National Communication also states: 'The decision on the target range was made after considering efforts pledged by other Annex I countries, environmental, social and economic factors, international relations aspects, and the results of public consultation' (MfE, 2009c, p5). Nevertheless, none of these statements include the express (or implied) consideration that any national ghg emissions reduction target must represent the nation's fair share of safe global emissions, or express (or implied) consideration that in setting a target NZ has ethical obligations to those who are most vulnerable to climate change.

Since 2009 the NZ government has consistently stated in various climate change policy-related documents that it wants to do its 'fair share' on climate change (see, for example, Smith, 2010; Groser, 2011; Bridges, 2012).

Following the 2012 NZ government decision not to sign up to a legally binding Kyoto Protocol CP2, in 2013 the government announced a new non-binding and unconditional responsibility target of 5\% below 1990 emissions levels by 2020. The purpose was to 'allow [NZ] to participate meaningfully in the international negotiations currently under way (due for completion by December 2015) for a post-2020 climate change agreement' (MfE, 2013a, p1). The 2013 Cabinet paper on 'New Zealand's unconditional 2020 target' that led to the announcement states: 'Our target must be affordable and demonstrate that New Zealand is doing its "fair share" to address global climate change' and that 
it 'could be met through existing domestic policy settings, so would not incur new costs for New Zealand households or businesses. Such a target would also demonstrate New Zealand doing its fair share towards international climate change efforts, as it would be broadly in line with the actions of comparator countries' (MfE, 2013a, p2). The paper also proposed that the government's existing conditional pledge from 2009 remain should its target range conditions be met prior to 2020 (MfE, 2013a).

Once again, however, there is no discourse in the 2013 Cabinet paper that includes the express (or implied) consideration that any national ghg emissions reduction target must represent the nation's fair share of safe global emissions, or express (or implied) consideration that in setting a target NZ has ethical obligations to those who are most vulnerable to climate change. NZ's current non-binding unconditional target of $5 \%$ below 1990 levels by 2020 is well below the IPCC's recommendation for developed nations of reducing ghg emissions by $25 \%$ to $40 \%$ below 1990 levels by 2020 .

In 2011 the NZ government announced a ghg emissions reduction target of $50 \%$ below 1990 levels by 2050. The government's 2050 target also falls well below the IPCC recommended $80 \%$ to $95 \%$ reduction of ghg emissions by 2050 for developed countries if the world is to have any reasonable chance of limiting warming to 2 degrees Celsius. A 2011 Minister's position paper on the 2050 target states:

The Government is committed to implementing an economically sound and environmentally effective climate change policy. A part of this will be a credible long-term emissions reduction target. To provide certainty for business over the long-term direction of climate change policy, the Government proposes to notify in the New Zealand Gazette a long-term emissions reduction target for New Zealand. (MfE, 2011a, p1)

The position paper goes on to state:

Setting a target is a balance between achieving the reductions in greenhouse gases we want and the impact on the economy and our lifestyle. Achieving the 2050 emissions reduction target could mean higher costs for consumers and businesses as we transition to a low-carbon economy. However, a less ambitious target would undermine New Zealand's clean, green environmental reputation. The proposed 2050 emissions reduction target balances these demands and reflects a fair contribution by New Zealand to the international effort to reduce greenhouse gas emissions. (MfE, 2011a, p4)

Following a public consultation process the NZ government-proposed $50 \%$ below 1990 levels by 2050 non-binding target was gazetted under the Climate Change Response Act 2002 in March 2011, with the Minister for Climate Change Issues Nick Smith stating: 'This target will need to be regularly reviewed to take into account the latest science, development of new technologies, and progress by other countries. New Zealand's contribution to global emissions is very small and our objective should be neither to lead nor lag but do our fair share' (MfE, 2011b).

The statement in the 2013 Cabinet paper concerning the NZ government's primary climate change objective can be seen as much weaker compared to the 2009 Cabinet paper statement. For example, the 2013 Cabinet paper states:

A key climate change objective for New Zealand is to secure an effective long-term global agreement. . .. New Zealand will also continue to play its part and contribute towards global efforts. We have already committed to reduce greenhouse gas emissions by 50 per cent from 1990 by the year 2050 . This is a stiff challenge given that half of our current emissions come from agriculture. ... In achieving this longer-term objective we must also maximise short and medium-term economic and environmental benefits. This is consistent with the Government's Business Growth Agenda that seeks to make better use of our natural resources so we can continue to grow our economy and look after our environment. (MfE, 2013a, p3) 
Despite what appears to be some implied ethical consideration from the 2009 Cabinet paper, the explanations given as to how the government has taken fairness into consideration in setting NZ's 2020 (and 2050) reduction target revolve around NZ's standard utilitarian economic interests and what other UNFCCC nations' responses are, and not on ensuring that gross ghg emissions levels are on a safe pathway (Hadley, 2014). The current NZ government can therefore be seen as acting highly unethically and contributing strongly to the high risk of failing to meets its 2009 climate change policy objective of '[securing] an effective long term global agreement to meet the objective of the United Nations Framework Convention on Climate Change (UNFCCC) to stabilise greenhouse gas concentrations in the atmosphere at a level that prevents dangerous human induced climate change' (Hadley, 2014; MfE, 2009b, p1).

This narrowly self-interested approach to climate change policy involves the position of wanting to follow and not lead international progress (Hadley, 2014; Morton, 2014), as well as what appears to be a deliberate domestic policy of publicly highlighting that NZ's emissions account for a small portion of global emissions whilst omitting to mention NZ's exceptionally high per capita emissions rate. This political strategy is somewhat at odds with a NZ government climate change webpage entitled 'Doing our fair share > Our responsibility' (MfE, n.d.), which noted that per capita emissions rates are important. However, this site does not suggest that per capita emissions are (or should be) a key element of determining a global agreement and meeting the objectives of the UNFCCC. A recent example of this apparent prevarication on NZ's emissions mitigation came about in a 2014 press conference by the NZ Prime Minister John Key, where he stated:

\footnotetext{
When it comes to [climate change] adaptation and mitigation, New Zealand is taking these issues seriously. The only point l'd make overall on climate change is we're 0.2 per cent of world emissions. In the end we can only do so much and that's actually a pretty small amount on our own. We need the big emitters around the world to take climate change seriously, because irrelevant of what New Zealand does, unless the big countries that emit a lot around the world change then I think, you know, this problem will get worse. (New Zealand Herald, 2014)
}

The 2013 Cabinet paper also stated: 'If there is any lesson to be drawn from international climate negotiations, in respect of comparability, it is that there is no universal formula to calculate what a country "should do" in respect of its own level of ambition' (MfE, 2013a, p4). The paper's stance on what it calls the 'self-elected metrics of "fair share"' (MfE, 2013a, p4) appears to demonstrate the need for the critical overarching context of sustainable development to be integrated into the UNFCCC process so that a 'universal formula' or global ethic that accounts for sustainable development's operational conclusions can be calculated (see, further, answer to question 10) (Hadley, 2014).

3. Given that any national ghg emissions target is implicitly a position on achieving an atmospheric ghg concentration that will avoid dangerous climate change, to what extent has the nation identified the ghg atmospheric concentration stabilization level that the national emissions reduction target seeks to achieve in cooperation with other nations?

A March 2009 Cabinet decision on 'Climate Change International Negotiations: Update and New Zealand Position' by the incumbent NZ government had 'agreed that, informed by the IPCC, New Zealand support the lowest feasible global goal of long-term stabilisation of all greenhouse gases in the atmosphere at no higher than 450 ppm $\mathrm{CO}_{2}$-equivalent' (NZ Cabinet, 2009a, p2).

The 2009 Cabinet paper on 'New Zealand's 2020 Emissions Reduction Target' proposed a conditional target range of between $12 \%$ and $20 \%$ below 1990 levels by 2020 which included the condition of 
creating a global agreement that sets the world on a pathway to limit global average temperature rise of not more than 2 degrees Celsius. The paper explains that the IPCC assessed that ghg concentrations could be stabilized at 450 parts per million (ppm) of $\mathrm{CO}_{2}$ e if developed countries reduce their emissions by $25 \%$ to $40 \%$ below 1990 levels in 2020 along with a considerable deviation in emissions by major developing countries and further reductions continue after 2020 (MfE, 2009b). At 450ppm there is a $50 \%$ chance of limiting global temperature rise to 2 degrees Celsius (MfE, 2009b). Inclusion of the IPCC stabilization information and the 2 degrees condition in the 2009 Cabinet paper implies that the NZ government has identified what ghg atmospheric concentration stabilization level the national emissions (conditional) reduction target range seeks to achieve in cooperation with other nations.

However, the 2013 Cabinet paper on 'New Zealand's unconditional 2020 target' does not identify the ghg atmospheric concentration stabilization level that its proposed, and recently announced, national emissions reduction target seeks to achieve in cooperation with other nations. The paper does include the proposal that the NZ government's existing conditional pledge remain and refers to the 2009 Cabinet decision on 'New Zealand's 2020 Emissions Reduction Target' and details the conditions.

The 2011 Minister's position paper and press release on NZ's 2050 emissions reduction target makes no reference to the identification of the ghg atmospheric concentration stabilization level that the 2050 target seeks to achieve in cooperation with other nations (MfE, 2011a; MfE, 2011b). The omission of the ghg concentration stabilization level in the position paper and the press release occurs despite an earlier Cabinet paper on 'Climate Change International Negotiations: Update and New Zealand Position' stating 'IPCC analysis suggests that a goal of 450ppm $\mathrm{CO}_{2}$-eq can be met if developed countries as a group reduce their total emissions by $80-95 \%$ below 1990 levels by 2050' (MfE, 2009a, p4), and the 2011 position paper stating that: 'There is international agreement that we need to limit global temperature increase to no more than 2 degrees Celsius to avoid dangerous climate change' (MfE, 2011a, p2).

\section{Given that any national ghg emissions target is implicitly a position on the nation's fair share of safe global emissions, to what extent has the nation identified the ethical and justice considerations that it took into account in allocating a percentage of global ghg emissions to the nation through the identification of a ghg emissions reduction commitment?}

With the exception of the incumbent NZ government's statements on fairness in answer to question 2 , the answers to questions 1 and 2 show that there has been no express identification of the ethical and justice considerations that it took into account in allocating a percentage of global ghg emissions to the nation through the identification of a ghg emissions reduction commitment. Moreover, there has been a very limited amount of what can be deemed as implied ethical and justice considerations in allocating a percentage of global ghg emissions to the nation through the identification of a ghg emissions reduction commitment (mainly from the 2009 NZ Cabinet paper on 'New Zealand's 2020 Emissions Reduction Target').

As explained in answer to question 2, the government's consideration of equity in setting NZ's 2020 (and 2050) reduction target revolves around NZ's standard utilitarian economic interests and what other UNFCCC nations' responses are, and not on ensuring that gross ghg emissions levels are on a safe pathway. To reiterate the analysis in question 1, there has been no express consideration by the NZ government that any reduction target must represent the nation's fair share of safe global emissions and only one instance of implied consideration that any reduction target must represent 
the nation's fair share of safe global emissions. Furthermore, as explained in answer to question 2, in instances where the nation's 'fair share' is expressly justified, it is done by reference to NZ's small contribution to global emissions, omitting any reference to its high per capita emissions. This approach detracts attention from the fact that the size of a nation's emissions is not relevant to determining its fair proportionate share of safe global emissions.

Overall the incumbent NZ government can be seen as operating under a particularly narrow, highly unethical and unjust form of self-interest (Hadley, 2014).

\section{To what extent, if at all, has the nation acknowledged that nations emitting ghg above their fair share of safe global emissions have a responsibility to fund reasonable adaptation measures or unavoidable losses and damages in poor developing countries?}

The author is not aware of any acknowledgment by the NZ government that a nation emitting above its fair share of safe global emissions has a duty to fund reasonable adaptation measures or losses and damages in poor developing nations. The issue of loss and damage is treated as part of the broader adaptation framework.

As explained in answer to question 2, the current NZ government's consideration of fairness in setting NZ's 2020 and 2050 reduction targets revolve around its highly unethical and unjust 'self-elected [metric] of "fair share"', particularly narrow (and possibly tragic) standard self-interest approach (MfE, 2013a, p4) (Hadley, 2014).

Successive NZ governments' efforts to support developing countries reduce emissions and adapt are seen as being very limited (Wilson et al, 2011). The United Nations Environment Programme's The Emissions Gap Report 2013 (UNEP, 2013, p2) also explains that there is a significant gap between the adaptation funds that have been made available by major multilateral funding mechanisms and the adaptation finance that developing countries need.

At the Conference of the Parties to the UNFCCC (COP) 19, two Pacific Island nations were reported as being particularly critical of the unhelpful attitude of NZ and the lack of leadership shown by NZ and Australia. Tuvalu was reported to have commented: 'For Tuvalu, loss and damage is critical. It is a question of compensation. It deeply saddens me that our South Pacific neighbours have been so unhelpful in these discussions. It is almost back to denial' (Graham, 2013).

\section{What formal mechanisms are available in the nation for citizens, NGOs and other interested organizations to question/contest the nation's ethical position on climate change?}

Following invitation the NZ public is able to submit comments on proposed NZ government policy. However, the public do not always get this opportunity, as seen with the government's unconditional 2020 reduction target decision. In a section entitled 'Consultation', the 2013 Cabinet paper on 'New Zealand's unconditional 2020 target' states: 'Public consultation on a target is not formally required, and in my view there would be little value to be gained from additional consultation beyond what has been completed to date. Public consultation on New Zealand's 2020 emissions target occurred in 2009' (MfE, 2013a, p8).

The NZ public can also have an opportunity to question/contest the nation's ethical position on climate change through the NZ Parliament's select committee process when new legislation is introduced. The NZ public can also signal their approval/disapproval of a government's ethical position on climate change by voting at the triennial NZ general election. 
At the national level, the main means by which to question/contest NZ's ethical position on climate change is via Parliamentary debate. In this regard, the NZ Green Party has been very active in raising ethical issues and attempting to hold the NZ government to account for its irresponsible policies (Green Party of Aotearoa New Zealand, 2013).

7. How is the concept of climate justice understood by the current government? Have they articulated any position on climate justice issues that arise in setting ghg emissions policy or in regard to the adaptation needs of vulnerable nations or people?

The NZ government's very limited implied ethical and justice considerations in allocating a percentage of global ghg emissions to the nation through the identification of a ghg emissions reduction commitment suggests that the government is aware of its UNFCCC obligations and therefore what climate justice entails. However, as explained in previous answers, the NZ government can be currently seen as operating under a particularly narrow, highly unethical and unjust form of self-interest.

In terms of adaptation, up until 2012 the incumbent NZ government has consistently voiced to the COP its 'responsibility to assist our Pacific Island neighbours who are vulnerable to the impacts of climate change' (Smith, 2010; Groser, 2011; Bridges, 2012). However, and consistent with its particularly narrow self-interested approach, the current NZ government has not expressly considered ethics or justice issues in the national statements on adaptation to the COP. The author is also not aware of any instance where the incumbent NZ government has expressly considered ethics and justice issues in its treatment of climate change adaptation at the domestic level.

At the 2013 COP19 NZ's language in the national statement on adaptation had changed notably to previous years, with Minister for Climate Change Issues Tim Groser now limiting the statement to 'Our place in the Pacific is important to us', before providing some details of money spent in the region (Groser, 2013). Again, as noted above with previous NZ COP statements, there was no express reference to climate justice in NZ's high-level statement to the COP19.

Domestically, for the most part, adaptation to climate change has been left up to NZ local government. This decentralized approach to adaptation has led to academics voicing concerns over what, like for poor developing countries, has been labelled a 'significant adaptation deficit' (Fensome, 2014).

8. Are you aware of any regional, state, provincial, or local governments in your country that have acknowledged some ethical responsibility for climate change? If so, what have they said?

The Dunedin City Council recently made a decision to divest itself of fossil fuel extraction investments as part of an ethical investment policy. The Otago Daily Times quotes Dunedin Mayor Dave Cull as saying: 'It would be "inconsistent" for the council to be taking measures to mitigate the effects of climate change while investing in "the things that actually cause" it' (Elder, 2014).

The author is not aware of any other regional or local government in NZ that has acknowledged some ethical responsibility for climate change.

9. Has your national government taken any position on or otherwise encouraged individuals, businesses, organizations, subnational governments, or other entities that they have some ethical duty to reduce greenhouse gas emissions?

The NZ government has not expressly stated that it has an ethical duty to reduce ghg emissions, and has not expressly encouraged individuals, businesses, organizations, subnational governments, or other entities that they have some ethical duty to reduce greenhouse gas emissions. 
As explained in answer to question 1, there has been a very limited amount of what can be deemed as implied ethical and justice considerations by the current government in allocating a percentage of global ghg emissions to the nation through the identification of a ghg emissions reduction commitment.

As mentioned in question 1 in relation to the implied consideration of ethical obligations, the author's 2014 study found three important cases of advocacy where prior NZ governments were seen to urge the objective of the UNFCCC to the international community and an instance where a prior government was deemed to have urged national citizens to support the UNFCCC's objective (Hadley, 2014).

Furthermore, since 2004 the NZ government has centralized its control over climate change mitigation through a number of legislative amendments removing competence from local government (Harker et al, 2013). The NZ government's weakening of subnational power over sustainability issues generally and climate change mitigation in particular (Harker et al, 2013) appears to involve the absence of a 'universal formula' that would critically account for sustainable development's operational conclusions and includes issues such as national economic wellbeing and state security (Hadley, 2014).

\section{What recommendations would you make to get the nation or civil society to take ethics and justice issues seriously in climate change policy formulation?}

The nation and civil society need to understand the enormous practical significance for NZ climate change and associated sustainability policies of seeing climate change as an ethical problem. There needs to be wider recognition and discussion of the 'significant consensus around the broad overarching operational conclusions of sustainable development', in order to achieve the apparent desired ideal of global sustainability (Hadley, 2014). The significant consensus on the broad operational conclusions of sustainable development involves global individual welfare being upheld and humanity keeping within planetary boundaries, as well as comparatively extremely limited macroeconomic formulations/broad modes of operation for humanity (Hadley, 2014).

The NZ government and wider society, including higher education, NZ non-governmental organizations (NGOs) and the NZ media, must be made aware of the nation's current particularly narrow, highly unethical and unjust approach to climate change policy and the serious implications of not addressing the operational conclusions of sustainable development. An example of what is involved in addressing the operational conclusions of sustainable development includes understanding that the mainstream scientific community has concluded that to prevent dangerous climate change the world must constrain global ghg emissions by adoption of a global carbon budget which will limit warming to acceptable levels, and that the total acceptable emissions entailed by the budget must be allocated among all nations in the world. The IPCC's Fifth Assessment Report has identified, with analysis up until 2011, a limit of future carbon emissions of approximately 275 gigatonnes carbon (GtC) to have a greater than $66 \%$ chance of limiting warming to less than 2 degrees Celsius since the industrial era (IPCC, 2013). The below 2 degrees Celsius warming limit has been agreed to by the international community including NZ as necessary to prevent potentially catastrophic climate change.

Prior to the recent September 2014 NZ general election which saw the incumbent National-led government win a third term, a non-partisan consortium of NZ NGOs formed the Climate Voter initiative, which stated that it 'aims to empower climate concerned citizens to use their vote in the September 2014 election to make a difference for the good of present and future generations' (Climate Voter, n.d.). On 3 September 2014 the Climate Voter initiative held a debate on climate change policy between most of the major political parties, including the top three polling parties. The political parties appeared 
to participate in the Climate Voter debate under the understanding that the planet is warming due to increased concentrations of heat-trapping gases in the atmosphere and that most of the increase in the concentration of these gases over the last century is due to human activities (Climate Voter, 2014). The Climate Voter initiative is an example of a forum in which the NZ government and wider society can be made aware of the ethical implications of climate change (and sustainability) and the direct practical relevance for determining climate change and associated sustainability policies.

Another significant initiative that could get NZ along with other nations and civil society to take ethics and justice seriously in climate change policy formation is the recently formed We Mean Business coalition. This coalition is made up of seven organizations working with thousands of companies around the world and includes The B Team which was co-founded by NZ entrepreneur Derek Handley. The B Team states that '[the We Mean Business coalition] will use our collective voice and energy to accelerate the transition to a low-carbon economy and help achieve climate justice' (The B Team, 2014). The We Mean Business coalition explains that it accepts the assessment that humanity must limit global temperature rise to 2 degrees Celsius and in doing so collective emissions cannot exceed 1 trillion tons of carbon, before noting that humanity has already emitted 0.58 trillion tons since the start of industrialization (We Mean Business, n.d.).

In reference to the answer to question 6, in order to address what can be seen as limited involvement of the public in climate change policy formation, New Zealanders could perhaps be given the opportunity to express their views on, or debate the formulation of, international climate change policy prior to annual international treaty negotiations.

Ethical analysis should also be extended to lobby groups which are seen to prevent or delay climate change policy development that allows NZ to meet the objective of the UNFCCC. The NZ government should also:

[advocate] to the international community to achieve, and amongst their people to support, the objective of the UNFCCC, whilst advocating at the national and international levels for a science informed global ethic on [sustainable development]; and . . . [simultaneously formulate] whole-of-Government strategies to help provide solutions, and prepare for, a future associated global socio-economic transformation in the Anthropocene. (Hadley, 2014).

Wider society needs to be aware of these recommendations and, as explained above, the reasons for them. Given the nature of the sustainable development issue, an additional forum which the NZ government could advocate at is the UN Security Council following NZ's recent election as a nonpermanent member. The Council has considered the international security implications of climate change, a number of times, in recent years (Statement by the President, 2011). 


\section{Notes}

1 'A responsibility target means that New Zealand can meet its target through a mixture of domestic emission reductions, the sequestration of carbon in forests, and the purchase of emissions reductions in other countries' (MfE, 2013a, p1). Formal confirmation of New Zealand's Kyoto Protocol CP1 balance will occur in 2015.

2 The author defines 'most vulnerable' broadly. This definition involves taking into account the overarching context of this global change and planetary boundary issue, being sustainable development and its operational conclusions (Hadley, 2014). Therefore 'most vulnerable' is defined as many/most of humanity in the short term and possibly all of humanity at some point in the long term.

3 Australian/NZ Reference Centre, Index New Zealand (INNZ), Opposing Viewpoints in Context, ProQuest Central News \& Newspapers.

\section{References}

Ad Hoc Working Group on Long-term Cooperative Action (AWG-LCA) (2012) 'Report on the workshop on equitable access to sustainable development: Revised report by the Chair', United Nations, http://unfccc.int/resource/ docs/2012/awglca15/eng/inf03r01.pdf

Bridges, S. (2012) New Zealand National Statement to UNFCCC Conference of the Parties (COP18), New Zealand Government, Wellington, http://www.beehive.govt.nz/speech/new-zealand-national-statement-unfcccconference-parties-cop18, accessed 22 December 2012

Brown, D. A. (2011) Ten Practical Policy Consequences of Acknowledging That Climate Change Is An Ethical Problem, http://rockblogs.psu.edu/climate/2011/08/ten-practical-policy-consequences-of-acknowledgingthat-climate-change-is-an-ethical-problem.html, accessed 20 August 2012

Brown, D. A. (2013) Climate Change Ethics: Navigating the Perfect Moral Storm, Routledge, London and New York

Climate Voter (n.d.), http://www.climatevoter.org.nz/, accessed 20 September 2014

Climate Voter (2014) The Great \#ClimateVoter Debate - Raw Footage, http://www.climatevoter.org.nz/, accessed 20 September 2014

Coates, B. (2012) 'Time to act for the health of the planet', The Press, 11 December, http://www.stuff.co.nz/thepress/opinion/8061757/Time-to-act-for-the-health-of-the-planet

Day, S. (2012) 'How green should we be?', The Sunday Star-Times, 4 November, http://www.stuff.co.nz/ environment/7903874/How-green-should-we-be

Elder, V. (2014) 'Opponents query cost of "visionary" decision', The Otago Daily Times, 15 May, http://www.odt. co.nz/news/dunedin/302303/opponents-query-cost-visionary-decision, accessed 5 July 2014

Emissions Trading Scheme Review Panel (ETS Review Panel) (2011) Doing New Zealand's Fair Share - Emissions Trading Scheme Review 2011: Final Report, Ministry for the Environment, Wellington, http://www. climatechange.govt.nz/emissions-trading-scheme/ets-review-2011/review-report.pdf

Fensome, A. (2014) 'Climate change: Report a "wake up call” for NZ', 31 March, http://www.stuff.co.nz/ environment/9887196/Climate-change-Report-a-wake-up-call-for-NZ, accessed 10 October 2014

Fray, P. (2009) 'NZ leader puts his faith in science, not politicians in Copenhagen', The Sydney Morning Herald, 20 November, http://www.smh.com.au/environment/nz-leader-puts-his-faith-in-science-not-politicians-incopenhagen-20091119-iovy.html, accessed 10 August 2014

Graham, K. (2013), http://blog.greens.org.nz/2013/11/22/not-to-be-hypercritical-but-analysing-minister-grosersstatement-to-un-cop19/

Green Party of Aotearoa New Zealand (2013) 'Kennedy Graham questions the Minister for climate change issues on tackling climate change and Yeb Saño's UN statement', https://home.greens.org.nz/oralquestions/ kennedy-graham-questions-minister-climate-change-issues-tackling-climate-change-and-ye, accessed 26 October 2014 
Groser, T. (2011) 'National Statement to COP 17: Durban', 8 December, New Zealand Government, Wellington, http://www.beehive.govt.nz/speech/national-statement-cop-17-durban, accessed 25 January 2012

Groser, T. (2013) 'New Zealand's national statement in Warsaw', 21 November, New Zealand Government, Wellington, http://www.beehive.govt.nz/speech/new-zealand\%E2\%80\%99s-national-statement-warsaw, accessed 10 January 2014

Hadley, C. (2014) 'The sustainability of New Zealand climate change policy: an ethical overview', Environment, Development and Sustainability, DOI 10.1007/s10668-014-9555-4

Harker, J., Austin, P., Howell, M., Lenihan, S.-K. and Taylor, P. (2013) 'Slip Sliding Away: Auckland's Response to the Political Erosion of Climate Change Mitigation Initiatives', State of Australian Cities Conference 2013, http://www.soacconference.com.au/wp-content/uploads/2013/12/Harker-Environment.pdf

Intergovernmental Panel on Climate Change (IPCC) (2013) 'Summary for Policymakers', in Climate Change 2013: The Physical Science Basis - Contribution of Working Group I to the Fifth Assessment Report of the Intergovernmental Panel on Climate Change, Cambridge University Press, Cambridge, New York

MfE (n.d.) 'Our responsibility', Ministry for the Environment, Wellington, http://www.climatechange.govt.nz/ reducing-our-emissions/our-responsibility.html, accessed 20 September 2014

MfE (2009a) 'Climate Change International Negotiations: Update and New Zealand Position', Ministry for the Environment, Wellington, http://www.mfe.govt.nz/issues/climate/resources/cabinet-papers/cab-09-120. pdf, accessed 10 January 2012

MfE (2009b) 'Climate Change: New Zealand's 2020 Emissions Reduction Target', Ministry for the Environment, Wellington, http://www.mfe.govt.nz/issues/climate/emissions-target-2020/cab-paper-2020.html, accessed 15 January 2012

MfE (2009c) New Zealand's Fifth National Communication under the United Nations Framework Convention on Climate Change, Ministry for the Environment, Wellington, http://www.mfe.govt.nz/publications/climatechange/new-zealands-fifth-national-communication-under-united-nations-framew-18

MfE (2009d) 'New Zealand's 2020 Target - further analysis and options', Ministry for the Environment, Wellington, http://www.mfe.govt.nz/issues/climate/emissions-target-2020/09-b-01825.html, accessed 15 January 2012

MfE (2009e) 'Statement made by New Zealand Ambassador for Climate Change, Dr Adrian Macey, to the United Nations Climate Change negotiating session, 10 August 2009 in Bonn, Germany', Ministry for the Environment, Wellington, http://www.mfat.govt.nz/Media-and-publications/Media/MFAT-speeches/2009/010-August-2009.php, accessed 15 January 2012

MfE (2011a) 'Gazetting New Zealand's 2050 Emissions Target - Minister's Position Paper', Ministry for the Environment, Wellington, http://www.mfe.govt.nz/publications/rma/gazetting-new-zealands-2050emissions-target-ministers-position-paper/gazetting-new

MfE (2011b) 'Govt sets - $50 \%$ by 2050 emissions reduction target', Ministry for the Environment, Wellington, http:// beehive.govt.nz/release/govt-sets-50-2050-emissions-reduction-target, accessed 18 January 2012

MfE (2011c) 'Slowing of ETS recommended by Review Panel', Ministry for the Environment, Wellington, http:// www.beehive.govt.nz/release/slowing-ets-recommended-review-panel, accessed 9 January 2012

MfE (2013a) 'International Climate Change: New Zealand's unconditional 2020 target', Ministry for the Environment, Wellington, https://www.mfe.govt.nz/more/cabinet-papers-and-related-material-search/cabinet-papers/ climate-change/international-climate, accessed 1 June 2014

MfE (2013b) New Zealand's Sixth National Communication under the United Nations Framework Convention on Climate Change and the Kyoto Protocol, Ministry for the Environment, Wellington, http://mfe.govt.nz/ publications/climate/nz-sixth-national-communication/index.html

MfE (2014) New Zealand's Greenhouse gas Inventory \& Net Position Report 1990-2012: Snapshot April 2014, Ministry for the Environment, Wellington, http://mfe.govt.nz/publications/climate/greenhouse-gas-inventory2014-snapshot/index.html

Morton, J. (2014) 'Govt urged to enforce goals', The New Zealand Herald, 3 July, http://www.nzherald.co.nz/nz/ news/article.cfm?c_id=1\&objectid=11286518, accessed 10 September 2014 
Nelson Mail, The (2014) 'Climate action derided'

New Zealand Herald, The (2014) 'PM John Key on climate change', http://www.nzherald.co.nz/national/news/ video.cfm?c_id=1503075\&gal_cid=1503075\&gallery_id=14206, accessed 15 September 2014

NZ Cabinet (2009a) 'Climate Change International Negotiations: Update and New Zealand Position', CAB Min (09) 10/4, NZ Cabinet, Wellington, http://www.mfe.govt.nz/more/cabinet-papers-and-related-material-search/ cabinet-minutes/cab-min-09-104-climate-change

NZ Cabinet (2009b) 'Climate Change: New Zealand's 2020 Emissions Reduction Target', CAB Min (09) 28/9, Ministry for the Environment, Wellington, http://www.mfe.govt.nz/issues/climate/emissions-target-2020/ cab-min-09-28-9.html, accessed 15 January 2012

Statement by the President of the Security Council, S/PRST/2011/15* (July 2011), http://www.securitycouncilreport. org/atf/cf/\%7B65BFCF9B-6D27-4E9C-8CD3-CF6E4FF96FF9\%7D/CC\%20SPRST\%202011\%205.pdf, accessed 4 November 2014

Smith, N. (2010) 'New Zealand's National Statement to COP 16: Cancun, Mexico', New Zealand Government, Wellington, http://beehive.govt.nz/speech/new-zealand039s-national-statement-cop-16-cancun-mexico, accessed 16 January 2012

The B Team (2014) 'We Mean Business on Climate', http://bteam.org/the-b-team/b-team-we-mean-business/, accessed 25 September 2014

United Nations (1992) United Nations Framework Convention on Climate Change, United Nations, New York, http://unfccc.int/resource/docs/convkp/conveng.pdf

United Nations Environment Programme (UNEP) (2013) The Emissions Gap Report 2013: A UNEP Synthesis Report, November, UNEP, Nairobi, http://www.unep.org/pdf/UNEPEmissionsGapReport2013.pdf

Waikato Times, The (2013) 'Lowering the hurdles'

We Mean Business, 'About', http://www.wemeanbusinesscoalition.org/about, accessed 25 September 2014

Wilson, N., Chapman, R. and Howden-Chapman, P. (2011) 'End-of-term review of the New Zealand Government's response to climate change: a public health perspective', New Zealand Medical Journal, vol 124, no 1345, pp90-95 


\section{The Netherlands' Consideration of Ethics and Justice Issues in Formulating Climate Change Policies}

\section{Vivian Ike}

This report responds to the research questions of the Project On Deepening National Responses to Climate Change On The Basis of Ethics and Justice, a joint project of the University of Auckland, School of Architecture and Planning and Widener University, School of Law, Environmental Law Center. The research questions and responses are as follows:

1. To what extent has the national debate about how the nation should respond to climate change by setting a ghg emissions reduction target expressly considered that the nation not only has economic interests in setting the target but also ethical obligations to those who are most vulnerable to climate change and that any national ghg emissions reduction target must represent the nation's fair share of safe global emissions? In answering this question, identify the national ghg emissions reduction target, if any, that the nation has committed to under the United Nations Framework Convention on Climate Change (UNFCCC).

The Netherlands is a member state of the European Union (EU). As a result, some $80 \%$ of its legislation on the environment is derived from EU legislation and the Netherlands emissions reduction target is set in accordance with the EU ghg emissions reduction regulations (Government of the Netherlands). The EU as a whole has set up the Europe 2020 strategy for smart, sustainable and inclusive growth, the roadmap for moving to a competitive low-carbon economy in 2050. This includes cutting greenhouse gases by $20 \%$ ( $30 \%$ if international agreement is reached), reducing energy consumption by $20 \%$ through increased energy efficiency, and meeting $20 \%$ of the EU's energy needs from renewable sources (European Union). In the first Kyoto commitment, the Netherlands set the emissions reduction target of $6 \%$ below 1990 base level for the 2008-2012 period. In the current second commitment, the Netherlands committed to reduce ghg emissions by $20 \%$ below the 1990 base level for the 2013-2020 period (UNFCCC, 2014).

However, in the Netherlands, the Ministry of Infrastructure and the Environment is responsible for the overall national climate change policy framework (Government of the Netherlands). In the latest report, the 'Climate Agenda: Resilient, Prosperous and Green', the Ministry of Infrastructure and the Environment stipulated the Netherlands' climate policy ambitions and its firm objectives for reducing greenhouse gas emissions (Ministry of Infrastructure and the Environment, 2014). However, in expressing its set ghg emissions reduction target and its policy plans to reduce ghg emissions the government of the Netherlands did not consider the nation's ethical obligations to those who are most vulnerable to climate change. It also did not express that its set ghg emissions reduction target represents the Netherlands' fair share of safe global emissions. According to the government, the main goal of the 'Climate Agenda' is to enable the Netherlands to withstand more extreme weather conditions, and to respond creatively and adaptively to severe climate changes. Also to ensure national survival and comfort by economically using virtually only renewable and clean energy sources. As a 
result, the majority of the policy objectives are intended to provide affordable and clean energy supply, jobs, and opportunities for the Netherlands in the market for clean technologies.

Conversely, the Netherlands is a member of the EU, and the EU as a whole is committed to the United Nations Framework Convention on Climate Change (UNFCCC) principle of 'equity' and 'common but differentiated responsibilities'; the EU stresses that each Party to the UNFCCC should make commitments to limit or reduce their emissions in accordance with each country's responsibilities and capabilities as well as national circumstances and development needs (Pauw et al, 2014). Furthermore, it is worth mentioning that the collective $20 \%$ emissions reduction target of the EU is shared among member states under the burden-sharing agreement. This takes into account the differences of the emissions contribution of its member states and the differences in expectations for economic growth, the energy mix, and the industrial structure of the respective member states (Official Journal of the European Union, 2010). However, to this end, the government of the Netherlands has not expressly considered that the nation not only has economic interests in setting the target but also ethical obligations to those who are most vulnerable to climate change and that any national ghg emissions reduction target must represent the nation's fair share of safe global emissions.

2. In making a national commitment to reduce ghg emissions under the UNFCCC, to what extent, if at all, has the nation explained how it took equity and justice into consideration in setting its ghg emissions reduction target?

As explained in answer to the first question, the government of the Netherlands has not explained how it took equity and justice into account in determining its ghg emissions reductions.

3. Given that any national ghg emissions target is implicitly a position on achieving an atmospheric ghg concentration that will avoid dangerous climate change, to what extent has the nation identified the ghg atmospheric concentration stabilization level that the national emissions reduction target seeks to achieve in cooperation with other nations?

The government of the Netherlands has partially identified the ghg atmospheric concentration stabilization level that the national emissions reduction target seeks to achieve in cooperation with other nations. The government mentioned in its latest climate policy agenda that it has the intention to limit the global temperature increase to no more than $2^{\circ} \mathrm{C}$ by working in cooperation with other nations. According to the government, the global temperature increase should be limited to no more than $2^{\circ} \mathrm{C}$ as stated in the Intergovernmental Panel on Climate Change report and other systematic scientific research. It also believes that the threats of climate change can be turned into fresh prospects for achieving growth of global prosperity and welfare. Thus, the Netherlands is pursuing an ambitious international climate policy and is striving for concrete solutions in association with other like-minded countries. It is also pushing for a $40 \%$ increase in the ghg emissions reduction target of the EU in 2030 and is seeking to inspire others to take more far-reaching climate measures (Ministry of Infrastructure and the Environment, 2014).

4. Given that any national ghg emissions target is implicitly a position on the nation's fair share of safe global emissions, to what extent has the nation identified the ethical and justice considerations that it took into account in allocating a percentage of global ghg emissions to the nation through the identification of a ghg emissions reduction commitment? 
The government of the Netherlands has not identified how its ghg emissions reduction commitments took into consideration ethics and justice issues in establishing the emissions reduction targets. According to the government, the Netherlands' 'adapt and prevent' approach to achieving its set ghg emissions reduction target of $20 \%$ below 1990 base level for the period 2013-2020 is about safeguarding prosperity and welfare within the capacity of the Earth. It is also about becoming a climate ghg-neutral nation by the year 2050 (Ministry of Infrastructure and the Environment, 2014).

\section{To what extent, if at all, has the nation acknowledged that nations emitting ghg above their fair share of safe global emissions have a responsibility to fund reasonable adaptation measures or unavoidable losses and damages in poor developing countries?}

The Netherlands has not expressly acknowledged that a nation emitting above its fair share of safe global emissions has a duty to fund reasonable adaptation measures or unavoidable losses and damages in developing nations. However, the Netherlands has made substantial financial and nonfinancial contributions to assist developing country Parties that are particularly vulnerable to the adverse effects of climate change to help them to meet the costs of adaptation to those adverse effects. For instance, according to the UNFCCC, with regard to the most recent financial contributions to enhance the implementation of the Convention by developing countries, the Netherlands has committed $€ 300$ million as its contribution towards fast-start finance in 2010-2012 to support climate adaptation and mitigation in developing countries (UNFCCC, 2014). This pledge was fulfilled at the end of 2012 and consists exclusively of mitigation and adaptation projects that have been allocated the Organisation for Economic Co-operation and Development 'Rio marker'.

Furthermore, the Netherlands in cooperation with the EU is contributing to help developing countries meet the challenge of climate change; the EU and its member states have adopted a strategy on climate change in the context of development cooperation to meet immediate adaptation needs, including facing severe weather events and other adverse impacts of climate change. For instance, the EU has pledged financial assistance of $€ 7.2$ billion over the period $2010-12$ to help developing countries make a fast start on strengthening their capacities to tackle climate change for both adaptation and mitigation including forestry (European Union). According to the EU, in 2010 the European Commission mobilized $€ 50$ million, which has been allocated in a balanced manner between adaptation and mitigation (including REDD+):

- Adaptation: $€ 25$ million under the Global Climate Change Alliance (GCCA) to accelerate action to help least developed countries and Small Island Developing States adapt and build resilience to the impacts of climate change.

- Mitigation: $€ 18$ million to accelerate the transition to a low-emissions economy and to reduce greenhouse gas emissions. Funding is promoting projects on: capacity building for monitoring, reporting and verification (MRV) and the development of nationally appropriate mitigation actions and low-emissions development strategies in Latin America, Africa and Asia; renewable energy in Africa; and capacity building to develop sectoral crediting mechanisms in emerging economies.

- REDD+: $€ 7$ million to reduce greenhouse gas emissions by reducing deforestation and forest degradation in developing countries.

As a group of countries, the EU is the biggest historical emitter of greenhouse gases (European Environmental Agency, 2012). It acknowledges this fact as well as the 'common but differentiated responsibilities' principle of the UNFCCC as explained in answer to the first question. However, to this end, the government of the Netherlands has not expressly acknowledged that a nation emitting 
above its fair share of safe global emissions has a duty to fund reasonable adaptation measures or unavoidable losses and damages in developing nations.

6. What formal mechanisms are available in the nation for citizens, NGOs and other interested organizations to question/contest the nation's ethical position on climate change?

In the Netherlands, there are no known formal mechanisms available for citizens, NGOs and other interested organizations to question/contest the nation's ethical position on climate change. The overall responsibility for climate change policy-making lies within the Ministry of Infrastructure and the Environment of the Netherlands, and a number of national institutions are involved in the implementation of this policy (Government of the Netherlands). However, as stated in the Netherlands biennial report to the UNFCCC, the Netherlands ensures public access to information. To that end, after adoption, all laws and underlying legislative arrangements in the Netherlands are published in one of several official government bulletins and/or directly on the website. The Freedom of Information Act and the Environmental Management Act also provide public access to information regarding the enforcement of environmental rules and regulations (UNFCCC, 2013).

7. How is the concept of climate justice understood by the current government? Have they articulated any position on climate justice issues that arise in setting ghg emissions policy or in regard to the adaptation needs of vulnerable nations or people?

The Netherlands' concept of climate justice has not been expressly identified by the government. Neither has the government articulated any position on climate justice issues that arise in setting ghg emissions policy or in regard to the adaptation needs of vulnerable nations or people. However, as explained in answer to the third question, the government has expressed concern for the adverse global and national consequences of climate change. It has also made unilateral and bilateral contributions together with the EU to help vulnerable and developing nations, as explained in answer to the fifth question. In particular, according to the UNFCCC (2014), the Netherlands provided financial resources related to the implementation of the Convention through bilateral, regional, multilateral and other civil society channels, including the Global Environment Facility, the Least Developed Countries Fund, the World Bank, the REDD+ mechanism, among others, to support scientific, technological, training, mitigation and adaptation programmes.

8. Are you aware of any regional, state, provincial, or local governments in your country that have acknowledged some ethical responsibility for climate change? If so, what have they said?

Although the national policy on the environment is the responsibility of the Ministry of Infrastructure and the Environment, provincial government is responsible for translating these guidelines into the regional context (Government of the Netherlands). However, there is no official account of the climate change policies of the provincial governments and, therefore, there is no information on whether they acknowledge any ethical responsibility for climate change.

9. Has your national government taken any position on or otherwise encouraged individuals, businesses, organizations, subnational governments, or other entities that they have some ethical duty to reduce greenhouse gas emissions?

The Netherlands is striving for concrete solutions in association with the national/international business community, national/international umbrella organisations of cities, local authorities, NGOs, academia 
and members of the public. According to the government, the Netherlands is working together with organisations like the Dutch Sustainable Growth Coalition (DSGC), the C40 Cities initiative and the Climate Proof City and Local Climate Ambassadors coalitions, as a means to transform itself into a strong and sustainable country (Ministry of Infrastructure and the Environment, 2014).

However, the government has not taken any position on or otherwise encouraged individuals, businesses, organizations, subnational governments, or other entities that they have some ethical duty to reduce greenhouse gas emissions.

\section{What recommendations would you make to get the nation or civil society to take ethics and justice issues seriously in climate change policy formulation?}

Generating widespread public awareness of ethical and justice issues in relation to climate change is a key way to enable civil society to take ethics and justice issues more seriously in the Netherlands. This is because increased public awareness will in turn enable the government to seriously consider ethics and justice issues when formulating national climate change policies. There are various channels available for the government to enable civil society to take ethics and justice issues seriously. This can include but is not limited to the following recommendations:

- The government should encourage educational organisations and institutions at all levels to teach environmental studies with an emphasis on ethical and justice issues in relation to climate change.

- Likewise, the government should encourage other members of civil society such as businesses, industries, NGOs and other organisations, especially social media organisations, to raise public awareness on the societal importance of understanding and taking seriously ethics and justice issues in relation to climate change.

- Also, the government should make it mandatory for provincial and other levels of government to take account of ethics and justice issues when formulating regional/local climate change policies and mandates. 


\section{References}

Europa (2011) 'Kyoto Protocol on climate change', http://europa.eu/legislation summaries/environment/tackling climate change/l28060 en.htm, accessed 11 August 2014

European Environmental Agency (2012) 'Greenhouse gas emissions per capita and per unit of GDP in purchasing power standards in 2008', http://www.eea.europa.eu/data-and-maps/figures/greenhouse-gas-emissionsper-capita-1, accessed 17 August 2014

European Union (N.A.) 'The EU climate policy agenda, the road map to 2050', http://eeas.europa.eu/, accessed 11 August 2014

Government of the Netherlands (N.A. a) Environmental Management Act, http://www.government.nl/, accessed 11 August 2014

Government of the Netherlands (N.A. b) EU legislation, http://www.government.nl/, accessed 11 August 2014

Government of the Netherlands (N.A c) Ministry of Infrastructure and the Environment, http://www.government. nl/, accessed 11 August 2014

Ministry of Infrastructure and the Environment (2013) Climate Agenda: Resilient, Prosperous and Green, http:// www.government.nl/files/documents-and-publications/reports/2014/02/17/climate-agenda-resilientprosperous-and-green/climate-agenda-resilient-6-prosperous-and-green-def.pdf, accessed 11 August 2014

Official Journal of the European Union (2010) 'Commission decision determining the respective emission levels allocated to the community and each of its member states', http://eur-lex.europa.eu/, accessed 16 August 2014

Pauw, P., Bauer, S., Richerzhagen, C., Brandi, C. and Schmole, H. (2014) Different Perspectives on Differentiated Responsibilities: A State-of-the Art Review of the Notion of Common but Differentiated Responsibilities in International Obligations, http://www.die-gdi.de/uploads/media/DP_6.2014..pdf, accessed 16 August 2014

UNFCCC (2010) Fifth Netherlands' National Communication under the United Nations Framework Convention on Climate Change, http://unfccc.int/resource/docs/natc/nld_nc5.pdf, accessed 11 August 2014

UNFCCC (2012) 'Response to Joint Message: Workstream on the 2015 Agreement', https://unfccc.int/files/... from.../adp eu workstream1_17102012.pdf, accessed 16 August 2014

UNFCCC (2013) The Netherlands First Biennial Report under the United Nations Framework Convention on Climate Change, https://unfccc.int/files/national_reports/biennial_reports_and_iar/submitted_biennial_reports/ application/pdf/the_netherlands_br1.pdf, accessed 16 august 2014

UNFCCC (2014) Sixth Netherlands' National Communication under the United Nations Framework Convention on Climate Change, unfccc.int/files/national_reports/annex_i.../the netherlands_nc6[1].pdf, accessed 11 August 2014 


\title{
Concerns of Ethics and Justice in Russian Climate Politics
}

\author{
Katia Vladimirova
}

This report responds to the research questions of the Project On Deepening National Responses to Climate Change On The Basis of Ethics and Justice, a joint project of the University of Auckland, School of Architecture and Planning and Widener University, School of Law, Environmental Law Center. The research questions and responses are as follows:

1. To what extent has the national debate about how the nation should respond to climate change by setting a ghg emissions reduction target expressly considered that the nation not only has economic interests in setting the target but also ethical obligations to those who are most vulnerable to climate change and that any national ghg emissions reduction target must represent the nation's fair share of safe global emissions? In answering this question, identify the national ghg emissions reduction target, if any, that the nation has made under the United Nations Framework Convention on Climate Change (UNFCCC).

Russia, one of the top $\mathrm{CO}_{2}$ emitters and the largest country in the world, has been engaged in climate politics for over thirty years. In June 1992, Russia was among the first countries to sign the United Nations Framework Convention on Climate Change (UNFCCC). In 2004 it was Russia's decision to ratify the Kyoto Protocol which saved the UNFCCC-based climate regime from collapsing after the United States withdrew its support in 2001. During the first period of the Kyoto Protocol (2008-2012) Russia committed to keep its $\mathrm{CO}_{2}$ emissions at a level not exceeding the levels of 1990 - but its actual emissions were almost 30\% lower than in 1990.

From a certain perspective, Russia's role in global climate politics might appear as positive. However, these achievements are rather illusory and, placed in a historical context, do not stand up to scrutiny. Following perestroika and other events, in December 1991 the Soviet Union broke down into 15 independent states. The Russian Federation as a country which took commitments under the UNFCCC at a meeting in Rio in June 1992 was only six months old, in a rapidly deteriorating state threatening its very existence. Economic collapse triggered by political crisis escalated exponentially. During the 1990s, Russia's economy went into deep recession, and $\mathrm{CO}_{2}$ emissions shrank for reasons completely unrelated to climate change by $40 \%$ (Kokorin, 2013, p5).

For more than a decade the country was in a state of severe social crisis, including unprecedented unemployment, demographic recession, healthcare deterioration, crime rate increase, and significant loss of human capital. In such conditions it was no surprise that the dangers of global warming did not make it to the top of the country's political agenda. It is safe to say that there was no such thing as a 'national debate' on global warming and climate change in Russia in the 1990s. Actions taken by the country in an international arena during those years reflected rather geopolitical and international image concerns of the ruling political elites than a position that emerged out of a national debate.

Influenced by internal factors, Russia's position in international climate negotiations in the 1990s was 'defensive and almost unnoticed' (Korppoo et al, 2006). The main concern expressed by the country's representatives regarding the Framework Convention was related to how the new commitments would 
affect the country's energy export revenues (Afionis and Chatzopoulus, 2010). On this matter, Russia repeatedly sided with OPEC countries to question existing commitments as inadequate, stressing the role of scientific uncertainty (Oberthuer, 1996). Russia also argued in favour of low commitments for the economies in transition (like itself and some former USSR members) and for the inclusion of forests as carbon sinks in the regime (Afionis and Chatzopoulus, 2010).

Due to internal uncertainty and crisis, Russia agreed to reduction levels under the Kyoto Protocol that left plenty of room for economic recovery after the recession. A steep decline in GDP meant, however, that Russia obtained a significant amount of 'extra' quotas (also called 'hot air') that could have been traded under the Kyoto framework. This contributed to the formation of a certain way of thinking among Russia's political elites, known as the 'Kyoto mentality'. In essence this approach meant that Russia, due to its large territory, forests, and $\mathrm{CO}_{2}$ absorption capacity, was some kind of unique climate 'donor' saving the planet and that this position entitled the country to special treatment by other developed states (Kokorin, 2012).

While during official international meetings Russia mentioned the role of justice concerns in climate politics (among the most recent - UNFCCC 2014), the 'Kyoto mentality' persisted way into the first decade of the 21 st century. Russia's ethical stand was shaped by its national interest (which included profits from oil and gas exports) and by the fact that its rapid GDP decline had already contributed greatly to the common effort to reduce overall emissions. Russia participated in international cooperation on climate change as long as it provided opportunities for potential gains, economic or geopolitical (Kokorin, 2012).

Geopolitics and international image considerations continued to dominate Russia's position regarding climate change in the 2000s. After the United States withdrew its support for the Kyoto Protocol it was critical that Russia joined the treaty to guarantee participation of countries accounting for more than $55 \%$ of global $\mathrm{CO}_{2}$ emissions. It is commonly agreed that Russia's ratification of the Kyoto Protocol was a symbolic gesture (as it required no substantial actions from the country) made in exchange for a promise from the EU to support Russia's accession to the World Trade Organization (Korppo et al, 2006).

With the changing international situation and growth of China and India, the paradigm of international climate politics started to shift in the middle of the first decade of the 2000s. From 2007, Russia repeatedly underlined that the old Kyoto division as an ethical foundation for national commitments made less and less sense in the emerging global context (Kokorin, 2012, p6). In Copenhagen in 2009, Russian President Dmitry Medvedev announced that Russia was ready to sign a legally binding climate treaty (RIA Novosti, 2009). However, it is noted that each country's reduction targets can only be defined by the country itself on a voluntary basis.

An important step at the national level was taken by Russia in 2009 when the government passed the Climate Doctrine of the Russian Federation. Even though the document was vague about specific measures, it was a significant milestone on the way to recognizing climate change as a problem. The Doctrine reaffirmed its commitment under the UNFCCC to the principle of common but differentiated responsibility of countries according to their levels of socio-economic development (Climate Doctrine, 2009). In 2011 the government passed a more detailed plan of implementation of the Climate Doctrine. The plan contained no mention of climate justice concerns (Plan of Implementation, 2011); however, the issues of potential support from Russia to more vulnerable states were raised during the preparatory process - but did not make it to the final text (Kokorin, 2012). 
If during the 1990s there were almost no discussions about climate change and global warming at all, the situation started to change in the early 2000s. An active role in initiating a national debate was played by NGOs, especially WWF and Greenpeace. However, it soon became clear that only arguments framed in a certain way make it to decision-makers (Kokorin, 2014). Only actions inside the country were supported, mostly in conservation and adaptation (not mitigation).

The motivation for this support was drawn from inside the country, from its 'national interest', and not from a sense of international obligation and cooperation. In order to achieve any action NGOs had to speak to the government and business in the language of cost and benefit and occasionally with references to the country's natural and cultural heritage. This influenced the national debate and shifted it away from international justice concerns towards Russian national interest.

At the heart of Russia's national and international climate positions there is a failure to recognize climate change as a threat to Russia itself (e.g. Korppoo and Moe, 2007). Many still do not consider climate change as a serious environmental problem. This view is reinforced by widespread climate scepticism among Russian scientists (e.g. Kotov, 2004; Izrael, 2005, 2007). The Russian Academy of Sciences, the most authoritative scientific institution, is known for its sceptical views of climate change threat (Prokofiev, 2011), while Russian climate scientists took an active part in the IPCC and share the views of global science.

Historically, the dominant view in Russia was of man as a ruler of nature (Korppoo and Moe, 2007). This view was not accidental but instrumental in overcoming hardships of nature in spreading human influence throughout the vast territory of the Soviet Union (building roads and railroads through Siberia to the Far East, exploring and extracting natural resources in areas with harsh natural conditions, etc.). Deeply embedded in the Russian mentality, this view contrasts strongly with the foundations for global action on climate change. The most progressive part of Russian society, including environmental NGOs, has been trying to change this view but an underlying shift in values takes time to happen.

\section{Methodological challenge of this study}

At this point it is important to note that there are at least two methodological challenges in assessing Russia's climate change politics and national debate.

First, in answering the first question it is important to distinguish between two ways a nation can 'consider' ethical obligations in deciding how it should respond to climate change. There are declarative statements and there are actual discussions and debates that lay a foundation for the formulation of policies. Concerns of justice and the responsibility of developed states to help vulnerable members of the global community are expressed primarily in international statements of Russia's officials but these statements are declarative in nature.

The other difficulty has to do with the angle of this study and its focus on specific ethical concerns. It is relatively easy to find proof when some concerns are represented in a debate. But it becomes much more difficult to prove that these concerns are absent from or have no weight in a discussion and to avoid 'wishful thinking', especially when the concerns in question are universal.

Russia's national debate about climate change, in its rudimentary state, and the position of the government, are predominantly about the economic interests of the country. They place no real weight on concerns of international intra- and intergenerational climate justice in discussing the country's actions on climate change. These concerns get mentioned from time to time, in preambles of some documents, in some public speeches, but this lip service does not mean that these concerns are 
actually considered as a powerful factor in determining the country's position. No document or government official representing the national position would state explicitly that justice concerns are not accounted for - they simply would not be discussed or only mentioned superficially. Therefore, the view presented in this study relies primarily on the general sense given by the literature and key legal documents, as well as by discussions with some Russian climate change experts conducted by the author for the purpose of this study.

2. In making a national commitment to reduce ghg emissions under the UNFCCC, to what extent, if at all, has the nation explained how it took equity and justice into consideration in setting its ghg emissions reduction target?

As explained in the answer to the first question, Russia has not elaborated on to what extent it considered justice in setting its ghg emissions reduction target.

3. Given that any national ghg emissions target is implicitly a position on achieving an atmospheric ghg concentration that will avoid dangerous climate change, to what extent has the nation identified the ghg atmospheric concentration stabilization level that the national emissions reduction target seeks to achieve in cooperation with other nations?

Russia has not identified the ghg atmospheric concentration stabilization level as part of a discussion of its national $\mathrm{CO}_{2}$ emissions reduction target. The key concern in setting up the target in the Kyoto Protocol was Russia's national interest expressed in economic terms that required recovery from a large-scale recession.

4. Given that any national ghg emissions target is implicitly a position on the nation's fair share of safe global emissions, to what extent has the nation identified the ethical and justice considerations that it took into account in allocating a percentage of global ghg emissions to the nation through the identification of a ghg emissions reduction commitment?

In joining the Kyoto Protocol Russia did not explicitly identify ethical and justice considerations and historical responsibility as key factors shaping its commitment. However, as a Party to the UNFCCC, Russia subscribed to the principle of 'common but differentiated responsibility' and other ethical principles stated in the Convention.

5. To what extent, if at all, has the nation acknowledged that nations emitting ghg above their fair share of safe global emissions have a responsibility to fund reasonable adaptation measures or unavoidable losses and damages in poor developing countries?

Russia acknowledged the role of most developed states in helping more vulnerable countries to combat climate change in many statements made at UNFCCC meetings. However, its initial position as an economy in transition and not a donor country (Annex II UNFCCC) shaped Russia's approach to climate aid as an entirely voluntary action. Russia has repeatedly expressed support to its immediate neighbours from the Commonwealth of Independent States, as well as some other developing nations, like Cuba and Angola, which historically have been of geopolitical interest to Russia. During the COP19 in Warsaw in 2013 when a discussion about the Loss and Damage Mechanism took place, the Russian team of negotiators argued that there was no need of a separate mechanism for this matter and that efforts should instead be focused on strengthening the capacity of developing countries by improving the efficiency of the adaptation, technology, and financing mechanisms. 
6. What formal mechanisms are available in the nation for citizens, NGOs and other interested organizations to question/contest the nation's ethical position on climate change?

Russian governmental officials meet occasionally with representatives of the academic community and non-governmental organizations but these meetings are almost entirely aimed at discussing environmental issues inside the country (e.g. Kremlin.ru, 2011). During international negotiations NGOs and other interested organizations normally have access to Russia's official delegation and can through personal networking lobby certain issues. There is also an avenue to bring certain questions to the media but, like other parts of Russian society, the media has little interest in covering climate change in general and international climate justice concerns in particular.

7. How is the concept of climate justice understood by the current government? Have they articulated any position on climate justice issues that arise in setting ghg emissions policy or in regard to the adaptation needs of vulnerable nations or people?

Climate justice is not a well-developed concept in Russia. In spite of some efforts from academia to clarify the ethical dimension of national responsibility (Prokofiev, 2011), climate justice has not gained much attention either from the government or from the public. According to experts, national and international NGOs in Russia also prefer to take a different stand, tailored to Russian reality, when they try to convince governments to act on climate change (Kokorin, 2014).

The arguments that get through and make at least some difference are those which emphasize Russia's national interest, including population health, loss of natural resources, and environmental degradation. Appeals to international obligations, to issues of international intra- and intergenerational justice, especially framed in monetary terms, have no success in triggering action or even response from the Russian government.

Climate justice was not mentioned in Russia's Climate Doctrine (2009) or in the following Plan of Implementation of Climate Doctrine until 2020 (2011).

8. Are you aware of any regional, state, provincial, or local governments in your country that have acknowledged some ethical responsibility for climate change? If so, what have they said?

Some local governments tend to be more inclined to take part in climate change-related joint implementation projects but this is done for pragmatic reasons rather than ethical ones.

9. Has your national government taken any position on or otherwise encouraged individuals, businesses, organizations, subnational governments, or other entities that they have some ethical duty to reduce greenhouse gas emissions?

No, Russia's government has not taken such measures.

10. What recommendations would you make to get the nation or civil society to take ethics and justice issues seriously in climate change policy formulation?

Climate change debate and understanding in Russia are framed in terms different than in most other developed states. A sense of the country's uniqueness and its special position as a climate donor contribute to a common vision of its responsibilities as minimal. The debate is not shaped in terms such as 'responsibility to the planet' but rather 'responsibility to other members of the global community'. At the heart of Russia's international and national climate politics there are geopolitical 
and economic interests which are from time to time covered with fig leaves of justice concerns required by international diplomatic protocol.

Transforming this debate to bring it more in line with international justice concerns would take many years and might not be sufficient in the end. Russia's position is a reflection of the dominant mentality. Russians are protective of their wealth accumulated the hard way following the collapse of the Soviet Union. Any conversations about giving away this hard-earned wealth do not look appealing either to the citizens or to the government that they elect. But most importantly, this position is supported and reinforced by dominant climate scepticism widely spread among Russia's scientific community. Even if the IPCC is constituted of international scientists and is aimed to represent their consensual agreement, the opinion of national climate scientists still attracts more interest and the trust of the general Russian public than the conclusions of the IPCC. The Russian community of climate scientists are active to promote IPCC views in the country but they do not use ethical argumentation at all and focus on the positive and negative climate change effects in Russia.

Russia's failure at all levels to recognize climate change as a threat to Russia itself, in my view, is the key obstacle in the way of integrating ethical concerns into its national and international climate policies. Moral obligations only make sense if the understanding of why they feature is shared. As long as Russia does not share the view that climate change is an issue of global importance, relevant to all countries, and that Russia itself is an integral part of the global community, climate justice concerns may not make much difference in formulating it position. 


\section{References}

Afionis, S. and Chatzopoulus, I. (2010) 'Russia's role in UNFCCC negotiations since the exit of the United States in 2001', International Environmental Agreements: Politics, Law and Economics, vol 10, pp45-63

Climate Doctrine of the Russian Federation (2009) 'Presidential Decree from 17.12.2009 No. 861-pП "On Climate Doctrine of the Russian Federation"', http://www.garant.ru/products/ipo/prime/doc/2070243/

Izrael, Yuri (2007) ‘Climate: Putting panic in perspective’, RIA Novosti, 18 April

Karas, Jacqueline (2004) 'Russia and the Kyoto Protocol: Political Challenges', Briefing Note, Sustainable Development Programme, Royal Institute of International Affairs

Kokorin, A., Head of Climate and Energy Program, WWF, Russia, interview with the author, August 2014.

Kokorin, A. (2012) 'Contemporary climate politics of the world community and its implications for Russia', WWF Russia

Korppoo, A., Karas, J. and Grubb, M. (eds) (2006) Russia and Kyoto: Problems and Opportunities, Chatham House, London

Korppoo, A. and Moe, A. (2007) 'Russian climate politics: Light at the end of the tunnel?', Briefing Paper, Climate Strategies, London

Kotov, Vladimir (2004) '“Greening of policies”: Perspectives in Russia', paper presented in Greening of Policies Interlinkages and Policy Integration conference, 3-4 December, Berlin, Germany

Kremlin.ru (20011) 'Dmitry Medvedev met the representatives of non-governmental ecological organizations', http://www.kremlin.ru/news/11505, http://www.kremlin.ru/news/11505

Oberthur, S. (1996) 'The second conference of the parties', Environmental Policy and Law, vol 26, no 5, pp195-201

Plan of Implementation of the Climate Doctrine of the Russian Federation for the Period until 2020 (2011) Approved by a Decree of the Government of the Russian Federation from 25 April 2011 No. 730-p, http://www.consultant.ru/document/cons_doc_LAW_133663/?frame=1\#p26

Prokofiev, A. (2011) 'Climate justice: Russian context', Ethical Thought, issue 11, pp86-107

RIA Novosti (2009) 'Russia prepared to sign a legally binding climate treaty', 18 December

Russian Federation (2014) Submission of information, views and proposals on the work of the Ad Hoc Working Group on the Durban Platform for Enhanced Action: approaches to 2015 Agreement, http://unfccc.int/files/ bodies/awg/application/pdf/submission-awg-dp-russia-april_2014-eng.pdf 



\section{South Africa's Consideration of Ethics and Justice Issues in Formulating Climate Change Policies}

\section{Radhika Perrot}

This report responds to the research questions of the Project On Deepening National Responses to Climate Change On The Basis of Ethics and Justice, a joint project of the University of Auckland, School of Architecture and Planning and Widener University, School of Law, Environmental Law Center. The research questions and responses are as follows:

1. To what extent has the national debate about how the nation should respond to climate change by setting a ghg emissions reduction target expressly considered that the nation not only has economic interests in setting the target but also ethical obligations to those who are most vulnerable to climate change and that any national ghg emissions reduction target must represent the nation's fair share of safe global emissions? In answering this question, identify the national ghg emissions reduction target, if any, that the nation has made under the United Nations Framework Convention on Climate Change (UNFCCC).

Within the United Nations Framework Convention on Climate Change (UNFCCC), South Africa is a Non-Annex I country and is a signatory to the Kyoto Protocol. South Africa ratified the Kyoto Protocol in 2002 , obliging it to adhere to the obligations imposed by the Convention, but as a developing country, South Africa did not have to meet the targets under the Protocol until 2012. However, during the 2009 Copenhagen climate change negotiations, South Africa voluntarily announced that it would act to reduce domestic ghg emissions by $34 \%$ by 2020 and $42 \%$ by 2025 below business as usual, which are ambitious targets for a country that is highly energy-intensive and coal-dependent.

These targets made under the UNFCCC were informed by a scientific analysis called the LongTerm Mitigations Scenarios (LTMS) ${ }^{1}$ which formed the basis for South Africa's negotiation policy in Copenhagen in 2009. South African policy-makers have recognized that the future will need to be carbon-constrained and that South Africa's emissions will have to stop growing, stabilize and decline before mid-century. Given that there is also emphasis put on economic growth policies, the LTMS policy sees emissions peaking between 2020 and 2025, before levelling out and declining in real terms from 2036.

South Africa's economy is heavily dependent on coal, and according to the World Energy Council, its coal resources were estimated at around 34 billion tonnes - 95\% of African coal reserves and $4 \%$ of world reserves. Coal provided an estimated $72 \%$ share of the country's total primary energy supply in 2007 and accounts for about $85 \%$ of electricity generation capacity. Coal is also a major feedstock for the country's synthetic fuel industry, and its energy supply is therefore heavily carbon-intensive. South Africa is aware that it is the African continent's largest greenhouse gas emitter.

As a climate change response objective, the emissions trajectory described above is considered a 'fair contribution' by the government in order to keep global emissions reductions at a $2^{\circ} \mathrm{C}$ goal or that required by science (RBS) scenario as projected in the LTMS. In 2011 at the COP17 in Durban, South 
Africa launched a National Climate Change Response (NCCR) policy, ${ }^{2}$ where the Minister of Water and Environmental Affairs, Edna Molewa, confirmed that climate change was 'already a measurable reality, and along with other developing countries, South Africa is especially vulnerable to its impacts'. She further reiterated that '[e]arly impacts are being felt on agricultural production, food prices and food security, which will have disastrous social and economic consequences if we do not take bold steps to address climate change', and added that the future of South Africa's sustainable development, economic growth and quality of life would, as with other countries, largely hinge on the impacts of climate change.

South Africa's response to climate change has two main objectives: the first is to effectively manage the inevitable climate change impacts through interventions that 'build and sustain South Africa's social, economic and environmental resilience and emergency response capacity'; and the second is to make 'a fair contribution to the global effort to stabilise greenhouse gas (GHG) concentrations in the atmosphere' (NCCR, 2004). Thus proving that the climate change debate is mainstreamed into the development objectives of the country, and according to Boyd et al this mainstreaming 'will be as important in the future of NAMAs as climate policy itself' (Boyd et al, 2014, p13).

The term NAMA is not found explicitly in the NCCR but actions with potential mitigation effects are framed under the 'Near-term Priority Flagship Programmes' (Boyd et al, 2014). Seven of the eight programmes have emissions mitigation potential: public works; water conservation and demand management; renewable energy; energy efficiency and energy demand management; transport; waste management; carbon capture and sequestration. The eighth focuses on adaptation, more specifically on adaptation research, that will help generate knowledge required to create an adaptation strategy for the country. The Department of Environmental Affairs (DEA) is currently leading a wide-ranging mitigation potential analysis to review current and future emission trends of key sectors, and analyse mitigation options, due to be released in 2014. A national policy tool, the Integrated Resource Plan (IRP) 2010 asserts that this will assist 'in fulfilling South Africa's commitments to mitigate climate change as expressed in Copenhagen' (Department of Energy, 2011), and to which end the electricity sector has been carbon-constrained by $275 \mathrm{MtCO}_{2} \mathrm{e}$.

\section{In making a national commitment to reduce ghg emissions under the UNFCCC, to what extent, if at all, has the nation explained how it took equity and justice into consideration in setting its ghg emissions reduction target?}

The climate change response in South Africa has been framed within the context of enormous poverty, inequality and unemployment, the three most daunting development challenges, exacerbated by the legacy of apartheid. And, therefore, the creation of 'green jobs' with its assumed effect on poverty reduction is one of the justifications given to climate change action and is considered a fundamental policy driver at the national level. This has also been articulated in the New Growth Path of 2011, which as a growth plan aims to address unemployment, inequality and poverty by unlocking employment opportunities in South Africa's private sector. 'Co-benefits' such as clean air, reduced household expenditure on energy, or better housing for the poor, for example, have been articulated as key determinants for required climate change action (Boyd et al, 2014).

South Africa is ranked among the top 20 countries measured by absolute carbon dioxide $\left(\mathrm{CO}_{2}\right)$ emissions. The vast majority of South Africa's $\mathrm{CO}_{2}$ emissions (about $80 \%$ ) are produced by the electricity sector, the metals industry and the transport sector. The electricity sector's reliance on low-cost fossil fuels-based electricity generation is one of the main reasons for the carbon-intensive 
nature of the economy, and these already high levels of ghg emissions are expected to increase as the economy grows. Emissions reduction has been explained on grounds that it will redefine the country's competitive advantage and structurally transform the economy by shifting from an energyintensive to a climate-friendly path as part of a pro-growth, pro-development and pro-jobs strategy. The government recognizes that South Africa will need to reduce ghg emissions whilst working to ensure economic growth, increase employment, and reduce poverty and inequality.

South Africa has a 'proactive' outlook and a nationally driven response to climate change as far as policy articulation in national and international forums are concerned. It has set itself concrete ghg emissions reduction targets, acknowledging that the target, if pursued, could be at the compromise of the economy if appropriate actions are not taken. Peter Lukey, Acting Deputy Director-General of Climate Change, said: 'We have to be completely honest in that in terms of restructuring our economy over the next 20 years there is no doubt that there are certain industries that are going to be affected. The reality of this policy is that everything will not stay the same. And if everything does stay the same, then we're heading for disaster' (Porteous, 2011). South African policy-makers are aware that there will be costs associated with ghg emission reduction efforts and there will be significant short- and longterm social and economic benefits as well, including improved international competitiveness from the transition to a low-carbon economy.

Other than the economic reasoning, there has been no specific mention of how equity or justice was considered in establishing the national emissions reduction goals.

\section{Given that any national ghg emissions target is implicitly a position on achieving an atmospheric ghg concentration that will avoid dangerous climate change, to what extent has the nation identified the ghg atmospheric concentration stabilization level that the national emissions reduction target seeks to achieve in cooperation with other nations?}

At COP17, the South African government declared that it recognizes that the stabilization of greenhouse gas concentrations in the atmosphere will require international implementation of an effective and binding global agreement on, among others, greenhouse gas emission reductions. It has therefore been acknowledged: 'That, together with all the other countries responsible for significant greenhouse gas emissions and considering its developing country status, South Africa, as a responsible global citizen, is committed to reducing its own greenhouse gas emissions in order to successfully facilitate the agreement and implementation of an effective and binding global agreement on, among others, greenhouse gas emission reductions' (NCCR, 2004). And in his presidential statement at COP17 in Durban in 2011, Jacob Zuma did highlight that: 'We need to think creatively to accommodate each other and create the space to decide how to address problems for which possible solutions at present are perhaps not matured enough' (Van Der Merwe, 2011).

The LTMS that also informs national climate policy sees emissions peaking between 2020 and 2025, before levelling out and declining in real terms from 2036. The government has admitted that the achievement of these national targets is subject to the availability of significant financial, technological and other support from the international community or developed countries. In 2009 South Africa joined with China, India and Brazil to form the BASIC group of countries, which has become a distinct voice in climate change negotiations. Under this group, the bloc of four large newly industrialized countries committed to act jointly at the Copenhagen climate summit, including a possible united walkout if their common minimum position was not met by the developed nations. The four countries 
also said they will announce their plans to cut greenhouse gas emissions as agreed to in Copenhagen, and furthermore the group discussed the possibility of providing financial and technical aid to the poorer nations of the G77. This move was apparently intended to shame richer nations into increasing their funding for climate mitigation in poorer nations.

These countries, including South Africa, made clear that developed nations should be ready to contribute funds and share green technology if they expected the developing and poor nations to take major actions on environmental protection. The BASIC group decided not to allow rich nations to make climate change an excuse to set up trade barriers or resort to trade protectionism. In their opinion, rich countries should be ready to contribute funds to stop forest degradation including the destruction of the Amazon valley in Brazil, and invest in the process of creating new forests. Deforestation is one of the biggest causes of climate change in many African countries. Developing nations are no longer willing to accept pressure from developed countries to establish legally binding emissions targets. These BASIC countries want to be allowed to reduce emissions voluntarily and only accept what they consider 'nationally appropriate actions'.

So while the government is open to cooperation in combating climate change it has also recognized that it should act locally and adapt to the unavoidable impact of climate change in whatever way it could, despite deadlocks that often arise in international negotiations. A comment by the Department of Treasury in 2010, managing South Africa's national government finances, has recognized climate change as a global problem and is aware of deadlocks in international cooperation ' $\mathrm{t}$ ] $\mathrm{o}$ combat climate change, which is by definition a global problem, [and] a full-scale worldwide response is required. While there is a degree of global cooperation, a fully coordinated and concerted response is not on the immediate horizon: governments are unlikely to reach consensus on an equitable burden of shared responsibility for emissions reductions, or on an international carbon price, in the near future.'3

Clearly, South Africa expects all developed countries to respond with leadership, taking on legally binding, absolute reductions in their emissions, and only by all agreeing to their respective responsibilities will it be possible to agree on a long-term goal, which the planet so urgently needs (Winkler, 2007).

4. Given that any national ghg emissions target is implicitly a position on the nation's fair share of safe global emissions, to what extent has the nation identified the ethical and justice considerations that it took into account in allocating a percentage of global ghg emissions to the nation through the identification of a ghg emissions reduction commitment?

South Africa is aware that it is the largest ghg emitter in the African continent, and because of its coal-intensive-based industries it is also one of the largest ghg emitters in the world. Yet, although it feels responsible in this regard, ethical and justice considerations in allocating a percentage of global emissions to the national ghg emissions reduction commitment have never been identified by the South African government.

5. To what extent, if at all, has the nation acknowledged that nations emitting ghg above their fair share of safe global emissions have a responsibility to fund reasonable adaptation measures or unavoidable losses and damages in poor developing countries?

At COP15 President Jacob Zuma said: 'The principle of equity must be addressed in the context of sustainable development.' He said parties would need to do more to reach the agreed long-term global goal of limiting the average temperature increase to below 2 degrees Celsius. He called on the international community to honour international commitments, and not to shy away from them. $\mathrm{He}$ 
said: 'The Durban conference is taking place on the African continent, which is particularly vulnerable to the impact of climate change. In this context, the low level of ambition is a serious concern' (BuaNews, 2011).

South Africa has been playing a prominent role in international climate change negotiations, inter alia supporting and promoting the interests of the African continent and, periodically, of the wider group of developing countries. According to Bond, South African negotiators, that led the G77, demanded that 'at least $1 \%$ of global GDP should be set aside by rich nations' so as to help developing countries conduct research, improve flood control, protect their coastlines, create seed banks, and take other steps to cope with the severe storms and droughts linked to climate change (Bond, 2010). In the negotiators' opinion, such money could also help poor countries obtain technology to reduce their carbon emissions. Alf Wills, a top South African environmental official, summed up its position going into Copenhagen: 'No money, no deal' (Bond, 2010 and South African Press Association, 2009b).

In 2011 South Africa's Planning Minister, Trevor Manuel, said he expected the North to pay South Africa up to US\$2 billion a year through the Green Climate Fund. Trevor Manuel was elected as one of the three co-chairs of the Transitional Committee for the design of a Green Climate Fund in Cancún, Mexico. The fund is aimed at helping the developing world deal with mitigating the effects of and adapting to climate change, and industrialized nations promised that the fund would have US\$100 billion a year by 2020 (Omar, 2011). He outlined some of the challenges of raising funds for a global fund and added that: 'The problem with climate change is that it is a global issue, so we need global solutions. We are talking about a spirit of multilateralism, where taxes are imposed in one country and allocated in another' (Omar, 2011).

So, in Copenhagen, South Africa as a member of the BASIC group demanded that developed countries allow developing countries 'equitable space for development' as well as provide them with finance, technology and capacity-building support, based on their 'historical responsibility for climate change'. A leading official of the World Wildlife Fund dubbed South Africa the 'star' of Copenhagen, prior to the Copenhagen Accord. Even a month after the Accord was signed, according to Themba Linden of Greenpeace Africa: 'The BASIC countries have to lead the world in light of no leadership from developed world' (Bond, 2010).

\section{What formal mechanisms are available in the nation for citizens, NGOs and other interested organizations to question/contest the nation's ethical position on climate change?}

South Africa has recognized the pervasive nature of climate change, necessitating multiple levels of governance, need of policy coherence and institutional climate policy coordination. In this regard, it has instituted a National Climate Change Coordinating Committee (NCCC), which provides a forum for wide-ranging stakeholder input into the policy development process and acts as a means to disseminate information to stakeholders. The NCCC was established in 1996 as an advisory body to the Minister of Environmental Affairs and Tourism, comprising government departments, representatives from business and industry, mining, labour and NGOs. Outside of the formal NCCC framework, a range of stakeholders plays a crucial role in addressing climate change issues, not often in agreement but occupying the same policy space, interacting with each other, sharing ideas and competing to influence government and other levers of power (Goldblatt and Middleton, 2007).

So both the NCCC and the climate policy network outside of the government's formal structure are evidences of the accommodation of a broad range of stakeholder interests, including ethical positions 
of various stakeholders. This stems from the South African government's highly inclusive approach to development, including climate change, in a way to attempt and redress the closed and exclusive approach of the previous apartheid government.

However, there are a few challenges facing the NCCC, such as the inability to integrate climate policy into the economic planning process. Although the NCCC serves as a lobbying forum for stakeholder interests, most interests were not always formulated in the broad national interest. Government officials saw their role as representing positions on climate change that were aligned with the broad state policies and aimed at national interest - rather than serving the interests of any single stakeholder grouping (Goldblatt and Middleton, 2007).

In fact, when the LTMS was presented to stakeholders in 2007, there was little process coherence, and the stakeholder feedback process was constantly revised. It is said that separate meetings were called with business, labour and NGOs, and were poorly organized by the Department of Environmental Affairs and Tourism (Hallowes, 2008). The labour and NGO meetings were hastily called in 2008, and no one arrived at the labour meeting, while the NGO meeting was poorly attended (Hallowes, 2008).

Further, Section 24 of the Constitution of the Republic of South Africa (1996) stipulates that everyone has the right to an environment that is not harmful to their health or wellbeing; and to have the environment protected, for the benefit of present and future generations, through reasonable legislative and other measures. The National Environmental Management Act (NEMA) provides the underlying framework for environmental law in South Africa, and articulates that 'environmental justice must be pursued so that adverse environmental impacts shall not be distributed in such a manner as to unfairly discriminate against any person, particularly vulnerable and disadvantaged persons'. Legislation for access to environmental information and contestation of policies on the basis of equity and justice includes the Promotion of Access to Information Act (2 of 2000) and the Promotion of Administrative Justice Act (3 of 2000).

\section{How is the concept of climate justice understood by the current government? Have they articulated any position on climate justice issues that arise in setting ghg emissions policy or in regard to the adaptation needs of vulnerable nations or people?}

South Africa believes that global greenhouse gas reduction efforts must work in tandem with a propoor adaptation agenda. Such an agenda, in their opinion, will empower the poor and vulnerable and ensure human dignity (Climate Action, 2011). This is because the poorest, such as those on the African continent, have contributed least to greenhouse gas concentrations in the atmosphere, but face some of the worst consequences and generally have the least capacity to cope with climate change impacts.

South Africa's Department of International Relations and Cooperation (DIRCO) and the Department of Environmental Affairs (DEA) have characterized COP17 as 'an African COP', saying that South Africa is simply a venue for a meeting that belongs to Africa. The DEA has also indicated that South Africa will be 'negotiating for outcomes that benefit Africa's poor and marginalized communities, especially the rural [poor]', and has reiterated that climate change is not only a 'sustainable development challenge' but also a 'poverty issue' and a challenge to achieving the MDGs (Millennium Development Goals) (Mabudafhasi, 2011).

8. Are you aware of any regional, state, provincial, or local governments in your country that have acknowledged some ethical responsibility for climate change? If so, what have they said? 
Located in the local province of Gauteng, the city of Johannesburg is the economic and industrial hub of South Africa and a major contributor to greenhouse gas (ghg) emissions in the country. To contribute to the reduction of ghg emissions and adapt to the effects of climate change, the Gauteng Provincial Government (GPG), Department of Agriculture and Rural Development has developed a Gauteng Climate Change Response Strategy (GCCRS) and Action Plan. ${ }^{4}$ The strategy addresses the problem of climate change in two ways. Firstly, Gauteng acknowledges that human activities have contributed a great deal to the release of greenhouse gases (ghg) into the atmosphere, and that climate change is already evident through the change of weather patterns over the years. This calls for a need to reduce the amount of ghg released into the atmosphere, through mitigation actions. Climate change poses a risk of undermining the sustainable development initiatives in South Africa and Gauteng Province. Secondly, the need to adapt to the impacts of climate change by means of assessing the vulnerability of the Gauteng Province to climate change and subsequently developing adaptation actions is now universally recognized. This is in view of the fact that ghg have long lifetimes in the atmosphere and their accumulated impacts on the local environment require an appropriate response.

The national government and the Gauteng Province are aware that emissions from vehicles have been identified as a growing problem in South Africa, with approximately $40 \%$ of these operational within Gauteng (Department of Transport, 2008). The Gauteng Integrated Energy Strategy set a target of a reduction in energy consumption of $15 \%$ by 2025 through households and industries. The implementation of these mitigation measures is foreseen to require adaptation actions that integrate climate change responses with socio-economic development.

In the City of Tshwane's official document, climate change mitigation and adaptation are integrated into development policies. Policy-makers, decision-makers and politicians are expected to influence the adoption of the principles of sustainable development, environmental justice, community wellbeing and empowerment and ecological integrity within the city's urban development path.

\section{Has your national government taken any position on or otherwise encouraged individuals, businesses, organizations, subnational governments, or other entities that they have some ethical duty to reduce greenhouse gas emissions?}

Changing South Africa's fuel mix, three-quarters dependent on coal, is at least a medium-term challenge, and is so central to the economy that it is likely to take decades to change dramatically as it will require changing economic structures (Winkler and Marquand, 2009). It is also striking that the power sector is responsible for $45 \%$ of South Africa's emissions, compared to just $26 \%$ globally. The government is of the view that heavy emitters, in particular the minerals-energy complex industry and the transportation sector, have an 'ethical' duty to reduce their emissions and meet the national targets. A Carbon Disclosure Project (CDP) for businesses was established in 2000 with the aim to accelerate emission reductions at the national level, and although 'ethical' considerations have not been put forth explicitly, the implications of such steps can be derived from the government's inclusive development approach to climate change.

\section{What recommendations would you make to get the nation or civil society to take ethics and justice issues seriously in climate change policy formulation?}

A critical criticism is over South Africa's vaguely promised 34\% emissions cut below anticipated 2020 levels, even though the Long-Term Mitigation Scenarios (LTMS) acknowledged that absolute decline would only begin after 2030 . The $34 \%$ cut that is the national target reduction by 2020 is found to be a 'Growth without Constraint' (GWC) or business-as-usual scenario within the LTMS, leading a local 
environmental activist to remark that: 'The South African government has pulled a public relations stunt' (Bond, 2010). In the absence of an official quantification of South Africa's commitment, the 'Growth without Constraints' scenario in the LTMS provides a proxy for 'business as usual', which forms the baseline of South Africa's commitment. It is critical that absolute commitment should be quantified and disclosed as a matter of urgency, so that emitters in South Africa are able to develop strategies and set appropriate targets for emissions reductions. It is expected that, if the economy and society do not change their behavioural patterns, and economic growth is as expected in the future, emissions are projected to increase almost $50 \%$ by 2020 from 2010 levels and more than triple by 2050 . Moreover, it is unrealistic to make national emissions goals contingent upon behavioural changes.

South Africa and many other developing countries are especially vulnerable to the effects of climate change given their economic dependence on the primary sector (agriculture, fisheries, mining, and so on), and about $64 \%$ of people in Southern Africa are employed in the primary sector. According to some estimates, a temperature increase of $3-4^{\circ} \mathrm{C}$ could lead to a $15 \%$ decline in African crop yields, with extremely negative consequences in sub-Saharan Africa, where only about $4 \%$ of arable land is irrigated. Projections suggest that a global temperature increase of $3^{\circ} \mathrm{C}$ would reduce crop yields, leading to food shortages for up to 550 million people, more than half of whom live in Africa. As the continent's largest emitter, South Africa should be more accountable to the climate change needs of other African countries, and within its capacity fund and provide technology to these other African countries.

The country's popular role in international climate change negotiations has raised questions about how South Africa is perceived by other sub-Saharan countries, including if its diplomatic and political communities are in fact promoting the idea of an 'African COP' that is fair and equitable for the continent and, more broadly, for the developing world at large. Some critics have questioned South Africa's priorities - especially given its already overburdened agenda and lack of resources to deliver on all its promises. It has been suggested that South Africa needs to use its limited resources judiciously and strategically, prioritize carefully, consult widely with other countries to build trust, be open to suggestions and respond flexibly. In so doing, South Africa must be able to ensure that these agreements are inclusive, fair and effective; reflect a balance between adaptation and mitigation responses; and recognize that solving the climate problem is only possible if developing countries' priorities of eradicating poverty and promoting sustainable development are taken into consideration. South Africa needs to consolidate its own competing national priorities and interests with others in the region and work alongside African Union member states in strengthening their common voice.

Despite many of its political statements, voluntary commitments and positioning at international forums, South Africa has also indulged in climate injustice. ${ }^{5}$ It is highly likely that although the government allows for an open and equal platform for stakeholders in contesting policies and decisions taken up by the government, the vested interests of some large private and public organizations seem to have greater political power than other stakeholders such as NGOs and social communities. During climate change negotiations and national policy deliberations, South Africa should be mindful of the path-dependent nature of its minerals-energy complex, in which large mining companies and large industries have often been successful in directing national policies. 


\section{Notes}

1 The Long Term Mitigations Scenarios (LTMS) are a set of evidence-based scenarios of future possible mitigation actions by South Africa. This LTMS covers the 'Growth without Constraints' (GWC), 'Required by Science' (RBS), and several intermediate scenarios or strategic options for mitigation that South Africa can embark upon. It must be noted that the LTMS is a study of South Africa's mitigation potential in order to inform policy and action, not a mitigation plan.

2 The LTMS policy is guided by the country's Constitution, Bill of Rights, National Environmental Management Act, Millennium Declaration and the UN Framework Convention on Climate Change. Embedded within the Bill of Rights is a clause that provides that 'everyone has the right to an environment that is not harmful to their health or well-being'.

3 National Treasury of the Republic of South Africa, Reducing Greenhouse Gas Emissions: The Carbon Tax Option, Discussion Paper for Public Comment, 2010.

4 The GCCRS and Action Plan has developed practical actions that address sustainable energy supply, transportation, industrial and agricultural activities, and urban development and infrastructure that build on the economic gains and development trajectory in Gauteng Province.

5 For example, allowing the World Bank to make a US\$3.75 billion loan to the country's utility and monopoly Eskom for a large coal-fired power plant. 


\section{References}

Bond, P. (2010) 'Climate debt owed to Africa: What to demand and how to collect?', African Journal for Science, Technology, Innovation and Development, vol 2, no 1, pp83-113

COP17, 2011, 'What is Government doing?', www.cop17-cmp7durban.com, accessed 4 September 2014

Dasgupta, S. (2009) 'Copenhagen conference: India, China plan joint exit', The Times of India, 28 November, http://timesofindia.indiatimes.com/india/Copenhagen-conference-India-China-plan-joint-exit/ articleshow/5279771.cms, accessed 3 September 2014

Earthlife Africa (2009) 'Press Release: South Africa's Emissions Offer', Johannesburg, 10 December, http:// earthlife.org.za/2009/12/press-release-south-africas-emissions-offer/, accessed 4 September 2014

French Embassy (2014) 'South-Africa and France facing climate change together', COP17 brochure, 30 June , http://www.ambafrance-rsa.org/South-Africa-and-France-facing

Hallowes, D. (2008) 'A critical appraisal of the LTMS', prepared for the Sustainable Energy and Climate Change Project (SECCP) of Earthlife Africa, Johannesburg

Mabudafhasi, R. (2011) 'Speech delivered by Deputy Minister of Water and Environmental Affairs during the Local Climate Solutions for Africa 2011 International Conference', ICC, Cape Town, http://www.dwaf.gov.za/ Communications/MinisterSpeeches/2011/localclimateconferenceDM.pdf, accessed 4 September 2014

NCCR (2004), National Climate Change Response: White Paper, Department of Water and Environmental Affairs, South Africa, http://www.sanbi.org/sites/default/files/documents/documents/national-climate-changeresponse-white-paper.pdf, accessed September 2014

Omar, Y. (2011) 'We can raise finance for Green Climate Fund', The Mercury, 9 December, http://www.iol.co.za/ mercury/we-can-raise-finance-for-green-climate-fund-1.1195514?ot=inmsa.ArticlePrintPageLayout.ot, accessed September 2014

Parramon-Gurney, M. and Gilder, A. (2012) 'South Africa and the Durban Climate Change Negotiations: Challenges and Opportunities as Hosts of COP 17', Institute of Global Dialogue, Occasional Paper No. 62

Porteous, C. (2011) 'South Africa serious about reducing greenhouse gas emissions', TheSouth African.com, 19 October, http://www.thesouthafrican.com/new-policy-will-aim-to-show-other-nations-that-south-africa-isserious-about-reducing-greenhouse-gas-emissions, accessed 4 September 2014

Van Der Merwe, Christy (2011) 'Funding shortfall will not impact COP 17 quality - Minister', Engineering News, 9 September, http://www.engineeringnews.co.za/article/sa-to-host-adequate-cop-17-despite-possiblefunding-shortfall-minister-2011-09-09, accessed 5 November 2014

Winkler, H. (2007) Long-Term Mitigation Scenarios: Technical Report, prepared for Department of Environmental Affairs and Tourism, South Africa, http://www.erc.uct.ac.za/Research/publications/07-Winkler-LTMSTechnical\%20Report.pdf, accessed September 2014

Winkler, H. and Marquand, A. (2009) 'Changing development paths: From an energy-intensive to low-carbon economy in South Africa', Climate and Development, vol 1, no 1, pp47-65 


\title{
An Overview of South Korea's Consideration of Ethics and Justice in its Climate Policy
}

\author{
Sun-Jin Yun and Rakhyun E. Kim
}

This report responds to the research questions of the Project On Deepening National Responses to Climate Change On The Basis of Ethics and Justice, a joint project of the University of Auckland, School of Architecture and Planning and Widener University, School of Law, Environmental Law Center. The research questions and responses are as follows:

1. To what extent has the national debate about how the nation should respond to climate change by setting a ghg emissions reduction target expressly considered that the nation not only has economic interests in setting the target but also ethical obligations to those who are most vulnerable to climate change and that any national ghg emissions reduction target must represent the nation's fair share of safe global emissions? In answering this question, identify the national ghg emissions reduction target, if any, that the nation has made under the United Nations Framework Convention on Climate Change (UNFCCC).

Despite being an OECD member, South Korea has maintained a 'special' status as a Non-Annex I Party under the UNFCCC. ${ }^{1}$ This 'Non-Annex I developed country' status has caused controversies within and beyond the nation, and has had significant impact on South Korea's approach to ghg emissions reduction target-setting.

By the rate of annual $\mathrm{CO}_{2}$ emissions from fossil fuel combustion (as of 2011), South Korea is ranked 4th in the OECD and 7th in the world (IEA, 2013), and by the amount of accumulated emissions (1990-2010), at 8th among OECD member countries and 14th in the world (IPCC, 2014). In 2011, South Korea's carbon emissions per capita ranked 10th among the OECD countries and 21st in the world. Its rate of increase in carbon emissions between 1990 and 2011 was highest in the OECD. With respect to climate change, South Korea has moved from being a creditor to a debtor, and this transformation has increased the international community's expectation on the country to participate in a future post-Kyoto arrangement in a legally binding manner.

The South Korean government, however, heavily influenced by corporate powers, has been (re) asserting its 'developing country' status, and has not paid much attention to the issue of climate justice. NGOs, on the other hand, have generally been critical of the government's stance, arguing that South Korea's climate policy should be guided by the concept of climate justice and that the government should assume a more active role in the global effort to combat climate change.

South Korea signed the UNFCCC in 1993 and ratified the Kyoto Protocol in 2002. Between 1999 (when South Korea submitted its first National Communication to the UNFCCC) and 2007, South Korea's climate policy responses were modest and defensive. This was largely due to deep-seated concerns about potential economic burdens that may derive from a stringent climate policy. However, South Korea became more proactive after Lee Myung-bak took office in February 2008. The Lee administration's proactive stance on climate change was in part influenced by the increase in international climate change activities since 2000. Climate change has become one of the most important items on the 
policy agenda at high-level political forums such as the G8 Summit, especially after the Kyoto Protocol entered into force in 2005.

During the special speech to celebrate the 60th anniversary of national independence in August 2008, Lee Myung-bak announced a new development paradigm named 'Low Carbon Green Growth'. What he envisioned was economic growth coupled with environmentally sensible low-carbon emissions. Right before this event, Lee had announced at the G20 meeting in Toyako, Japan in July 2008 that South Korea will be an 'early mover' in terms of climate change response, and promised to establish a 2020 ghg emissions reduction target by 2009. At that time, most developed countries and several developing countries including emerging economies had declared, or promised to establish, their midterm national ghg reduction targets in the run-up to COP15 in Copenhagen, Denmark.

As part of the green growth policy, the South Korean government set a voluntary ghg emissions reduction target of $30 \%$ below the projected levels of emissions in 2020 under the business-asusual (BAU) scenario (Fig. 1). This is equivalent to $4 \%$ below 2005 levels. At the time, it was the most ambitious pledge made by any Non-Annex I country, and the level of commitment conformed to the upper limit of the range of EU-recommended ghg emissions reduction targets for developing countries.

Figure 1.1 South Korea's ghg emissions trend under the BAU scenario (green) and its emissions reduction target trajectory (blue)

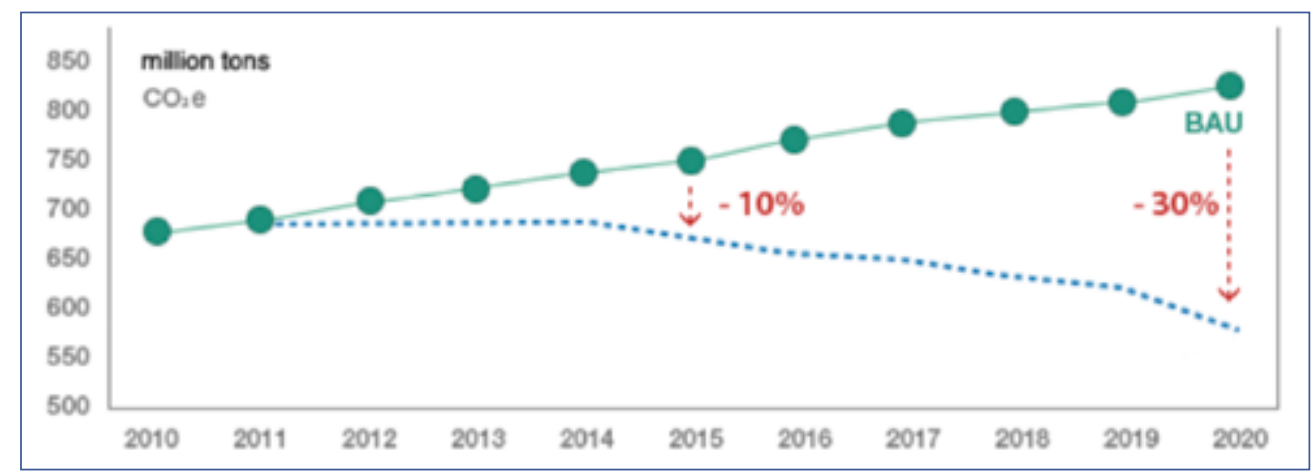

Source: http://www.gir.go.kr/home/index.do?menuld=22.

The Presidential Committee on Green Growth (PCGG) was a key player in the national target-setting process (Yun et al, 2014). Its key aim was to meaningfully participate in the international mitigation efforts to tackle climate change and accomplish low-carbon green growth by fostering green technologies and industries as new growth engines (PCGG, 2009). More specifically, the government regarded setting a national reduction target as a practical goal and an essential strategy to achieve low-carbon green growth. Although South Korea had no legal obligation to reduce its ghg emissions under the Kyoto Protocol, the government was of the view that it would be more appealing on the global stage to have a national target and show leadership. The government also feared the potential negative impact on its economy (and image) from not making substantial emissions reduction commitments. Those concerns included the direct blow on its exports to developed countries with ghg regulation as a trade barrier, the opportunity loss of the industry and people to gain economic benefits through costeffective energy efficiency improvement instruments, and the increasing damage to the environment and people's health resulting from accelerating climate change. The government promoted green 
industry as a new growth engine with more investment in green technology (e.g. ghg reduction technologies) with a view to becoming a competitive leader in the global green market.

South Korea's emissions status is closely related to its energy-intensive industrial structure and rapid economic growth. Thus, a significant ghg emissions reduction commitment could place a heavy burden on its economy if industries do not quickly adapt and find innovative ways to reduce its emissions. Thus, the business sector was very reluctant to accept any national targets (Yun, 2009; Yun and Won, 2012; Yun et al, 2014). Industries argued that it is not necessary for South Korea (technically a 'developing country' under the Kyoto Protocol) to set itself a national target. They asked the government to maintain the status quo and argued that a minimal reduction target would suffice, if at all necessary. The government persuaded the industries, which eventually accepted the government's decision on the target. The government's political will was strong, and pressures from NGOs and the international community could not simply be ignored. However, the business sector still complains that South Korea's target is set too high and that the target needs to be adjusted by reflecting the significant increase in ghg emissions during recent years.

Many NGOs in South Korea have been deeply concerned about the issue of climate justice. They severely criticized the government because the national target - 30\% below projected levels of emissions in 2020 - was, to them, too low and malleable. Importantly for them, the target-setting process did not take into account the principle of common but differentiated responsibility and the notion of climate justice. NGOs requested the government to assume a true leadership role on the global stage by committing to a more ambitious target and, therefore, making a breakthrough to resolve the stalemate between developed countries and developing countries in climate negotiations. They argued that climate justice - arguing differentiated responsibilities based on historical emissions and capabilities - is not an issue of choice but obligation. NGOs recommended four guiding principles for target-(re)setting:

(1) prioritizing the principle of the shared vision, not exceeding 2 degrees Celsius from the preindustrialized level;

(2) the principle of differentiation (more responsibility of developed countries);

(3) the principle of just transformation considering the vulnerable; and

(4) a baseline year-based approach (for example, an X\% emissions reduction below the 1990 level as opposed to the projected level of emissions in 2020). (Yun, 2009)

Based on these principles, NGOs applied the methodology of the Greenhouse Development Right paradigm with the responsibility capacity indicator, and made a case, in 2009 , for a $25 \%$ reduction below the 2005 emissions level by 2020 . However, this recommendation was not accepted by the decision-makers in the government. It was difficult for NGOs to persuade the government, businesses, and the public when even the countries historically responsible for today's climate change (such as the United States) have refused to take on stringent ghg emissions reduction commitments.

\section{In making a national commitment to reduce ghg emissions under the UNFCCC, to what extent, if at all, has the nation explained how it took equity and justice into consideration in setting its ghg emissions reduction target?}

As aforementioned, the South Korean government did not adopt the principles of equity and justice when it set up the national target. The government stated that it would like to establish a voluntary reduction target to the extent that the potential impact on the national economy was bearable and to 
take on a global leadership role in climate negotiations. Also, the government stated that it intended to participate in keeping the global agreement to the shared vision and applied the reduction level proposed by the EU for 2020 national targets. The EU had proposed a 25-40\% reduction from 1990 levels for developed countries, and for developing countries, 15-30\% below the projected levels of ghg emissions in 2020 under BAU scenarios. The PCGG developed three scenarios with $21 \%, 27 \%$ and $30 \%$ reductions from the $2020 \mathrm{BAU}$ with consideration of the country's reduction potential and the EU proposal. Then, the highest target was selected based on three surveys directed at experts and the general public. For Korea, international political pressure, the direction of international market change, and its reduction potential were key criteria in the target-setting process (Yun et al, 2014).

3. Given that any national ghg emissions target is implicitly a position on achieving an atmospheric ghg concentration that will avoid dangerous climate change, to what extent has the nation identified the ghg atmospheric concentration stabilization level that the national emissions reduction target seeks to achieve in cooperation with other nations?

In official documents, the South Korean government makes reference to the IPCC assessment reports. It emphasizes the importance of recognizing a tipping point (e.g. the two-degree limit) and reaching an international consensus on the shared vision. However, South Korea's national reduction target was not set in view of the above. The IPCC assessment reports were considered as authority, not necessarily because their recommendations were actually followed, but rather because the country has a culture of respecting international authority. The government views its responsibility to climate change as rather limited because it regards South Korea as a developing country. This view is generally supported by the populace. Therefore, the government considers its ghg emissions reduction target as comparable to those of other countries.

4. Given that any national ghg emissions target is implicitly a position on the nation's fair share of safe global emissions, to what extent has the nation identified the ethical and justice considerations that it took into account in allocating a percentage of global ghg emissions to the nation through the identification of a ghg emissions reduction commitment?

The South Korean government wanted its emissions reduction target to be set at an appropriate level for a 'bridging nation' between developed and developing countries. Such an approach was also deemed to fit well with the country's brand image in the global society. The government declared that its BAU reduction target was to be $4 \%$ below the 2005 emissions level, while the major developed countries' commitments ranged between 13 and 30\% below the 2005 level. NGOs criticized the level of commitment as a bare minimum. The South Korean government emphasized that its target conforms to the highest level of commitment recommended for developing countries. At the same time, the government persuaded the industry sector by emphasizing that South Korea (as an OECD member) had been requested by the international community to be considered as a developed country or, at least, to take differentiated reduction commitments from other emerging economies such as China and India. The government's argument implies it did not voluntarily take a responsibility for climate change from a perspective of climate ethics or justice. Instead, international pressure and other countries' targets are the basis of setting the national emissions reduction target. Because South Korea does not perceive itself as a major political power in the global society (only a 'middle power'), it is very sensitive to international politics due to its export-oriented economy. 


\section{To what extent, if at all, has the nation acknowledged that nations emitting ghg above their fair share of safe global emissions have a responsibility to fund reasonable adaptation measures or unavoidable losses and damages in poor developing countries?}

The South Korean government acknowledges the responsibility of developed countries to fund reasonable adaptation measures in the face of unavoidable losses and damage in vulnerable developing countries. However, it is not clear whether the government considers South Korea as one of those responsible developed countries: most likely not. It categorizes itself as a 'most advanced developing country' situated somewhere between the developed and developing worlds. It has not explicitly addressed its responsibility. Nonetheless, the government has been providing official development assistance (ODA) to developing countries in support of climate adaptation and risk management, which is in addition to what it might otherwise have provided.

\section{What formal mechanisms are available in the nation for citizens, NGOs and other interested organizations to question/contest the nation's ethical position on climate change?}

The South Korean government has organized and conducted meetings, panel discussions, public hearings, and public opinion polls. However, the government has generally been more sensitive about the interests of industries. The number of meetings with NGOs is far fewer than those with industries. According to the PCGG, the ghg emissions reduction target was set after 44 meetings, among which were 15 panel discussions organized by the PCGG, 14 meetings between the PCGG and eight major industries, three panel discussions held by the national assembly, four local hearings, and three panel discussions organized by NGOs. Most governmental committees such as the PCGG include members of civil society, but only limited numbers are allowed (Lee and Yun, 2011). Furthermore, the opinions and perspectives of such members are usually overlooked under the principle of majority rule. NGOs have issued critical statements about the government's policies and actions, but they have been virtually ignored by the government.

\section{How is the concept of climate justice understood by the current government? Have they articulated any position on climate justice issues that arise in setting ghg emissions policy or in regard to the adaptation needs of vulnerable nations or people?}

The current government has little interest in the concept of climate justice. In setting the voluntary ghg emissions reduction target, South Korea did not justify why it represents a fair share of the burden. Consideration of issues of justice or fairness was absent from the debate. In fact, it is not even immediately clear to the general public why the government has taken action on climate change. It can only be inferred from the analysis of key policy documents that its position was articulated based principally on the policy vision to reduce ghg emissions to live up to the country's international status (Fourth Comprehensive Plan on Countermeasures to Climate Change, 2007). Neither science nor ethics motivated its policy position. This point can also be observable in the country's main climate change legislation, the Framework Act on Low Carbon Green Growth, of which Article 61 on international cooperation states (emphasis added):

(2) The State shall endeavor to provide developing countries with financial support, so that they can cope with climate change effectively and facilitate sustainable development, to earnestly perform its national responsibilities meeting the expectations of international society, and to heighten the State's diplomatic stature.

(3) The Government shall exert itself to cope with climate change actively, strengthen international cooperation, and provide relevant information sufficiently so as to heighten the national stature and 
reputation in reliable national indexes for evaluation of countermeasures against climate change, which are announced by international organizations and related institutions.

The South Korean government is well aware that its ghg emissions are significant and growing rapidly, and that it needs to participate in the international emissions reduction efforts in one way or another. The government has shown sensitivity to how other countries view South Korea by referring to the reports published by overseas organizations such as the Wuppertal Institute, Germanwatch, and Point Carbon. The government prefers to be seen as a bridge between rich and poor nations (which is in fact why South Korea was favoured by some countries as the host nation for the Global Carbon Fund Secretariat), hence having relatively low responsibilities towards mitigating climate change and helping vulnerable nations or people.

\section{Are you aware of any regional, state, provincial, or local governments in your country that have acknowledged some ethical responsibility for climate change? If so, what have they said?}

Many local governments have established their own emissions reductions targets and localized plans to address climate change. For example, in 2007, Gwangju City adopted a 'Solar Energy City' municipal ordinance to promote the construction of energy-efficient buildings. In the same year, Gwacheon City adopted a local emissions trading scheme for its jurisdiction to meet the voluntary ghg emissions reduction target set at $5 \%$ below 2005 levels by 2015 .

However, ethical considerations were absent when setting such local emissions reduction targets. Yeosu City, for example, took into account the level of political commitment, current emissions levels, future emissions projections, emissions reductions potential, and budget, but not climate justice. Under the leadership of Mayor Park Won-soon, Seoul City has been one of the most progressive local governments in terms of climate policy (Mayor Park is also the Chair of the World Mayors Council on Climate Change). However, it is still not obvious if ethical considerations have played a significant role in shaping its policy.

\section{Has your national government taken any position on or otherwise encouraged individuals, businesses, organizations, subnational governments, or other entities that they have some ethical duty to reduce greenhouse gas emissions?}

The national government has been encouraging other entities to reduce ghg emissions and help in meeting the national emissions reduction target declared in 2009. Notable mechanisms used to promote wide participation from businesses and individuals include the Emissions Trading Scheme (to be implemented from 2015, but uncertainties remain due to opposition from the business sector), the Green Certification system, the Green Card system, and the Carbon Point system. However, the national government has not put any emphasis on mitigating climate change as an ethical duty or an issue of justice or fairness. As previously mentioned, the national government itself has not recognized the concept of climate justice.

10. What recommendations would you make to get the nation or civil society to take ethics and justice issues seriously in climate change policy formulation?

There are at least three key reasons why South Korea has failed to pay any consideration to ethics and justice in climate change policy formulation:

(1) The national economy is highly dependent on energy-intensive manufacturing industries;

(2) Both the government and civil society identify South Korea as still a developing country; and 
(3) The government is unwilling to take on legally binding ghg emissions reduction commitments in the post-Kyoto era.

In order to rectify the situation, we make the following recommendations:

(1) To better inform decision-makers and the public about the uneven distribution of causes and effects of climate change.

(2) To press the government to take on legally binding ghg emissions reduction targets, which should be set while paying due regard to climate justice.

It is worth noting here that civil society has already embraced and actively promoted the climate justice concept. The Korean National Commission for UNESCO held the Climate Change Ethics Forum in 2009. A network of over 20 NGOs called the Climate Justice Coalition was later established in 2011. These NGOs emphasize that climate justice is not simply about how to justly allocate emissions reduction responsibilities: they go to the roots of climate change and criticize the capitalist market economy. 


\section{Notes}

1 South Korea joined the OECD in 1996, so it was considered as a developing country at the time of the adoption of the UNFCCC.

\section{References}

Government of the Republic of Korea (2007) Fourth Comprehensive Plan on Countermeasures to Climate Change

Government of the Republic of Korea (2010) Framework Act on Low Carbon Green Growth, Statute No. 11965, last amended July 2013

Korea Federation for Environmental Movements et al (2009) 'The Korean government should be awakened from irresponsibility on climate risk', co-statement of NGOs, http://kfem.or.kr/?p=13262, accessed 11 August 2014

Lee, Jung-Hwan and Yun, Sun-Jin (2011) 'A comparative study of governance in state management: Focusing on the Roh Moo-hyun government and the Lee Myung-bak government', Development \& Society, vol 40, no 2 , pp289-318

Presidential Committee on Green Growth (2009) 'The PCGG suggested the national GHG reduction target', press release of the Blue House on 4 November 2009

Presidential Committee on Green Growth (2009) 'The plan to promote the establishment of national midterm (2020) GHG reduction target', http://www.mofa.go.kr/webmodule/htsboard/template/read/ korboardread.jsp?typelD=12\&boardid=8120\&seqno=307944 and http://www.korea. $\mathrm{kr} / \mathrm{common} / \mathrm{download}$. do?tblKey=EDN\&fileld=197619, accessed 11 August 2014

Yun, Sun-Jin (2009) 'An exploration of governance options for preventing and mitigating social conflicts over policy responses to climate change', National Governance Studies, vol 4, no 2, pp125-160 [in Korean]

Yun, Sun-Jin and Won, Gil-Yeon (2012) 'Social acceptance of Lee Myung-bak's green growth-based climate change policy regime: An evaluation based on a survey of experts' perceptions', ECO, vol 16, no 2, pp7-50 [in Korean]

Yun, Sun-Jin, Ku, Dowan and Han, Jin-Yi (2014) 'Climate policy networks in South Korea: Alliance and conflicts', Climate Policy, vol 14, no 2, pp283-301 


\title{
Thailand: Shirking Away from Ethical Responsibility to Respond to Climate Change
}

\author{
Danny Marks
}

This report responds to the research questions of the Project On Deepening National Responses to Climate Change On The Basis of Ethics and Justice, a joint project of the University of Auckland, School of Architecture and Planning and Widener University, School of Law, Environmental Law Center. The research questions and responses are as follows:

1. To what extent has the national debate about how the nation should respond to climate change by setting a ghg emissions reduction target expressly considered that the nation not only has economic interests in setting the target but also ethical obligations to those who are most vulnerable to climate change and that any national ghg emissions reduction target must represent the nation's fair share of safe global emissions? In answering this question, identify the national ghg emissions reduction target, if any, that the nation has made under the United Nations Framework Convention on Climate Change (UNFCCC).

From 1992 to 2010 , Thailand rose from 33rd to 22nd in the global emissions ranking, its emissions rising 9\% from 228.5 million tonnes of $\mathrm{CO}_{2}$ equivalent in 2009 to 248.5 million tonnes in 2010 (Rogers, 2012). Further, the capital city of Bangkok ranks as one of the highest-emitting cities in the world per capita. A World Bank study revealed that in 2005 Bangkok emitted 43 million tonnes of $\mathrm{CO}_{2}$, one million ton less than London, and $70 \%$ of the level of New York which has a much higher population (Croci, 2011).

However, despite Thai national policy-makers declaring the positive benefits of mitigating climate change and policy documents which express the country's plans to do so, Thailand still has not committed to any national quantitative targets for emissions reduction. Unlike a number of other middle-income countries, the government did not make any voluntary emissions pledge under the Copenhagen Accord in 2009 or 2010 and has not submitted any Nationally Appropriate Mitigation Action (NAMA) plan to the United Nations Framework Convention on Climate Change (UNFCCC). The previous government, led by Prime Minister Yingluck Shianwatra, had drafted a National Climate Change Master Plan 2013-2050 in which the country pledged to reduce ghg emissions by $7-20 \%$ compared to business-as-usual and which would serve as the basis for Thailand's NAMA. The 7\% would be the result of domestic initiatives; while the additional $13 \%$ would be the result of international support. However, there is no mention in the Master Plan about why this number range was chosen and no discussion of Thailand's ethical obligation to reduce emissions. The Master Plan does not refer to the need to limit the rise of global emissions to 2 degrees Celsius. Moreover, the draft has not been passed yet. While it was finalized at the end of July 2013, it was not passed by the previous government and the new military government has not shown any interest in climate change mitigation thus far (Nuntavorakarn et al, 2014).

Further, the national leaders have not used any language of ethics and justice when arguing why the country should reduce its emissions. For example, in a speech in 2009, previous Prime Minister Abhisit Vejjajiva stated: 'Thailand has long recognized the seriousness of climate change - which 
could have extensive damaging consequences for its environment, economic growth, and sustainable development' (Vejjajiva, 2009). Also, in 2013, the ex-Prime Minister Yingluck Shinawatra proclaimed: 'Emphasis should be made on solving problems at the source as well as diminishing human activities that would create climate change. From my own experience, the costs of collaborative planning and investment in prevention are less than damages incurred by problem solving and recovery after disaster and inundation' (Shinawatra, 2013). The Deputy Secretary of the National Economic and Social Development Board, Ladawan Kumpa, also framed the rationale for reducing emissions in terms of an economic cost-benefit analysis in a speech in 2012: 'Many studies show that the cost of no-action (or business as usual: BAU) is far greater than the cost of mitigation and adaptation measures. In other words, the benefits ... will always exceed the costs' (Kumpa, 2012).

More positively, in two master plans of the government, the Alternative Energy Development Plan (AEDP) 2012-2021 for renewable energy development and the 20-Year Energy Efficiency Development Plan (2011-2030) for energy efficiency, the government promises that increased renewable energy usage and improved energy efficiency respectively will lead to a reduction in carbon emissions of 125 million tonnes per year (Partnership for Market Readiness, 2013). However, this commitment is not binding and once again the rationale for reducing emissions is framed in terms of economic benefits, rather than ethical obligations. Further, if Thailand finally decides to reduce greenhouse gas emissions, as the Finnish NGO Kepa predicts, it will be due to the 'economic aspect, for example, less expenses, cost reduction, increased income' rather than any moral obligation (Nuntavorakarn et al, 2014, p34).

\section{In making a national commitment to reduce ghg emissions under the UNFCCC, to what extent, if at all, has the nation explained how it took equity and justice into consideration in setting its ghg emissions reduction target?}

As explained in answer to the first question, Thailand has not made a national commitment to reduce greenhouse gases. Further, Thailand has sought to block any international treaty which would require it and other developing countries to make emissions pledges under the UNFCCC. In the most recent UNFCCC Conference of the Parties (COP) in Warsaw in 2013, Thailand became a member of the LikeMinded Developing Countries (LMDC) group. Consisting of 12 other countries, this group has proposed that under any international treaty, only developed countries should be forced to cut emissions, not developing countries. Thailand's decision to join this group suggests that Thailand is trying to shirk away from becoming obligated to reduce emissions despite its significant level of emissions and therefore is not taking equity and justice into consideration (Fuhr et al, 2013).

3. Given that any national ghg emissions target is implicitly a position on achieving an atmospheric ghg concentration that will avoid dangerous climate change, to what extent has the nation identified the ghg atmospheric concentration stabilization level that the national emissions reduction target seeks to achieve in cooperation with other nations?

As explained in answer to the first question, the Thai government does not currently have any national ghg target, although in its Climate Change Master Plan, which still has not been passed, it sets a target of $7-20 \%$ emissions reduction. In the Master Plan, the government does not explain why it has set this range nor does it link this target to acceptable global atmospheric stabilization targets, such as limiting warming to 2 degrees Celsius. However, it is uncertain, given that there has been a military coup, whether the new government will pass this Master Plan and stick to these targets. 
4. Given that any national ghg emissions target is implicitly a position on the nation's fair share of safe global emissions, to what extent has the nation identified the ethical and justice considerations that it took into account in allocating a percentage of global ghg emissions to the nation through the identification of a ghg emissions reduction commitment?

Thailand emits a little over $1 \%$ of global greenhouse gas emissions and is the 19th largest emitter worldwide. However, as mentioned above, the country has not identified any ethical or justice considerations when taking into account its percentage of global greenhouse gas emissions. Rather, in UNFCCC negotiations, it adheres to the position that developed countries should make emissions reductions while developing countries should be able to continuing emitting until their countries become developed.

5. To what extent, if at all, has the nation acknowledged that nations emitting ghg above their fair share of safe global emissions have a responsibility to fund reasonable adaptation measures or unavoidable losses and damages in poor developing countries?

Thailand has not demonstrated any interest in funding adaptation measures or unavoidable losses and damages in lesser developed countries, such as its neighbouring countries. However, Thailand's funding of energy projects, including some which would reduce Thailand's emissions, in these countries has actually made them more vulnerable to climate change. For example, Thailand is importing approximately 2000 megawatts (MW) from nine hydropower dams in Laos (Middleton, 2012) and is currently planning to import additional electricity from new hydropower dams and lignite power plants in Laos and Burma. These projects, however, have negative environmental impacts and are hurting local communities there. For example, Thailand's funding of the construction of dams on the Mekong River, such as the Xayaburi dam, disrupts flood pulses and shrinks wetlands, thereby causing fish populations to decline. Large dams can also diminish the amount of sediments and nutrients supplied to downstream ecosystems because of sediment becoming trapped in reservoirs (Sarkkula et al, 2009). Local communities have been forced to resettle and receive inadequate compensation. Therefore, Thailand's actions can be deemed unethical.

6. What formal mechanisms are available in the nation for citizens, NGOs and other interested organizations to question/contest the nation's ethical position on climate change?

There are currently very limited mechanisms for citizens and interested organizations to question the nation's ethical position on climate change. Previously, NGOs lambasted the National Strategy on Climate Change 2008-2012 for giving inadequate scope for public participation - instead it gives higher priority to the interests and views of government officials and the private sector. In January 2011 Prime Minister Abhisit Vejjajiva responded to their criticisms by demanding that the Office of Natural Resources and Environmental Policy and Planning (ONEP), the author of the plan, revise it so that all stakeholders could be involved. Afterwards, ONEP did hold public hearings about the nation's climate change plan (Asean Affairs, 2011).

However, with an authoritarian military government now in control of the country, there are no mechanisms available for the public to question the government's position.

7. How is the concept of climate justice understood by the current government? Have they articulated any position on climate justice issues that arise in setting ghg emissions policy or in regard to the adaptation needs of vulnerable nations or people? 
No understanding of climate justice is displayed by the current government or past governments. The only understanding so far expressed by government agencies in favour of climate change mitigation is in terms of cost-benefit analysis. At the same time, the government blamed the 2011 floods on climate change which it used as an excuse for its poor response to the crisis (Marks, 2013). However, despite attributing the cause of the flooding to climate change, after the floods subsided, it did not make any efforts to mitigate climate change. This suggests that the government is not serious about mitigating climate change or reducing the country's vulnerability to flooding.

\section{Are you aware of any regional, state, provincial, or local governments in your country that have acknowledged some ethical responsibility for climate change? If so, what have they said?}

Klang Municipality in Rayong Province (in Eastern Thailand) which has a population of only 18,000 is renowned in Thailand for its environmentally friendly practices. The municipal government has set a goal of becoming a carbon-neutral city. It has worked in partnership with the Thailand Greenhouse Gas Management Organization as a pilot city to develop a greenhouse gas inventory as well as creating a handbook on how to develop a low-carbon city which will be disseminated to other municipalities nationwide. The Mayor Somchai Chariyacharoen has initiated a waste management system to reduce carbon output, improved energy efficiency, increased renewable energy usage, and has developed two low-carbon learning centres. The Mayor has initiated this programme because he believes that cities should be sustainable and emit a low amount of carbon. While he does not explicitly use the language of ethics, it seems that he believes that cities have an ethical obligation to reduce their carbon emissions and become more environmentally friendly (Chariyacharoen, 2010). However, few other municipalities have so far followed his lead.

In contrast, despite emitting about the same amount of carbon as London, the Bangkok Metropolitan Authority (BMA) has neither made any firm commitment to reduce its overall emissions nor has acknowledged any ethical responsibility for climate change. Instead, it has merely organized small single-day events to promote climate change mitigation which have had limited effect and have not slowed down the city's emissions. For example, in 2007 it organized the 'Use Compact Fluorescent Lamps' and 'Stopping Engines While Parked' campaigns. None of the campaigns significantly lowered the city's overall emissions, nor did the BMA offer any ethical rationale for why people should reduce their emissions, instead linking these campaigns to economic benefits (World Bank, 2009).

\section{Has your national government taken any position on or otherwise encouraged individuals, businesses, organizations, subnational governments, or other entities that they have some ethical duty to reduce greenhouse gas emissions?}

As explained in response to the previous question, while some local governments have encouraged individuals that they have some ethical duty to reduce greenhouse gas emissions, not all have done so. Moreover, the national government has not yet done so.

However, a group of civil society organizations, entitled the 'Thai Working Group for Climate Justice', has tried to help fill this gap. The Working Group's key goal is 'time promoting economic, political, and social justice aspects in the climate debate and climate policy, on both mitigation and adaptation parts'. In their recommendations to the Thai governments, they proclaim: 'Thailand is not obliged to reduce its emissions under the Kyoto Protocol; however, a large number of civil society groups and communities have come to an agreement that Thailand should signify its development towards [a] livable [sic] and sustainable society with low carbon emission.' They also add that '[f]urther 
development in Thailand from now on therefore has to put more emphasis upon local communities and environmental protection' (Thai Working Group for Climate Justice, 2009). Given Thailand's high degree of vulnerability to climate change, ranking it 16th most vulnerable in the world, this group's call to protect local communities, who are highly vulnerable to these impacts, suggests an ethical dimension to their position. However, the government has yet to adopt these recommendations.

10. What recommendations would you make to get the nation or civil society to take ethics and justice issues seriously in climate change policy formulation?

Even though the greenhouse gases sinking Bangkok and intensifying extreme weather events originate primarily from China, the US, the EU and India, which together emit over half of global emissions - meaning that a Thai effort will not have a significant effect on its own salvation Thailand should immediately make a commitment to mitigate its emissions at an appropriate level of need to prevent more than 2 degrees of global warming. It should do this to demonstrate that it is an ethical global citizen. Moreover, by demonstrating that Thailand can adhere to high ethical standards, the government will put pressure on other countries, such as regional neighbours and India and China, to follow suit.

Therefore, Thailand should also immediately change its stance in UNFCCC negotiations. It should work with other countries to pressure the major emitters to do more to cut their emissions. While smaller developing countries can rightly argue that developed countries should make deep cuts and assist developing countries to both mitigate and adapt, they need to collectively exert more pressure on big developing countries, especially China and India, to curb their emissions. 


\section{References}

Asean Affairs (2011) 'Thai PM requests new climate document', 7 January, http://www.aseanaffairs.com/thailand news/environment/thai_pm requests new_climate document

Chariyacharoen, S. (2010) 'Low-Carbon Activities in a Small City', http://lcs-rnet.org/past/meetings locarnet/2010/11/pdf/D1S3_2_Chariyacharoen.pdf

Croci, E., Melandro, S. and Molteni, T. (2011) 'Comparing Mitigation Policies in Five Large Cities: London, New York City, Milan, Mexico City, and Bangkok', in D. Hoornweg, Mila Freire, Marcus J. Lee, Perinaz Bhada-Tata and Belinda Yuen (eds), Cities and Climate Change: Responding to an Urgent Agenda, The International Bank for Reconstruction and Development and The World Bank, Washington, DC, pp55-85

Fuhr, L., Schalatek, Liane, Ugryn, Katazyrna and Permpibul, Wanun (2013) 'After COP 19 in Warsaw - Checkmate for International Climate Politics', 3 December, Heinrich Böll Stiftung / The Green Political Foundation, http:// www.boell.de/en/2013/12/03/after-cop-19-warsaw-checkmate-international-climate-politics

Kumpa, L. (2012. 'Opening Speech - Economic[s] of Climate Change Forum: Perspectives from Korea and Thailand', 29 February, eaneo.nesdb.go.th/pdf/104001-002.pdf

Marks, D. (2013) 'After the floods, have lessons been learnt?', Bangkok Post, 5 December, http://www.bangkokpost. com/opinion/opinion/383252/after-the-floods-have-lessons-been-learnt

Middleton, C. (2012) 'Transborder Environmental Justice in Regional Energy Trade in Mainland South-East Asia', ASEAS - Austrian Journal of South-East Asian Studies, vol 5, no 2, pp292-315

Nuntavorakarn, S., Triratsakulchai, Napha, Nuntavorakarn, Buddhina, Sopapum, Navin and Wongsakul, Patchara (2014) The Survey and Assessment of the Appropriate Share of Climate Change Mitigation Actions in Developing Countries: The Case of Thailand, April, Healthy Public Policy Foundation, Thailand

Partnership for Market Readiness (2013) 'Thailand', https://www.thepmr.org/country/thailand-0

Rogers, S. (2012) 'World carbon emissions: the league table of every country', The Guardian, 21 June, http://www. theguardian.com/environment/datablog/2012/jun/21/world-carbon-emissions-league-table-country

Sarkkula, J., Keskinen, M., Koponen, J., Kummu, M., Richey, J. E. and Varis, O. (2009) 'Hydropower in the Mekong Region: What Are the Likely Impacts upon Fisheries?', in François Molle, Tira Foran and Mira Käköken (eds) Contested Waterscapes in the Mekong Region: Hydropower, Livelihoods and Governance, Earthscan, London, pp227-249

Shinawatra, Y. (2013) 'Opening Statement by H.E. Ms. Yingluck Shinawatra Prime Minister of Thailand on the Inauguration of the 2nd Asia-Pacific Water Summit', 20 May, http://www.waterforum.jp/en/what_we_do/ pages/policy_recommendations/APWF/2nd_APWS/outcome/doc/Opening_Statement_H.E_Yingluck_ Shinawatra.pdf

Thai Working Group for Climate Justice (2009) 'Thai Civil Society's Recommendations to Thai Government Towards COP15, December 2009', http://oilwatch-sea.org/content/view/247/1/

Vejjavija, A. (2009) 'Statement by H.E. Mr. Abhisit Vejjajiva, "The Cool Earth Seminar" Santi Maitri Building, Government House Bangkok, Thailand', http://www.thaiembassy.sg/press_media/speeches/statement-byhe-mr-abhisit-vejjajiva-\%E2\%80\%9Cthe-cool-earth-seminar\%E2\%80\%9D-santi-maitri-buil

World Bank, The (2009) Climate Change Impact and Adaptation Study for Bangkok Metropolitan Region: Final Report, March, https://openknowledge.worldbank.org/handle/10986/3113 


\section{Uganda's Consideration of Ethics and Justice Issues in Formulating Climate Policies}

\section{Akampurira Andrew}

This report responds to the research questions of the Project On Deepening National Responses to Climate Change On The Basis of Ethics and Justice, a joint project of the University of Auckland, School of Architecture and Planning and Widener University, School of Law, Environmental Law Center. The research questions and responses are as follows:

1. To what extent has the national debate about how the nation should respond to climate change by setting a ghg emissions reduction target expressly considered that the nation not only has economic interests in setting the target but also ethical obligations to those who are most vulnerable to climate change and that any national ghg emissions reduction target must represent the nation's fair share of safe global emission? In answering this question, identify the national ghg emissions reduction target, if any, that the nation has made under the United Nations Framework Convention on Climate Change (UNFCCC).

Uganda spans almost $236,000 \mathrm{~km}^{2}$ and has a population of nearly 33 million. Climate is considered as one of the major resources. In general, the country experiences two rain seasons but there are inter-annual variations in both the onset and the total amounts. Rain-fed agriculture is the mainstay of the economy accounting for about $70 \%$ of GDP and over $95 \%$ of merchandise exports and therefore the growth of the agricultural sector greatly determines the performance of the economy. It provides employment for about $80 \%$ of the population and is the economic base for much of the manufacturing and service industries. Negative climate change would adversely affect the economy. ${ }^{1}$ National policies must therefore be evolved to tackle the problem of global warming associated with greenhouse gas emissions. The key impacts of climate change are likely to strongly affect the following sectors:

- agriculture

- forestry

- natural ecosystems and wildlife

- water resources

- fisheries

- human settlements

- energy

- transport and industry

- human health

- air quality and ultraviolet intensities

Due to the relatively low level of industrialisation in Uganda, the major emissions are from fuel-wood combustion for domestic activities. Solar energy has been introduced to reduce carbon emissions. There are national and international NGOs which are on the ground urging local communities to plant trees in order to reduce carbon emission effects. This is being done but has nothing much to do with the question of equity, ethics and justice as part of national policy and law. 
Variability has long been a characteristic of Uganda's climate, and dealing with it is part and parcel of rural livelihoods. However, the capacity of individuals to respond to climate variability remains generally low, particularly in rural contexts. Livelihoods are particularly sensitive to fluctuations in seasonal rainfall. Uganda is highly vulnerable to climate change and variability - its economy and the wellbeing of its people are tightly bound to climate. New international financial and political attention on climate change also has the potential to strengthen weak institutions and to reduce the social vulnerability and inequity which has long been a target of development assistance. However, although pockets of excellent technical expertise and disparate activities on climate change are emerging, in part through response to the UNFCCC, action by government to date falls well short of what is needed to climate-proof Uganda's development. A reduction in global greenhouse gas emissions is not only the goal of environmentalists but also of pretty much every government in the world. Uganda's ranking according to greenhouse gas emissions per capita in 2009 is based on data for carbon dioxide, methane, nitrous oxide, perfluorocarbon, hydrofluorocarbon and sulfur hexafluoride emissions compiled by International Energy Statistics from a variety of sources. ${ }^{2}$

Figure 1.1 Uganda's ranking according to greenhouse gas emissions per capita in 2009

\begin{tabular}{|c|c|c|c|c|c|c|}
\hline Table id & Rank, 2009 & $\begin{array}{c}\text { Country or } \\
\text { region }\end{array}$ & $\begin{array}{c}2008, \text { mil } \\
\text { tonnes }\end{array}$ & $\begin{array}{c}2009, \text { total, } \\
\text { mil tonnes }\end{array}$ & $\begin{array}{c}2009, \text { per } \\
\text { capita, } \\
\text { tonnes }\end{array}$ & $\begin{array}{c}\text { \% change, } \\
2008 \text { to } \\
2009\end{array}$ \\
\hline 175 & 152 & Uganda & 1.99 & 1.93 & 0.06 & -3 \\
\hline
\end{tabular}

Climate change threats continue to pose the greatest challenges not only at the global level but also in Uganda. Global efforts aimed at tackling the rising emissions of greenhouse gases (ghg) associated with global warming due to human activities continue to dominate the international agenda. Uganda, as a Party to the UNFCCC and its Kyoto Protocol, has commitments and obligations to comply with as part of contributing to tackling climate change. At the national level, the institutional arrangements to handle climate change adaptation and mitigation including addressing the cross-cutting areas of awareness, mainstreaming, and means of implementation through financing, technology transfer, and capacity building are already in place. Climate change mitigation which broadly covers tackling the root cause of greenhouse gas emissions and taking advantage of clean technologies is important in Uganda's context as part of contributing to the sustainable development of the country. Indeed the National Development Plan (NDP) emphasizes among the strategic objectives under climate change the need to promote the low-carbon development pathway for the country and climate-proof our national development.

\section{Uganda's eight priority NAMAs}

Eight NAMAs out of a long list of 40 NAMAs have been identified as priority actions for Uganda's mitigation action on climate change, as listed below (note: all NAMA proposals are still under final technical review):

\section{Promotion of upland rice (agriculture sector)}

This NAMA seeks to increase rice production in Uganda for both domestic and export markets by promoting the cultivation of high-yielding upland rice combined with a reduction in total acreage of paddy rice. 


\section{Mitigation of emissions resulting from livestock (agriculture sector)}

This NAMA seeks to develop methods and technical options to reduce ghg emissions from livestock production in Uganda.

\section{Institutional stoves in educational institutions (energy sector)}

The purpose of this NAMA is to promote the use of energy-efficient institutional stoves in educational institutions.

\section{Vehicle fuel efficiency (energy sector)}

Through the implementation of a Fuel Efficiency Initiative and the promotion of more efficient vehicles, this NAMA seeks to reduce greenhouse gas emissions in the transport sector.

\section{Bus rapid transit for Kampala (transport sector)}

The purpose of this NAMA is to improve the efficiency of public transport while saving and reducing emissions associated with public transportation in the Kampala metropolitan region.

\section{Enforce periodic vehicle inspection for emissions and roadworthiness (transport sector)}

This NAMA seeks to reduce emissions in the transport sector by establishing a compulsory regular emissions check-up for vehicles. Such a policy is needed in Uganda because of the high potential for economic growth and prosperity that will lead to increased vehicle importation and use.

\section{Municipal solid waste compost for smaller urban areas (waste sector)}

The purpose of the NAMA is to extend a successful municipal solid waste compost programme to smaller urban areas. It will extend mitigation actions to as many parts of the country as possible, improve waste management, and increase the utilization of agricultural waste for compost manure.

\section{Integrated wastewater treatment (waste sector)}

This NAMA will encourage ghg emissions reductions from agro-industry wastewater. ${ }^{3}$

With support from the Ugandan Parliament, GIZ, and the Ministry of Water and Environment, the Parliamentary Forum on Climate Change (PFCC) convened a regional climate change symposium in Kampala, Uganda in 2010. This brought together policy-makers from the East African Community and Southern Africa to discuss regional climate change concerns. ${ }^{4}$ The symposium concluded with an urgent call to governments across the continent to develop national climate change policies and treat climate change mitigation/adaptation as a development concern. Negotiations are currently ongoing with different donors on mechanisms for providing funding to the strategic plan and other forum processes. The mission during the new intervention timeframe is to 'ensure proactive and coordinated actions from all stakeholders so that the most vulnerable sectors of the economy are climate proofed and sustainable development is achieved'. Despite the various attempts to make and maintain good climate in Uganda, there are no concrete government policies or programmes on ghg emission reduction per se. The reality is that caring for the environment is not among the priorities of the Ugandan government. Uganda, like many other developing countries, has not taken considerations of ethics and justice into account in developing national policy and law.

Under the UNFCCC, Uganda has acknowledged the responsibility to reduce ghg emissions and it is trying to make reductions, but the fact is that little has been done. Under the Green House Gas Inventory Component, the need for compiling a national ghg inventory as an international obligation of the country has been affirmed. In 2008 the government established a Climate Change Unit and 
an institutional framework for the Clean Development Mechanism. Generally, Uganda is committed towards the conventions and multilateral agreements that have been ratified.

2. In making a national commitment to reduce ghg emissions under the UNFCCC, to what extent, if at all, has the nation explained how it took equity and justice into consideration in setting its ghg emissions reduction target?

Uganda is a Non-Annex I signatory of the United Nation Framework Convention on Climate Change (UNFCCC) and acceded to the Kyoto Protocol in March 2002. As explained in answer to the first question, the Ugandan government has not taken considerations of ethics and justice into account in developing national policy and law. Uganda continues to pilot the National Adaptation Programmes of Action as a means for responding to short-term needs. The government strongly believes in and supports the establishment of a more inclusive regime that combines both voluntary and supported mitigation actions consistent with the principles of equity and common but differentiated responsibility. ${ }^{5}$

3. Given that any national ghg emissions target is implicitly a position on achieving an atmospheric ghg concentration that will avoid dangerous climate change, to what extent has the nation identified the ghg atmospheric concentration stabilization level that the national emissions reduction target seeks to achieve in cooperation with other nations?

As explained in answer to the first question, Uganda has not taken considerations of ethics and justice into account in developing national policy and law. However, in 2008 the government established a Climate Change Unit and an institutional framework for the Clean Development Mechanism. A Climate Change Policy Committee and an Inter-institutional Climate Change Technical Committee were also established. The Parliamentary Forum on Climate Change and the participation of the President of Uganda, Museveni Yoweri, in the Committee of African Heads of State and Government on Climate Change demonstrate political involvement and commitment at the highest level. Generally, Uganda is committed towards the conventions and multilateral agreements that have been ratified. ${ }^{6}$ Under the Green House Gas Inventory Component the need for compiling a national ghg inventory as an international obligation of the country has been affirmed. In this regard, the government will take responsibility to ensure that it is conducted according to international norms and requirements. ${ }^{7}$

4. Given that any national ghg emissions target is implicitly a position on the nation's fair share of safe global emissions, to what extent has the nation identified the ethical and justice considerations that it took into account in allocating a percentage of global ghg emissions to the nation through the identification of a ghg emissions reduction commitment?

As explained in answer to the first question, Uganda has not taken considerations of ethics and justice into account in developing national policy and law. The country is developing and needs to address the needs of its people. It is particularly vulnerable to climate change, hence it cannot take stronger mitigation actions unless supported by mitigation and technology transfers. There are various national initiatives that demonstrate the political will of the government and determination of the people of Uganda towards addressing climate change challenges. However, these initiatives are greatly constrained by a low level of development associated with weak institutional capacity, and lack of efficient and appropriate technologies. The support of developed countries is therefore crucial in complementing national efforts for developing countries like Uganda. 
5. To what extent, if at all, has the nation acknowledged that nations emitting ghg above their fair share of safe global emissions have a responsibility to fund reasonable adaptation measures or unavoidable losses and damages in poor developing countries?

Uganda, as a Party to the UNFCCC and its Kyoto Protocol, has commitments and obligations to comply with as part of contributing to tackling climate change. However, Uganda is a developing country and so it does not fall into the category suggested here of big polluters (Uganda's ranking according to greenhouse gas emissions per capita in 2009 is noted in the response to the first question above).

6. What formal mechanisms are available in the nation for citizens, NGOs and other interested organizations to question/contest the nation's ethical position on climate change?

It is difficult for citizens to contest government decisions. Moreover, when land is taken by the government or it places restrictions on land for the purposes of environmental protection, there is little if any compensation. However, either formally or informally, concerned NGOs and embassies/ consulates meet with officials in serious environmental cases. Occasionally, NGOs/embassies hold talks with the public and sometimes make recommendations to the government.

7. How is the concept of climate justice understood by the current government? Have they articulated any position on climate justice issues that arise in setting ghg emissions policy or in regard to the adaptation needs of vulnerable nations or people?

As explained in answer to previous questions, Uganda has not taken considerations of ethics and justice into account in developing national policy and law. Uganda is a developing country and so it does not fall into the category suggested here of big polluters. Instead, developed countries should support Uganda financially and in providing appropriate technology among other things to complement national efforts to address climate change challenges.

8. Are you aware of any regional, state, provincial, or local governments in your country that have acknowledged some ethical responsibility for climate change? If so, what have they said?

The government has acknowledged this responsibility. Regarding ghg emissions, the Ugandan government usually talks of it generally as a global issue. In this way, it somehow acknowledges some responsibility, but does not do much. The concept of recycling and healthy urban transport that does not pollute, as well as the sustainable development of renewable energy sources, are some of the ideas that have been raised but unfortunately have always been on paper, and have not been put into practice. We have to take note of the fact that these ideas are not much related with ethics and justice. The government decided, in agreement with DFID (Department for International Development - UK), to reflect this need for long-term flexibility and focus instead on the capacity to adapt. For many communities in Uganda, already challenged in dealing with current climate conditions, responding to future climate variables will require them to modify their characteristics, and potentially transform their structure and how they organize themselves in order to successfully adapt. ${ }^{8}$ Importantly, communities face the challenge not only of responding to changes in climate, but of changing development pressures too, such as shifting patterns of internal/external migration, changing economic models, and rapid population growth. Also important to bear in mind is that adaptive capacity is context-specific and varies from district to district, community to community, between social groups and individuals, and over time (Smit and Wandel, 2006). 


\section{Has your national government taken any position on or otherwise encouraged individuals, businesses, organizations, subnational governments, or other entities that they have some ethical duty to reduce greenhouse gas emissions?}

As stated in answer to the previous question, Uganda has acknowledged the responsibility but does not do much since it is seen more as a global issue 'we' than a country issue 'l'. To a small extent, Uganda provides guidance on how to approach climate change challenges, but despite some efforts, we must assert clearly that the Ugandan government has not taken considerations of ethics and justice into account in developing national policy and law.

10. What recommendations would you make to get the nation or civil society to take ethics and justice issues seriously in climate change policy formulation?

\section{Raise awareness of the international causes of climate change}

At the moment, there is very low awareness in Uganda of the 'political injustice of climate change' - many people perceive climate change to be a local issue. Climate change communicators should aim at increasing awareness of the fact that industrialized countries are responsible (to a great extent) for causing climate change. Civic awareness can be created through media reports on the role of the industrialized nations in causing climate change. However, communicators must take great care to ensure that raising this awareness does not encourage people to avoid taking responsibility for adapting to climate change. Uganda may not have caused climate change, but it will face its effects. Climate change must become a national governance issue.

\section{Make local and national leaders accountable for taking action on climate change}

It is not something that can be tackled without coordinated government programmes. A national campaign could be initiated for addressing failed government commitments or donors that do not support the needs and demands of developing countries in international climate summits.

\section{Engage the media on climate change issues}

The media is not fully engaged in covering climate change - certainly not to the extent warranted by the seriousness of the threat. Training programmes to engage both journalists and editors are essential, but civil society organizations must also improve the way they engage with the media, packaging information in a clear and simple way and actively attracting the media's attention.

\section{Bridge the communication divide on climate change}

Local languages lack terms for many key concepts involved in climate change - including 'climate change' itself. Communicators should attempt to explain climate change using terms that already exist, using graphic examples of local environmental problems and innovative communication methods (e.g. dramatization) to get the message across.

\section{Take action on the international causes of climate change}

At a national and international level, politicians are not being held to account for taking action on climate change - but this is partly because there is such little awareness of the international causes of climate change. Raising awareness about the role of industrialized nations in causing climate change, and pressuring national politicians to make greater progress at international negotiations is critical.

\section{Catalyse action on climate change at the local politics level}

At the local level, politicians tend to be poorly informed about climate change, yet local government structures represent a crucial opportunity for reaching large numbers of ordinary citizens. Sensitization 
campaigns should focus on local politicians as a key constituency that can catalyse action on climate change.

\section{Supplement indigenous understanding with scientific information on climate change}

Indigenous knowledge about land management and the environment is incredibly valuable when trying to engage people on climate change, but it must be supplemented with scientific information about the causes and consequences of climate change. Climate change represents a significant challenge to indigenous ways of understanding the weather and farming - and so people must be supported with additional knowledge and information wherever possible, including the improved dissemination of meteorological information through local radio stations.

\section{Coordinate climate change activities across sectors}

At the national level, issues of climate change are poorly mainstreamed across sectors. Government development plans give little recognition to the impacts of climate variability and change on existing operations, and do not sufficiently promote actions to support adaptation and enhance adaptive capacity. This has direct implications for local planning, as centrally disbursed funds to local governments are largely limited to Uganda's five National Priority Programme Areas (education, health, clean and safe water, feeder roads, and agriculture (NAADS)). This requires better processes of coordination and governance among all relevant development partners to ensure that all five areas are addressed within the community. This is not to say that every individual development intervention should strive to address all five areas. Rather, as a collective, government and development partners should ensure they are coordinating activities so that, where relevant, they can best support adaptive capacity at the local level.

\section{Educate future generations for climate change adaptation}

To achieve climate stabilization will necessitate radical changes in lifestyle and behaviour, and education has the power to equip future generations with the skills and knowledge they will need to thrive and survive.

\section{Encourage developed nations to honour their ethical obligations to developing countries}

Those who have benefited and still benefit from emissions in the form of ongoing economic development and increased wealth, mainly in industrialized countries, have an ethical obligation to share benefits with those who are today suffering from the effects of these emissions, mainly vulnerable people in developing countries.

\section{Comply with international treaties and cooperate with other nations to tackle climate change}

The Ugandan government should adhere to the international treaties regarding ghg emissions and should cooperate with other nations as one way to solve the problem.

\section{Instil the concept of individual and collective responsibility for climate change from} childhood

Educate children from an early age about the responsibility of each person, community, and country in the global problem of climate change. In this way, the people will be conscious of the problem and the implications and impacts of their activities and the activities of their government. 


\section{Notes}

1 US Global Change Research Information Office, www.gcrio.org/.../ugan..., accessed 19 August 2014.

2 Rogers, Simon and Evans, Lisa (2011) 'World carbon dioxide emissions data by country: China speeds ahead of the rest', The Guardian online, http://www.theguardian.com/news/datablog/2011/jan/31/world-carbondioxide-emissions-country-data-co2, accessed 19 August 2014. International Energy Statistics, http://tonto. eia.doe.gov/cfapps/ipdbproject, accessed 19 August 2014.

3 Isabirye, P. and Chebet, M. (n.d.) 'Uganda's Eight Priority NAMAs', http://mitigationpartnership.net/ugandastakeholder-involvement-development-nationally-appropriate-mitigation-actions-namas, accessed 19 August 2014.

4 Parliament of Uganda, www.parliament.go.ug/...parliament, accessed 4 August 2014.

5 Kamuntu, Ephraim (2013) Statement to COP19/CMP9, http://unfccc.int/files/meetings/warsaw_nov_2013/ statements/application/pdf/cop19 hls uganda.pdf, accessed 10 September 2014.

6 Kamuntu, Ephraim (2012), Statement to COP18/CMP8, http://unfccc.int/resource/docs/cop18_cmp8_hl_ statements/Statement\%20by\%20Uganda.pdf, accessed 11 September 2014.

7' Nationally appropriate mitigation actions (NAMAs)', http://www.undp-alm.org/projects/bf-uganda-nama, accessed 20 August 2014.

8 Parliamentary Forum on Climate Change (PFCC), http://www.parliament.go.ug/new/index.php/18parliament-of-uganda/members-of-parliament?start=6, accessed 18 August 2014. 


\section{References}

Basu, A. et al (2013) 'Nationally appropriate mitigation action study on sustainable charcoal in Uganda', http:// eldis.org/go/home\&id=63698\&type=Document\#.U NY6qPRQwo, accessed 19 August 2014

Ford, J., Smit, B. and Wandel, J. (2006) 'Vulnerability to climate change in the Arctic: A case study from Arctic Bay, Nunavut', Global Environmental Change, vol 16, no 2, pp145-160

International Energy Statistics, http://tonto.eia.doe.gov/cfapps/ipdbproject, accessed 19 August 2014

Isabirye, P. and Chebet, M. (n.d.) 'Uganda's Eight Priority NAMAs', http://mitigationpartnership.net/ugandastakeholder-involvement-development-nationally-appropriate-mitigation-actions-namas, accessed 19 August 2014

Kamuntu, Ephraim (2012) Statement to COP18/CMP8, http://unfccc.int/resource/docs/cop18_cmp8 hl statements/Statement\%20by\%20Uganda.pdf, accessed 11 September 2014

Kamuntu, Ephraim (2013) Statement to COP19/CMP9, http://unfccc.int/files/meetings/warsaw_nov_2013/ statements/application/pdf/cop19_hls_uganda.pdf, accessed 10 September 2014

'Nationally appropriate mitigation actions (NAMAs)', http://www.undp-alm.org/projects/bf-uganda-nama, accessed 20 August 2014

Parliament of Uganda, www.parliament.go.ug/...parliament, accessed 4 August 2014

Parliamentary Forum on Climate Change (PFCC), http://www.parliament.go.ug/new/index.php/18-parliament-ofuganda/members-of-parliament?start=6, accessed 18 August 2014

Rogers, Simon and Evans, Lisa (2011) 'World carbon dioxide emissions data by country: China speeds ahead of the rest', The Guardian online, http://www.theguardian.com/news/datablog/2011/jan/31/world-carbondioxide-emissions-country-data-co2, accessed 19 August 2014

Smit, B. (2010) 'Climate change, agriculture and weeds', in K. N. Harker (ed.) The Politics of Weeds, Topics in Canadian Weed Science, vol 7, Canadian Weed Science Society, Pinawa, Manitoba, pp13-23

The Sphere Project (2011) Humanitarian Charter and Minimum Standards in Humanitarian Response, http://www. sphereproject.org/dmdocuments/What_is_new_in_the_2011_edition_of_the_Sphere_Handbook_final.pdf, accessed June 4, 2014

UNEP (2003) 'Innovative communities: Community centered approaches to sustainable environmental management', http://www.unep.or.jp/ietc/kms/data/226.pdf, accessed 27 January 2014.

Wandel, J., Young, G. and Smit, B. (2009) ‘The 2001-2002 drought: Vulnerability and adaptation in Alberta's special areas', Prairie Forum, vol 34, no 1, pp211-234 



\section{The United States of America's Consideration of Ethics and Justice Issues in Formulating Climate Change Policies}

\section{Donald A. Brown}

This paper responds to the research questions of the Project On Deepening National Responses to Climate Change On The Basis of Ethics and Justice, a joint project of the University of Auckland, School of Architecture and Planning and Widener University, School of Law, Environmental Law Center. The research questions and responses are as follows:

1. To what extent has the national debate about how the nation should respond to climate change by setting a ghg emissions reduction target expressly considered that the nation not only has economic interests in setting the target but also ethical obligations to those who are most vulnerable to climate change and that any national ghg emissions reduction target must represent the nation's fair share of safe global emissions? In answering this question, identify the national ghg emissions reduction target, if any, that the nation has made under the United Nations Framework Convention on Climate Change (UNFCCC).

After two decades of international negotiations on climate change during which the United States made no greenhouse gas (ghg) emissions reduction target commitments, on 25 November 2009 US President Obama announced a ghg emissions reduction target of $17 \%$ below 2005 levels by 2020 (US DOE, 2009). At the same time that he announced this goal, President Obama made reference to a goal of $83 \%$ reduction in ghg emissions by 2050 which was based on pending legislation which was never passed by the US Congress (US DOE, 2009). In 2009 the United States also agreed with other G8 countries to reduce US ghg emissions by $80 \%$ by 2050 , although the US disagreed with the other G8 nations except Japan that the baseline year should be 1990 (Wintour and Elliot, 2009). The United States' preferred baseline year is 2005.

The US has not explained why the $17 \%$ below 2005 emissions reduction commitment or $80 \%$ reduction below 2005 emissions by 2050 aspiration represents the US fair share of safe global emissions. In fact, the Obama administration has been silent on how issues of justice or fairness have influenced the US quantitative determination of its ghg emissions reduction commitments.

Although it is speculation, it would appear that the reference by the United States to a needed $80 \%$ reduction by 2050 was derived from a 2007 report by the Intergovernmental Panel on Climate Change (IPCC, 2007, p776) which concluded that developed nations needed to reduce ghg emissions by $25 \%$ to $40 \%$ below 1990 emissions levels by 2020 and $80 \%$ to $95 \%$ by 2050 for the world to have any reasonable chance of limiting warming to $2^{\circ} \mathrm{C}$. If this is the case, the US government has not explained why the US believes it need only achieve the lower end of the $80 \%$ to $95 \%$ reduction range for 2050 emissions for developed nations identified by the IPCC in 2007 nor why the current commitment of $17 \%$ below 2005 emissions in 2020 is justified given the much higher $25 \%$ to $40 \%$ reduction targets by 2020 recommended by the IPCC in 2007 for developed nations. 
It would also appear when determining any of its ghg commitments that the United States has not considered the most recent carbon budget identified by the IPCC's 5th Assessment Report (IPCC, 2013, p27). A carbon budget is a limit of total ghg emissions for the entire world that must constrain global emissions to have any reasonable hope of limiting warming to $2^{\circ} \mathrm{C}$ or any other temperature limit. The IPCC budget is understood to define a limit of future carbon emissions of approximately 270 gigatonnes carbon (GtC) to have a $66 \%$ chance of limiting the warming to $2^{\circ} \mathrm{C}$ (Pidcock, 2013). The $2^{\circ} \mathrm{C}$ warming limit has been agreed to by the international community including the United States as necessary to prevent potentially catastrophic climate change.

Because any US ghg target is implicitly a position on the US fair share of safe global emissions, any US emissions reduction target may only be justified as a matter of ethics and justice by explaining why the US commitment is a fair share of an acceptable global carbon emissions budget. Yet, the Obama administration has made no attempt to explain or justify its commitment target in reference to a global carbon budget or a warming limit.

Recently, President Obama also announced a proposed new regulation that would limit emissions from the electricity generation sector by $30 \%$ by 2030 (Davenport, 2014). Yet this announcement was made without any explanation of how this reduction amount was linked to the US fair share of safe global emissions. In fact, President Obama justified the new regulation on the basis of how it would protect the health of US citizens (McCarthy, 2014). In justifying this new regulation on the health of Americans, rather than on reduced potential harms caused by US emissions to hundreds of millions of some of the world's poorest people who are most vulnerable to climate change, President Obama failed to acknowledge US ethical responsibilities to reduce the threat of climate change to the rest of the world including future generations.

During a speech at Georgetown University in June 2013, President Obama did acknowledge in very general terms that the United States has responsibility for climate change when he said:

[A]s the world's largest economy and second-largest carbon emitter, as a country with unsurpassed ability to drive innovation and scientific breakthroughs, as the country that people around the world continue to look to in times of crisis, we've got a vital role to play. We can't stand on the sidelines. We've got a unique responsibility. (Obama, 2014)

Yet President Obama has never identified the US policy implications of having a responsibility to the world for its ghg emissions.

The debate about climate change in the United States has for over 35 years focused almost exclusively on two kinds of issues. These issues have been framed by opponents of proposed US climate change policies. For the most part the US government and NGOs have responded to these issues ignoring ethical justification for US policy.

The first issue has been whether there has been sufficient scientific certainty about human causation of harmful climate change to warrant climate policies given the likely costs of climate change policies to certain sectors of the US economy.

The second issue which has dominated US climate policy debates for the last few decades is based on claims that proposed climate law and policies would impose unacceptable costs on the US economy. The cost arguments have taken several forms (Brown, 2012b, p57). These arguments have included that proposed climate legislation and policies would destroy jobs, reduce US GDP, damage specific businesses such as the coal and petroleum industries, increase the cost of fuel, or simply 
that proposed climate policies and legislation are unaffordable (Brown, 2012b, p57). Another common implicit cost argument frequently made in opposition to US climate change policies has been that the United States should not act until China, or other countries that pose significant economic competition for the United States, act (see, for example, American Farmland Trust, 2014).

Although both the scientific uncertainty and cost arguments made in opposition to US climate law and policies can be shown to be ethically problematic because they ignore US ethical obligations to others (see Brown, 2012b, pp57-137), these arguments have failed to be examined in the US press or responded to by the US government through an ethical lens (Brown, 2009; Brown, 2012b). In response to arguments that the United States should not reduce its emissions until China does so, for instance, the US government and US NGOs have sometimes said that the world needs US leadership rather than acknowledging that the US has ethical obligations to reduce its emissions to people and nations who are vulnerable to climate change and that current US emissions are and will continue to cause harm unless reduced from current levels.

With very few exceptions, the US press has utterly failed to cover climate change as an ethical and moral issue while focusing on the scientific and economic arguments against taking action that have been framed by opponents of US climate change policies.

By focusing on the cost issues to the US economy, the US press has reinforced the ethically problematic notion that cost to the US economy alone is an acceptable justification for inaction on climate change.

One rare exception to the absence of coverage of the ethical dimensions of climate change was a 2013 New York Times report that the international climate change negotiations were increasingly focusing on issues of importance to developing countries such as who should pay for adaptation and damage to poor nations that have done little to cause climate change (Meyers and Kulish, 2013). Yet this story failed to discuss how the ethical obligations of high-emitting nations to poor vulnerable nations and people has practical significance for US climate change policies.

Despite recent increases in the number of climate change stories in the US media in response to Hurricane Sandy's destruction in New York and New Jersey, the new Obama regulations on the electric power sector, and severe drought in California among other recent harsh climate anomalies in the United States, there has been virtually no US press coverage of whether the Obama administration's commitment to reduce US ghg by $17 \%$ below 2005 levels corresponds to US ethical obligations. Moreover, the US press's focus on cost issues to the United States of proposed climate change policies while ignoring the ethical duties of the United States to poor people and nations most vulnerable to climate change has had the effect of legitimating the idea that US climate policy should be set on the basis of US interests rather than on ethical obligations to others.

The US government has rarely if ever acknowledged that ethical and justice issues are relevant to US climate change policy with perhaps one exception. Recently, the US Environmental Protection Agency created a climate justice website (EPA, 2014). Yet this website encourages US citizens to identify places in the United States which are most vulnerable to climate change, thereby reinforcing the ethically problematic idea that US impacts, and therefore US self-interest alone, rather than ethical obligations to those outside the United States is a legitimate criterion for determining the acceptability of US climate change policy.

The United States agreed when it ratified the United Nations Framework Convention on Climate Change in 1992 that it would: 
protect the climate system for the benefit of present and future generations of humankind, on the basis of equity and in accordance with their common but differentiated responsibilities and respective capabilities. Accordingly, the developed country Parties should take the lead in combating climate change and the adverse effects thereof. (UNFCCC, 1992, Art. 3)

Yet the climate debate covered in the US media has consistently ignored the fact that the United States agreed, when it ratified the UNFCCC in 1992, that it should take the lead on climate change and that the US policies should be based upon 'equity' and 'common but differentiated responsibilities' rather than on national economic interest. In fact, there has been very little coverage in the US mainstream media of the fact that the United States committed to reduce its emissions to levels to prevent dangerous anthropogenic climate change based upon 'equity' and 'common but differentiated responsibilities'.

The following issues are almost completely missing from the debate on US climate change policies that has appeared in the US mainstream media: ${ }^{2}$

- Whether the US has a responsibility to the rest of the world for climate change given:

- US historical emissions;

- US per capita emissions;

- it is the poorest people around the world who are most harmed by climate change.

- What is the US fair share of safe global emissions?

- What is the US responsibility for adaptation costs and compensation for losses and damages in poor nations which have done little to cause climate change?

- Whether the US has responsibility for climate refugees?

- What does 'equity' mean under the UNFCCC?

- What ghg atmospheric concentration should any US climate change commitment be designed to achieve?

The US press frequently reports that China is now a larger of emitter of ghgs than the United States although rarely mentions that the United States is still a significantly larger emitter of ghg than China on a per capita and historical basis, facts which are relevant for determining a nation's fair share of safe global emissions.

According to the US Energy Information Agency (US EIA) the United States in 2012 emitted 18.1 tonnes of $\mathrm{CO}_{2}$ per capita while China emitted 6.3 tonnes per capita (US EIA, 2013). According to the Netherlands Environment Assessment Agency in 2011 China emitted 9697 million tonnes (Mt) or $28.6 \%$ of global emissions while the US emitted $5420 \mathrm{Mt}$ or $16.0 \%$ of global emissions (NEA, 2014). Yet in terms of historical emissions between 1850 and 2007 according to the World Resources Institute, the US was by far the world's largest emitter of $\mathrm{CO}_{2}$ with $339,174 \mathrm{MtCO}_{2}$ or $28.8 \%$ while China emitted $105,915 \mathrm{MtCO}_{2}$ or $9.0 \%$ of global emissions (WRI, 2014).

The US media's almost exclusive focus on China's larger share of total tonnes of ghg emitted has helped to legitimate in the United States the notion that China is more culpable for climate change despite the US exceeding China significantly in historical and current per capita emissions.

Despite unambiguous ethical responsibilities of high-emitting nations to reduce their ghg emissions without regard for what other nations have done (Brown, 2008), there has been almost no discussion 
in the US media that the United States has an ethical duty to reduce its ghg emissions without regard to what China does.

2. In making a national commitment to reduce ghg emissions under the UNFCCC, to what extent, if at all, has the nation explained how it took equity and justice into consideration in setting its ghg emissions reduction target?

As explained above, the United States government has not explained how it took equity and justice into account in determining the Obama administration's commitment on US ghg emissions reductions. In fact, the United States has not explained why its ghg reduction commitments of $17 \%$ below 2005 emissions by 2020 or $80 \%$ below 2005 by 2050 are justifiable on any grounds.

3. Given that any national ghg emissions target is implicitly a position on achieving an atmospheric ghg concentration that will avoid dangerous climate change, to what extent has the nation identified the ghg atmospheric concentration stabilization level that the national emissions reduction target seeks to achieve in cooperation with other nations?

As explained above, the United States government has not explained how its ghg emissions reduction commitments are designed to achieve any ghg atmospheric concentration. Any national emissions reduction commitment is implicitly a position on an acceptable global atmospheric stabilization goal, an issue of ethical significance because by specifying an atmospheric ghg goal a nation is taking a position on how much harm it is willing to inflict on those who are most vulnerable to climate change. In fact, despite the IPCC global carbon budget entailed by limiting warming to $2^{\circ} \mathrm{C}$ requiring that the world keep global emissions below $270 \mathrm{GtC}$, a case can be made that a high-emitting nation should ethically seek to achieve a lower carbon budget because some people are already being severely harmed by current elevated levels of atmospheric ghgs and the $270 \mathrm{GtC}$ identified by the IPCC only provides a $66 \%$ chance of limiting warming to $2^{\circ} \mathrm{C}$. Moreover, there is some scientific evidence that the global warming limit should be lower than $2^{\circ} \mathrm{C}$ to prevent dangerous climate change. ${ }^{3}$

4. Given that any national ghg emissions target is implicitly a position on the nation's fair share of safe global emissions, to what extent has the nation identified the ethical and justice considerations that it took into account in allocating a percentage of global ghg emissions to the nation through the identification of a ghg emissions reduction commitment?

As explained above, the United States government has not explained how the US ghg emissions reduction commitments took into consideration ethics and justice issues in establishing US emissions reduction targets. The United States has not explained why a $17 \%$ reduction below 2005 by 2020 has any connection with the US fair share of acceptable global ghg emissions. In fact, it would appear that this commitment is solely based upon politically and economically feasible reduction levels rather than global ethical obligations.

Also as noted above, the United States has failed to explain why the United States ghg emissions reductions are consistent with what 'equity' or 'common but differentiated responsibilities' require of it under the UNFCCC.

5. To what extent, if at all, has the nation acknowledged that nations emitting ghg above their fair share of safe global emissions have a responsibility to fund reasonable adaptation measures or unavoidable losses and damages in poor developing countries? 
The United States has not acknowledged that a nation emitting above its fair share of safe global emissions has a duty to fund reasonable adaptation measures or losses and damages in developing nations. In fact, US Special Envoy on Climate Change Todd Stern said in 2009:

I actually completely reject the notion of a debt or reparations or anything of the like. For most of the 200 years since the Industrial Revolution, people were blissfully ignorant of the fact that emissions caused a greenhouse effect. It's a relatively recent phenomenon. (Revkin and Zeller, 2009)

The United States, along with several other developed nations, has strongly opposed the creation of a 'losses and damages' mechanism under the UNFCCC, which has recently been strongly advocated for by vulnerable developing nations, if the funding for such a mechanism is derived on the basis of compensation obligations of high-emitting nations (Lefton and Taraska, 2013).

6. What formal mechanisms are available in the nation for citizens, NGOs and other interested organizations to question/contest the nation's ethical position on climate change?

The United States regularly meets with interested NGOs before and during climate negotiations under the UNFCCC although comments in such meetings are informal. When the United States government develops domestic regulations under US law, citizens have a right to comment and the US government must respond to comments on the proposed regulations. The US Environmental Protection Agency (EPA) recently announced procedures for citizens to submit formal comments and testify on proposed climate change regulations for power plants (US EPA, 2014).

7. How is the concept of climate justice understood by the current government? Have they articulated any position on climate justice issues that arise in setting ghg emissions policy or in regard to the adaptation needs of vulnerable nations or people?

As explained in previous answers, the United States has not explained its position on climate justice issues except to deny responsibility for losses and damages as noted in answer to question 5 . The US government has supported raising money for the adaptation needs of developing countries but not as a matter of any US compensation obligations.

8. Are you aware of any regional, state, provincial, or local governments in your country that have acknowledged some ethical responsibility for climate change? If so, what have they said?

Many US cities and at least 30 US states have adopted climate change action plans (C2ES, 2011), and 22 US states have established ghg emissions reductions targets (C2ES, 2011). US states' emissions reduction targets vary widely from state to state. Some states have only short-term ghg reduction targets, while some states have short-and long-term targets although some states with long-term targets have no long-term target date (C2ES, 2014). However, California, Connecticut, Colorado, Florida, Michigan, Minnesota, New Jersey and New York have committed to reducing ghg emissions by $80 \%$ by 2050 although they use different baseline years in achieving this goal (C2ES, 2014). Those states which have committed to the $80 \%$ reduction levels have not explained in the publicly available documents how they have taken into account ethics and justice issues in determining their target.

Two states, New York and California, however, have somewhat acknowledged the need to consider ethics and justice in formulating climate change policy. For instance, during the formulation of climate policy, New York acknowledged the need to consider equity when it said: 
Determining how much individual states or nations should reduce emissions through mid-century requires consideration of allocation equity and reduction effectiveness. The UNFCCC approach to apportioning GHG emission reduction requirements between developed and developing nations considers a broad spectrum of parameters, including population, gross domestic product (GDP), GDP growth, and global emission pathways that lead to climate stabilization. Applying these parameters, the UNFCCC concludes that, to reach the $450 \mathrm{ppm} \mathrm{CO}_{2}$ e stabilization target, developed countries need to reduce GHG emissions by 80 to 95 percent from 1990 levels by 2050. (New York State, 2009)

Yet when New York set a ghg target in 2009, it set a target of $80 \%$ below 1990 levels by 2050 without explaining how it took ethics and justice into account despite its recognition that ethical and justice considerations might require up to a 95\% reduction by 2050 (C2ES, 2014).

Although a California statute expressly requires California to consider environmental justice issues in setting climate change policies, this law is focused on justice issues that affect the United States and its domestic population rather than global environmental justice. ${ }^{4}$

The US EPA has developed an outreach programme for US state and local governments which includes guidance on how to develop ghg inventories and action plans, but none of this guidance identifies the need to consider equity, justice, or ethics in setting ghg policies (USEPA, 2014b).

One thousand and sixty US cities have agreed to develop climate action plans and set emissions reduction targets that support the US achieving its national target of reducing emissions by $17 \%$ below 2005 by 2020 (U.S. Conf, 2014). According to the International Council of Local Environmental Initiatives (ICLEI), an organization which supports climate change planning by local governments, 204 US local governments also set additional specific ghg reduction targets (ICLEl, 2010, pp40-42). These targets vary greatly in their ambition, with some being quite modest, although 34 US local governments have set long-term targets of at least $80 \%$ reductions by 2050 , and Annapolis, Maryland and Northfield, Minnesota have promised to be carbon neutral by 2050 and 2033 respectively (ICLEI, 2010, p41). The publicly available descriptions of these targets do not reveal which of these cities, if any, considered ethics and justice when setting the target.

\section{Has your national government taken any position on or otherwise encouraged individuals, businesses, organizations, subnational governments, or other entities that they have some ethical duty to reduce greenhouse gas emissions?}

As mentioned in answer to the previous question, the US EPA provides guidance on reducing ghg emissions to subnational entities. This guidance also supports individuals who wish to reduce their ghg emissions by providing an individual ghg calculator and identifying steps that an individual can take to reduce one's carbon footprint (US EPA, 2014c). Yet this guidance does not include any encouragement to consider ethical and justice issues in setting individual ghg goals.

\section{What recommendations would you make to get the nation or civil society to take ethics and justice issues seriously in climate change policy formulation?}

The utter failure of the US government and mainstream media to expressly discuss and consider ethics and justice issues when formulating climate change policies can be attributed to the following causes according to Brown (2012b):

(a) The power of the climate change denial industry and other opponents of climate change policies with economic interests in fossil fuel production or consumption to frame climate change policy issues. 
(b) The dominance of 'value-neutral' policy languages, particularly economics, to frame climate change policy issues without critical reflection from the press or US NGOs on the ethically problematic assumptions of these disciplines.

(c) The failure of higher education in the United States to train environmental professionals to spot ethical issues that arise in environmental policy formation.

(d) The failure of departments of philosophy and academic environmental ethics institutions to focus on ethics issue spotting in actual policy arguments.

(e) The failure of civil society, including US NGOs who are proponents of climate change policies, to identify ethical questions about policy matters.

There is little hope that the US government will consider the ethics and justice issues entailed by climate change that are relevant to US climate policy unless more US citizens better understand why climate change raises civilization-challenging ethical issues that have practical significance for policy and call for the United States to acknowledge its ethical and justice responsibilities in determining US climate policy.

Yet to really understand these issues, one must understand that:

(a) The mainstream scientific community has concluded that to prevent dangerous climate change the world must constrain global ghg emissions by a global carbon budget which will limit warming to acceptable levels.

(b) The total acceptable emissions entailed by the budget must be allocated among all nations in the world.

(c) Some nations and people much more than others have been putting poor nations and people at great risk.

(d) Achieving an adequate global solution to climate change will require high-emitting nations, organizations, subnational governments, businesses and individuals to reduce their ghg emissions at much greater levels than others.

To generate this wider understanding, the US press must begin to cover the policy implications of the climate ethics and justice issues. To achieve greater US media coverage of these issues, higher education and US NGOs must put the ethics and justice dimensions of climate change near the top of their agenda and demand that the US government and media acknowledge the ethical and justice dimensions of climate policy issues including but not limited to ethical issues that arise in setting ghg emissions reduction targets and when considering national responsibility for adaptation and for losses and damages in poor, vulnerable countries. US NGOs must also demand that the US government articulates how any US ghg emissions reduction target seeks to achieve an atmospheric ghg stabilization goal that protects those most vulnerable to climate change and how any percentage reduction in a US ghg reduction target has taken into account issues relevant to a US fair national ghg allocation including national per capita emissions and historical emissions. 


\section{Notes}

1 See Brown, 2002, pp13-48 for a detailed history of the US climate debate from 1970 through 2001; Brown, 2012b, pp20-53 for a detailed history of the US climate debate from 2002 to 2012.

2 The conclusions in this section are derived from well over 40 articles in Ethics and Climate, a blog on climate change ethics which has followed the US climate debate from January 2007 until the present (Brown, 20072014). For instance, under the Start Here and Index Tab of ethicsandclimate.org there are 16 articles on the failure of the US press to identify the ethical and justice dimensions of climate change during this period. Other articles on how the United States government has ignored the ethical and justice dimensions of climate change can be found among the 140 articles on ethicsandclimate.org.

3 See, for example, the statement of Christina Figueres, Executive Secretary of the UNFCCC, that the warming limit should be $1.5^{\circ} \mathrm{C}$ (Harvey, 2011).

4 For a discussion of the California statutory provision requiring consideration of environmental justice, see Kaswan, 2008. 


\section{References}

American Farmland Trust (2014) 'Myths and facts surrounding climate change legislation', http://www.farmland. org/documents/climatechangemythandfact-AmericanFarmlandTrust_002.pdf, accessed 22 July 2014

Brown, D. (2002) American Heat: Ethical Problems with the United States' Response to Global Warming, Roman and Littlefield, Latham, Maryland

Brown, D. (2007-2014) Ethics and Climate blog, http://blogs.law.widener.edu/climate/, accessed 23 July 2014

Brown, D. (2008) 'Nations must reduce greenhouse gas emissions to their fair share of safe emissions without regard to what other nations do', http://blogs.law.widener.edu/climate/2008/06/08/nations-must-reducegreenhouse-gas-emissions-to-their-fair-share-of-safe-global-emissions-without-regard-to-what-othernations-do/, accessed 25 July 2014

Brown, D. (2009) 'The most crucial missing element in U.S. media coverage of climate change: The ethical duty to reduce GHG emissions', ThinkProgress, 14 August 2009, http://thinkprogress.org/ climate/2009/08/14/204506/media-climate-ethics-reduce-ghg-emissions/, accessed 22 July 2014

Brown, D. (2012a) 'The US media's grave failure to communicate the significance of understanding climate change as a civilization challenging ethical issue', ethicsandclimate.org, http://blogs.law.widener.edu/ climate/2012/10/31/the-us-medias-grave-failure-to-communicate-the-significance-of-understandingclimate-change-as-a-civilization-challenging-ethical-issue/, accessed 22 July 2014

Brown, D. (2012b) Navigating the Perfect Moral Storm: Climate Change Ethics in Light of a Thirty-Five Year Debate, Routledge-Earthscan, New York

Center for Climate and Energy Solutions (C2ES) (2011) 'Local Action', http://www.c2es.org/docUploads/ climate101-local.pdf

Center for Climate and Energy Solutions (C2ES) (2014) 'Greenhouse Gas Emissions Targets', http://www.c2es.org/ us-states-regions/policy-maps/emissions-targets, accessed 22 July 2014

Davenport, C. (2014) 'Obama to take action to slash coal pollution', The New York Times, 1 June, http://www. nytimes.com/2014/06/02/us/politics/epa-to-seek-30-percent-cut-in-carbon-emissions. html? $r=0$, accessed 22 July 2014

Freedman, A. (2013) 'IPCC report contains "grave" carbon budget message', Climate Central, 4 October, http://www.climatecentral.org/news/ipcc-climate-change-report-contains-grave-carbon-budgetmessage-16569, accessed 22 July 2014

Harvey, F. (2011) 'UN chief challenges world to agree tougher target for climate change', The Guardian, 1 June, http://www.theguardian.com/environment/2011/jun/01/climate-change-target-christiana-figueres, accessed 21 July 2014

Hossol, J. (2007) 'Presidential Climate Action Project, Questions and Answers, Emissions Reductions Needed to Stabilize Climate', The White House, http://www.climatecommunication.org/wp-content/uploads/2011/08/ presidentialaction.pdf, accessed 22 July 2014

Intergovernmental Panel on Climate Change (IPCC) (2007) 4th Assessment, Working Group III, Chapter 13, p776, http://www.ipcc.ch/publications_and_data/ar4/wg3/en/contents.html, accessed 22 July 2014

Intergovernmental Panel on Climate Change (IPCC) (2013) Working Group I, The Physical Science Basis, Summary for Policymakers, http://www.climatechange2013.org/images/report/WG1AR5_SPM_FINAL.pdf, accessed 22 July 2014

International Council on Local Environmental Initiatives (ICLEI) (2010) Empowering Sustainable Communities, http://www.icleiusa.org/about-iclei/annual-reports, accessed 21 July 2009

Kaswan, A. (2008) 'Environmental Justice and Domestic Climate Policy', Environmental Law Reporter, 38 ELR, 30287, http://papers.ssrn.com/sol3/papers.cfm?abstract_id=1077675, accessed 23 July 2014

McCarthy, T. (2014) 'Obama says carbon pollution caps will "protect health of vulnerable”', The Guardian, 2 June 2014, http://www.theguardian.com/environment/2014/jun/02/obama-climate-change-carbon-emissionslive, accessed 22 July 2014 
Netherlands Environmental Agency (NEA) (2012) 'Trends in global CO2 emissions; 2012 report', http://www.pbl.nl/ en/publications/2012/trends-in-global-co2-emissions-2012-report, accessed 22 July 2014

New York State (2009) Climate Change Issue Brief, New York Energy Plan 2009, www.nysenergyplan.com/final/ Climate_Change_IB.pdf\#sthash.eMLWTwTq.dpuf, accessed 11 May 2013

Meyers, S. and Kulish, M. (2013) 'Growing Clamor About Inequities of Climate Crisis', The New York Times, 16 November 2013, http://www.nytimes.com/2013/11/17/world/growing-clamor-about-inequities-of-climatecrisis.html? r=1\&, accessed 22 July 2014

Obama, B. (2014) 'Remarks by the President on Climate Change', Georgetown University, White House Press Office, 25 June, http://www.whitehouse.gov/the-press-office/2013/06/25/remarks-president-climatechange, accessed 22 July 2014

Revkin, A. and Zeller, T. (2009) 'U.S. Negotiator Dismisses Reparations for Climate', The New York Times, 9 December 2009, http://www.nytimes.com/2009/12/10/science/earth/10climate.html\#sthash.nUpS8vGX. dpuf.dpuf, accessed 22 July 2014

Romm, J. (2009) 'The United States Needs a Tougher Greenhouse Gas Emissions Reduction Target for 2020', Center for American Progress, 13 January, http://www.americanprogress.org/issues/green/ report/2009/01/13/5472/the-united-states-needs-a-tougher-greenhouse-gas-emissions-reduction-targetfor-2020/, accessed 22 July 2014

United Nations Framework Convention on Climate Change (UNFCCC) (1992) 1771 UNTS 107; S. Treaty Doc No. 102-38; U.N. Doc. A/AC.237/18 (Part II)/Add.1; 31 ILM 849

U.S. Conference of Mayors (U.S. Conf) (2014) 'Cities That Have Signed On', date undetermined, http://www. usmayors.org/climateprotection/climatechange, accessed 21 July 2014

United States Department of Energy (US DOE) (2009) 'President Obama Sets a Target for Cutting U.S. Greenhouse Gas Emissions', EERE News Archives \& Events, 2 December, http://apps1.eere.energy.gov/news/news detail.cfm/news id =15650, accessed 17 July 2014

United States Environmental Protection Agency (US EPA) (2014a) 'How to Comment on the Clean Power Plan Proposed Rule', date undetermined, http://www2.epa.gov/carbon-pollution-standards/how-commentclean-power-plan-proposed-rule, accessed 22 July 2014

United States Environmental Protection Agency (US EPA) (2014b) 'Local Climate and Energy Program', date undetermined, http://www.epa.gov/statelocalclimate/local/index.html, accessed 22 July 2014

United States Environmental Protection Agency (US EPA) (2014c) 'Individual Greenhouse Gas Emissions Calculator', date undetermined, http://www.epa.gov/climatechange/ghgemissions/individual.html, accessed 22 July 2014

UnitedStatesInformationAgency(USEIA)(2013)InternationalEnergyStatistics, 'PerCapitaCarbonDioxideEmissions from the Consumption of Energy (Metric Tons of Carbon Dioxide per Person)', http://www.eia.gov/cfapps/ ipdbproject $/$ iedindex3. $\mathrm{cfm}$ ?tid=90\&pid $=45 \&$ aid $=8 \& \mathrm{cid}=$ regions \& syid $=1980 \&$ eyid $=2010 \&$ unit $=$ MMTCD, accessed 22 July 2012

World Resources Institute (WRI) (2014) 'Cumulative Emissions', Chapter 6 in Navigating the Numbers: Greenhouse Gas Data and International Climate Policy, date undetermined, http://pdf.wri.org/navigating_numbers chapter6.pdf, accessed 22 July 2014 




\section{IUCN}

IUCN Environmental Law Programme

Environmental Law Centre

Godesberger Allee 108-112

53175 Bonn, Germany

Phone: ++ 49228 / 2692231

Fax: $\quad++49228$ / 2692250

elcsecretariat@iucn.org

www.iucn.org/law 